\title{
toen
}

INSTITUTO DE PESQUISAS ENERGÉTICAS E NUCLEARES AUTARQUIA ASSOCIADA À UNIVERSIDADE DE SÃO PAULO

\section{DESENVOLVIMENTO DE MÉTODO MULTIRRESÍDUO PARA DETERMINAÇÃO DE PESTICIDAS BENZIMIDAZÓIS, CARBAMATOS E TRIAZINAS EM MILHO POR CROMATOGRAFIA LÍQUIDA ACOPLADA À ESPECTROMETRIA DE MASSAS EM TANDEME SUA CERTIFICAÇÃO}

\section{TEREZA ATSUKO KUSSUMI}

\author{
Dissertação apresentada como parte \\ dos requisitos para obtenção do Grau \\ de Mestre em Ciências na Área de \\ Tecnologia Nuclear- Materiais. \\ Orientador: \\ Dr. José Oscar Vega Bustillos
}

São Paulo 


\section{AGRADECIMENTOS}

Ao Dr. José Oscar Bustillos, pela orientação, incentivo, compreensão, amizade e dedicação que foram essenciais para a realização deste trabalho.

À Diretora do Instituto Adolfo Lutz, Dra. Marta Salomão; ao Diretor da Divisão de Bromatologia e Química, Dr. Odair Zenebon, e ao Diretor do Serviço de Química Aplicada, Paulo Tiglea, pela oportunidade, apoio e confiança.

Ao Hélio Martins Júnior, da Applied Biosystems do Brasil, pelo apoio, amizade, colaboração na execução da parte experimental e orientação em LC/MS/MS.

Ao Instituto de Pesquisas Energéticas e Nucleares (IPEN), pelo oferecimento da infra-estrutura necessária para a realização do trabalho.

À Dra. Maria Aparecida Faustino Pires, pela contribuição, autorização e realização da etapa experimental do estudo.

Aos colegas da Seção de Aditivos e Pesticidas Residuais, do Instituto Adolfo Lutz, pela compreensão e carinho.

A todos os colegas e amigos do Centro de Química do Meio Ambiente, pela amizade e agradável convívio.

À Applied Biosystems do Brasil, pelo apoio do suporte instrumental.

Aos meus familiares e amigos, pelo carinho, incentivo, apoio emocional e compreensão.

A todos que, diretamente ou indiretamente, contribuíram para a realização deste trabalho, 
Desenvolvimento de método multirresíduo para determinação de pesticidas benzimidazóis, carbamatos e triazinas em milho por Cromatografia Líquida acoplada à Espectrometria de Massas em Tandem e sua certificação.

Tereza Atsuko Kussumi

\section{RESUMO}

O presente trabalho apresenta os dados obtidos no estudo para o desenvolvimento de método multirresíduo de pesticidas dos grupos de benzimidazol (carbendazim, tiabendazol e tiofanato metílico), carbamatos (aldicarbe, aldicarbe sulfona, aldicarbe sulfóxido, carbaril, carbofurano, metomil, metiocarbe, pirimicarbe, propoxur) e triazinas (atrazina e simazina) em amostras de milho verde. Os pesticidas foram extraídos em acetona, sob agitação, diluídos em água e injetados no sistema LC/MS/MS. A técnica analítica de quantificação e confirmação utilizada foi a Cromatografia Líquida acoplada à Espectrometria de Massas em Tandem com ionização por Electrospray no modo positivo. A validação do método multirresíduo foi submetida em conformidade com a norma EC/2002/657 da Comunidade Européia. Para quantificação dos analitos utillizouse as curvas analíticas dos princípios ativos, nas concentrações que variaram de 0,04 a $8,0 \mathrm{ng} / \mathrm{ml}$, correspondentes a 2,0 a $400 \mu \mathrm{g} \cdot \mathrm{kg}^{-1}$ na amostra. Para o estudo da recuperação, os pesticidas foram avaliados em cinco níveis, de $1 / 2$ Limite de quantificação (LOQ) a $5 \mathrm{LOQ}$, correspondentes a níveis de fortificação de 4,0 a $200 \mu \mathrm{g} \cdot \mathrm{kg}^{-1}$. Os resultados da recuperação apresentaram, em níveis aceitáveis, na faixa de 80 a $110 \%$ e com precisão satisfatórias, CV $\leq 20 \%$, com exceção de aldicarbe e de aldicarbe sulfona. Os limites de quantificação do método variaram de 8 a $40 \mu \mathrm{g} \cdot \mathrm{kg}^{-1}$ e os limites de detecção do método, de 0,2 a 2,9 $\mu \mathrm{g} \cdot \mathrm{kg}^{-1}$. Os limites de quantificação do método atendem aos limites máximos de resíduos da legislação brasileira em vigor. Nas amostras estudadas, não foram encontrados resíduos de pesticidas acima do limite de quantificação do método. Por outro lado, todos os pesticidas, exceto carbaril e pirimicarbe, foram detectados em todas as amostras e em níveis acima dos limites de detecção do método. A alta incidência da presença de resíduos de pesticidas se deve possivelmente ao uso inadequado de agrotóxico, quando não autorizado o seu uso para a cultura de milho no Brasil ou proveniente de alguma contaminação, como o tratamento de agrotóxicos aplicados em outras culturas plantadas no mesmo solo. 
Development of a multiresidue method for the determination of benzimidazolic pesticides, carbamates and triazines in corn by Liquid Chromatography coupled to tandem Mass Spectrometry and its certification. Tereza Atsuko Kussumi

\begin{abstract}
The present work presents the results of a study of development about a multiresidue method for determining pesticides of the following groups in corn: benzimidazolic compounds (carbendazim, thiabendazol and methyl thiofanate), carbamates (aldicarb, aldicarb sulfone, aldicarb sulfoxide, carbaryl, carbofuran, methomyl, methiocarb, pirimicarb, propoxur), and triazines (atrazine and simazine). The pesticides were extracted in acetone under constant stirring, diluted in water and injected in the LC/MS/MS system. The analytical technique for quantification and confirmation was Liquid Chromatography coupled to tandem Mass Spectrometry with Electrospray ionization in the positive mode The validation of the multiresidue method underwent the European Community $\mathrm{EC} / 2002 / 657$ standard. For the quantification of the analytes, calibration curves of the substances in concentrations ranging from 0.04 to $8.0 \mathrm{ng} / \mathrm{mL}$ were used, corresponding to 2.0 to $400 \mu \mathrm{g} \cdot \mathrm{kg}^{-1}$ in the sample. For recovery tests, the pesticides were assessed on five levels, from $1 / 2$ Limit of Quantification (LOQ) to 5 $\mathrm{LOQ}$, corresponding to the fortification levels of 4.0 to $200 \mu \mathrm{g} \cdot \mathrm{kg}^{-1}$. The results of the tests showed a recovery of $80-110 \%$ with satisfactory precision, and CV $\leq 20 \%$, except for aldicarb and aldicarb sulfone. The limits of quantification of the method ranged from 8 to $40 \mu \mathrm{g} \cdot \mathrm{kg}^{-1}$ and the limits of detection ranged from 0.2 to 2.9 $\mu \mathrm{g} \cdot \mathrm{kg}^{-1}$. The limits of quantification of the method meet the maximum residue limit allowed by the Brazilian law. In the studied samples, pesticide residues above the limit of quantification of the method were not found. On the other hand, all pesticides, except for carbaryl and pirimicarb, in all samples, were detected and level above the limits of detection of the method. The high incidence of residues of these pesticides is probably due to their inadequate use, since it is not allowed on corn cultures in Brazil, or any kind of contamination like the use of such pesticides on other cultures over the same soil.
\end{abstract}




\section{SUMÁRIO}

Página

1. INTRODUÇÃO 17

2. OBJETIVOS 22

2.1. Objetivo Geral 22

2.2. Objetivos específicos 22

3. REVISÃO DA LITERATURA 24

3.1. Milho. Produto agrícola. Importância alimentar 24

3.2. Defensivos agrícolas. Agrotóxicos ou pesticidas.

Contexto atual $\quad 26$

3.3. Pesticidas 28

3.3.1. Inseticidas - Carbamatos 30

3.3.1.1. Aldicarbe, aldicarbe sulfóxido e aldicarbe sulfona 30

3.3.1.2. Carbaril 32

3.3.1.3. Carbofurano 33

3.3.1.4. Metiocarbe 34

3.3.1.5. Metomil 35

3.3.1.6. Pirimicarbe $\quad 35$

3.3.1.7. Propoxur 36

3.3.2. Herbicidas - Triazinas

3.3.2.1. Atrazina 37

3.3.2.2. Simazina 38

3.3.3. Fungicidas - Benzimidazóis 39

3.3.3.1. Carbendazim 40

3.3.3.2. Tiabendazol 40

3.3.3.3. Tiofanato metílico 41

3.4. Método analítico 42

3.4.1. Método multirresíduo 43

3.4.1.1. Extração - Método multirresíduo 43

3.4.2. Quantificação e/ou confirmação 44 
3.4.3. Espectrometria de massas

3.5. Programa de monitoramento 51

4. METODOLOGIA 62

4. 1. Coleta de amostras 62

4.2. Preparação das amostras 63

4.3. Reagentes 63

4.4. Equipamentos utilizados 64

4.4.1. Sistema HPLC - MS/MS 64

4.5. Curvas analíticas 64

4.6. Preparação dos extratos $\quad 65$

4.6.1. Cálculos. Análise qualitativa e quantitativa 65

4.7. Estudos de recuperação 66

4.7.1. Cronograma do experimento de recuperação 67

4.7.2. Cálculos de Recuperação 67

4.8. Validação do método analítico 68

4.8.1. Linearidade $\quad 69$

4.8.2. Faixa linear e faixa linear de trabalho 70

4.8.3. Seletividade $\quad 70$

4.8.4. Exatidão 70

4.8.5. Precisão 72

4.8.6. Níveis críticos (CCa e $\mathrm{CC} \beta \alpha)$

4.8.6.1. Limite de decisão $\mathrm{CC \alpha}$

4.8.6.2. Capacidade de detecção (CC $\beta \alpha)$

4.8.7. Incerteza $\quad 75$

4.8.7.1. Cálculo das variâncias 76

4.8.7.2. Cálculo de medida de incerteza (U)

4.8.8. Limite de quantificação 77

4.8.9. Limite de detecção 78

5. RESULTADOS E DISCUSSÃO 79

5.1. Otimização do equipamento - cromatografia líquida 79

5.2. Espectrometria de massas 80

5.3. Curvas analíticas 81 
5.4. Extração 93

5.5.Teste de Testemunha - Seletividade 94

5.6. Recuperação 96

5.7. Linearidade das recuperações 96

5.8. Níveis críticos - CCa e CC $\beta \quad 124$

5.9. Cálculo da incerteza 125

5.10. Limite de quantificação do método 127

5.11. Limite de detecção do método 129

5.12. Resultado das amostras 134

6. CONCLUSÕES 137

7. REFERÊNCIAS BIBLIOGRÁFICAS 139 


\section{LISTA DE TABELAS}

Página

Tabela 1 Pesticidas estudados e seus pesos moleculares. Classificação e Limite Máximo de Resíduo (LMR) estabelecido na legislação brasileira, Codex Alimentarius

e União Européia

Tabela 2 Resultado das amostras domésticas, por grupo de alimentos em 2003 (EUA)

Tabela 3 Resultados da amostras importadas, por grupo de alimentos em 2003, (EUA)

Tabela 4 Resultado do programa nacional de monitoramento em 2004, EU

Tabela 5 Amostras in natura de frutas, vegetais e cereais

Tabela 6 Amostras de fiscalização, em níveis acima LMREC, de frutas, verduras e cereais

Tabela $7 \quad$ Data e coleta das amostras 62

Tabela 8 Padrões estudados, procedência e grau de pureza 63

$\begin{array}{lll}\text { Tabela } 9 & \text { Cronograma do experimento } & 67\end{array}$

Tabela 10 Níveis de recuperação e média de recuperação 71

Tabela 11 Níveis de recuperação e faixa de coeficiente de variação 72

Tabela 12 Programação do gradiente de eluição da coluna cromatográfica

Tabela 13 Tempo de retenção (Tr) dos analitos estudados

Tabela 14 Condições de detecção do espectrômetro de massas usando modo MRM

Tabela 15 Resultados da curva analítica para aldicarbe

Tabela 16 Resultados da curva analítica para aldicarbe sulfona 
Tabela 18 Resultados da curva analítica para carbaril

Tabela 19 Resultados da curva analítica para carbofurano

Tabela 20 Resultados da curva analítica para metiocarbe

Tabela 21 Resultados da curva analítica para metomil

Tabela 22 Resultados da curva analítica para pirimicarbe

86

Tabela 23 Resultados da curva analítica para propoxur

Tabela 24 Resultados da curva analítica para atrazina

Tabela 25 Resultados da curva analítica para simazina

Tabela 26 Resultados da curva analítica para carbendazim

Tabela 27 Resultados da curva analítica para tiabendazol

Tabela 28 Resultados da curva analítica para tiofanato metílico

90

Tabela 29 Linearidade das curvas analíticas

Tabela 30 Resultado da precisão instrumental da curva analítica para todos os analitos estudados neste trabalho

Tabela 31 Resultado da extração das amostras testemunhas fortificadas com diferentes solventes

Tabela 32 Equações das retas dos experimentos 1, 2 e 3 para aldicarbe

Tabela 33 Equações das retas dos experimentos 1, 2 e 3 para aldicarbe sulfona

Tabela 34 Equações das retas dos experimentos 1,2 e 3 para aldicarbe sulfóxido

Tabela 35 Equações das retas dos experimentos 1, 2 e 3 para carbaril

Tabela 36 Equações das retas dos experimentos 1, 2 e 3 para carbofurano

Tabela 37 Equações das retas dos experimentos 1, 2 e 3 para metiocarbe 
Tabela 38 Equações das retas dos experimentos 1,2 e 3 para metomil

Tabela 39 Equações das retas dos experimentos 1,2 e 3 para pirimicarbe

Tabela 40 Equações das retas dos experimentos 1,2 e 3 para propoxur

Tabela 41 Equações das retas dos experimentos 1, 2 e 3 para atrazina

Tabela 42 Equações das retas dos experimentos 1, 2 e 3 para simazina

Tabela 43 Equações das retas dos experimentos 1, 2 e 3 para carbendazim

Tabela 44 Equações das retas dos experimentos 1, 2 e 3 para tiabendazol

Tabela 45 Equações das retas dos experimentos 1,2 e 3 para tiofanato metílico

Tabela 46 Resultados da média de exatidão, do desvio padrão e do coeficiente de variação dos experimentos 1, 2 e 3 para aldicarbe

Tabela 47 Resultados da média de exatidão, do desvio padrão e do coeficiente de variação dos experimentos 1,2 e 3 para aldicarbe sulfona

Tabela 48 Resultados da média de exatidão, do desvio padrão e do coeficiente de variação dos experimentos 1, 2 e 3 para aldicarbe sulfóxido

Tabela 49 Resultados da média de exatidão, do desvio padrão e do coeficiente de variação dos experimentos 1, 2 e 3 para carbaril

Tabela 50 Resultados da média de exatidão, do desvio padrão e do coeficiente de variação dos experimentos 1, 2 e 3 para carbofurano

Tabela 51 Resultados da média de exatidão, do desvio padrão e do coeficiente de variação dos experimentos 1, 2 e 3 para metiocarbe 
Tabela 52 Resultados da média de exatidão, do desvio padrão e do coeficiente de variação dos experimentos 1, 2 e 3 para metomil

Tabela 53 Resultados da média de exatidão, do desvio padrão e do coeficiente de variação dos experimentos 1, 2 e 3 para pirimicarbe

Tabela 54 Resultados da média de exatidão, do desvio padrão e do coeficiente de variação dos experimentos 1, 2 e 3 para propoxur

Tabela 55 Resultados da média de exatidão, do desvio padrão e do coeficiente de variação dos experimentos 1, 2 e 3 para atrazina

Tabela 56 Resultados da média de exatidão, do desvio padrão e do coeficiente de variação dos experimentos 1, 2 e 3 para simazina

Tabela 57 Resultados da média de exatidão, do desvio padrão e do coeficiente de variação dos experimentos 1, 2 e 3 para carbendazim

Tabela 58 Resultados da média de exatidão, do desvio padrão e do coeficiente de variação dos experimentos 1, 2 e 3 para tiabendazol

Tabela 59 Resultados da média de exatidão, do desvio padrão e do coeficiente de variação dos experimentos 1, 2 e 3 para tiofananto metílico

Tabela 60 Resultados da média das recuperações, dos desvios padrões e dos coeficientes de variação.

Tabela 61 Média de CCa e CC $\beta$ do experimento 1 a 3

Tabela 62 Resultados de variâncias e incerteza dos experimentos 1,2 e 3

Tabela 63 Resultados das amostras de milho verde 


\section{LISTA DE FIGURAS}

Página

Figura 1a Estrutura química de aldicarbe 30

Figura 1b Estrutura química de aldicarbe sulfóxido 30

Figura 1c Estrutura química de aldicarbe sulfona 31

Figura 2 Estrutura química de carbaril 32

Figura 3 Estrutura química de carbofurano 33

Figura 4 Estrutura química de metiocarbe 34

Figura 5 Estrutura química de metomil 35

Figura $6 \quad$ Estrutura química de pirimicarbe 35

$\begin{array}{lll}\text { Figura } 7 & \text { Estrutura química de propoxur }\end{array}$

$\begin{array}{lll}\text { Figura } 8 & \text { Estrutura química de atrazina } & 37\end{array}$

Figura 9 Estrutura química de simazina 38

Figura 10 Estrutura química de carbendazim 40

Figura 11 Estrutura química de tiabendazol 40

Figura 12 Estrutura química de tiofanato metílico 41

Figura 13 Total de vendas por classe de defensivos agrícolas, no período do ano de 1989-2005

Figura 14 Porcentagem das amostras de frutas, vegetais e cereais com resíduos múltiplos, no período de 1997 a 2004

Figura 15 Resultado de monitoramento no período de 1996 a 2004

Figura 16 Curva analítica para quantificação de aldicarbe 81

Figura 17 Curva analítica para quantificação de aldicarbe sulfona 82 
Figura 18 Curva analítica para quantificação de aldicarbe sulfóxido

Figura 19 Curva analítica para quantificação de carbaril

Figura 20 Curva analítica para quantificação de carbofurano 84

Figura 21 Curva analítica para quantificação de metiocarbe 84

Figura 22 Curva analítica para quantificação de metomil 85

Figura 23 Curva analítica para quantificação de pirimicarbe 86

Figura 24 Curva analítica para quantificação de propoxur 86

Figura 25 Curva analítica para quantificação de atrazina 87

Figura 26 Curva analítica para quantificação de simazina 88

Figura 27 Curva analítica para quantificação de carbendazim 88

Figura 28 Curva anlítica para quantificação de tiabendazol 89

Figura 29 Curva analítica para quantificação de tiofanato metílico 90

Figura 30 Cromatograma da amostra testemunha 94

Figura 31 Cromatograma da amostra fortificada 95

Figura 32 Equação de reta do experimento 1 - Aldicarbe 97

Figura 33 Equação de reta do experimento 2 - Aldicarbe 97

Figura 34 Equação de reta do experimento 3 - Aldicarbe 97

Figura 35 Equação de reta do experimento 1 - Aldicarbe sulfona 98

Figura 36 Equação de reta do experimento 2 - Aldicarbe sulfona 98

Figura 37 Equação de reta do experimento 3 - Aldicarbe sulfona 99

Figura 38 Equação de reta do experimento 1 - Aldicarbe sulfóxido 99

Figura 39 Equação de reta do experimento 2 - Aldicarbe sulfóxido 100

Figura 40 Equação de reta do experimento 3 - Aldicarbe sulfóxido 100

Figura 41 Equação de reta do experimento 1-Carbaril 101 
Figura 42 Equação de reta do experimento 2 - Carbaril 101

Figura 43 Equação de reta do experimento 3 - Carbaril 101

Figura 44 Equação de reta do experimento 1-Carbofurano 102

Figura 45 Equação de reta do experimento 2-Carbofurano 102

Figura 46 Equação de reta do experimento 3 - Carbofurano 103

Figura 47 Equação de reta do experimento 1-Metiocarbe 103

Figura 48 Equação de reta do experimento 2 - Metiocarbe 104

Figura 49 Equação de reta do experimento 3 - Metiocarbe 104

Figura 50 Equação de reta do experimento 1-Metomil 105

Figura 51 Equação de reta do experimento 2-Metomil 105

Figura 52 Equação de reta do experimento 3 - Metomil 105

Figura 53 Equação de reta do experimento 1-Pirimicarbe 106

Figura 54 Equação de reta do experimento 2 - Pirimicarbe 106

Figura 55 Equação de reta do experimento 3 - Pirimicarbe 107

Figura 56 Equação de reta do experimento 1 - Propoxur 107

Figura 57 Equação de reta do experimento 2 - Propoxur 108

Figura 58 Equação de reta do experimento 3 - Propoxur 108

Figura 59 Equação de reta do experimento 1 - Atrazina 109

Figura 60 Equação de reta do experimento 2 - Atrazina 109

Figura 61 Equação de reta do experimento 3 - Atrazina 109

Figura 62 Equação de reta do experimento 1-Simazina 110

Figura 63 Equação de reta do experimento 2 - Simazina 110

Figura 64 Equação de reta do experimento 3 - Simazina 111

Figura 65 Equação de reta do experimento 1-Carbendazim 111 
Figura 66 Equação de reta do experimento 2 - Carbendazim

Figura 67 Equação de reta do experimento 3 - Carbendazim

Figura 68 Equação de reta do experimento 1 - Tiabendazol

Figura 69 Equação de reta do experimento 2 - Tiabendazol

Figura 70 Equação de reta do experimento 3 - Tiabendazol

Figura 71 Equação de reta do experimento 1 - Tiofanato metílico

Figura 72 Equação de reta do experimento 2 - Tiofanato metílico

Figura 73 Equação de reta do experimento 3 - Tiofanato metílico

Figura 74 Cromatograma de aldicarbe, concentração de 0,05 ng. $\mathrm{mL}^{-1}$

Figura 75 Cromatograma de aldicarbe sulfona, concentração de $0,10 \mathrm{ng} \cdot \mathrm{mL}^{-1}$

Figura 76 Cromatograma de aldicarbe sulfóxido, concentração de $0,05 \mathrm{ng} \cdot \mathrm{mL}^{-1}$

Figura 77 Cromatograma de carbaril, concentração de 0,05 ng. $\mathrm{mL}^{-1}$

Figura 78 Cromatograma de carbofurano, concentração de $0,05 \mathrm{ng} \cdot \mathrm{mL}^{-1}$

Figura 79 Cromatograma de metiocarbe, concentração de $0,05 \mathrm{ng} \cdot \mathrm{mL}^{-1}$

Figura 80 Cromatograma de metomil, concentração de $0,05 \mathrm{ng} \cdot \mathrm{mL}^{-1}$

Figura 81 Cromatograma de pirimicarbe, concentração de $0,04 \mathrm{ng} \cdot \mathrm{mL}^{-1}$

Figura 82 Cromatograma de propoxur, concentração de $0,05 \mathrm{ng} \cdot \mathrm{mL}^{-1}$

Figura 83 Cromatograma de atrazina, concentração de $0,10 \mathrm{ng} \cdot \mathrm{mL}^{-1}$

Figura 84 Cromatograma de simazina, concentração de 0,10 ng. $\mathrm{mL}^{-1}$ 
Figura 85 Cromatograma de carbendazim, concentração de $0,05 \mathrm{ng} \cdot \mathrm{mL}^{-1}$

Figura 86 Cromatograma de tiabendazol, concentração De $0,05 \mathrm{ng} \cdot \mathrm{mL}^{-1}$

Figura 87 Cromatograma de tiofanato metílico, concentração de $0,20 \mathrm{ng} \cdot \mathrm{mL}^{-1}$

Figura 88 Cromatograma de carbendazim da amostra 7

Figura 89 Cromatograma de carbendazim da amostra 7 


\section{INTRODUÇÃO}

Nas últimas décadas, a agricultura tem feito um grande esforço para aumentar anualmente a produção de alimentos para suprir os mercados interno ou externo. O uso de pesticidas está intimamente ligado à necessidade de suprimento de alimentos em função do crescimento populacional. Prevendo que a população mundial duplicará nos próximos trinta e ou quarenta anos e, ainda, que, no presente momento, somente um terço da humanidade tem alimento suficiente, as perspectivas futuras mundiais de alimentos não cumprirão as demandas. Segundo os prognósticos, as Nações Unidas prevêem que os suprimentos alimentares precisam ser triplicados até o fim do século, objetivando proporcionar a todos os países do mundo um nível de nutrição razoável (Macedo, 2002).

O agronegócio ocupa no Brasil uma posição de destaque na economia, com expressivos $33 \%$ do Produto Interno Bruto (PIB). Este mercado movimenta bilhões de dólares anualmente, trazendo divisas e contribuindo para 0 crescimento da economia. No cenário mundial, o Brasil ocupa a primeira posição como exportador de grãos, carne bovina, carne de frango, tabaco, couro e calçados de couro. A safra de grãos no Brasil apresentou crescimento de 131\% desde 1990, com produção relatada em 2002/2003 de 52 milhões de toneladas de grãos contra pouco mais de quinze milhões de toneladas produzidas em 1990/1991 (Martins, 2005). Neste contexto, que enquadra o Brasil como um país com grande potencial agrícola, especial atenção deve ser destinada à produção e ao desenvolvimento desta área de negócios. O crescimento da economia do país nos últimos anos está diretamente ligado à produtividade em larga escala dos principais produtos agrícolas (Martins, 2005).

Sob o aspecto da escassez de alimentos, a produtividade passou a ser prioridade para os governos, particularmente europeus, propiciando o surgimento de novas tecnologias (Pereira, 2005). Atualmente, com a disponibilidade de várias ferramentas que levam ao incremento da produção de alimentos, a maior 
preocupação dos governos passou a ser em relação à segurança e à qualidade do alimento. A globalização influencia diferentes aspectos da vida humana, incluindo a segurança da cadeia alimentar, que pode ser relacionada à presença ou não de contaminantes químicos ou microrganismos indesejáveis. A segurança alimentar tem sido um tema cada vez mais importante em metas governamentais, não apenas no sentido de garantir que a população dos países tenha acesso a alimentos, mas que estes estejam dentro de padrões de qualidade nutricional e dentro dos limites de resíduos químicos ou de microrganismos que causem prejuízos à população.

Dentre os produtos químicos que podem gerar resíduos nos alimentos se encontram os pesticidas, amplamente utilizados no Brasil. Esses compostos são utilizados tanto em produtos consumidos no mercado nacional quanto em produtos para exportação.

A intensificação das regulamentações e o aumento das fiscalizações indicam que, tanto no âmbito nacional como internacional, a situação do mercado de alimentos requer grande esforço dos países para que sua adequação aos sistemas de controle e segurança, o que pode facilitar os acordos de reconhecimento mútuo, beneficiando o comércio internacional.

$\mathrm{Na}$ Tabela 1, encontram-se discriminados os pesticidas aqui estudados, pesos moleculares, os grupos funcionais químicos e o Limite Máximo de Resíduo e outros, não autorizados, pela Agência Nacional de Vigilância Sanitária, recomendados pelo Codex Alimentarius e pela União Européia.

O Limite Máximo de Resíduo (LMR) para resíduo de pesticidas é o máximo de concentração de um resíduo (expresso em $\mathrm{mg} / \mathrm{kg}$ ) legalmente permitido no alimento ou produto agrícola e animal. Os LMR são baseados em dados de Boas Práticas Agrícolas. Os alimentos ou produtos agrícolas que estão de acordo com os LMR são considerados toxicologicamente aceitáveis. Quando os pesticidas estão em níveis de concentração superiores aos LMR significa que houve violação das Boas Práticas Agrícolas. Se os LMR são excedidos, comparados à exposição da Ingestão Diária Aceitável (IDA) e/ou Dose de Referência Aguda $\left(D R_{f}\right)$, serão indicativos de um possível risco de contaminação crônica ou aguda (EU, 2007).

Os LMR para pesticidas da legislação brasileira diferem quando comparados com os dos organismos internacionais como Codex Alimentarius 
(Codex Alimentarius, 2007) e a União Européia (EFSA, 2007), valores mencionados na Tabela 1.

Tabela 1 - Pesticidas estudados e seus pesos moleculares. Classificação e Limite Máximo de Resíduo (LMR) estabelecido na legislação brasileira, Codex Alimentarius e União Européia

\begin{tabular}{|c|c|c|c|c|c|}
\hline Composto & $\begin{array}{l}\text { P.M. } \\
(\mathrm{g} / \mathrm{mol})\end{array}$ & Grupo & $\begin{array}{c}\mathbf{L M R}^{\mathbf{1}} \\
(\mathrm{mg} / \mathrm{kg})\end{array}$ & $\begin{array}{c}\mathbf{L M R}^{2} \\
(\mathrm{mg} / \mathrm{kg})\end{array}$ & $\begin{array}{c}\mathbf{L M R}^{\mathbf{3}} \\
(\mathrm{mg} / \mathrm{kg})\end{array}$ \\
\hline Aldicarbe & 190,264 & Carbamato & NA & 0,05 & 0,05 \\
\hline Aldicarbe Sulfona & 222,263 & Carbamato & NA & NA & NA \\
\hline Aldicarbe Sulfóxido & 206,264 & Carbamato & NA & NA & NA \\
\hline Atrazina & 215,683 & Triazina & 0,25 & NA & NA \\
\hline Carbaril & 201,221 & Carbamato & NA & 0,02 & 0,5 \\
\hline Carbendazim & 191,187 & Benzimidazol & NA & NA & 0,1 \\
\hline Carbofurano & 221,252 & Carbamato & $0,1^{*}$ & 0,05 & 0,1 \\
\hline Metiocarbe & 225,308 & Carbamato & NA & 0,05 & NA \\
\hline Metomil & 162,211 & Carbamato & 0,1 & 0,02 & 0,05 \\
\hline Pirimicarbe & 238,286 & Carbamato & NA & NA & NA \\
\hline Propoxur & 209,242 & Carbamato & NA & NA & NA \\
\hline Simazina & 201,657 & Triazina & 0,02 & NA & NA \\
\hline Tiabendazol & 201,249 & Benzimidazol & $0,2^{*}$ & NA & 0,05 \\
\hline Tiofanato metílico & 342,482 & Benzimidazol & NA & NA & NA \\
\hline
\end{tabular}

PM: Peso Molecular NA: Não autorizado * : autorizado em semente

LMR ${ }^{1}$ : Limite Máximo de Resíduo estabelecido pela ANVISA - Agência Nacional de Vigilância Sanitária, Ministério da Saúde, Brasil (ANVISA, 2006 a).

LMR ${ }^{2}$ : Limite Máximo de Resíduo recomendado pelo Codex Alimentarius (Codex Alimentarius, 2007)

LMR $\mathbf{L}^{3}$ : Limite Máximo de Resíduo estabelecido pela União Européia (EFSA, 2007) 
Para os alimentos destinados à exportação, neste caso o milho, os LMR a serem obedecidos são referentes aos países de destino do produto, muitas vezes menores que os estabelecidos para o mercado brasileiro. Tendo em vista o mercado externo, vale ressaltar a importância da escolha de uma metodologia analítica com alta sensibilidade, principalmente para a emissão de um certificado de análise de produtos destinados à exportação.

Os dados recentes do monitoramento nacional PARA (Programa de Análise de Resíduos de Agrotóxicos em Alimentos), em seu relatório à ANVISA (ANVISA, 2006b), permitem concluir que o maior problema brasileiro, em relação aos níveis de agrotóxicos no alimento in natura, não está na forma de aplicação do produto em alimento, mas sim no uso indiscriminado de agrotóxicos não recomendados para determinados alimentos, resultando, em sua grande maioria, em irregularidades. Em relatório recente, referente ao período de 2001 a 2006, a situação brasileira em relação a resíduos de pesticidas em alimentos permanece inalterada (ANVISA, 2007).

Outro fato a ressaltar é que o uso generalizado e intensivo de agrotóxicos pode ocasionar a resistência de espécies combatidas às substâncias empregadas e danos em espécies não visadas. $O$ desequilíbrio ecológico pode agravar o surgimento e a proliferação de pragas e doenças e, conseqüentemente, aumentar a necessidade de agrotóxicos. Os agrotóxicos podem causar efeitos tóxicos em humanos, nos animais domésticos e silvestres, nos organismos aquáticos e ao ambiente. Os consumidores de alimentos, se ingerirem resíduos acima dos LMR permitidos, podem estar sob risco de exposição crônica a agrotóxicos.

O desenvolvimento de um método analítico pode contribuir para o fortalecimento da capacidade técnica de investigação de resíduos de agrotóxicos, trazendo novas informações e conhecimentos no que diz respeito à realidade de resíduos de agrotóxicos. O método analítico estudado pode contribuir para estabelecimentos de LMR na autorização de uso em cultura e para verificação do uso abusivo da formulação de agrotóxicos não autorizados por órgãos competentes, contribuindo para a segurança alimentar quanto à qualidade do alimento consumido pela população.

Nesse sentido, o presente trabalho teve por objetivo o desenvolvimento de um método multirresíduo e sua validação para determinação de pesticidas dos 
grupos benzimidazol, carbamatos e triazinas, em milho verde. A técnica de confirmação e quantificação utilizada foi a cromatografia líquida acoplada ao espectrômetro de massas com ionização e por electrospray (LC-ESI/MS/MS). 


\section{OBJETIVOS}

\subsection{Objetivo Geral}

Desenvolvimento e validação de método multirresíduo para a determinação de pesticidas dos grupos benzimidazol (carbendazim, tiabendazol e tiofanato metílico), carbamatos (aldicarbe, aldicarbe sulfona, aldicarbe sulfóxido, carbaril, carbofurano, metomil, metiocarbe, pirimicarbe e propoxur) e triazinas (atrazina e simazina) em milho verde, utilizando a técnica de quantificação e confirmação por Cromatografia Líquida acoplada à Espectrometria de Massas em Tandem com ionização por Electrospray (LC-ESI/MS/MS).

\subsection{Objetivos Específicos}

- Caracterizar os compostos nos modos MS e MS/MS para interpretação dos íons precursores/produtos utilizados no modo MRM (Multiple Reaction Monitoring);

- Desenvolver a técnica de extração e sua aplicação na determinação dos princípios ativos em milho;

- Desenvolver metodologia analítica para a determinação direta em amostras de milho;

- Validar o método multirresíduo segundo a norma EC/2002/657 da Comunidade Européia empregando o software ResVal (versão 2.0);

- Discutir o desempenho e a aplicabilidade do método analítico desenvolvido; 
- Aplicar a metodologia estudada em amostras comerciais, provenientes de diferentes locais de venda direta ao consumidor, e discutir os resultados como uma ferramenta para auxiliar a qualidade e segurança alimentar dos alimentos consumidos pela população em relação a agrotóxicos. 


\section{REVISÂO DA LITERATURA}

\subsection{Milho. Produto agrícola. Importância alimentar}

O milho no Brasil é um produto agrícola de expressiva consideração, devido sua grande produtividade crescente nos últimos anos. A partir da segunda metade do século $\mathrm{XX}$, o desenvolvimento de espécies híbridas aumentou a produtividade e a qualidade do milho. O milho e a soja contribuem com cerca de $80 \%$ de produção brasileira de grãos. Em 2001, a principal região produtora foi o Estado do Paraná, com mais de 5 milhões de toneladas, representando $26 \%$ da produção nacional, seguido por Minas Gerais (13\%), Rio Grande do Sul (12\%), São Paulo (10\%), Goiás (9\%) e Santa Catarina (8\%) (EMBRAPA, 2007).

De acordo com o IBGE (Instituto Brasileiro de Geografia e Estatística), a produção agrícola nacional de milho vem crescendo nos últimos anos; de 1990 a 2004 a produção foi de 21.348 para 41.806 mil toneladas (MAPA, 2006).

Segundo dados da FAO (Food Agriculture Organization), os maiores produtores mundiais de milho são Estados Unidos, China e Brasil; que, em 2005, produziram, em milhões de toneladas, 280,2; 131,1; e 35,9, respectivamente (EMBRAPA, 2007).

Os primeiros registros do cultivo de milho, datados há 7.300 anos, foram encontrados em pequenas ilhas próximas ao litoral do México. Seu nome, de origem caribenha, significa "sustento de vida". Estudos realizados por escavações arqueológicas, geológicas e pelas medições por desintegração radioativa tornam evidente de que é cultivado há pelo menos 5.000 anos. Foi a alimentação básica de várias civilizações importantes ao longo dos séculos tais como: Maias, Astecas e Incas reverenciavam o cereal na arte e religião e grande parte de suas atividades diárias eram ligadas ao seu cultivo.

Com a descoberta da América e as grandes navegações do século $\mathrm{XVI}$, a cultura do milho se expandiu para outras partes do mundo. Provavelmente, o milho é a mais importante planta comercial com origem americana. Logo depois do descobrimento da América, foi levado para a Europa, onde era cultivado em 
jardins, até que seu valor alimentício tornou-se conhecido (ABIMILHO, 2006). No Brasil, o cultivo do milho vem desde antes da chegada dos europeus. Os índios, principalmente os guaranis, tinham o cereal como o principal ingrediente de sua dieta. Com a chegada dos portugueses, o consumo aumentou e novos produtos à base de milho foram incorporados aos hábitos alimentares dos brasileiros. No final da década de 1950, graças a uma grande campanha em favor do trigo, o cereal começou a perder espaço na mesa brasileira. Atualmente, embora o nível de consumo do milho no Brasil venha crescendo, ainda está longe de ser comparado a países como o México e aos da região do Caribe (Wilkipédia, 2007).

$\mathrm{O}$ milho é um dos alimentos considerados mais nutritivos. Na forma pura ou como ingredientes de outros produtos é uma importante fonte energética para o ser humano, rico em carboidratos (açúcares), essencialmente o amido (Capobiango et al., 2006; EMBRAPA, 2007). As cascas dos grãos são ricas em fibras e cada 100 gramas do alimento têm cerca de $360 \mathrm{Kcal}$, sendo $70 \%$ de glicídios, $10 \%$ de protídeos e $4,5 \%$ de lipídios (Alessi et al., 2003). Ao contrário do trigo e do arroz, que são refinados durante seus processos de industrialização, o milho conserva sua casca, que é rica em fibras, fundamental para a eliminação das toxinas do organismo humano.

O grão de milho é classificado botanicamente como uma cariopse. Apresenta basicamente três partes: pericarpo, endosperma e embrião. $O$ pericarpo é a camada fina e resistente que constitui a parede externa da semente, rica em fibra (Callegaro et al., 2005). O endosperma é a parte mais volumosa do grão, envolvida pelo pericarpo, e é constituída de substância reserva, basicamente $\mathrm{o}$ amido. A porção mais externa do endosperma e em contato com 0 pericarpo denomina-se camada de aleurona, rica em proteínas e enzimas que desempenham papel importante no processo de germinação. A proporção dos componentes anatômicos do grão de milho é endosperma, $82,3 \%$, embrião, $11,5 \%$ e pericarpo 5,3\% (Alessi et al., 2003). O grão de milho é rico em carboidratos; proteínas, que chegam até 9,5\%; vitaminas (complexo B1, B2 e E); sais minerais (ferro, fósforo, potássio, cálcio); óleo e grandes quantidades de açúcares, gorduras, celulose e calorias (Thé et al., 1989; EMBRAPA, 2007).

$\mathrm{Na}$ alimentação humana é comumente consumido como milho verde in natura, produto farináceo e constitui ingrediente básico de uma série de produtos industrializados formulados (Alessi et al., 2003). Cinqüenta gramas de farinha de 
milho fornecem (em proteínas) valores iguais aos de um pãozinho francês de mesmo peso, mas com 33\% a mais de calorias. Isso significa que o produto pode suprir as necessidades nutricionais da população, além de ser excelente complemento alimentar, in natura ou na forma de farinha de milho, de fubá, de canjica, de polenta, de cuscuz e outras (ABIMILHO, 2006). Os produtos industrializados podem ser componentes para a fabricação de balas, biscoitos, pães, chocolates, geléias, sorvetes, maionese e cerveja.

Além disso, grande parte de sua produção é utilizada na alimentação animal, como componente de rações para bovinos (Marques et al., 2000), suínos (Moreira et al., 2001) e aves (Rodrigues et al., 2001; Freitas et al., 2005), chegando até a alimentação humana na forma de diversos tipos de carne (bovina, suína, aves e peixes). Atualmente, somente $15 \%$ de produção nacional se destinam ao consumo humano e, mesmo assim, de maneira indireta, na composição de outros produtos. No Brasil, com imensas áreas cultiváveis e com graves problemas de desnutrição, mais do que simplesmente uma questão comercial, o consumo de milho por parte da população poderia ser, antes de tudo, uma solução social.

\subsection{Defensivos agrícolas, agrotóxicos ou pesticidas. Contexto atual}

Segundo a FAO, o mercado mundial de agrotóxicos alcançou 32 bilhões de dólares em 2000, sendo que a parcela de contribuição dos países em desenvolvimento foi de 3 bilhões de dólares. Os países em desenvolvimento têm empregado os agrotóxicos essencialmente na agricultura, mas também na saúde pública, como, por exemplo, os inseticidas para combater os mosquitos que provocam a malária (FAO, 2001).

A partir do fim da Segunda Guerra Mundial, o emprego dos pesticidas em áreas agrícolas passou a crescer de forma ininterrupta, como parte de um conjunto de ações que permitiu que se obtivesse a chamada "Revolução Verde". Desde então, a contaminação pelos pesticidas tem sido verificada, principalmente nos países mais desenvolvidos tecnologicamente. O Brasil, em 1970, tornou-se o terceiro consumidor de pesticidas do mundo, perdendo apenas para França e Estados Unidos. Sabe-se que, em média, apenas 1\% dos pesticidas aplicados consegue atingir efetivamente as pragas ou insetos a que se destina, o restante 
vai para solo, ar e água. Em 1991, o Brasil utilizou aproximadamente 3,2 milhões de toneladas de defensivos, sendo que apenas 300 mil toneladas cumprem a sua função (Matos, 2001).

No mercado brasileiro existem cerca de 600 ingredientes ativos, utilizados na formulação de pesticidas e registrados para uso específico na agricultura (Galli et al., 2006). Destes, 350 contribuem com 98\% dos pesticidas mais utilizados, sendo que $80 \%$ deles são rotineiramente usados na agricultura de países da América do Sul (Galli et al., 2006).

O crescimento da agricultura no Brasil tem provocado o aumento da venda de defensivos agrícolas; de 1993 a 2005, de 1.050 para 4.244 milhões de dólares. Em 1993, do total das vendas de defensivos agrícolas, cada classe representou, em milhões de dólares: herbicidas (589), inseticidas (196), fungicidas (176), acaricidas (74) e outros (25). Em 2005, as mesmas passaram a 1.736, 1.181, 1.090, 83 e 155 (em milhões de dólares), respectivamente (MAPA, 2005). Segundo o Instituto de Economia Agrícola (IEA, 2006), a participação das classes no valor de vendas de defensivos agrícolas no Estado de São Paulo foi de 40,9\%, para herbicidas; 27,8\%, para inseticidas; 25,7\%, para fungicidas; 1,9\%, acaricidas, e 3,7\%, para outras classes. Vale destacar que, tanto em âmbito mundial como nacional, a classe dos herbicidas representa a maior parcela.

Há crescimento nos estados, quando observados dados de 2006, obtidos do Sindicato dos Defensivos Agrícolas. Segundo esses dados, a venda de defensivos (no valor total de US\$ 348,1 milhões) perfizeram 104.233 toneladas; sendo $43,1 \%$ de herbicidas, $30,1 \%$ de inseticidas, $16,6 \%$ de fungicidas, $7,6 \%$ de acaricidas e 2,6\% de outras classes. Em 2006, o Estado de São Paulo foi o maior consumidor em todo o Brasil, perfazendo $20,6 \%$ do total consumido no país, seguidos de 17,9\% para o Estado de Mato Grosso e 13,4\% para o Paraná. As vendas de herbicidas em São Paulo estão voltadas principalmente para as culturas de cana-de-açúcar, soja, milho e café (SINDAG, 2007).

No aspecto econômico, dados referentes a 2000 indicam que 0 mercado mundial de agroquímicos movimenta US\$30 bilhões, sendo o Brasil, atualmente, o quinto maior consumidor de pesticidas, com a movimentação de US\$ 2,5 bilhões. Em 2006, o Brasil vendeu US\$ 3,92 bilhões de defensivos agrícolas (MAPA, 2005; SINDAG, 2007). 
O aumento da produção e aplicação de pesticidas para a agricultura e outros fins tem causado poluição do ar, solo e superfície de água, o que envolve sérios riscos ao meio ambiente bem como à saúde humana. Estes riscos se devem da direta exposição ou da ingestão direta por meio de alimentos. No mundo é relevante a presença de níveis de pesticidas e seus metabólitos (Sattler et al., 2007) no ar (Duyzer, 2003; Harner et al., 2006; Hamers et al., 2001), em mananciais e águas superficiais (Palma et al., 2004; Worral e Besien, 2005; Guzella et al. 2006; Du Preez et al., 2005), nas águas para consumo humano (Jones et al., 1995; Lambropoulou et al., 2007), em águas marinhas (Bocquené et al., 2005), no solo (Craven e Hoy, 2005; Close et al., 1998), bem como nos alimentos (Veneziano et al., 2004; ANVISA, 2006b; ANVISA, 2007; Ortelli et al., 2004; FDA, 2005; Looser et al., 2006; EU, 2007) e materiais biológicos (Proença et al., 2004). Os pesticidas estão entre os contaminantes sintéticos que mais se destacam na degradação dos recursos hídricos e cujos efeitos atingem diversos graus de toxicidade (Macedo, 2002). No Brasil, na sub-bacia do Pirapó, na bacia do Paraná, 97,2\% das amostras de água de abastecimento e 100\% das amostras procedentes dos mananciais apresentaram resíduos de pesticidas (Matos, 2001).

\subsection{Pesticidas}

Há inúmeras denominações e definições na literatura quanto aos agrotóxicos. E inúmeras denominações para designar sua ação: pesticidas, agrotóxicos, praguicidas, biocidas, defensivos agrícolas (Lara e Batista, 1992).

Dentre as definições, a legislação brasileira estabelece como agrotóxicos e afins como os:

produtos e agentes de processos, físicos, químicos e/ou biológicos destinados ao uso nos setores de produção, no armazenamento e beneficiamento de produtos agrícolas, nas pastagens, na proteção de florestas, nativas ou plantadas, e de outros ecossistemas e de ambientes urbanos, hídricos e industriais, cuja finalidade seja alterar a composição da flora ou da fauna, a fim de preservá-la da ação danosa de seres vivos considerados nocivos, bem como as substâncias e produtos empregados como desfolhantes, dessecantes, estimuladores e inibidores de crescimento (Brasil, 2002). 
Segundo Raven et al. (1995), pesticidas são grupos de substâncias químicas utilizadas na agricultura e em animais para controlar pestes e doenças; por exemplo, inseticidas para controlar os insetos, herbicidas para controle de plantas daninhas, fungicidas para fungos, rodenticidas para roedores, nematicidas para nematóides, carrapaticidas para controle de carrapatos. Os produtos agrícolas utilizados na agricultura recebem também o nome de defensivos agrícolas e seus remanescentes são os resíduos de pesticidas ou agrotóxicos.

No Codex Alimentarius, contaminante é qualquer substância que está presente em determinado alimento, não adicionada intencionalmente no alimento, como resultado da produção (incluídas as operações realizadas na agricultura, zootecnia e medicina veterinária), da fabricação, da elaboração, do tratamento, do envase, do empacotamento, do transporte ou do armazenamento de determinado alimento como resultado da contaminação ambiental. Este termo não se aplica aos fragmentos de insetos, roedores e outros materiais estranhos (FAO, 2007).

Pesticidas é qualquer substância destinada a prevenir, destruir, atrair, repelir ou combater qualquer praga, incluídas as espécies indesejadas de plantas ou animais, durante a produção, armazenamento, transporte, distribuição e elaboração de alimentos, produtos agrícolas ou alimentos para animais, que pode ser administrada aos animais para combater os ectoparasitos. O termo inclui também substâncias destinadas como reguladoras de crescimento de plantas, desfolhantes, dessecantes, agentes para reduzir a densidade da fruta ou inibidores de germinação e as substâncias aplicadas para os cultivos antes ou depois da colheita para proteger o produto contra a deterioração durante o armazenamento e o transporte. O termo não inclui os fertilizantes, nutrientes de origem vegetal ou animal, aditivos alimentares e medicamentos para animais (Codex Alimentarius, 2007).

Os agrotóxicos podem ser classificados quanto à ação e ao grupo químico. Os grupos químicos de agrotóxicos mais utilizados são: organoclorados, organofosforados, carbamatos, piretróides, ditiocarbamatos, benzimidazóis, triazinas e outros. Alguns grupos químicos, porém, podem apresentar diversos modos de ação. 
Os primeiros pesticidas sintéticos foram introduzidos nos anos 1940, porém após várias décadas de uso intenso, tornou-se evidente que estes produtos, pela sua característica de persistência e toxicidade, trariam efeitos prejudiciais aos organismos para os quais não se destinavam, inclusive os seres humanos (Macedo, 2002; Benn, 1991)

\subsubsection{Inseticidas - Carbamatos}

Os pesticidas n-metilcarbamatos são inseticidas alternativos da família dos organoclorados que têm aumentado o seu uso nos últimos anos devido à polaridade, labilidade, baixa persistência no meio ambiente e baixa toxicidade nos mamíferos (Delgado et al., 2001; Sun et al., 2003). Os carbamatos são um grupo de compostos com estrutura geral $\mathrm{R}_{1} \mathrm{OCONR} \mathrm{R}_{3}$, derivados do ácido carbâmico, com a introdução de diferentes substituintes (Delgado et al., 2001). Dentre os inúmeros carbamatos os mais usados mundialmente são aldicarbe, aldicarbe sulfona, aldicarbe sulfóxido, carbaril, carbofuran, metomil, metiocarbe, oxamil, pirimicarbe e propoxur (Goto et al., 2006). Os carbamatos em geral e seus produtos de transformação são de natureza polar e termicamente lábeis; estas propriedades limitam o uso de técnica de cromatografia gasosa para sua quantificação (Jeong et al., 1999; Delgado et al., 2001).

\subsubsection{Aldicarbe, aldicarbe sulfóxido e aldicarbe sulfona}
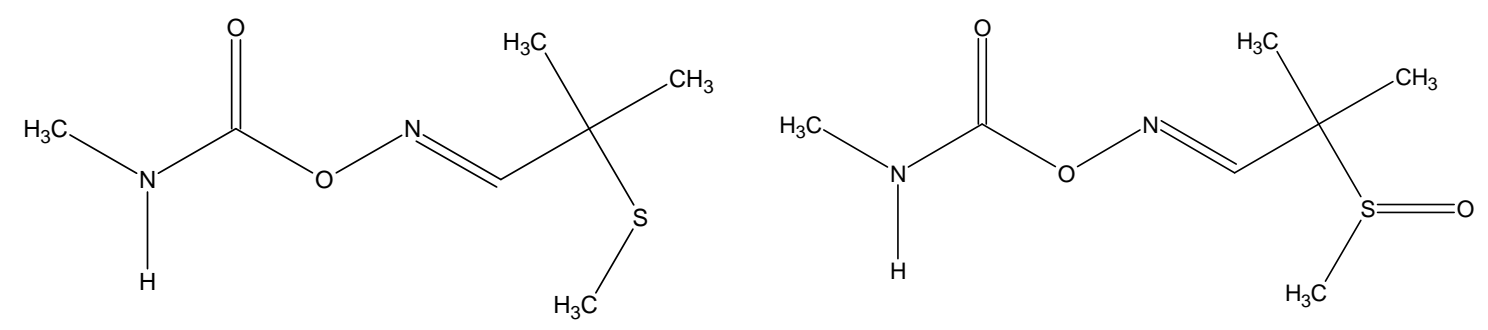

Figura 1 a - Estrutura química de aldicarbe Figura 1 b - Estrutura química de aldicarbe sulfóxido 


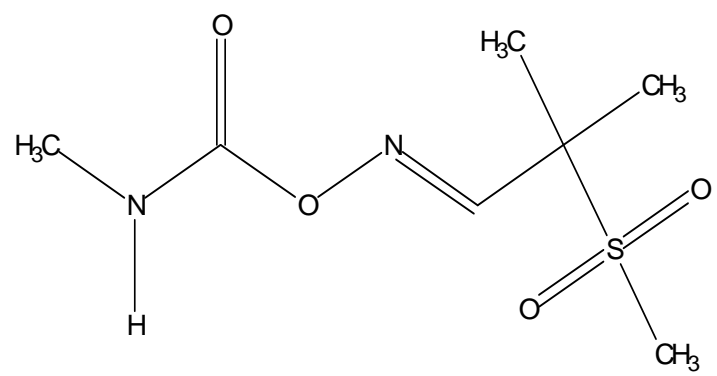

Figura 1 c - Estrutura química de aldicarbe sulfona

O aldicarbe, nome químico (IUPAC): 2-methyl-2(methylthio)propionaldehyde O-methylcarbamoyloxime, com estrutura química (Figura 1 a), conhecido como "Temik", é um inseticida sistêmico, acaricida e nematicida com ação de contato e estomacal. Na planta sua ação é sistêmica, com toxicidade aguda extremamente forte em mamíferos (Tomlin, 1994; IPCS, 2007; ANVISA, 2006a). Segundo a IARC (International Agency for Research on Cancer), o aldicarbe apresenta toxicidade aguda alta, mas não há dados para avaliar a carcinogenicidade no ser humano (IARC, 2007). O aldicarbe, no ser humano, pode ser absorvido via trato gastrintestinal, em contato com a pele e pela inalação na forma de pó. Quanto à toxicologia, o aldicarbe é classificado como um potencial cancerígeno, indutor de tumores, não havendo evidências de mutagenicidade e teratogenicidade. Aldicarbe é não cumulativo e é rapidamente metabolizado em plantas e animais. O produto inicial da degradação é muito tóxico para mamíferos (IPCS, 2007). Os inseticidas agrícolas nos locais onde são aplicados, além de atuarem sobre os insetos e pragas, podem causar a morte de outros animais, como aves, peixes, o que pode alterar o ecossistema, atingindo inclusive o ser humano.

No solo é aplicado para controle de diversos tipos de insetos, aranhas e nematóides. Tem sua ação de controle nos produtos como: batata-doce, beterraba, morango, batata, alho e centeio. É aplicado também em culturas de: uva, amendoim, soja, frutas cítricas, banana, café, sorgo, pecã, algodão, batatadoce, cana-de-açúcar e outros grãos (Tomlin, 1994).

Depois da aplicação, o aldicarbe é gradualmente transformado em aldicarbe sulfóxido (conforme estrutura química na Figura 1. b), e aldicarbe sulfona (conforme Figura 1. c), que pode degradar-se em oxima e na forma de nitrila. Em muitos casos, estes dois produtos da degradação podem sofrer 
hidrólise, formando produtos mais tóxicos que os de origem (Jones e Estes, 1995; Nunes, 2000). O aldicarbe é oxidado rapidamente para sulfóxido; $48 \%$ da conversão para sulfóxido ocorrem durante 7 dias depois da aplicação em certos tipos de solos. O sulfóxido é oxidado mais lentamente para sulfona. O aldicarbe sulfóxido é o composto de maior importância, devido à alta atividade sistêmica e à persistência da atividade inseticida em solo (Nunes, 2000). Em geral, a exposição da população por aldicarbe ocorre principalmente através de alimentos. A ingestão de alimentos contaminados conduz à incidência de metabólitos tóxicos (sulfóxido e sulfona).

\subsubsection{Carbaril}

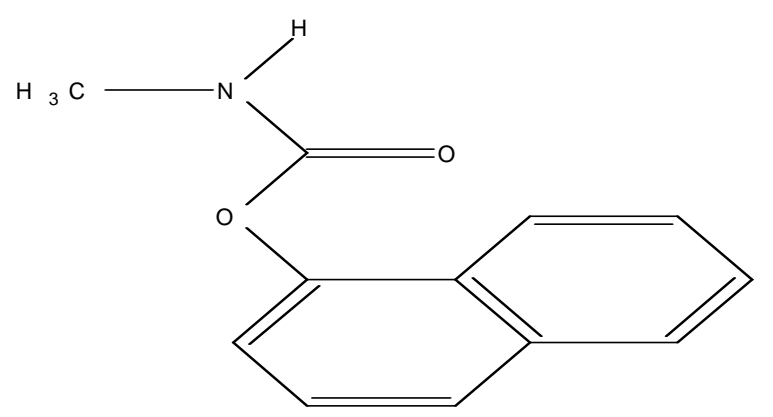

Figura 2 - Estrutura química de carbaril

O carbaril, nome químico (IUPAC): 1-naphthyl methylcarbamate e com estrutura química, conforme a Figura 2, é um inseticida com fraca propriedade sistêmica e com ação de contato e estomacal. Fraco inibidor de colinesterase, também age como regulador de plantas (Tomlin, 1994; IPCS, 2007; ANVISA, 2006a). Quanto à toxicidade de carbaril, não há evidências carcinogênicas, em camundongos, pelo crescimento de tumores, quando administrada a máxima dose diária no nível de $400 \mathrm{mg} / \mathrm{kg}$ (20 mg/kg/dia) por 80 semanas. A teratogenicidade é observada em descendentes de cachorros, com dose diária administrada de 6,35 mg/kg. Não foram observadas evidências de um efeito potencial mutagênico. O carbaril é moderadamente tóxico em humano, facilmente metabolizado, mas é provável o risco em dose aguda. Pode ser absorvido pela mucosa da boca, inalação do pó e em contatos extensivo através da pele (IPCS, 2007). Na agricultura é aplicado no controle de insetos de mais de 120 tipos de grãos, incluindo vegetais e frutas. Normalmente é utilizado em culturas de mangas, banana, morango, noz, videira, oliveira, amendoim, soja, algodão, arroz, 
fumo, beterraba, milho, sorgo, alfafa, batata, plantas ornamentais e matas (Tomlin, 1994; IPCS, 2007; ANVISA, 2006a).

\subsubsection{Carbofurano}

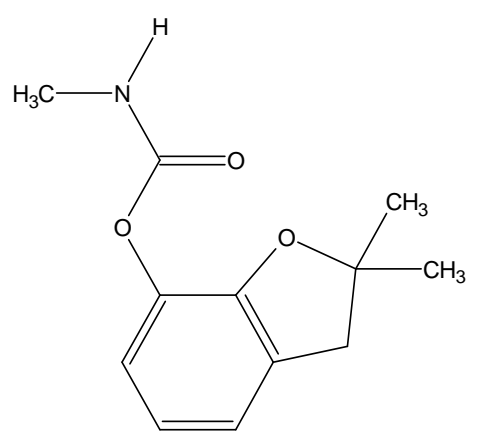

Figura 3 - Estrutura química de carbofurano

O carbofurano, nome químico (IUPAC): 2,3-dihydro-2,2dimethylbenzofuran-7-yl methylcarbamate e com estrutura química na Figura 3, é um inseticida e um nematicida com ação predominantemente de contato e estomacal, com ação de inibidora da colinesterase (Tomlin, 1994; IPCS, 2007; ANVISA, 2006). Não há evidência (a longo prazo) de carcinogenicidade, nas doses diárias administradas de $100 \mathrm{mg} / \mathrm{kg}$ (em ratos), $500 \mathrm{mg} / \mathrm{kg}$ (em camundongos) e, em cachorros dose de $400 \mathrm{mg} / \mathrm{kg}$. Quanto à teratogenicidade, não tem sido observadas evidências, considerando-se experimentos em rato em gestação, na administração de $1,20 \mathrm{mg} / \mathrm{kg} / \mathrm{dia}$ por 6 dias. Estudos em camundongos não consideram mutagenicidade para estes animais. No ser humano, pode ser absorvido no trato gastrintestinal, pelo contato com a pele, pela inalação do pó ou na forma de spray (IPCS, 2007). O carbofurano é empregado no controle do solo, de insetos foliares e nematóides em vegetais como: beterraba, milho, sorgo, couve-flor, grãos oleosos, batata, alfafa, amendoim, soja, cana-de-açúcar, arroz, algodão, café, tabaco, lavanda, laranja, videira, morango, bananas, cogumelos e outros grãos (Tomlin, 1994; IPCS, 2007; ANVISA, 2006a). Em animais, como em ratos, o carbofurano é metabolizado com mecanismo hidrolítico e mecanismo oxidativo. Depois de 24 horas de tratamento, $72 \%$ da dose é eliminada na urina, $2 \%$ nas fezes e em torno de $43 \%$ da dose administrada são hidrolisados. Acima de $95 \%$ do material excretado na urina é na forma de metabólitos conjugados 3-cetocarbofurano fenólico e 3-hidroxicarbofurano. Ambos 
os metabólitos estão presentes na forma livre. Nas plantas, o carbofurano é rapidamente metabolizado nos inseticidas 3-hidroxicarbofurano e cetocarbofurano. Em solo e água, decompõe-se de 30 a 60 dias após a aplicação (IPCS, 2007).

\subsubsection{Metiocarbe}

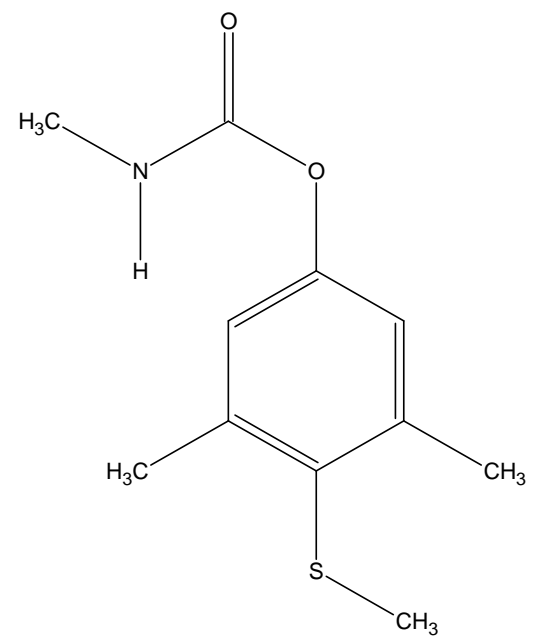

Figura 4 - Estrutura química de metiocarbe

O metiocarbe, nome químico (IUPAC): 4-methyltio-3,5-xylyl methylcarbamate e estrutura química na Figura 4, é um inseticida não-sistêmico e acaricida com ação de contato e estomacal. É um molusquiticida com ação neurotóxica (Tomlin, 1994; IPCS, 2007; ANVISA, 2006). De acordo com a Organização Mundial da Saúde, o metiocarbe, como ingrediente ativo e com grau técnico, é considerado como fortemente tóxico (WHO, 2004). É utilizado na cultura de milho, beterraba e também na criação de aves, como repelente. $O$ metiocarbe é aplicado também como controle de alguns insetos em pomares de frutas, morangos, batatas, milho, vegetais e plantas ornamentais (Tomlin, 1994; IPCS, 2007; ANVISA, 2006). 


\subsubsection{Metomil}

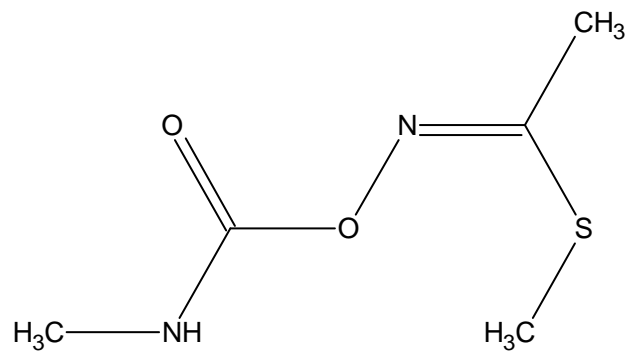

Figura 5 - Estrutura química de metomil

O metomil, nome químico (IUPAC): S-methyl N-(methylcarbamoyloxy) thioacetamidate e estrutura química (Figura 5), é um inseticida sistêmico e acaricida com ação de contato e estomacal (Tomlin, 1994; IPCS, 2007; ANVISA, 2006). Não há evidências de carcinogenicidade em estudos realizados em ratos, teratogenicidade em coelhos (na administração diária na dieta em níveis de 50 a $100 \mathrm{mg} / \mathrm{kg}$ por 8 a 16 dias de gestação). Não há evidências de alterações celulares em estudos realizados em coelhos. No ser humano, é absorvido no trato gastrointestinal, pelo contato com a pele e pela inalação do pó e na forma de spray (IPCS, 2007). O inseticida tem largo espectro para o controle de inúmeros insetos e aracnídeos de pequeno porte, sendo utilizado em frutas, videira, vegetais, plantas ornamentais, plantação de grãos, fibra, algodão, tabaco e soja (Tomlin, 1994; IPCS, 2007; ANVISA, 2006a).

\subsubsection{Pirimicarbe}

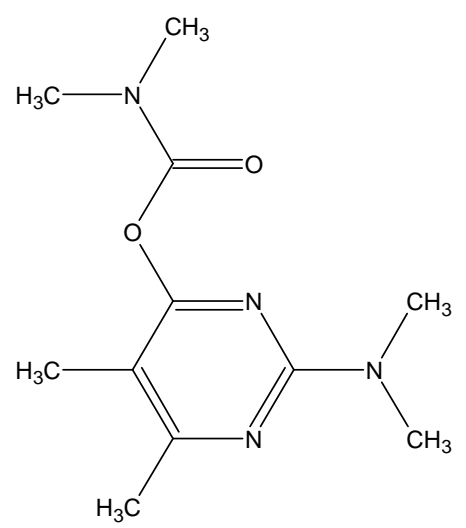

Figura 6 - Estrutura química de pirimicarbe

O pirimicarbe, nome químico (IUPAC): 2-dimethylamino-5,6dimethylpyridin-4-yl-dimetylcabamatee com estrutura química conforme Figura 6 , é um inseticida seletivo com ação de contato, estomacal e respiratório (Tomlin, 1994; IPCS, 2007; ANVISA, 2006). De acordo com a Organização Mundial da 
Saúde, o pirimicarbe, como ingrediente ativo e grau técnico, é considerado moderadamente tóxico (WHO, 2004). Para mamíferos não é carcinogênico e não apresenta efeitos reprodutivos adversos (Tomlin 1994). É utilizado em cereais, frutas, plantas ornamentais, morangos, batatas, cana-de-açúcar e forragem de beterraba, algodão, oliva, tabaco e grãos (Tomlin, 1994; IPCS, 2007; ANVISA, 2006a).

\subsubsection{Propoxur}

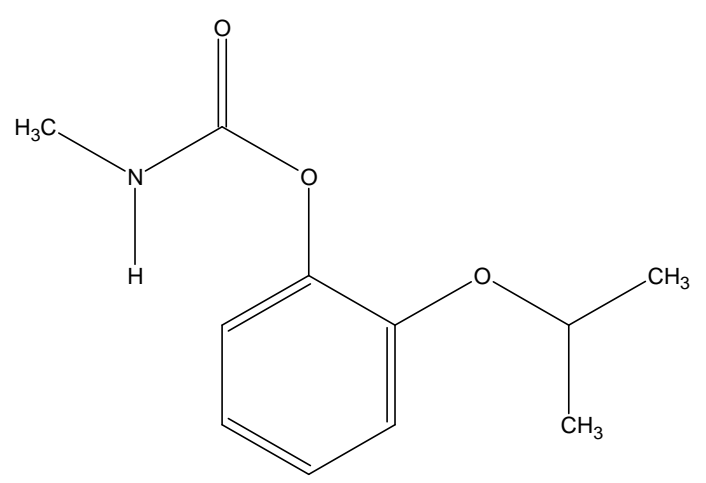

Figura 7 - Estrutura química de propoxur

O propoxur, nome químico (IUPAC): 2-isopropoxyphenyl methylcarbamate e estrutura química,conforme Figura 7, é um inseticida nãosistêmico com ação de contato e estomacal (Tomlin, 1994; IPCS, 2007; ANVISA, 2006a). De acordo com a Organização Mundial da Saúde, propoxur, como ingrediente ativo e grau técnico, é considerado moderadamente tóxico (WHO, 2004). Em estudos realizados em camundongos, o propoxur não apresentou efeito carcinogênico e teratogênico em camundongos. Em relação ao efeito mutagênico, não há dados para avaliação (IPCS, 2007). É utilizado nas culturas, áreas de estocagem de alimentos, casas domésticas e animais domésticos. É utilizado para combate em frutas, vegetais, plantas ornamentais, uva, milho, alfafa, soja, algodão, cana-de-açúcar, arroz, cacau e mata (Tomlin, 1994; IPCS, 2007; ANVISA, 2006a).

Os carbamatos são lipossolúveis e penetram no organismo pela pele íntegra, não necessitando de solução de continuidade. Esses produtos tóxicos não se acumulam no organismo, mas os efeitos podem se prolongar por períodos de várias semanas. Os compostos carbamatos atuam de maneira similar aos organofosforados, inibindo a enzima colinesterase, essencial para transmissão do impulso dos nervos (Proença et al., 2004; Macedo, 2002). A diferença é que a 
ligação química dos carbamatos com a enzima é fraca, a inibição é dita "reversível" e o desacoplamento molecular pode ocorrer rapidamente e espontaneamente, mas é normalmente de curta duração. A enzima colinesterase inibida pode ser reativada em questão de minutos ou horas, espontaneamente, e se tornar funcional novamente. Os compostos carbamatos não são retidos no organismo, por isso não apresentam efeito cumulativo. Este grupo é representado por grande número de inseticidas agrícolas e domésticos (Macedo, 2002).

\subsubsection{Herbicidas - Triazinas}

Outro grupo importante de herbicidas são as triazina. Um dos quais é a atrazina que, nos Estados Unidos, foi uma das que apresentou, nos últimos anos, o maior índice de venda. A descoberta das moléculas deste grupo químico ocorreu no início da década de 1950 pela empresa Geigy Química, de origem suíça. O uso comercial foi iniciado na década de 1960 e, desde então, a atrazina é o herbicida de maior uso mundial, devido ao extenso espectro de aplicação, principalmente no controle de folhas largas (Solomon et al., 1996). Estes herbicidas são derivados simétricos clorados da triazina, que é o produto da polimerização do cloro de cianogênio na presença de cloreto de alumínio anidro como catalisador (Macedo, 2002). O estudo sobre herbicidas (atrazina e simazina) tem importância devido à presença destes pesticidas em solos e águas de superfície por suas características de alta persistência e forte solubilidade, constituindo-se, assim, grande preocupação ao meio ambiente (Cai et al., 2004).

\subsubsection{Atrazina}

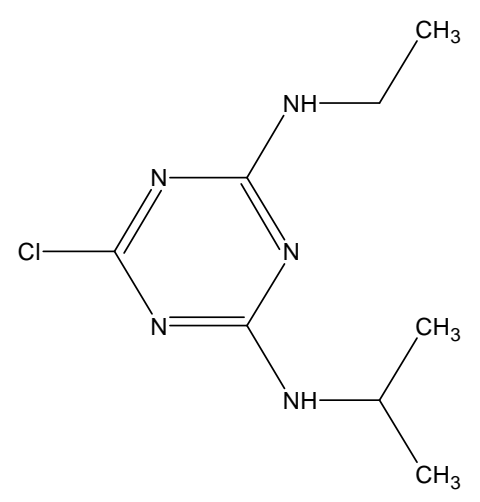

Figura 8 - Estrutura química de atrazina 
A atrazina, nome químico (IUPAC): 6 -chloro- $\mathrm{N}^{2}$-ethyl- $\mathrm{N}^{4}$-isopropyl-1, 3,5-triazine-2,4-diamine e com estrutura química conforme Figura 8, é um herbicida sistêmico, absorvido principalmente pelas raízes, mas também pelas folhagens (Tomlin, 1994). A atrazina tem apresentado toxicidade a longo prazo em ratos, camundongos e cachorro, mas não é considerada com evidências convincentes da carcinogenicidade em animais (IPCS, 2007). Segundo a IARC (2007), é considerada possivelmente cancerígena ao ser humano, com limite de evidência para animais de experimentação. Quanto à teratogenicidade, a atrazina demonstrou ser tóxica e letal em embriões, mas não em ratos e coelhos, quando administrada em doses tóxicas. Os resultados de testes de ensaio mostram a ausência de mutagenicidade. A atrazina pode ser absorvida pelo ser humano pelo trato gastrointestinal, inalação e pelo contato com a pele (IPCS, 2007). A atrazina é um herbicida pré e pós-emergente com eficiente bloqueio fotossintético, além do que interfere em outros processos enzimáticos. Este herbicida propicia um seletivo controle de gramas ou de erva daninha em plantações de: milho, sorgo, aspargo, uvas, frutas de pomares, frutas de bosque, cana-de-açúcar, banana, abacaxi, goiaba, café, palmeira e rosa. Na agricultura, pode ser aplicada em combinação com outros herbicidas (Tomlin, 1994; IPCS, 2007; ANVISA, 2006).

\subsubsection{Simazina}

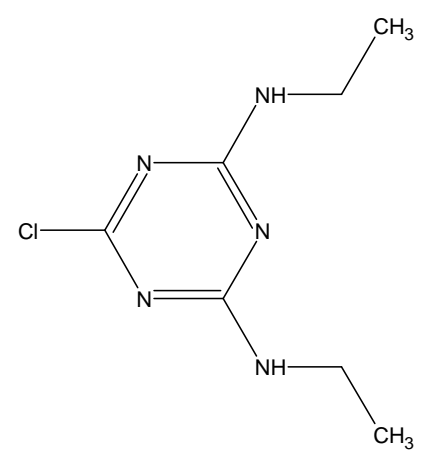

Figura 9 - Estrutura química de simazina

A simazina, nome químico (IUPAC): 2-chloro- $\mathrm{N}^{2}, \mathrm{~N}^{4}$ - diethyl- 1, 3, 5triazine-2,4-diamine e com estrutura química conforme Figura 9, é um herbicida seletivo sistêmico, absorvido pelas raízes (Tomlin, 1994; IPCS, 2007; ANVISA, 2006). De acordo com a Organização Mundial da Saúde, é desconhecida a toxicidade da simazina como ingrediente ativo e grau técnico em uso normal (WHO, 2004). É utilizada no controle de gramas, pomares de frutas, frutas cítricas 
e em culturas de: uva, morango, noz, oliveira, abacaxi, feijão, ervilha, milho, cereal doce, aspargo, alfafa, cana-de-açúcar, cacau, café, borracha, palmeira, chá, plantas ornamentais e florestas (Tomlin, 1994; IPCS, 2007; ANVISA, 2006a).

Tanto a simazina como a atrazina são usadas em plantações de milho e outros produtos agrícolas, sendo que a primeira tem importante aplicação, pois, em altas dosagens, extermina ervas daninhas de modo persistente e não seletivo, sendo usada nas margens de rodovias e ferrovias (Benn, 1991).

\subsubsection{Fungicidas - Benzimidazóis}

Os pesticidas fungicidas são largamente utilizados na indústria, agricultura e em uso doméstico, com grande número de propósitos: no processo de estocagem e durante a embarcação, para proteção de grãos e sementes. São enormes os efeitos potenciais, causando efeitos adversos à saúde humana (Blasco et al., 2003).

Os pesticidas sistêmicos são fungicidas largamente usados na agricultura, principalmente no tratamento pré e pós-colheita, para controle de pragas em frutas, verduras e vegetais patógenos. São pesticidas muitos detectados durante os programas de monitoramento para avaliar a exposição destes fungicidas pelos alimentos. Os principais compostos da família dos benzimidazóis são: benomil, carbendazim, tiabendazol e tiofanato metílico.

O benomil é um fungicida sistêmico aplicado em solo para controle de doenças de uma variedade de frutas. O carbendazim se degrada em dois compostos, que são o benomil e o tiofanato metílico (Anastassiades et al., 1998), fungicidas sistêmicos usados também no combate de muitas doenças (Venenziano et al., 2004). É de se acreditar que a atividade fúngica do benomil é devida à presença de carbendazim (Guan et al., 1994). Por esta razão os fungicidas benzimidazóis em alimentos constituem um significante risco à saúde humana (Banks et al., 1997; Urani et al., 1995). 


\subsubsection{Carbendazim}

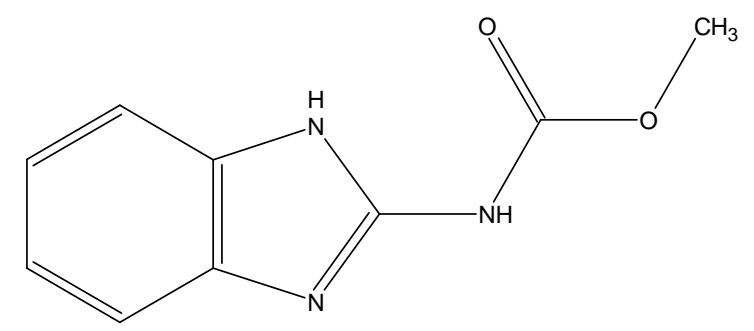

Figura 10 - Estrutura química de carbendazim

O carbendazim, nome químico (IUPAC): methyl benzimidazol-2ylcarbamate e com estrutura química (Figura 10), é um fungicida sistêmico com ação de proteção e curativa. É absorvido pela raiz e tecidos verdes (Tomlin, 1994; IPCS, 2007; ANVISA, 2006a). Em muitos estudos, efetuados em camundongos em ambos os sexos, a carcinogenicidade de carbendazim é observada pela presença de tumores. Carbendazim causa crescimento de células com máformações e anomalias em ratos com 7 a 16 dias de gestação, quando administrado em doses diárias acima de $10 \mathrm{mg} / \mathrm{kg} / \mathrm{dia}$. Não há efeitos dominantes adversos no teste de mutação letal ou fetal em ratos e camundongos. Não há dados para avaliação da absorção humana, somente em animais, nos quais o carbendazim é absorvido via trato gastrointestinal. Ele pode fracamente ser absorvido por inalação e através de contato com a pele (IPCS, 2007). É aplicado para o controle de doenças fúngicas nos cereais, frutas (cítricas, morangos, bananas, abacaxis, magas, abacate, uvas e outras), vegetais, plantas ornamentais, café, algodão, arroz, fibra, feijão, cana-de-açúcar, amendoim, borracha, fumo, cogumelo e outros grãos (Tomlin, 1994; IPCS, 2007; ANVISA, 2006a).

\subsubsection{Tiabendazol}

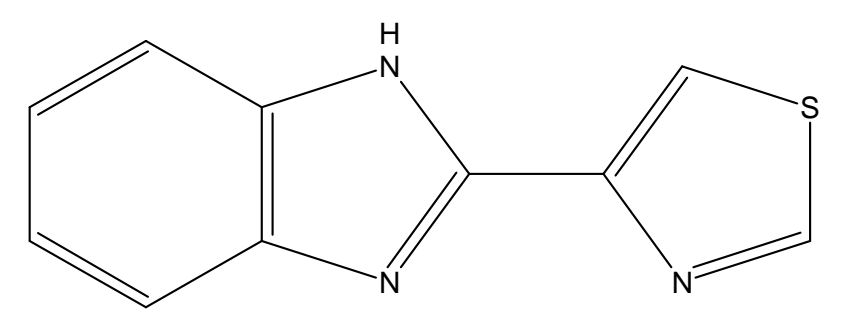

Figura 11. - Estrutura química de tiabendazol 
O tiabendazol, nome químico (IUPAC): 2-(thiazol-4-yl)benzimidazole; 2(1,3-thiazol-4-yl)benzimidazole e com estrutura química (Figura 11), é um fungicida sistêmico com ações de proteção e curativa (Tomlin, 1994; IPCS, 2007; ANVISA, 2006a). De acordo com a Organização Mundial da Saúde, é desconhecida a toxicidade do tiabendazol, como ingrediente ativo e grau técnico, em uso normal (WHO, 2004). É aplicado nas culturas de aspargo, abacate, banana, cevada, feijão, repolho, aipo, chicória, cereja, frutas cítricas, algodão, fibra, manga, cogumelo, aveia, cebola, plantas ornamentais, soja, morango, frutas de pomares, batata, arroz, beterraba, batata-doce, fumo, tomate, videira e trigo. É também utilizado no tratamento para controle de doenças de frutas estocadas (Tomlin, 1994; IPCS, 2007; ANVISA, 2006a).

\subsubsection{Tiofanato metílico}

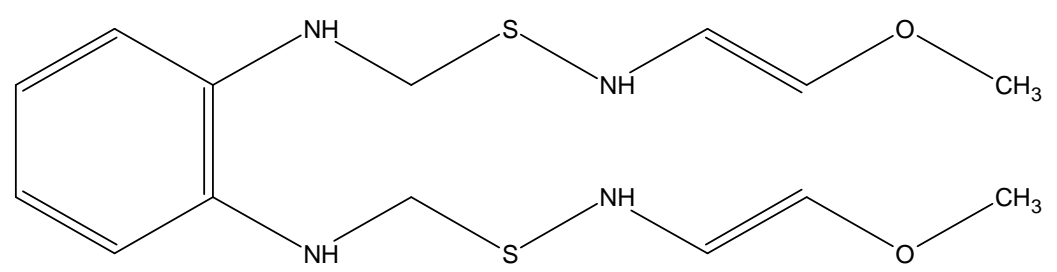

Figura 12. - Estrutura química de tiofanato metílico

O tiofanato metílico, cuja nomenclatura segundo a IUPAC é: dimethyl 4,4'-(o-phenylene)bis(3-thioallophanante) e com estrutura química (Figura 12), é um fungicida com ação de proteção e curativa de diversas doenças provocadas por fungos patogênicos em plantas (Tomlin, 1994; IPCS, 2007; ANVISA, 2006a). De acordo com a Organização Mundial da Saúde, é desconhecida a toxicidade do tiofanato metílico, como ingrediente ativo e grau técnico, em uso normal (WHO, 2004). É utilizado para o combate de inúmeros fungos que aparecem em: cereais, peras, maçãs, vegetais, morango, videira, oliveira, aipo, arroz, banana, soja, fumo, rosa, cana-de-açúcar, figos, amora, chá, café, amendoim, castanha e outro grãos (Tomlin, 1994; IPCS, 2007; ANVISA, 2006a).

A tendência atual é o desenvolvimento de pesticidas que tenham a meia-vida curta, com tempo suficiente para o controle de pragas, tal como os fungicidas sistêmicos, e que, embora altamente tóxicos, apresentam menor persistência no meio ambiente (Matos, 2001). 


\subsection{Método analítico}

A quantidade e a variedade de produtos aplicados na agricultura e na pecuária aumentaram verticalmente no Brasil (Figura 13), tornando necessário o monitoramento de eventuais resíduos no meio ambiente e nos alimentos (Sanches et al., 2003), bem como a avaliação de risco pela ingestão de alimentos (Caldas e Souza, 2000). A tendência das empresas fabricantes de defensivos agrícolas é pesquisar e sintetizar moléculas de maior complexidade e caráter polar com alta eficiência de ação pesticida. Por outro lado, se faz necessário o desenvolvimento de métodos analíticos de alta rastreabilidade para maior número de princípios ativos, com alta sensibilidade de quantificação e confirmação. Para tanto, têm sido desenvolvidos métodos analíticos para quantificar os resíduos de pesticidas, possibilitando mensurar e avaliar os riscos de contaminação humana.

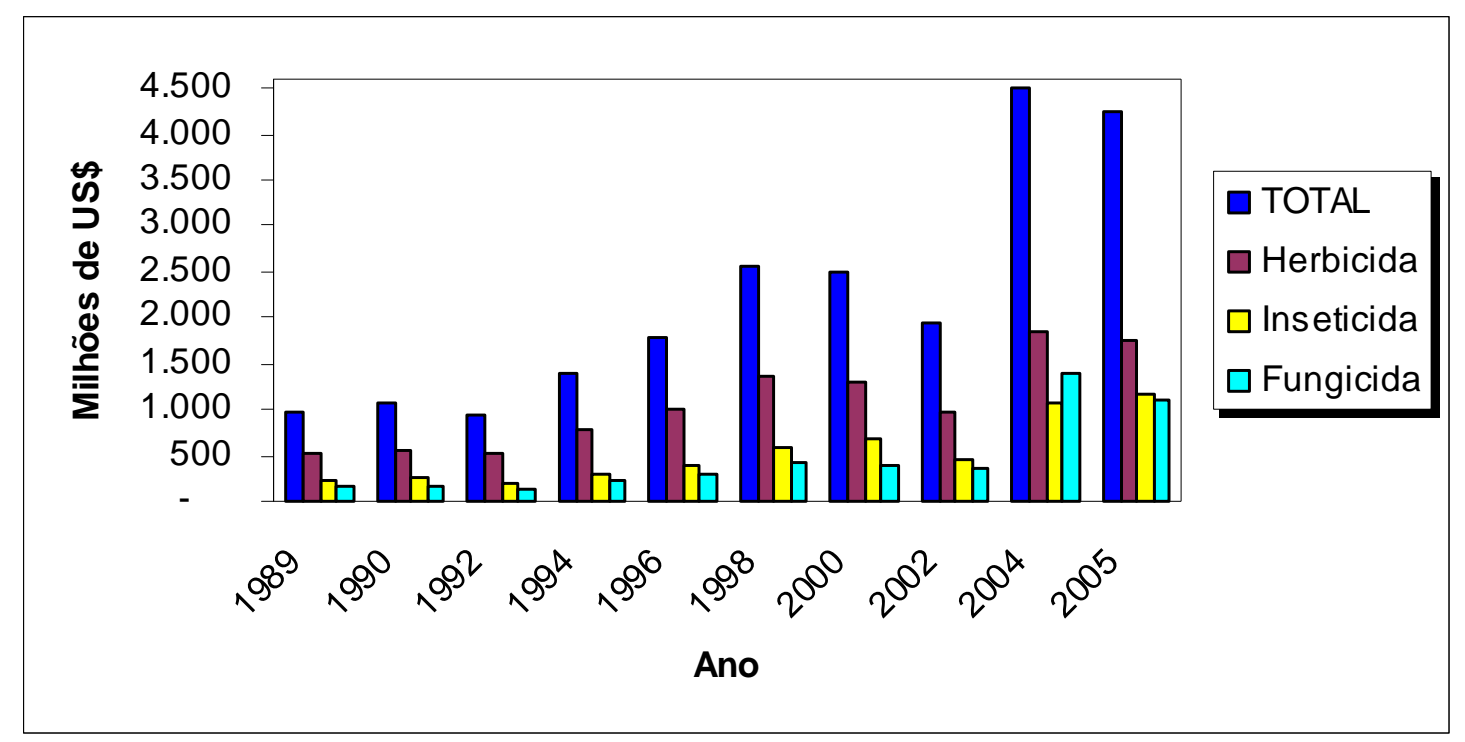

Fonte: MAPA, 2006

Figura 13 - Total de vendas por classe de defensivos agrícolas, no período do ano de 1989-2005

O avanço do conhecimento científico, aliado ao desenvolvimento tecnológico na área laboratorial, têm permitido a verificação da qualidade e segurança alimentar em relação à presença de agrotóxicos em níveis não prejudiciais ao ser humano (Martins, 2005). 


\subsubsection{Método multirresíduo}

O método multirresíduo, para determinação de resíduos de pesticidas é normalmente adotado em laboratórios, pela simplicidade de determinação de muitos pesticidas de diversas classes e de grande número de princípios ativos, após uma simples extração, facilitando a demanda rápida e eficiente do monitoramento (Hernandez et al., 2006). A preparação da amostra é, freqüentemente, a fase crítica de um método mutlirresíduo, com a possibilidade da diversidade de substâncias que podem ser extraídas (Ortelli et al., 2004) e a ineficiência de extração dos analitos de interesse aplicados em matrizes com características e composição próprias. Os pesticidas são moléculas de estruturas complexas, com características químicas diferentes, como polarizabilidades e estabilidades, e muitas vezes se degradam rapidamente, no procedimento analítico, a seus metabólitos ou a outros produtos.

\subsubsection{Extração - Método multirresíduo}

Muitos estudos de métodos multirresíduos de pesticidas do grupo de carbamatos, triazinas e benzimidazóis têm sido descritos utilizando diferentes solventes ou mistura de solventes na etapa de extração, aplicados em diferentes matrizes.

Pang et al. (2006) estudaram o método multirresíduo para a determinação de pesticidas do grupo organoclorados, organofosforados, carbamatos, triazinas, piretróides e outros, em tecidos animais, utilizando, para a extração, uma mistura de solventes: cicloexano e acetato de etila (1:1).

Métodos multirresíduos têm sido descritos utilizando um único solvente ou mistura de solventes para as extrações de pesticidas em alimentos como frutas, vegetais, cereais e alimentos infantis processados.

Pizzutti et al. (2007) utilizaram uma mistura de solventes, acetona, diclorometano e éter de petróleo na proporção de $(1: 1: 1)$, para o estudo da extração de pesticidas na soja.

O solvente acetato de etila foi empregado para a extração de pesticidas em diferentes matrizes de frutas, vegetais e cereais. Ortelli et al. (2004) utilizaram em matriz de frutas (limão, uva, morango, maçã, nectarina) e vegetais (salada 
verde, pepino, cenoura, espinafre, batata e pepino). Goto et al. (2006) extraíram em frutas e vegetais (espinafre, tomate, batata, maçã pepino e amendoim). Em outro estudo, o solvente acetato de etila, Jansson et al. (2004), utilizaram para a extração de pesticidas em misturas de frutas e vegetais. As misturas de frutas e vegetais eram divididas conforme as suas propriedades e o consumo do alimento. O mesmo solvente foi utilizado para a extração em frutas, tais como: laranja, tangerina, pêssego e nectarina por Blasco et al. (2005).

A mistura de solventes, acetonitrila e ácido acético (99:1), foram aplicados para a extração de pesticidas em alimento infantil à base de cereal, tomate e batata (Leandro et al. 2007); e para maçã, sendo esta técnica descrita por Kovalczuki et al. (2006).

Hernández et al. (2006) extraíram os pesticidas com solvente metanol: água (8:2) em 1\% de ácido fórmico em matrizes de frutas como tomate, limão, uva seca e abacate.

A solução de $20 \mathrm{mM}$ (milimolar) de acetato de amônio de metanol e água, em proporção de (95:5), foi utilizada para a extração de pesticidas em frutas (maçã, abacate, laranja); vegetais (cenoura e alface) e cereal (trigo) (Granby et al., 2004).

Em uvas, Otero et al. (2007), para a extração pelo método multirresíduo de fungicidas, utilizaram uma mistura de diclorometano: acetona $(75: 25, \mathrm{v} / \mathrm{v})$.

A mistura de solventes, acetona - diclorometano - hexano, na proporção de (50:20:30, v/v/v), foi utilizada para extração de maçãs e peras, método multirresíduo de pesticidas (Lacassie et al., 1998).

\subsubsection{Quantificação e/ou confirmação}

A quantificação de resíduos de pesticidas, nos mais diferentes meios e matrizes, é tradicionalmente realizada usando-se técnicas cromatográficas. Estas técnicas têm sua importância na análise química em função de sua facilidade para efetuar as separações, identificar, quantificar e confirmar as espécies presentes na amostra, por meios de detectores específicos (Sanches et al., 2003). 
As aplicações das técnicas cromatográficas cresceram intensamente nos últimos 50 anos; isto se deve não somente ao desenvolvimento de novos tipos de técnicas de preparação, separação e detecção, mas também pela necessidade crescente de técnicas mais precisas e sensíveis para a caracterização e quantificação de pesticidas de interesse em matrizes complexas, tais como alimentos, águas, ar, solo e fluidos biológicos (Sanches et al., 2003).

Pesticidas não-voláteis e termolábeis e altamente polares têm surgidos nos últimos anos, incluindo carboxiamidas, quinazolinas, pirimidinas, triazóis, carbamatos, neonicotinóides e morfolina. A cromatografia líquida tem sido uma técnica aplicada na determinação destes compostos (Sanino et al., 2004).

Para a quantificação de resíduos de pesticidas do grupo de carbamatos, benzimidazóis e triazinas em diferentes matrizes de alimentos, a técnica analítica de quantificação usual tem sido a cromatografia líquida de alta eficiência (HPLC), com diferentes detectores de ultravioleta (Pinto e Jardim, 2000; Melo et al., 2005), diodo array (Otero et al., 2007; López-Blanco et al., 2002), fluorescência (Caballo-López e Castro, 2003; Abad et al., 1999) e acoplado ao espectrômetro de massas. Atualmente, a técnica de cromatografia líquida (LC) acoplada ao espectrômetro de massas, com diferentes modos de ionização, analisadores e detectores, tem despontado como técnica analítica de alto potencial, na análise de resíduos de pesticidas de compostos com características polares, iônicos e baixas volatilidade.

\subsubsection{Espectrometria de massas}

Um espectrômetro de massas é um instrumento composto basicamente por três unidades fundamentais: uma fonte de íons, um analisador ou filtro de massas e um sistema de detecção. A fonte de íons tem a finalidade de gerar íons a serem analisados na fase gasosa a partir das amostras de interesse (Bustillos et al., 2003). O analisador de massas emprega combinações entre campos elétricos e magnéticos para separar íons gerados na fonte de ionização de acordo com as suas razões massa/carga $(\mathrm{m} / \mathrm{z})$. O detector tem a finalidade de quantificar os íons provenientes do analisador de massas (Ashcroff, 1997). 
Como fontes de ionização, diferentes técnicas podem ser empregadas em virtude do estado físico e propriedades da amostra, tais como a polaridade, a estabilidade térmica e o peso molecular. São muitas formas de ionização utilizadas em espectrometria de massas: ionização por elétrons (El), ionização química $(\mathrm{Cl})$, ionização por átomos/íons rápidos (FAB/FIB), ionização por termospray (TSP), ionização por electrospray (ESI), ionização química à pressão atmosférica $(\mathrm{APCl})$, fotoionização à pressão atmosférica (APPI), ionização por dessorção a laser assistida pela matriz (MALDI) e outros (Martins, 2005).

Os analisadores de massas são responsáveis pela separação ou resolução dos íons de acordo com a relação $\mathrm{m} / \mathrm{z}$. Estes analisadores são empregados de várias formas, dependendo da necessidade da resolução de massas, da compatibilidade com a interface e com o sistema de ionização empregado. Os analisadores de massas mais comumente empregados são: simples, quadrupolo, íon trap, time of flight (TOF) ou tempo de vôo e setor magnético (Martins, 2005).

Os sistemas de detecção responsáveis pela quantificação dos íons e conversão destes íons em sinais eletrônicos podem ser classificados como detectores com e sem multiplicação de elétrons. No primeiro grupo encontram-se os multiplicadores de elétrons, diodos contínuos e fotomultiplicadores. No segundo grupo estão incluídos os copos de Faraday (Faraday cups), que são dispositivos metálicos que geram uma corrente elétrica capturando o feixe de íons. Diferentes estratégias e configurações podem ser empregadas em cada constituinte dos espectrômetros de massas de acordo com a aplicação específica (Martins, 2005).

Equipamentos modernos de LC acoplado ao espectrômetro de massas têm mostrado resultados de altas sensibilidade e seletividade para resíduos de pesticidas, e são capazes de analisar em níveis de traços de ppb a ppt (partes por bilhão e partes por trilhão), em diferentes matrizes e compostos (Sanino et al., 2004). 
Em anos recentes, muitos estudos de quantificação e confirmação de resíduos de pesticidas das classes de carbamatos, triazinas e benzimidazóis em alimentos têm sido aplicados à cromatografia líquida acoplada à espectrometria de massas com diferentes tipos de ionização, analisadores e sistemas de detecção.

Fernández et al. (2001) estudaram a determinação de fungicidas benomil, carbendazim, imazalil, tiabendazol, tiofanato metílico em laranjas utilizando a técnica de cromatografia líquida (LC) acoplada ao espectrômetro de massas (MS) com ionização à pressão atmosférica (APCl). A média de recuperação em quintuplicatas obtidas em níveis de 0,05 a 5,0 (mg. $\left.\mathrm{kg}^{-1}\right)$ foi de 79\%, para carbendazim e benomil; 77\%, imazalil; 75\%, para tiabendazol, e 56\%, para tiofanato metílico. A baixa recuperação de tiofanato metílico se deveu possivelmente à conversão para carbendazim, que depende do $\mathrm{pH}$, e às condições de extração.

Estudo realizado por Nunes et al. (2000) utilizou uma comparação de técnica de LC com detector de fluorescência pós-coluna (FL) e a espectrometria de massas com ionização APCI para a determinação de aldicarbe, aldicarbe sulfóxido e aldicarbe sulfona em batata, laranja e tomate. A técnica de LC-FL mostrou resultados de melhor precisão e exatidão em nível de recuperação de $100 \mu \mathrm{g} . \mathrm{kg}^{-1}$. Os limites de detecção para a técnica LC-FL foram menores de 0,2 ng para aldicarbe e aldicarbe sulfóxido e 0,3 ng para aldicarbe sulfona. Para a técnica LC-MS os limites foram 0,5; 0,5 e 1,3 ng, respectivamente.

Hernández et al. (2006) estudaram 52 pesticidas por LC-MS/MS, ionização electrospray (ESI), em frutas como tomate, limão, uva seca e abacate. As recuperações (em nível de 0,01 e 0,1 mg. $\mathrm{kg}^{-1}$ ) apresentaram-se na faixa de 70 a $110 \%$, com precisão satisfatória de coeficiente de variação $\leq 15 \%$. Três pesticidas, metamidofós, aldicabe e etiofencarbe, apresentaram, em todas as matrizes, baixos níveis de recuperação, principalmente pela parcial degradação durante 0 tratamento da amostra. Muitos pesticidas de baixa polaridade mostraram baixa recuperação para abacate por serem de matriz com alta concentração de lipídio, o que provavelmente dificultou a extração com metanol: água (8:2). O limite de quantificação do método estabelecido foi de $0,01 \mathrm{mg} \cdot \mathrm{kg}^{-1}$ para todos os princípios ativos estudados. 
Goto et al. (2006) estudaram método para a análise de carbamatos em frutas, utilizando a técnica LC-MS/MS com ionização ESI. O estudo da recuperação, em níveis de 0,01 e $0,5 \mu \mathrm{g} \cdot \mathrm{g}^{-1}$ comparados durante 3 dias consecutivos do experimento, mostrou-se insatisfatório para aldicarbe, metiocarbe e pirimicarbe. O limite de quantificação estimado é de $0,005 \mu \mathrm{g} \cdot \mathrm{g}^{-1}$ para cada pesticida em frutas e vegetais.

Granby et al. (2004) propuseram a análise de 19 pesticidas como aldicarbe, aldicarbe sulfóxido, aldicarbe sulfona, carbaril, carbendazim, metiocarbe, propoxur, tiabendazol, tiofanato metílico e outros por LC-MS/MS com ionização ESI em frutas, legumes e cereais. A precisão do método foi estimada para material de referência certificado no teste de proficiência. Para muitos dos pesticidas a recuperação variou na faixa de 70 a $110 \%$. O limite de quantificação para muitos dos pesticidas em frutas e vegetais variou de 0,01 a 0,02 mg. $\mathrm{kg}^{-1}$.

Leandro et al. (2007) estudaram 52 pesticidas, dentre os quais: aldicarbe, aldicarbe sulfóxido, aldicarbe sulfona, carbaril, carbendazim, metomil e tiabendazol, para cereal tendo como base a tecnologia utilizada para alimentos infantis, laranjas e batatas. A técnica de quantificação e confirmação foi cromatografia líquida de ultra performance (LC UP) com ionização ESI. A recuperação do método (\%) e o coeficiente de variação $(\mathrm{CV})$ obtidos na maioria dos pesticidas fortificados em níveis de 0,10 e 1,00 mg. $\mathrm{kg}^{-1}$ foram de 73 a $124 \%$, CV < 18\% para batata; laranja, 66-118\%, CV < 17\% e cereal baseado em alimentos infantis, $73-114 \%$ e CV $<19 \%$.

Hiemstra e Kok (2007) estudaram método multirresíduo em frutas, vegetais e cereais utilizando a técnica de LC-MS/MS, com triplo quadrupolo e com ionização electrospray (ESI). Foram detectados 171 pesticidas e seus metabólitos em diferentes matrizes de grãos. Os resultados de recuperação, fortificados em três níveis que variaram de 0,01 a $0,10 \mathrm{mg} \cdot \mathrm{kg}^{-1}$, foram de 70 a 110\%, com desvio padrão relativo de até $15 \%$. O limite de quantificação de todos os analitos estudados foi de $0,01 \mathrm{mg} \cdot \mathrm{kg}^{-1}$.

Zamora et al. (2004), utilizando a técnica de LC-ESI-MS-MS, validaram o método de determinação de fungicidas (tridemorfe carbendazim, tiabendazole, imazalil, propiconazole e bitertanol) em laranjas e bananas. As amostras foram extraídas em uma única etapa de extração em acetona e acetonitrila. Dentre os solventes de extração, a acetona apresentou o resultado mais eficiente para estes 
compostos e matrizes. Os limites de detecção para todos os compostos variaram de 0,005 a $0,025 \mathrm{mg} \cdot \mathrm{kg}^{-1}$ e o limite de quantificação foi de $0,05 \mathrm{mg} \cdot \mathrm{kg}^{-1}$ para todos os compostos. Para o estudo da recuperação, em níveis de $0,05 \mathrm{mg} \cdot \mathrm{kg}^{-1} \mathrm{e}$ $1,0 \mathrm{mg} \cdot \mathrm{kg}^{-1}$, os resultados das médias de recuperações nos dois níveis variaram de 75 a 96\%, para banana, e 83 a 99\%, para laranja, e os coeficientes de variação de 3 a $12 \%$ e de 4 a $12 \%$ para banana e laranja, respectivamente. Dentre as 9 amostras de bananas analisadas, em 3 amostras foram detectadas bitertanol e imazalil, em 4 amostras, tiabendazol, e em 1 amostra, tridemorfe, sendo que em nenhuma amostra foi detectado carbendazim. Em 13 amostras de laranja analisadas, todas se apresentaram positivas para imazalil e em 11 amostras foi detectado tiabendazol, porém somente 1 das amostras apresentou (em níveis acima dos LMR) imazalil e tiabendazol. Em uma amostra foi detectado carbendazim e nenhuma das amostras apresentou sinais de bitertanole e tridemorfe. A presença da alta incidência de fungicidas pós-emergentes (tiabendazol e imazalil) em laranjas se deve à aplicação usual destes fungicidas em frutas cítricas. Nas amostras de banana, ocorreu detecção positiva de tiabendazol, bitertanole e imazalil em 3 amostras, sendo que somente uma amostra de banana apresentou níveis acima do LMR.

Jansson et al. (2004) apresentaram resultados da influência do efeito da matriz do método multirresíduo para carbamatos e benzimidazóis em misturas de frutas e verduras, por LC-MS/MS com ionização ESI. O efeito da matriz é variável, resultando em efeitos de supressão ou sobreposição para uma combinação específica de pesticidas e matrizes. Os resultados de quantificação dos pesticidas podem ser afetados em valores maiores ou menores de $30 \%$ na resposta do detector, resultante de efeitos positivo e negativo na matriz. Não é recomendado aplicar o efeito matriz para um determinado pesticida para predizer este efeito aos demais pesticidas. O efeito matriz depende de cada composto e da coeluição de componentes da matriz que interage com os pesticidas, na fase de ionização, na interface. As médias de recuperação dos pesticidas em níveis de fortificações de $0,01,0,05$ e $0,5 \mathrm{mg} \cdot \mathrm{kg}^{-1}$, na maioria dos casos, foi maior que $70 \%$ em cada nível e em todas as misturas de matrizes. O tiofanato metílico apresentou baixo resultado das médias de recuperações e altos coeficientes de variação em todos os níveis de recuperação estudados. Para o nível de fortificação de $0,01 \mathrm{mg} \cdot \mathrm{kg}^{-1}$, a média de recuperação foi de $44 \%$ e o coeficiente de 
variação cerca de $82 \%$; já em nível de $0,05 \mathrm{mg} \mathrm{kg}^{-1}, 54 \%$ e $56 \%$, respectivamente e para $0,5 \mathrm{mg} \cdot \mathrm{kg}^{-1}, 45 \%$ de recuperação e $43 \%$ de coeficiente de variação. Estes dados são decorrentes da decomposição de tiofanato metílco para carbendazim.

Pizzutti et al. (2007) desenvolveram método multirresíduo em grãos de soja utilizando a técnica LC-MS/MS com ionização ESI. Dos 169 pesticidas estudados, mais de $70 \%$ destes pesticidas analisados apresentaram recuperação variando de 70 a $120 \%$, com coeficiente de variação $\leq 20 \%$ em três níveis de fortificação, $10,50,100 \mu \mathrm{g} \cdot \mathrm{kg}^{-1}$. O limite de quantificação do método variou de 10 a $50 \mu \mathrm{g} \cdot \mathrm{kg}^{-1}$.

Em estudo realizado por Ferrer et al. (2005) utilizando o método multirresíduo em frutas e vegetais foi aplicada a técnica LC acoplado ao espectrômetro de massas com ionização (ESI) com analisador tempo de vôo (TOF). Foi estudado o efeito da matriz de 15 pesticidas em pimenta, limão, laranja, brócolis, maçã e tomate. O efeito da matriz foi avaliado em relação ao sinal supressão/intensificação comparando-se a inclinação da curva de calibração com o extrato da matriz/solvente. Dentre os pesticidas e matrizes estudados, observou-se que o carbendazim não interfere no efeito da matriz. Por outro lado, muito dos pesticidas, demonstraram forte interferência da matriz nos resultados da análise. $O$ efeito supressão ou intensificação das matrizes era freqüentemente observado em valores maiores que $20 \%$, principalmente para brócolis e frutas cítricas.

Goto et al. (2005) propuseram o método de determinação de carbamatos em sucos e vinhos utilizando a injeção direta das amostras em LC/ ESI/MS/MS após diluição das amostras em água. As amostras de sucos de uva, laranja, maçã e vinhos tinto e branco foram fortificadas em níveis de 0,1 a 0,5 ppm, durante um dia e entre 3 dias consecutivos. Os resultados da média de recuperação dos dois níveis estudados, para a avaliação entre dias, foram em valores iguais e maiores que $63,0 \%$ e o coeficiente de variação foi menor que $22,6 \%$. Para a avaliação diária, a média de recuperação foi de $59,6 \%$ ou mais e o coeficiente de variação igual ou abaixo de 6,9. 


\subsection{Programa de monitoramento}

Em programas de monitoramento de resíduos de pesticidas em alimentos normalmente são adotados métodos mutirresíduos. Os resultados permitem verificar as aplicações das boas práticas agrícolas, no uso abusivo da formulação de agrotóxicos, com respeito às doses mínimas do intervalo de carência e ao uso inadequado de agrotóxicos não autorizados por órgãos competentes. Os dados produzidos pelos programas permitem também avaliar e mensurar o potencial risco à saúde da população humana com relação ao consumo de alimentos. Através dos dados de programa de monitoramento é possível conhecer o cenário internacional e nacional de pesticidas do ponto de vista, das tendências de resíduos nos alimentos e dos aspectos importantes para o planejamento de estratégias de controle, de monitoramento e laboratoriais para se atingir os objetivos de forma eficiente e obter resultados satisfatórios.

Ortelli et al. (2004), utilizando a técnica de LC-MS/MS com ionização ESI, propuseram o método multirresíduo para o programa de monitoramento em frutas e verduras (na Suíça) de 74 pesticidas. Foram controladas 2.571 amostras de frutas e verduras no período de 2002 e 2003, onde 47,9\% das amostras apresentaram resíduos de um ou mais pesticidas e em 6,6\% foram encontrados resíduos que excederam os Limites Máximos de Resíduos (LMR). Muitos produtos agrícolas, como pequenas frutas e grãos, frutas cítricas ou vegetais folhosos, apresentaram índices de contaminação maiores que outros alimentos. Em muitos casos (grãos e pequenas frutas), foram encontradas grandes quantidades de fungicida, pela fragilidade que estes produtos apresentam. Para frutas cítricas, o maior problema encontrado foi em relação ao item "sem tratamento pós-colheita", onde os resultados mostraram a presença de larga quantidade de fungicidas, como o tiabendazol e o imazalil, que são fungicidas aplicados em tratamento pós-colheita. Outro problema identificado foi, a presença de grande número de resíduos por amostra, mais de $30 \%$ das amostras continham resíduos múltiplos. No caso específico de amostras, de uva, foram encontrados mais de 12 pesticidas diferentes embora em concentrações abaixo do LMR. 
Looser et al. (2006) analisaram 593 amostras de morangos comercializadas no Estado de Banden-Württemberg, Alemanha que eram provenientes da safra alemã, espanhola, italiana e marroquina e obtiveram $98 \%$ de resultados positivos para resíduos de pesticidas. A soma das concentrações de todos os pesticidas encontrados por amostra foi em média $0,41 \mathrm{mg} \mathrm{kg}^{-1}$. Os produtos provenientes da Itália continham os maiores índices e os da Alemanha, as menores concentrações. Os fungicidas foram mais freqüentemente detectados do que os inseticidas e os herbicidas sendo que os pesticidas mais detectados foram ciprodinila, fluodioxinila, fehexamida, tolifluanida e azostrobina, responsáveis por mais de $50 \%$ do total das detecções.

No Brasil, o monitoramento nacional, denominado Programa de Análise de Resíduos de Agrotóxicos em Alimentos, foi realizado em 4.001 amostras de frutas (banana, laranja, maçã, mamão, morango) e de vegetais (alface, batata, cenoura e tomate), no período de 2001 a 2004. Estas amostras foram coletadas em supermercados de grandes cidades em 13 estados brasileiros. O critério da amostragem foi baseado em: dados de consumo anual per capita em kg, alimentos fornecidos pelas cesta básica, os sistemas de cultivo e de manejo de pragas das diferentes culturas e a disponibilidade destes alimentos no comércio, nos diferentes estados inseridos no programa. As análises foram realizadas pelo método multirresíduo para 91 princípios ativos, exceto para os ditiocarbamatos, para os quais foi adotado uma metodologia analítica específica. Os resultados relatam que, das 4.001 amostras analisadas de julho de 2001 a dezembro de 2004, foram detectados resíduos em 3.271 amostras, sendo que 2.340 (71,5\%) foram regulares e $931(28,5 \%)$ das amostras foram irregulares. Vale salientar também que dentre as amostras detectadas positivas, muitas amostras apresentaram resíduos múltiplos. Das 931 amostras irregulares, 776 (83,4\%) amostras eram de uso irregular, não autorizado pela ANVISA, e 155 (16,6\%) estavam em níveis acima de LMR. Estes dados permitem concluir que, na realidade brasileira, o maior problema com relação aos níveis de agrotóxicos no alimento in natura, não está na forma de aplicação do produto em alimento, mas no uso indiscriminado de agrotóxicos não autorizados para determinadas culturas. Dentre os alimentos in natura analisados, as culturas de alface, cenoura, laranja e tomate apresentaram os maiores índices de irregularidades (ANVISA, 2006b). 
No programa de monitoramento de pesticidas em alimentos dos Estados Unidos, realizado pela FDA (Food and Drug Adminstration) em 2003, foram analisadas 7.234 amostras; sendo 2.344 amostras domésticas, provenientes de 45 estados, e 4.890 amostras importadas de 99 países, dentre elas, 55 amostras de origem brasileira (FDA, 2005).

O método empregado foi de multirresíduo, auxiliado por alguns métodos específicos, para a determinação de cerca de 360 pesticidas em alimentos; destes, foram encontrados 144 pesticidas. As amostras foram coletadas em rede de supermercados e mercearias na freqüência de quatro vezes ao ano, distribuídas em quatro regiões geográficas do país.

As amostras foram consideradas como "ausentes", quando não detectados os pesticidas, "não violadas" e "presença de resíduos violáveis". A presença de resíduos violáveis é definida como um resíduo que excede a tolerância ou um nível de resíduo com importância significativa que não tenha estabelecido a tolerância na amostra alimentar.

Foram analisadas 154 amostras domésticas e 215 importadas de grãos e derivados; das quais 21 e 59 amostras domésticas e importadas, respectivamente, de amostras de leite, ovos e derivados; 122 e 273 amostras de peixes e produtos aquáticos; 813 e 1.537 amostras de frutas; 1.132 e 2.494 de vegetais e 102 domésticas e 312 importadas do grupo de "outros" produtos. Dentre as amostras domésticas, 83\% eram frutas e vegetais (FDA, 2005).

Nos Estados Unidos, o registro para 0 uso dos pesticidas e 0 estabelecimento de LMR para alimentos são da competência da EPA (Environmental Protection Agency), exceto para carne, aves domésticas e alguns produtos de ovos, que são de responsabilidade do Food Safety and Inspection Service (FSIS) do United States Department of Agriculture (USDA).

$\mathrm{Na}$ Tabela 2, encontram-se os resultados de todas as amostras domésticas analisadas por grupo de alimentos que foram não-detectadas, violadas e ausentes e acima dos LMR. 
Tabela 2 - Resultado das amostras domésticas, por grupo de alimentos em 2003 (EUA)

\begin{tabular}{lccccc}
\hline Grupo de produtos & Total & $\begin{array}{c}\text { ND } \\
(\%)\end{array}$ & $\begin{array}{c}\text { Violadas } \\
(\%)\end{array}$ & $\begin{array}{c}> \\
\text { LMR }\end{array}$ & $\begin{array}{c}\text { Ausência } \\
\text { LMR }\end{array}$ \\
\hline Grãos e derivados & 154 & 74,0 & 0,0 & 0 & 0 \\
\hline Leite e derivados & 21 & 100,0 & 0,0 & 0 & 0 \\
\hline Peixes e derivados & 122 & 76,2 & 0,0 & 0 & 0 \\
\hline Frutas & 813 & 48,6 & 2,2 & 0 & 18 \\
\hline Vegetais & 1.132 & 69,2 & 1,9 & 1 & 21 \\
\hline Outros & 102 & 60,8 & 16,7 & 8 & 9 \\
\hline TOTAL & $\mathbf{2 . 3 4 4}$ & $\mathbf{6 2 , 6}$ & $\mathbf{2 , 4}$ & $\mathbf{9}$ & $\mathbf{4 8}$ \\
\hline
\end{tabular}

ND: não detectado

LMR: Limite Máximo de Resíduo

Fonte: FDA, 2005

Dentre todas as amostras domésticas analisadas, citadas na Tabela 2, $2,2 \%$ das amostras de frutas foram de caráter violável, seguido de vegetais $(1,9 \%)$, e amostras de outros grupos (16,7\%). No grupo de "outros alimentos" era composta por uma grande diversidade de alimentos, como: caju, coco, condimentos, mel, alimentos processados, água, bebidas e outros (FDA, 2005).

$\mathrm{Na}$ Tabela 3, encontram-se os resultados das amostras importadas, classificadas por grupos de alimentos para o monitoramento.

Tabela 3 - Resultados da amostras importadas, por grupo de alimentos em 2003, $(E \cup A)$

\begin{tabular}{lrrccc}
\hline Grupo de produtos & Total & $\begin{array}{c}\text { ND } \\
(\%)\end{array}$ & $\begin{array}{c}\text { Violadas } \\
(\%)\end{array}$ & $\begin{array}{c}> \\
\text { LMR }\end{array}$ & $\begin{array}{c}\text { Ausência } \\
\text { LMR }\end{array}$ \\
\hline Grãos e derivados & 215 & 88,4 & 1,4 & 0 & 3 \\
\hline Leite e derivados & 59 & 84,8 & 0,0 & 0 & 0 \\
\hline Peixes e derivados & 273 & 89,0 & 0,0 & 0 & 0 \\
\hline Frutas & 1.537 & 63,6 & 5,3 & 3 & 79 \\
\hline Vegetais & 2.494 & 72,5 & 6,7 & 15 & 152 \\
\hline Outros & 312 & 78,2 & 14,1 & 8 & 36 \\
\hline TOTAL & $\mathbf{4 . 8 9 0}$ & $\mathbf{7 1 , 8}$ & $\mathbf{6 , 0}$ & $\mathbf{2 6}$ & $\mathbf{2 7 0}$
\end{tabular}


Pelos resultados das amostras importadas, conforme Tabela 3, os grupos que apresentaram maiores índices de amostras violáveis, foram: 14,1\% de outros alimentos, 6,7\% do grupo de vegetais e 5,3\% de frutas. Para o grupo de vegetais e frutas de ambas as procedências o índice de amostras violáveis com relação a importado e doméstico foi aproximadamente na razão 3:1. As amostras dos Estados Unidos apresentaram maior porcentagem (37,3\%) de amostras violadas que as importadas (28,2\%), apesar do número de amostras analisadas ser maior em todos os grupos (FDA, 2005).

O milho foi analisado como um alimento de origem cereal e vegetal, sendo que das 70 amostras domésticas utilizadas, 24 era do grupo de cereal e 46 amostras de milho vegetal; das 39 amostras de milho importado, 13 eram do grupo do cereal e 15 amostras eram do grupo de vegetais. Dentre as amostras de milho domésticas, em $83,3 \%$ do grupo cereal e em $95,7 \%$ do grupo vegetal foram detectados resíduos de pesticidas, porém não foram encontrados resíduos violáveis em ambos os grupos.

Nas amostras de milho importadas, em 69,2\% do grupo cereal e em 96,0\% da amostragem vegetal foram detectados resíduos de pesticidas, porém nenhuma amostra foi encontrada com resíduo violável (FDA, 2005).

Foram analisadas 438 amostras domésticas e 60 importadas com finalidade de alimentação animal. Dentre as amostras domésticas, em 69,2\% não foram detectados resíduos e em 1,8\% os limites excediam a tolerância; enquanto que, nas amostras importadas, em 83,3\% não foram detectados resíduos de pesticidas e em 5,0\% houve excesso dos LMR.

Duas amostras de milho domésticas, provenientes de diferentes regiões, foram encontradas com concentrações 0,010 ppm e 0,086 ppm de clorpirifós metílico, porém a legislação EPA (Environmental Protection Agency) não estabelece os níveis de tolerância. Em outras duas amostras de milho coletadas em outros Estados foi encontrado malationa, nas concentrações de 26,7 e 11,3 ppm, excedendo o limite estabelecido pela EPA que é de 8 ppm e metoxicloro, (0,642 e 0,249 ppm), sem limite de tolerância por ter sido revogado, anteriormente, o limite de $2 \mathrm{ppm}$.

Dentre as amostras importadas, em uma amostra de milho da Argentina foi encontrada fenitrotiona na concentração de 1,66 ppm, apesar de não existir tolerância deste pesticida para esta cultura. Em 135 (30,8\%) das amostras 
domésticas e 10 (16,7\%) das importadas foram detectados pesticidas múltiplos; no total 206 resíduos de pesticidas, sendo 136 quantificados e 70 em nível de traços (FDA, 2005).

Dentre todas as amostras analisadas, não foram encontrados resíduos em $62,6 \%$ das amostras domésticas e em $71,8 \%$ das importadas. Somente em $2,4 \%$ das amostras domésticas e em 6,1\% das amostras importadas foram detectados resíduos violáveis. Destas amostras, foram quantificados 62 resíduos de malationa em níveis que variaram de 0,009 a 26,7 ppm; 13 resíduos de clorpirifós metílico em níveis 0,009 a 0,560 ppm; 7 resíduos de metoxicloro (pp' + op') em níveis de 0,010 a 0,642 ppm; 11 clorpirifós (0,008 a 0,400 ppm); 11 de diazinona $(0,010$ a $0,307 \mathrm{ppm}) ; 9$ de etoxiquin $(0,103$ a $50,0 \mathrm{ppm})$ e outros pesticidas: pirimifós metílico, azostrobina, tribufós, dieldrin, endosulfan, etiona, heptacloro epóxido e a cialotrina, de até 3 determinações quantificáveis de pesticidas, que variaram de 0,008 a $0,277 p p m$ (FDA, 2005).

No programa de monitoramento de resíduos de pesticidas de 2004, entre os membros da Comunidade Européia e outros países da Europa (Noruega, Islândia e Liechtenstein), foram analisadas 60.450 amostras de frutas, vegetais e cereais e produtos processados, incluindo alimentos infantis, pelo método multirresíduo. Os resultados do monitoramento estão na Tabela 4 (EU, 2007). Dentre todas as amostras analisadas, $87,5 \%$ foram realizadas em laboratórios credenciados.

$\mathrm{Na}$ Tabela 4, estão os resultados do monitoramento de frutas e vegetais, cereais, alimentos infantis processados e cereais processados. Dentre todas as amostras analisadas, em 55,6\% foram detectados resíduos de pesticidas, dos quais 39,7\% em níveis abaixo dos LMR e 2,9\% das amostras acima dos LMR da Comunidade Européia (LMREC). Dentre as amostras insatisfatórias, foram quantificados 324 diferentes pesticidas e seus metabólitos (EU, 2007). 
Tabela 4 - Resultados do programa nacional de monitoramento em 2004 (EU)

\begin{tabular}{|c|c|c|c|c|c|c|c|c|c|}
\hline Grupos & $\mathbf{N}$ & N ND & $\%$ & $\begin{array}{c}\mathrm{N} \\
<\text { LMR } \\
\text { ou } \\
<\text { LMREC }\end{array}$ & $\%$ & $\begin{array}{c}\text { N } \\
>\text { LMR } \\
\text { ou } \\
>\text { LMREC }\end{array}$ & $\%$ & $\begin{array}{c}\mathbf{N} \\
>\text { LMREC }\end{array}$ & $\%$ \\
\hline $\begin{array}{l}\text { Frutas } \\
\text { e } \\
\text { Verduras* }\end{array}$ & 50.428 & 26.689 & 53 & 21.232 & 42 & 2.507 & 5,0 & 1.519 & 3,0 \\
\hline $\begin{array}{l}\text { Frutas } \\
\text { e } \\
\text { verduras }\end{array}$ & 2.211 & 963 & 44 & 1.022 & 46 & 226 & 10,2 & 122 & 5,5 \\
\hline Cereais* & 2.719 & 1.912 & 70 & 777 & 29 & 30 & 1,1 & 28 & 1,0 \\
\hline $\begin{array}{l}\text { Produtos } \\
\text { processados, sem } \\
(\mathrm{Al})^{*}\end{array}$ & 3.678 & 2.755 & 75 & 879 & 24 & 44 & 1,2 & 17 & 0,5 \\
\hline $\begin{array}{l}\text { Alimentos infantis } \\
(\mathrm{Al})^{*}\end{array}$ & 1.334 & 1221 & 92 & 77 & 6 & 36 & 2,7 & 36 & 2,7 \\
\hline $\begin{array}{l}\text { Cereais } \\
\text { processados }\end{array}$ & 80 & 67 & 84 & 10 & 13 & 3 & 3,8 & 1 & 1,3 \\
\hline $\begin{array}{l}\text { Total } \quad \text { (sem } \\
\text { processamento) }\end{array}$ & 55.395 & 29.585 & 53 & 23.036 & 42 & 2.764 & 5,0 & 1.670 & 3,0 \\
\hline $\begin{array}{l}\text { Total } \\
\text { (processado) }\end{array}$ & 60.450 & 33.607 & 55,6 & 23.997 & 39,7 & 2.846 & 4,7 & 1.723 & 2,9 \\
\hline $\begin{array}{l}{ }^{*} \text { Amostras da fiscaliza } \\
\text { ** Amostras direciona } \\
\text { LMR: Limite Máximo }\end{array}$ & $\begin{array}{l}\text { ão } \\
\text { S Resíduo }\end{array}$ & $\begin{array}{l}\text { N: nú } \\
\text { N ND } \\
\text { LMRE }\end{array}$ & רúm & $\begin{array}{l}\text { mostras } \\
\text { de amost } \\
\text { Máximo }\end{array}$ & nã & $\begin{array}{l}\text { tectadas } \\
\text { da Com }\end{array}$ & ide & Fonte: EU & 007 \\
\hline
\end{tabular}

Para as amostras de frutas e vegetais, foram adotadas diferentes estratégias de amostragem. As amostras de fiscalização são coletadas sem qualquer suspeita, com relação a um produtor ou consignatório. As amostras de fiscalização podem ser incluídas também das amostras objetivando um especial problema; sendo exemplo o metamidofós em pepinos e cloromequate em peras de Estados com problemas previamente constatados. As amostras direcionadas são coletadas em caso de suspeita ou com violação previamente encontrada. A amostragem direcionada é feita diretamente para uma específica plantação/produtor ou um específico consignatório (EU, 2007).

Foram analisadas 50.428 amostras de frutas e vegetais in natura, provenientes da fiscalização, em $53 \%$ das amostras não foram detectados resíduos, $42 \%$ estavam abaixo de LMR ou LMREC e $3 \%$ das amostras apresentaram resíduos que excederam os LMR (EU, 2007).

Para os cereais, das 2.719 amostras analisadas provenientes da fiscalização, em 70\% não foram encontrados resíduos, 29\% estavam abaixo dos LMR e 1,1\% acima dos LMR. Os índices de amostras detectadas, maiores ou 
menores que LMREC em cereais apresentaram valores menores que os das frutas e vegetais (EU, 2007).

Nas amostras de frutas e vegetais, em 10,2\% (direcionadas) e em 5\% (de fiscalização) excederam os LMR. Estes dados revelam que as amostras de fiscalização e as direcionadas são distintas, desde a estratégia de amostragem até a análise dos resultados.

Para os alimentos infantis, foram analisadas 1.334 amostras, em 92\% não foram encontrados resíduos de pesticidas, em 6\% foram detectados, mas abaixo do LMR, e 2,7\% das amostras estavam acima do LMREC (EU, 2007).

Com relação às amostras com resíduos múltiplos, variando a presença de 2 a 8 ou mais resíduos presentes em uma mesma amostra, os dados relatados estão na Tabela 5.

Tabela 5 - Amostras in natura de frutas, vegetais e cereais

\begin{tabular}{|c|c|c|c|c|c|c|c|c|c|}
\hline & & $\begin{array}{c}2^{*} \\
\text { ou mais }\end{array}$ & 2 * & $3^{\star}$ & $4^{*}$ & $5^{\star}$ & $6^{*}$ & $7^{*}$ & $\begin{array}{c}8^{*} \\
\text { ou mais }\end{array}$ \\
\hline $\mathbf{N}$ & 55.395 & 12.986 & 5.695 & 3.220 & 1.850 & 955 & 544 & 283 & 439 \\
\hline$\%$ & 100 & 23,4 & 10,3 & 5,8 & 3,3 & 1,72 & 0,98 & 0,51 & 0,79 \\
\hline
\end{tabular}

Pelos resultados, apresentados na Tabela 5, a maior porcentagem de pesticidas dentre as amostras foi entre os que apresentaram 2 pesticidas; esta porcentagem decresce à medida que aumenta o número de pesticidas presentes em uma mesma amostra.

Pelos dados do mesmo programa (de 1998 a 2003), em 1998, 2\% das amostras apresentaram 4 ou mais pesticidas; em 2002, 2,8\%; em 2003, 6,5\%, e, em 2004, 7,3\% das amostras apresentam 4 ou mais pesticidas (EU, 2007).

$\mathrm{Na}$ figura 14 apresenta-se os resultados da presença de resíduos múltiplos de 2 ou mais pesticidas no período de 1997 a 2004, para amostras de frutas e vegetais e cereais em forma de percentagem. 


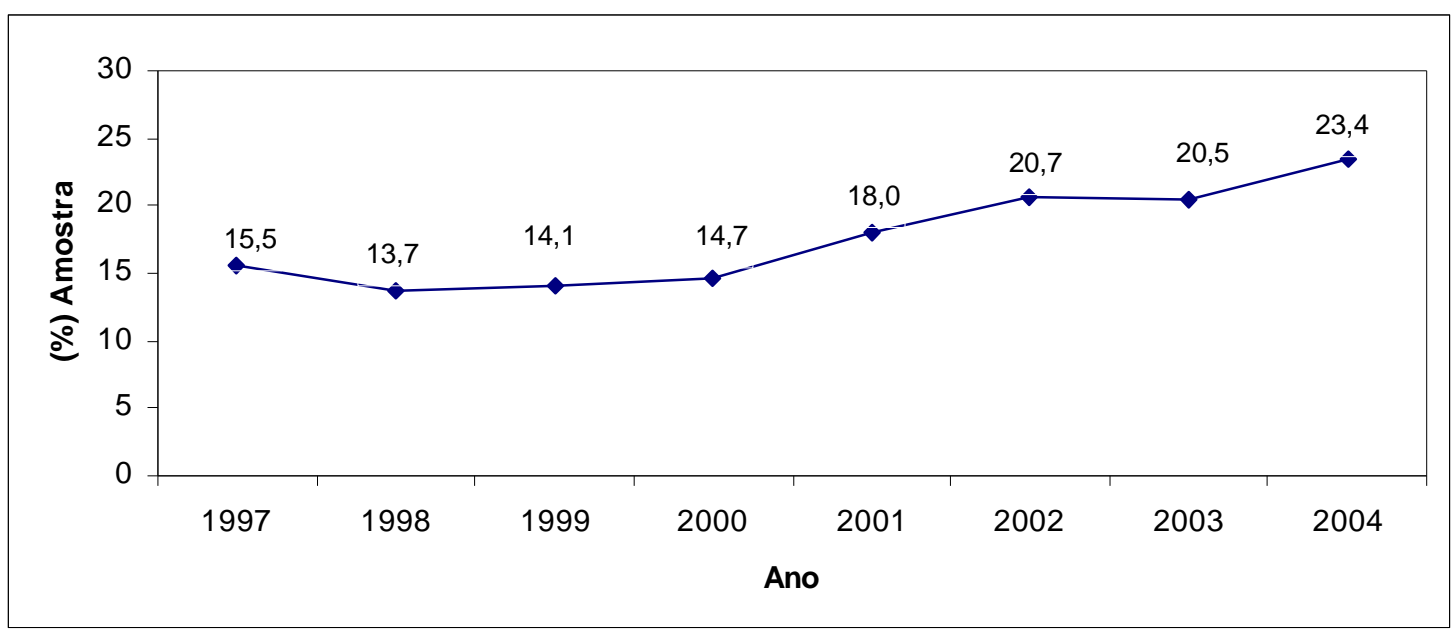

Figura 14 - Porcentagem das amostras de frutas, vegetais e cereais com resíduos múltiplos, no período de 1997 a 2004

Pelos resultados apresentados na Figura 14, observa-se crescimento no número percentual de amostras com 2 ou mais resíduos a partir de 2000.

$\mathrm{Na}$ Tabela 6, exclarece-se à procedência das amostras que estavam em níveis acima do LMREC.

Tabela 6 - Amostras de fiscalização, em níveis acima do LMREC, para frutas, verduras e cereais

\begin{tabular}{lccc}
\hline ORIGEM & $\mathbf{N}$ & $\mathbf{N}>$ LMREC & $\%$ \\
\hline União Européia & 42.359 & 1.020 & 2,4 \\
Importado & 9.523 & 650 & 6,8 \\
Desconhecido & 1.265 & 77 & 6,1 \\
\hline \multicolumn{1}{c}{ Total } & $\mathbf{5 3 . 1 4 7}$ & $\mathbf{1 . 7 4 7}$ & $\mathbf{3 , 3}$ \\
\hline
\end{tabular}

$\mathbf{N}$ : número de amostras analisadas

N>LMREC: número de amostras acima do Limite Máximo de Resíduo da Comunidade Européia

Conforme os resultados do programa, Tabela 6, os produtos importados apresentaram maiores índices em valores porcentuais de amostras que estavam acima dos LMREC que os produzidos na Europa.

Na Figura 15, estão os resultados do monitoramento no período de 1996 a 2004, quanto à tendência das amostras não-detectadas, detectadas em níveis menores e maiores em relação à legislação de LMREC. 


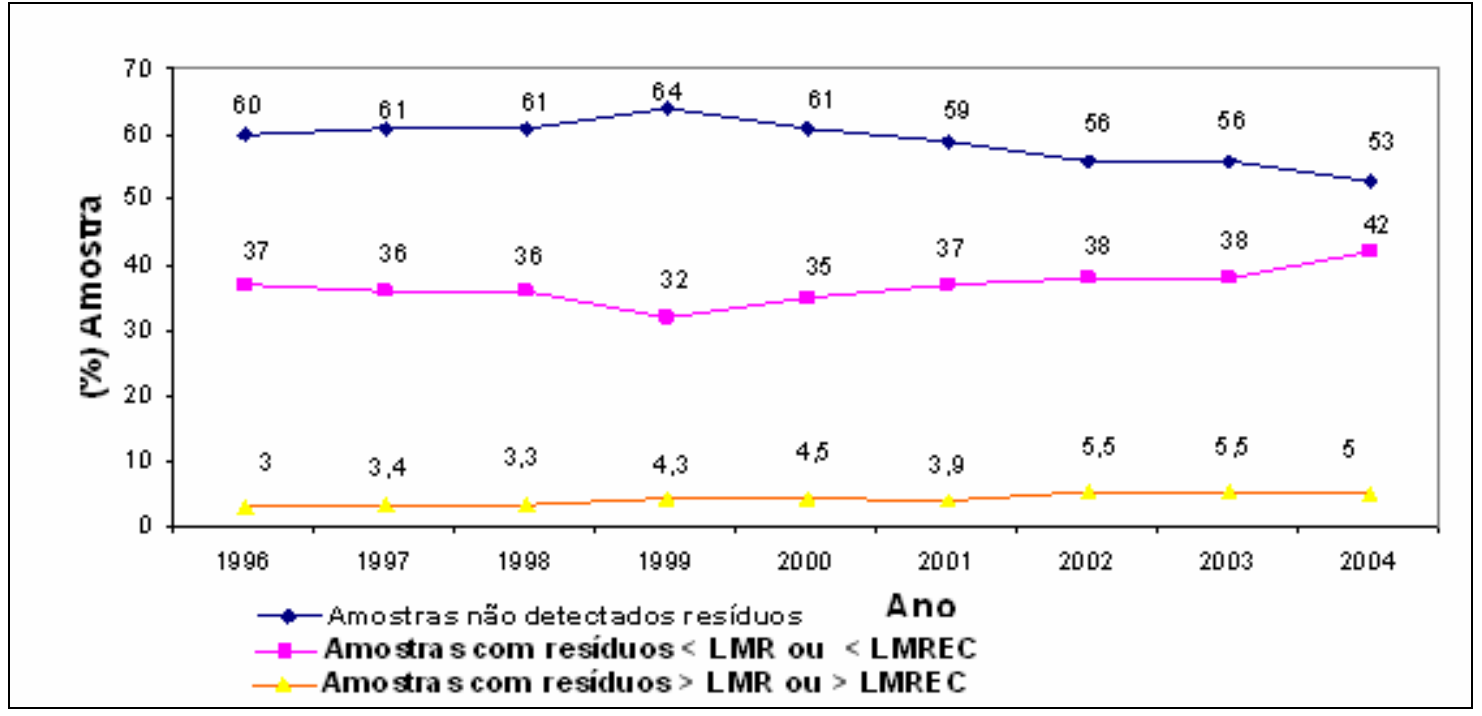

Fonte: EU, 2007

Figura 15 - Resultado do monitoramento no período de 1996 a 2004.

A Figura 15 mostra a tendência ao longo dos anos 1996 a 2004 da diminuição em porcentagem com relação à ausência de resíduos de pesticidas nas amostras monitoradas. Por outro lado, há crescimento quanto à presença de resíduos, tanto em níveis menores quanto acima dos LMR. Este aumento se deve a vários fatores, como a capacidade analítica laboratorial, atingindo menores limites de quantificação e maior número substâncias analisadas. Outro fato se deve aos programas de monitoramento, que diferem consideravelmente a cada ano. Em muitos países a prioridade dos programas de monitoramento é direcionada para níveis nacionais e são freqüentemente objetivados para um específico problema, tais como as informações de infrações recebidas na Europa e as infrações detectadas no próprio país (EU, 2007).

Dentre as amostras analisadas de frutas e verduras, as com maior incidência da presença de pesticidas foram: maçã, tomate, alface, morango, alhoporó, suco de laranja, repolho, aveia e centeio. Os pesticidas mais frequentemente encontrados foram: grupo do manebe, clorpirifós, imazalil, procimidone, grupo de benomil, iprodione, tiabendazol, clormequate, brometos e orto-fenilfenol.

Entre os cereais, os pesticidas mais encontrados foram: pirimifós metílico, mationa, clorpirifós, clorpirifós metílico, clormequate, deltametrina, glifosato, brometos, diclorvos e mepiquate. 
Em frutas e vegetais, as classes de pesticidas mais encontradas foram dos fungicidas e, nos cereais, a dos inseticidas.

A partir dos resultados do monitoramento, para os pesticidas encontrados em alta concentração em um alimento, calcula-se a dose de referência aguda para estimar o risco da exposição crônica a um determinado pesticida. $A$ dose de referência aguda $\left(A R_{f} D\right)$ é estimada pela quantidade da substância no alimento, expressa em peso de massa corpórea, que pode ser ingerida sobre um período de tempo, usualmente durante uma refeição ou um dia, sem risco para o consumidor. Este dado é comparado com a IDA do pesticida em determinado alimento. Se $A R_{f} D$ é maior, indica risco de ingestão do pesticida em determinado alimento (EU, 2007).

Pelos resultados do programa de monitoramento, muitos LMREC dos pesticidas, em determinado alimento, estão sendo revistos, dentre os quais, os pesticidas: deltametrina, dimetoato, a cialotrina, metomil e metidationa, para alface e maçã.

Dentre os pesticidas que ofereceram maior potencial de risco, estão: metamidofós para alface, grupo de manebe e oxidemeton, para alface e maçã (EU, 2007).

A avaliação de risco crônico da ingestão de resíduos de pesticidas na dieta européia é estimada pelos resultados obtidos pelo programa de monitoramento (EU, 2007). 


\section{METODOLOGIA}

A etapa experimental analítica do trabalho foi realizada no Laboratório de Centro de Química do Meio Ambiente do Instituto de Pesquisas Energéticas e Nucleares (IPEN).

\subsection{Coleta das amostras}

Foram coletadas 10 amostras de milho verde disponível para o consumidor final, na região Sul da cidade de São Paulo, adquiridas em rede de supermercados, feiras livres e nos popularmente denominados "sacolões", nos meses de agosto e setembro de 2005 (Tabela 7). Para o estudo de recuperação, foram utilizadas amostras de milho verde de origem "orgânica", denominadas também como amostras testemunhas, cultivadas sem tratamento com agrotóxicos, adquiridas em uma rede de supermercados

Tabela 7 - Data e local de coleta das amostras

\begin{tabular}{ccl}
\hline Amostra & Data de coleta & Local \\
\hline 1 & $05 / 08 / 2005$ & Feira - Bairro Jabaquara \\
2 & $05 / 08 / 2005$ & Supermercado - Bairro São Judas \\
3 & $03 / 09 / 2005$ & Supermercado - Bairro Santa Catarina \\
4 & $03 / 09 / 2005$ & Feira - Bairro Jabaquara \\
5 & $04 / 09 / 2005$ & Feira - Bairro Santa Catarina \\
6 & $03 / 09 / 2005$ & Feira - Bairro Conceição \\
7 & $03 / 09 / 2005$ & Feira - Bairro Jabaquara - Vila Guarani \\
8 & $03 / 09 / 2005$ & Sacolão - Bairro Jabaquara \\
9 & $04 / 09 / 2005$ & Sacolão - Bairro Santa Catarina \\
10 & $08 / 09 / 2005$ & Feira - Bairro Saúde \\
\hline
\end{tabular}




\subsection{Preparação das amostras}

As amostras de milho verde, após as coletas, foram cortadas e trituradas em trituradores domésticos e armazenadas em freezer, até a realização das análises. Todas as amostras foram armazenadas e mantidas em freezer à temperatura de $-4 \stackrel{\circ}{\circ}$, até a realização das análises. $\mathrm{O}$ mesmo prodedimento foi adotado para a amostra testemunha.

\subsection{Reagentes}

Os padrões dos princípios ativos utilizados foram de alta pureza (97,1 99,99\%), com certificação do próprio fabricante, conforme Tabela 8.

Tabela 8 - Padrões estudados, procedência e grau de pureza

\begin{tabular}{llc}
\hline Nome & Procedência & Pureza (\%) \\
\hline Aldicarbe & Riedel - de Häen & 99,0 \\
Aldicarbe sulfona & Riedel - de Häen & 99,0 \\
Aldicarbe sulfóxido & Riedel - de Häen & 97,1 \\
Carbaril & Riedel - de Häen & 99,8 \\
Carbofurano & FMC Química do Brasil Ltda & 99,6 \\
Metiocarbe & Riedel - de Häen & 99,7 \\
Metomil & Riedel - de Häen & 99,8 \\
Pirimicarbe & Riedel - de Häen & 99,8 \\
Propoxur & Riedel - de Häen & 99,9 \\
Atrazina & Riedel - de Häen & 99,2 \\
Simazina & Riedel - de Häen & 99,9 \\
Carbendazim & Riedel - de Häen & 99,6 \\
Tiabendazol & Dr. Ehrenstorfer GmbH & 99,5 \\
Tiofanato metílico & Riedel - de Häen & 99,7 \\
\hline
\end{tabular}

Os solventes foram todos de grau analítico HPLC de diferentes marcas: acetona, Mallinckrodt; acetato de etila, EM Sccience (Merck); acetonitrila, EMD (Omnisolv); e metanol, J.T. Baker. A água utilizada foi de grau analítico HPLC. 


\subsection{Equipamentos utilizados}

A pesagem do padrões certificados dos analitos foi efetuada em uma balança analítica, marca Sartorius, MC 210 S, com precisão da medida de pesagem de $\pm 0,00001$ grama.

As amostras foram pesadas em uma balança analítica, marca Mettler, № 206030, tipo H16, precisão da medida de pesagem de $\pm 0,0001$ grama.

Agitador marca Kline, modelo 255.

Centrífuga, marca Solumix.

\subsubsection{Sistema HPLC- MS/MS}

As quantificações e confirmações foram realizadas empregando-se um sistema LC-MS/MS composto de um espectrômetro de massas triploquadrupolar API $4000^{\mathrm{TM}}$ acoplado a um cromatógrafo líquido Agilent 1100 Series e o software Analyst ${ }^{\circledR}$, versão 1.4.1. O espectrômetro de massas utilizado foi o Applied Biosystems/MDS Sciex (Sciex, Concord, CA), equipado com cela de colisão LINAC $^{\circledR}$, fonte de ionização Turbo ${ }^{\mathrm{TM}}$, operada no modo TurbolonSpray ${ }^{\circledR}$ (electronspray), gerador de gases PEAK Generator (PEAK Scientific Instruments, Escócia) e bomba de infusão Harvard Apparatus (Holliston, MA, EUA). O cromatógrafo líquido utilizado foi o Agilent, modelo 1100, com bomba quaternária, injetor automático, degaseificador e forno para coluna analítica. As amostras foram injetadas em coluna Inertsil ODS-3 com dimensões de 7,5 cm x 4,6 mm x 3 $\mu \mathrm{m}$ sob fluxo de fase móvel de $700 \mu \mathrm{L} \mathrm{min}^{-1}$.

\subsection{Curvas analíticas}

As soluções padrões estoque para construção das curvas analíticas foram preparadas individualmente em balões volumétricos pela dissolução dos padrões dos princípios ativos em $10 \mathrm{~mL}$ de metanol, variando-se nas concentrações de $80,00 \mu \mathrm{g} / \mathrm{mL}$ a $400,00 \mu \mathrm{g} / \mathrm{mL}$, estocados a $-20 \stackrel{\circ}{ } \mathrm{C}$. A solução de trabalho foi preparada através de uma diluição em água de uma mistura da solução estoque nas concentrações que variaram de 80 a $400 \mathrm{ng} / \mathrm{ml}$. 
Para a construção da curva analítica, foram efetuadas diluições da solução de trabalho de uma mistura dos princípios ativos, em triplicata, em 6 níveis de concentrações de: 0,05; 0,10;0,20;0,40;1,00 e 2,00 ng/mL para aldicarbe sulfóxido, metomil, carbendazim, carbaril, tiabendazol, aldicarbe, propoxur, carbofurano e metiocarbe. Para simazina, atrazina e aldicarbe sulfona, as diluições foram de: 0,$10 ; 0,20 ; 0,40 ; 0,80 ; 2,00$ e $4,00 \mathrm{ng} / \mathrm{mL}$. Para tiofanato metílico, as concentrações foram de: 0,20;0,40;0,80;1,60;4,00 e 8,00 ng/mL. Para pirimicarbe foram de: 0,04; 0,08; 0,16;0,32; 0,80 e 1,60 ng/mL.

As misturas de padrões foram filtradas (filtros de porosidade 0,45 $\mu \mathrm{m}$ ) e injetadas $20 \mu \mathrm{L}$ de volume no equipamento, 2 injeções para cada mistura de padrões. Para a construção da curva analítica foram considerados os resultados de 6 injeções. Para testar a repetibilidade do equipamento foram injetadas seis replicatas $(n=6)$ da solução mais diluída.

\subsection{Preparação dos extratos}

Pesou-se 1,0000 grama da amostra de milho verde triturada e mantida à temperatura ambiente em um tubo com capacidade de $20 \mathrm{~mL}$. Foram adicionados $5 \mathrm{~mL}$ de acetona grau resíduo, agitados (agitador orbital) por 20 minutos e centrifugados por 15 minutos a $2.000 \mathrm{rpm}$. Pipetaram-se $100 \mu \mathrm{L}$ do extrato, diluídos para $1 \mathrm{~mL}$, com água. O extrato foi filtrado em filtro de porosidade 0,45 $\mu \mathrm{m}$ e injetado $20 \mu \mathrm{L}$ de volume no equipamento LC-ESI/MS/MS. Para o estudo da fortificação adotou-se o mesmo procedimento, utilizando a amostra testemunha.

\subsubsection{Cálculos. Análise qualitativa e quantitativa}

Os analitos foram quantificados com padronização externa pela construção de curvas analíticas dos compostos descritos no item 4.4. As concentrações dos analitos foram calculadas considerando o fator de diluição e a massa da amostra, pela equação 1 :

$$
\mathbf{R}=\frac{\mathrm{C} \times \mathrm{V}}{\mathrm{m}} \times \mathrm{f}
$$


onde:

R: resíduo do analito na amostra $(\mu \mathrm{g} / \mathrm{kg})$;

C: concentração do analito na solução final extraída $(\mathrm{ng} / \mathrm{mL})$;

V: volume da solução extraída $(\mathrm{mL})$;

m: massa pesada e extraída (g);

f: fator de diluição.

Todos os resultados foram expressos em $\mu \mathrm{g} / \mathrm{kg}$ (micrograma do analito por quilograma de amostra).

\subsection{Estudo de recuperação}

Segundo o Manual de orientação do INMETRO (2003), a recuperação do analito pode ser estimada pelas análises de amostras adicionadas com quantidades conhecidas do mesmo (spike). As amostras podem ser adicionadas em pelo menos quatro diferentes concentrações, como por exemplo, próximo ao limite de detecção, próximo à concentração máxima permissível, e em uma concentração máxima permissível em uma concentração próxima à média da faixa de uso do método.

Para o estudo de recuperação, foi preparada uma mistura de padrões em concentrações de: $80 \mathrm{ng} / \mathrm{mL}$ para pirimicarbe; $100 \mathrm{ng} / \mathrm{mL}$ para aldicarbe, aldicarbe sulfóxido, carbaril, carbofurano, metiocarbe, metomil, propoxur e carbendazim; $200 \mathrm{ng} / \mathrm{mL}$ para aldicarbe sulfona, atrazina, simazina e tiabendazol e $400 \mathrm{ng} / \mathrm{mL}$ para tiofanato metílico. Estas misturas de padões foram fortificadas em amostras testemunhas de milho, previamente preparadas (conforme o item 4.2), e mantidas à temperatura ambiente, para o estudo da recuperação em cinco níveis: $1 / 2$ LOQ (Limite de quantificação), 1 LOQ, 1 1 1/2 LOQ, 2 LOQ e 5 LOQ. Para o nível de $1 / 2 \mathrm{LOQ}$, foram adicionados volumes de: $50 \mu \mathrm{L}$ da mistura de padrões acima citada; $100 \mu \mathrm{L}$ para o nível de $1 \mathrm{LOQ} ; 150 \mu \mathrm{L}$ para 1 1/2 LOQ; $200 \mu \mathrm{L}, 2$ LOQ e $500 \mu \mathrm{L}$ para o nível de $5 \mathrm{LOQ}$. Após as fortificações, as amostras foram submetidas ao procedimento descrito no item 4.6 e, para quantificação, item 4.7.2. 


\subsubsection{Cronograma do experimento de recuperação}

Os pesticidas foram fortificados nas amostras testemunhas em cinco diferentes níveis de validação, correspondentes a 11/2, 1, 1 11/2, 2 e 5 LOQ, descritos nos itens 4.7. $O$ experimento foi realizado em 4 etapas, conforme a Tabela 9.

Tabela 9 - Cronograma do experimento

\begin{tabular}{cccccc}
\hline $\boldsymbol{n}$ & $\begin{array}{c}\text { Experimento } \\
\mathbf{1}\end{array}$ & $\begin{array}{c}\text { Experimento } \\
\mathbf{2}\end{array}$ & $\begin{array}{c}\text { Experimento } \\
\mathbf{3}\end{array}$ & $\boldsymbol{n}$ & $\begin{array}{c}\text { Experimento } \\
\mathbf{4}\end{array}$ \\
\hline 1 & Branco & Branco & Branco & & \\
6 & $1 / 2 \mathrm{LOQ}$ & $1 / 2 \mathrm{LOQ}$ & $1 / 2 \mathrm{LOQ}$ & 10 & Branco \\
6 & $1 \mathrm{LOQ}$ & $1 \mathrm{LOQ}$ & $1 \mathrm{LOQ}$ & & \\
\hline 6 & $11 \frac{1}{2} \mathrm{LOQ}$ & $11 / 2 \mathrm{LOQ}$ & $1 \frac{112 \mathrm{LOQ}}{}$ & & \\
1 & $2 \mathrm{LOQ}$ & $2 \mathrm{LOQ}$ & $2 \mathrm{LOQ}$ & 10 & $1 \mathrm{LOQ}$ \\
1 & $5 \mathrm{LOQ}$ & $5 \mathrm{LOQ}$ & $5 \mathrm{LOQ}$ & & \\
\hline
\end{tabular}

n: número de determinações.

Os experimentos de 1 a 4 foram executados em 4 dias, conforme a Tabela 9, consistindo em 21 experimentos durante os 3 dias diferentes e, no quarto dia, 20 experimentos, totalizando 83 experimentos. $O$ branco foi analisado em amostras testemunhas, isentas de pesticidas.

\subsubsection{Cálculos de recuperação}

Para o procedimento de validação do método analítico que será descrito a seguir no item 4.8, faz-se necessário o cálculo da recuperação que é feito segundo a equação 2 :

$$
\operatorname{Rec}(\%)=\frac{R}{C} \times 100
$$

onde:
$\operatorname{Rec}(\%)$ : recuperação (\%)
R: concentração da amostra fortificada $(\mu \mathrm{g} / \mathrm{kg})$;
C: concentração esperada $(\mu \mathrm{g} / \mathrm{kg})$. 
Os resultados foram expressos em "\% do recuperado" em relação à quantidade adicionada durante a fortificação da matriz. Neste estudo, os resultados foram reportados em concentração $(\mu \mathrm{g} / \mathrm{kg})$ e em \% de recuperação, bem como a média de recuperações, desvio padrão e o coeficiente de variação em todos os níveis e nos analitos estudados.

\subsection{Validação do método analítico}

Para garantir que um novo método analítico possa gerar informações confiáveis e interpretáveis sobre a amostra, ele deve sofrer uma avaliação chamada de validação. A validação de um método é um processo contínuo que começa no planejamento da estratégia analítica e continua ao longo de todo o desenvolvimento e transferência.

A validação é o processo de definir uma exigência analítica e confirmar que o método sob investigação tem capacidade de desempenho consistente com o que a aplicação requer. Na prática, a adequação ao uso dos métodos analíticos aplicados a ensaios rotineiros é geralmente avaliada pelos estudos de métodos. Tais estudos produzem dados quanto ao desempenho total e aos fatores de influência que podem ser aplicados à estimativa da incerteza associada aos resultados do método em uso normal (Eurachem Working Group, 1998).

Os parâmetros de validação de métodos têm sido definidos em diferentes grupos de trabalho de organizações nacionais ou internacionais e algumas definições são diferentes entre diversos grupos. Uma tentativa para harmonizar estas diferenças foi feita para aplicações farmacêuticas, pela ICH (International Conference of Harmonization). O que se pode notar é que organismos nacionais de credenciamento, como ANVISA e INMETRO, e órgãos internacionais de credenciamento como, IUPAC, ISO (ISO/IEC 17025) e ICH, em caso de credenciamento, exigem o item "validação de métodos analíticos" como um requisito fundamental para a qualidade assegurada e demonstração da competência técnica (ANVISA, 2003; INMETRO, 2003; IUPAC, 2002; ISO/IEC 17025, 1999; ICH, 1995a e ICH, 1995b). Em relação às normas, pode-se observar que não há um procedimento normatizado que estabeleça como executar a validação de métodos instrumentais de separação. 
No Brasil, só há uma resolução específica de validação de metodologia analítica para resíduos de pesticidas, porém com objetivos que diferem ao desenvolvimento de uma metodologia. A resolução enfatiza os procedimentos para a condução de ensaios de campo e para o estudo de ensaios de laboratório específicos e alguns critérios mínimos para quantificar os pesticidas presentes ou ausentes, resultados de estudos experimentais no campo. Os pesticidas quantificados serão avaliados para fins de registro e estabelecimento de LMR para determinada cultura (ANVISA, 2006b).

A validação do método neste trabalho foi conduzida em conformidade com a norma EC/2002/657 recomendada pela Comunidade Européia, empregando o software ResVal (versão 2.0) (Council Directive, 2002). Esta validação é conduzida dentro de um único laboratório, chamada de validação no laboratório (in house validation) alguns autores reportam como uma avaliação da reprodutibilidade interna. Muitos resultados obtidos foram submetidos a tratamentos estatísticos, auxiliados pelo programa Resval 2.0.

A escolha da norma para a condução da avaliação do desempenho do método foi por diversas razões: pela infra-estrutura laboratorial adequada, principalmente a instrumental; por atender aos objetivos propostos e por ser uma norma internacional, com melhor aceitabilidade e credibilidade.

Uma das estratégias para alcançar os objetivos, inicialmente, foi a de efetuar as otimizações analíticas do método: como a escolha de solvente para extração dos pesticidas na matriz e as condições cromatográficas do cromatógrafo líquido, como o espectrômetro de massas para os pesticidas e a matriz estudada. Os parâmetros de avaliação do desempenho do método estudado foram: linearidade e intervalo de trabalho, seletividade, especificidade, exatidão, precisão, repetibilidade, níveis críticos (CCa e $C C \beta)$, limite de detecção e limite de quantificação.

\subsubsection{Linearidade}

Linearidade é a habilidade de um método analítico em produzir resultados que sejam diretamente porporcionais à concentração do analito em amostras, em uma dada faixa de concentração (INMETRO, 2003). 
A norma Council Directive (2002) recomenda no mínimo quatro pontos para a curva analítica.

\subsubsection{Faixa linear e faixa linear de trabalho}

A faixa linear de trabalho de um método de ensaio é o intervalo entre os níveis inferior e superior da concentração do analito no qual foi demonstrado ser possível a determinação com a precisão, a exatidão e a linearidade exigidas, sob condições específicas para o ensaio. A faixa de trabalho deve cobrir a faixa de aplicação para o qual o ensaio vai ser usado. A concentração mais esperada da amostra deve, sempre que possível, se situar no centro da faixa de trabalho e linearmente correlacionada às concentrações. Isto requer que os valores medidos próximos ao limite inferior da faixa de trabalho possam ser distinguidos dos brancos dos métodos (INMETRO, 2003).

Com este propósito, foram efetuadas as análises dos reagentes e das amostras testemunhas do método (INMETRO, 2003), apesar da norma (Council Directive, 2002) não fazer nenhuma menção a respeito.

\subsubsection{Seletividade}

Uma matriz pode conter componentes que interferem no desempenho na medição do detector selecionado, sem causar um sinal visível no teste de especificidade. Os interferentes podem aumentar ou reduzir o sinal e a magnitude do efeito pode depender da concentração (Ribani et al., 2004).

A seletividade do método foi avaliada comparando a matriz isenta de substância e a matriz adicionada com o analito (padrão), para verificar os possíveis interferentes que possam eluir na região de interesse. Para avaliar a seletividade, foi realizado o experimento 4 , conforme cronograma do experimento disponível na Tabela 9, item 4.7.1.

\subsubsection{Exatidão}

A exatidão do método é definida como sendo a concordância entre o resultado de um ensaio e o valor de referência aceito como convencionalmente 
verdadeiro. Quando aplicada a uma série de resultados de ensaio, implica uma combinação de componentes de erros aleatórios e sistemáticos (tendência) (INMETRO, 2003).

Os procedimentos normalmente utilizados para avaliar a exatidão do método são: uso de materiais de referência certificados, participação de ensaios interlaboratoriais e relização de ensaios de recuperação (INMETRO, 2003).

Para avaliar o parâmetro exatidão da norma adotada para este estudo, foram executadas 6 repetições no $1 / 2$ LOQ (limite de quantificação), 1 LOQ e 1 1/2 LOQ e uma repetição para $2 \mathrm{LOQ}$ e $5 \mathrm{LOQ}$. Este procedimento é executado em três diferentes dias. O limite de quantificação, neste caso, compreende o limite de quantificação alvo para avaliação do desempenho do método analítico (Council Directive, 2002). Na Tabela 10 , estão os níveis de média de recuperação estabelecida pela norma Council Directive (2002).

Tabela 10 - Nível de recuperação e média de recuperação

\begin{tabular}{cc}
\hline Nível de recuperação & Intervalo de recuperação (\%) \\
\hline$\leq 1 \mu \mathrm{g} / \mathrm{kg}$ & $-50 \% \mathrm{a}+20 \%$ \\
$>1 \mu \mathrm{g} / \mathrm{kg} \mathrm{a} 10 \mu / \mathrm{kg}$ & $-30 \% \mathrm{a}+10$ \\
$\geq 10 \mu \mathrm{g} / \mathrm{kg}$ & $-20 \%$ a $10 \%$ \\
\hline
\end{tabular}

Fonte: Council Directive, 2002

Para outros órgãos, o intervalo de aceitabilidade para os valores individuais de recuperação é de 70 a 110\% (FAO/WHO, 1993) e na faixa de 70 a 120\% (ANVISA, 2006b; EPA, 1996).

Em relação à norma, a medida da média de recuperação deve ser avaliada em função da concentração do nível de fortificação, aspectos concordantes em relação a estudos experimentais. Oberva-se que, pelos resultados experimentais em geral, quanto menor o nível de concentração avaliada maiores são as chances de se obter baixas recuperações. 


\subsubsection{Precisão}

Precisão é um termo geral para avaliar a dispersão de resultado entre ensaios independentes, repetidos de uma mesma amostra, em condições experimentais definidas. É normalmente determinada para circunstâncias específicas de medição e as duas formas específicas de expressá-las são por meio da repetitividade e da reprodutibilidade, sendo usualmente expressa como desvio padrão ou desvio padrão relativo (INMETRO,2003; IUPAC, 2002).

A precisão é avaliada pela norma por meio de desvios padrão relativos ou coeficiente de variação calculado individualmente em relação à média de recuperações obtidas nos experimentos de recuperação em cada nível e em diferentes experimentos.

$\mathrm{Na}$ Tabela 11, estão descritos os níveis de coeficiente de variação aceitáveis recomendados pela norma Council Directive (2002), aplicados no presente estudo.

Tabela 11 - Níveis de recuperação e faixa de coeficiente de variação

\begin{tabular}{cc}
\hline Nível de recuperação & $\begin{array}{c}\text { Coeficiente de variação }(\mathrm{CV}) \\
(\%)\end{array}$ \\
\hline$\geq 10 \mu \mathrm{g} / \mathrm{kg}$ a $100 \mu / \mathrm{kg}$ & 20 \\
$>100 \mu \mathrm{g} / \mathrm{kg}$ a $1.000 \mu / \mathrm{kg}$ & 15 \\
$\geq 1.000 \mu \mathrm{g} / \mathrm{kg}$ & 10 \\
\hline
\end{tabular}

A norma estabelece os níveis de coeficiente de variação em relação ao nível de recuperação corroboram em resultados experimentais de resíduos de pesticidas. Quanto menor a concentração avaliada, maiores são as chances da dissipação dos resultados das recuperações. A ANVISA (2006b) estabelece o coeficiente de variação aceitável de até $20 \%$.

\subsubsection{Níveis críticos (CCa e CC $\beta$ )}

Os níveis do limite de decisão (CCa) e a capacidade de detecção (CC $\beta$ ) foram calculados e avaliados em conformidade com as recomendações da norma Council Directive (2002). 


\subsubsection{Limite de decisão $(C C \alpha)$}

A norma Council Directive (2002) define que limite de decisão $\left(C C_{\alpha}\right)$ é o limite a partir do qual se pode concluir que uma amostra é não conforme com uma probabilidade de erro $\alpha$. O erro a mede a taxa de resultados falsos nãoconformes.

O resultado de uma análise é considerado conforme se o conteúdo de uma determinada substância é menor que o limite de decisão (CCa). Neste caso, a substância não está presente, ou não foi identificada ou está em concentração menor que CCa. O resultado de uma análise deve ser considerado não-conforme caso se exceda o limite de decisão $(C C \alpha)$ do método de confirmação para o analito. A substância é identificada e em concentração maior ou igual a CCa. Em resumo, o limite de decisão (CCa) mede o limite acima do qual pode-se concluir com uma probabilidade de erro $\alpha=1 \%$ que uma amostra é não-conforme.

O CCa é calculado pelos resultados da reprodutibilidade intralaboratorial para cada analito. Para o cálculo de CC $\alpha$ são considerados os dados das 3 equações de reta dos experimentos 1, 2 e 3, conforme o cronograma do experimento descrito na Tabela 9, item 4.7.1, resultados de recuperações, para cada princípio ativo.

Para calcular o CCa ( para $\alpha=0,01$ ), pode ser calculado segundo a equação 3:

$$
\operatorname{CC} \alpha=\frac{\left.(\text { y_inters. }+2,33 \times \text { stdev y_inters. })-y \_ \text {inters. }\right)}{\text { coef.angular }}
$$

onde:

y_inters: $\quad$ o valor da ordenada na origem;

stdev y_inters: desvio padrão da reprodutibilidade intralaboratorial, erro relativo de regressão do esperado para cada valor de y na regressão; coef. angular: coeficiente angular. 
Para calcular o erro relativo de regressão do esperado para cada valor de y e x na regressão (steyx), aplicou-se a equação 4:

$$
s=\operatorname{steyx} \sqrt{\frac{\sum_{i} x_{i}{ }^{2}}{n \sum_{i}\left(x_{i}-x\right)^{2}}}
$$

onde:

s: desvio padrão de b, na equação da reta $(y=a x+b)$;

$\mathrm{x}_{\mathrm{i}}$ : nível do desempenho;

$\mathrm{x}$ : média do desempenho dos níveis.

Para cada princípio ativo, foram calculados CC $\alpha$ aplicando as equações 3 e 4, com dados provenientes da equação das retas obtidos dos resultados dos experimentos 1, 2 e 3, citados na Tabela 9, item 4.7.1. Para avaliar - CCa de cada analito, considerou-se a média da determinação dos CCa, calculadas a partir dos resultados das equações das retas dos experimentos 1, 2 e 3 .

Os resultados foram determinados pela média CCa, obtidos nos experimentos 1, 2 e 3 para cada analito e expressos em unidades de $(\mu \mathrm{g} / \mathrm{kg})$.

\subsubsection{Capacidade de detecção $(C C \beta)$}

A capacidade de detecção $(C C \beta)$ é o teor mais baixo (ou a menor quantidade de substância que pode ser detectada), identificado ou quantificado numa amostra com um erro de probabilidade $\beta(5 \%)$. O erro $\beta$ mede a taxa de resultados falsos conformes.

O $C C \beta$ é calculado pelos resultados da reprodutibilidade intralaboratorial, da mesma forma que o CCa.

Para calcular o $C C \beta$ ( para $\alpha=0,95$ ), utilizou-se a equação 5 :

$$
\operatorname{CC} \beta=\frac{\left.\left(y \_ \text {inters. }+2,33 \times \operatorname{stdev} y \_ \text {inters. }+1,64 \times \text { stdev } y \_ \text {inters. }\right)-y \_ \text {inters. }\right)}{\text { coef. angular }}
$$


onde:

y_inters.: $\quad$ o valor da ordenada na origem;

stdev y_inters.: desvio padrão da reprodutibilidade intralaboratorial;

coef. angular: coeficiente angular.

Os resultados de $C C \beta$ foram obtidos da mesma forma que $C C \alpha$, aplicados as fórmulas acima. Para cada princípio ativo, foram calculados $C C \beta$ nos experimentos 1, 2 e 3, conforme o cronograma do experimento descrito na Tabela 9, item 4.7.1. Para avaliar o $C C \beta$ de cada analito, considerou-se as médias de determinações dos $C C \beta$, calculadas individualmente, pelas equações das retas do experimento 1,2 e 3.

Os resultados foram determinados pela média $C C \beta$, obtidas nos experimentos 1, 2 e 3 para cada analito, e foram expressos em unidades de $(\mu \mathrm{g} / \mathrm{kg})$.

\subsubsection{Incerteza}

Incerteza é um parâmetro associado ao resultado de uma medição, que caracteriza a dispersão de valores que poderiam ser razoavelmente atribuídos ao mensurado. Para quantificar a incerteza é necessário conhecer todo o procedimento analítico e identificar as fontes. Há muitas formas de mensurar as incertezas em medidas, por meio de métodos estatísticos ou por uma série de observações (Eurachem Working Group, 1998). Para este estudo foram calculadas as incertezas no limite de quantificação do método para todos os pesticidas, obedecendo as recomendações da norma (Council Directive, 2002).

Para determinar a medida de incerteza foi necessário conhecer a variância da reprodutibilidade $\left(\boldsymbol{S}_{\boldsymbol{R}}{ }^{2}\right)$, que é a soma das variâncias entre experimentos $\left(\boldsymbol{S}_{\boldsymbol{L}}{ }^{2}\right)$ e a repetibilidade $\left(\boldsymbol{S}_{\boldsymbol{r}}{ }^{2}\right.$. A incerteza final, conhecida como incerteza combinada, é quantificada levando-se em consideração a variância da reprodutibilidade (experimentos 1 a 3 ), conforme o cronograma do experimento descrito na Tabela 9, item 4.7.1 e a variância da repetibilidade produzida pelo efeito matriz (experimento 4). 


\subsubsection{Cálculo das variâncias}

A variância da repetibilidade $\left(\boldsymbol{S}_{\boldsymbol{r}}^{2}\right)$ foi calculada de acordo com a equação 6:

$$
s_{r}^{2}=\frac{\sum_{i=1}^{p}\left(n_{i j}-1\right) s_{i j}{ }^{2}}{\sum_{i=1}^{p}\left(n_{i j}-1\right)}
$$

onae:

$\boldsymbol{S}_{\boldsymbol{r}}^{2}$ : variância da repetibilidade;

p: $\quad$ número de experimentos;

$n_{i j}$ : número de análise de cada experimento em um nível ;

$s_{i j}$ : desvio padrão de cada experimento em um nível.

A variância entre experimentos $\left(\boldsymbol{S}_{L}^{2}\right)$ é o cálculo das variâncias entre os experimentos $(1+2+3)$, com as equações 7 a 9 .

$$
\begin{aligned}
S_{L}^{2} & =\frac{S_{d j}^{2}-S_{r j}^{2}}{n_{j}} \\
s_{d j}{ }^{2} & =\frac{1}{p-1}\left[\sum_{i=1}^{p} n_{i j}\left(\bar{y}_{i j}\right)^{2}-\left(\overline{\bar{y}}_{j}\right)^{2} \sum_{i=1}^{p} n_{i j}\right] \\
n_{j} & =\frac{1}{p-1}\left[\sum_{i=1}^{p} n_{i j}-\frac{\sum_{i=1}^{p} n_{i j}^{2}}{\sum_{i=1}^{p} n_{i j}}\right]
\end{aligned}
$$

onde:

$\overline{Y i j}$ : média aritmética dos resultados de um experimento em um determinado nível;

$Y j$ : média geral de todos os resultados em determinado nível. 
A variância da reprodutibilidade $\left(\boldsymbol{S}_{\boldsymbol{R}}{ }^{2}\right)$ é calculada pela da equação 10:

$$
s_{R}^{2}=s_{r}^{2}+s_{L}^{2}
$$

onde:

$S_{r}^{2}$ : variância da reprodutibilidade;

$S_{L}^{2}$ : variância entre experimentos.

\subsubsection{Cálculo de medida de incerteza (U)}

O cálculo da incerteza $(U)$ é realizado em função da variância $\left(S_{R}{ }^{2}\right)$, da reprodutibilidade e da matriz $\left(S^{2}\right)$, pela equação 11 :

$$
U=2 \sqrt{S_{r}^{2}+S_{\text {matriz }}^{2}}
$$

onde:

$\mathrm{S}_{\mathrm{r}}^{2} \quad$ : variância da reprodutibilidade (experimentos $1+2+3$ );

$\mathrm{S}^{2}{ }_{\text {matriz }}$ : variância da matriz (experimento 4).

A média de incerteza no estudo foi calculada no valor do limite de quantificação do método obtido para cada analito $(X \pm U)$, em nível de confiança de aproximadamente $95 \%$.

Os resultados do limite de quantificação dos analitos estudados foram expressos em valor encontrado para cada analito ( $L O Q \pm U$ ), valores expressos em unidades de $\mu \mathrm{g} / \mathrm{kg}$.

\subsubsection{Limite de quantificação (LOQ)}

Muitos conceitos têm sido atribuídos ao limite de quantificação (LOQ), que representa a menor concentração do analito em exame e que pode ser medido, utilizando-se um determinado procedimento experimental (INMETRO, 2003; ICH, 1995b).

É a característica de desempenho que define a habilidade de um processo de medida química de quantificar um analito adequadamente (Currie, 1995). 
O limite de quantificação do método neste trabalho é definido como a menor concentração que o método analítico pode operar com precisão aceitável (IUPAC, 2002).

O cálculo para a determinação do limite de quantificação do método para os princípios ativos estudados, em conformidade com a norma Council Directive (2002), foi feito a partir de resultados obtidos nos experimentos de estudo das recuperações, conforme o organograma (Tabela 9, item 4.7.1). 0 limite de quantificação do método, para cada analito estudado, foi estabelecido a partir dos resultados de recuperação dos experimentos de 1 a 4 , avaliadas e satisfeitas as condições de desempenho de exatidão (item 4.8.4, Tabela 10) e precisão (item 4.8.5, Tabela 11) recomendadas pela norma.

O limite de quantificação do método neste trabalho é expresso em unidades de $\mu \mathrm{g} / \mathrm{kg}$, acrescido da medida de incerteza.

\subsubsection{Limite de detecção (LD)}

Existem muitos conceitos a respeito do limite de detecção de métodos analíticos. O limite de detecção (LD) representa a menor concentração do analito que pode ser detectada, mas não necessariamente quantificada, utilizando um determinado procedimento experimental (INMETRO, 2003 e ICH, 1995b).

É a menor quantidade do analito que pode ser medida com certeza estatisticamente razoável (AOAC, 1998).

É estabelecido por meio de análises de concentrações conhecidas e decrescentes do analito até o menor nível detectável. Pode ser estabelecido utilizando-se a relação de três vezes o ruído da linha de base (ANVISA, 2006 b).

Neste estudo, o limite de detecção instrumental foi calculado em função de sinal/ruído, em virtude da norma não referenciar o procedimento para determinar o limite de detecção. O limite de detecção do método foi expresso em unidades de $\mu \mathrm{g} / \mathrm{kg}$. 


\section{RESULTADOS E DISCUSSÃO}

\subsection{Otimização do equipamento - cromatografia líquida}

Para estudo de uma metodologia analítica é essencial a otimização quanto às condições operacionais do equipamento. Para o cromatógrado líquido, o sistema utilizado para a fase móvel foi água tratada e o solvente acetonitrila, em diferentes graus de eluição, a um fluxo constante de $700 \mu \mathrm{L} \mathrm{min}{ }^{-1}$, durante a corrida cromatográfica, apresentada na Tabela 12.

Tabela 12 - Programação do gradiente de eluição da coluna cromatográfica

\begin{tabular}{ccc}
\hline Tempo $(\min )$ & Fase A & Fase B \\
\hline$-3,00$ & 35 & 65 \\
1,00 & 35 & 65 \\
4,00 & 5 & 95 \\
6,00 & 5 & 95 \\
6,01 & 35 & 65 \\
7,00 & 35 & 65 \\
\hline
\end{tabular}

Fase A: solução de água com 1,25 $\mathrm{mmol} \mathrm{L}^{-1}$ de carbonato de amônio PA Fase B: acetonitila grau HPLC

Tabela 13 - Tempo de retenção (Tr) dos analitos estudados

\begin{tabular}{lc|lc}
\hline \multicolumn{1}{c}{ Analito } & $\operatorname{Tr}(\mathrm{min})$ & \multicolumn{1}{c}{ Analito } & $\operatorname{Tr}(\min )$ \\
\hline Aldicarbe & 2,69 & Pirimicarbe & 4,42 \\
Aldicarbe sulfona & 1,41 & Propoxur & 3,22 \\
Aldicarbe Sulfóxido & 2,64 & Atrazina & 4,91 \\
Carbaril & 3,90 & Simazina & 3,83 \\
Carbofurano & 3,27 & Carbendazim & 2,64 \\
Metiocarbe & 5,75 & Tiabendazol & 3,44 \\
Metomil & 1,59 & Tiofanato metílico & 3,16 \\
\hline
\end{tabular}


$\mathrm{Na}$ Tabela 13, estão os resultados do tempo de retenção dos analitos estudados; o aldicarbe sulfona foi o primeiro a eluir na coluna cromatográfica e o pirimicarbe foi o último, com o tempo de retenção de 4,42 minutos. A otimização das condições cromatográficas contribuiu para a rapidez do método.

\subsection{Espectrometria de massas}

Os compostos foram caracterizados por ionização electrospray no modo positivo, no qual os parâmetros do potencial de orifício (DP), energia de colisão (CE) e potencial da saída de colisão (CXP) foram otimizados para operação do espectrômetro de massas no modo Multiple Reaction Monitoring (MRM), apresentados na Tabela 14.

Tabela 14 - Condições de detecção do espectrômetro de massas usando modo MRM.

\begin{tabular}{|c|c|c|c|c|c|c|}
\hline Composto & $\begin{array}{c}\text { Transição } \\
(\mathrm{m} / \mathrm{z})\end{array}$ & Propósito & $\begin{array}{l}\text { DP } \\
\text { (V) }\end{array}$ & $\begin{array}{l}\text { CE } \\
(\mathrm{eV})\end{array}$ & $\begin{array}{c}\text { CXP } \\
(\mathrm{V})\end{array}$ & $\begin{array}{c}\text { Dwell } \\
\text { Time (ms) }\end{array}$ \\
\hline \multirow{2}{*}{ Aldicarbe } & $208,1>89,1$ & $\mathrm{C}$ & \multirow{2}{*}{31} & 23 & 16 & \multirow{2}{*}{40} \\
\hline & $208,1>116,1$ & $\mathrm{Q}$ & & 11 & 20 & \\
\hline \multirow{2}{*}{ Aldicarbe sulfona } & $223,1>86,2$ & $\mathrm{C}$ & \multirow{2}{*}{71} & 23 & $\overline{14}$ & \multirow{2}{*}{40} \\
\hline & $223,1>48,1$ & $\mathrm{Q}$ & & 15 & 26 & \\
\hline \multirow{2}{*}{ Aldicarbe Sulfóxido } & $160,1>132,2$ & $\mathrm{C}$ & \multirow{2}{*}{106} & 31 & 22 & \multirow{2}{*}{40} \\
\hline & $160,1>105,1$ & Q & & 39 & 18 & \\
\hline \multirow{2}{*}{ Carbaril } & $202,1>127,1$ & $\mathrm{C}$ & \multirow{2}{*}{56} & 45 & 22 & \multirow{2}{*}{40} \\
\hline & $202,1>145,1$ & Q & & 15 & 24 & \\
\hline \multirow{2}{*}{ Carbofurano } & $222,1>123,1$ & C & \multirow{2}{*}{66} & 31 & 22 & \multirow{2}{*}{40} \\
\hline & $222,1>165,2$ & $Q$ & & 17 & 28 & \\
\hline \multirow{2}{*}{ Metiocarbe } & $226,2>121,2$ & $\mathrm{C}$ & \multirow{2}{*}{61} & 23 & 20 & \multirow{2}{*}{40} \\
\hline & $226,2>169,1$ & $Q$ & & 13 & 30 & \\
\hline \multirow{2}{*}{ Metomil } & $163,1>122,0$ & $\mathrm{C}$ & \multirow{2}{*}{51} & 9 & 20 & \multirow{2}{*}{40} \\
\hline & $163,1>88,1$ & $\mathrm{Q}$ & & 13 & 14 & \\
\hline \multirow{2}{*}{ Pirimicarbe } & $239,2>182,3$ & $\mathrm{C}$ & \multirow{2}{*}{56} & 23 & 30 & \multirow{2}{*}{40} \\
\hline & $239,2>72,1$ & Q & & 35 & 12 & \\
\hline \multirow{2}{*}{ Propoxur } & $210,0>168,2$ & C & \multirow{2}{*}{56} & 13 & 28 & \multirow{2}{*}{40} \\
\hline & $210,0>111,2$ & Q & & 23 & 10 & \\
\hline \multirow{2}{*}{ Atrazina } & $216,0>132,0$ & $\mathrm{C}$ & \multirow{2}{*}{36} & 35 & 21 & \multirow{2}{*}{40} \\
\hline & $216,0>174,1$ & Q & & 25 & 30 & \\
\hline \multirow{2}{*}{ Simazina } & $202,0>104,1$ & $\bar{C}$ & & 33 & 8 & \\
\hline & $202,0>132,1$ & Q & 36 & 27 & 22 & 40 \\
\hline & $192,2>132,0$ & C & 56 & 43 & 22 & \\
\hline Carbendazim & $192,2>160,1$ & Q & 56 & 25 & 28 & 40 \\
\hline Tighondoral & $202,1>131,2$ & $\mathrm{C}$ & 86 & 45 & 22 & 10 \\
\hline Ilabendazol & $202,1>175,1$ & $Q$ & 86 & 35 & 30 & 40 \\
\hline Tiofanato metílico & $343,0>311,2$ & C & 76 & 17 & 28 & 40 \\
\hline I Iotanato metilıco & $343,0>151,2$ & Q & 16 & 27 & 16 & 40 \\
\hline $\begin{array}{l}\text { C: Confirma } \\
\text { DP: Potencial } \\
\text { CXP: Potencia }\end{array}$ & ifício & $\begin{array}{l}\text { Q: } \\
\text { CE: }\end{array}$ & & olisão & & \\
\hline
\end{tabular}




\subsection{Curvas analíticas}

Para a obtenção das curvas analíticas dos princípios ativos, foi injetada em duplicata, misturas de seis padrões com concentrações correspondentes a $1 / 4,1 / 2,1,2,5$ e 10 LOQ (Limite de Quantificação), descritos no item 4.5. Nas Figuras de 16 a 29, encontram-se as curvas analíticas, considerando os dados de seis injeções e os valores de área de integração cromatográfica na faixa de trabalho que variaram de 0,04 a $8,0 \mathrm{ng} / \mathrm{mL}$ para os princípios ativos estudados. Nas Tabelas de 15 a 28, encontram-se as concentrações teóricas, o resultado das médias de concentrações obtidas, o desvio padrão, o coeficiente de variação (CV) e a exatidão das curvas analíticas dos princípios ativos estudados.

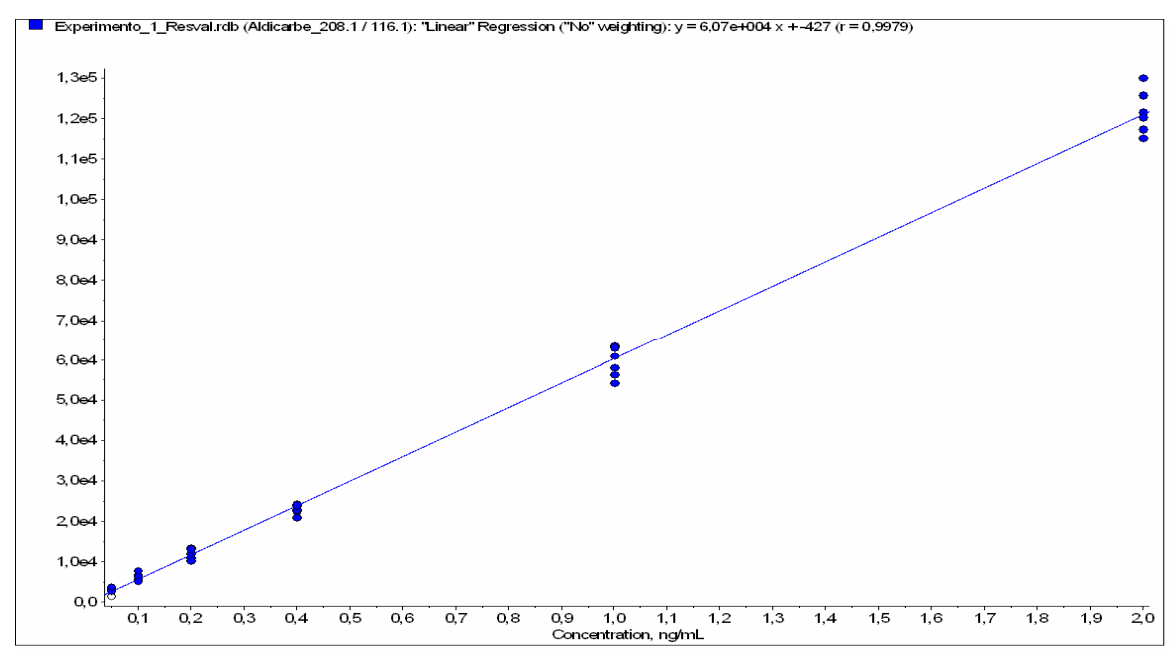

Figura 16 - Curva analítica para quantificação de aldicarbe

Tabela 15 - Resultados da curva analítica para aldicarbe

\begin{tabular}{ccccc}
\hline $\begin{array}{c}\text { Concentração } \\
(\mathrm{ng} / \mathrm{mL})\end{array}$ & $\begin{array}{c}\text { Média* }^{*}(\mathrm{ng} / \mathrm{mL}) \\
0,05\end{array}$ & $\begin{array}{c}\text { Desvio } \\
\text { Padrão }\end{array}$ & $\begin{array}{c}\text { CV } \\
(\%)\end{array}$ & $\begin{array}{c}\text { Exatidão } \\
(\%)\end{array}$ \\
\hline 0,10 & 0,0623 & 0,0063 & 10,15 & 124,64 \\
0,20 & 0,1111 & 0,0151 & 13,59 & 111,11 \\
0,40 & 0,1983 & 0,0227 & 11,44 & 99,18 \\
1,00 & 0,3858 & 0,0196 & 5,14 & 96,47 \\
2,00 & 0,9844 & 0,0632 & 6,42 & 98,44 \\
& 2,0099 & 0,0898 & 4,47 & 100,50 \\
\hline
\end{tabular}

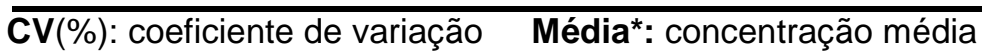




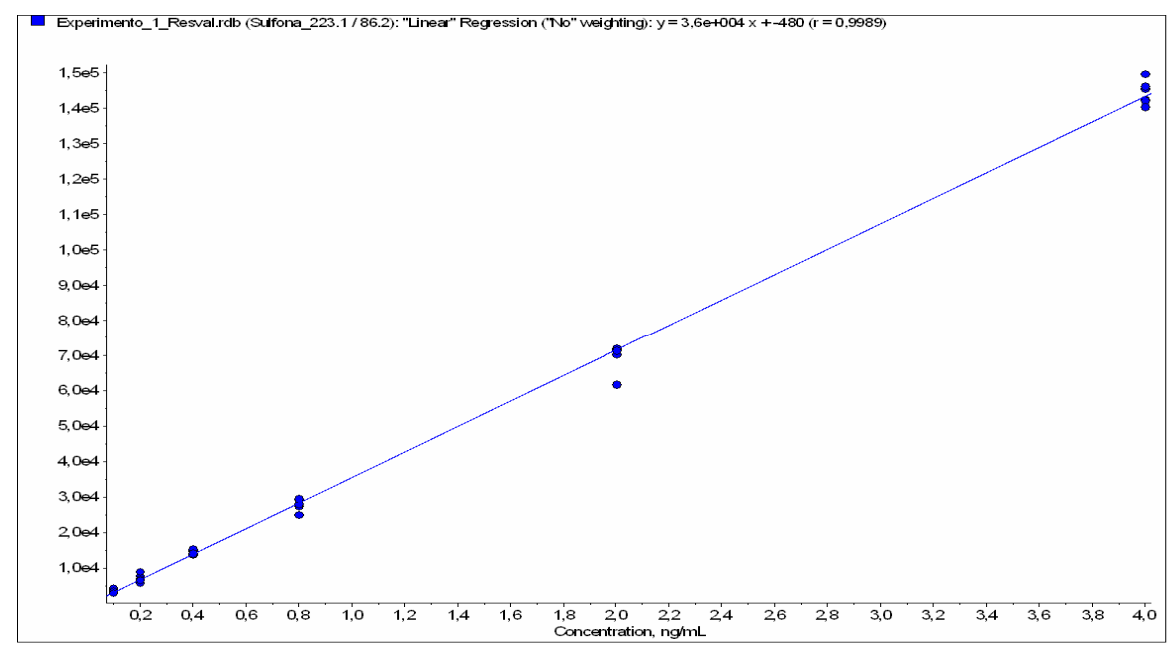

Figura 17 - Curva analítica para quantificação de aldicarbe sulfona

Tabela 16 - Resultados da curva analítica para aldicarbe sulfona

\begin{tabular}{ccccc}
\hline $\begin{array}{c}\text { Concentração } \\
(\mathrm{ng} / \mathrm{mL})\end{array}$ & $\begin{array}{c}\text { Média* }(\mathrm{ng} / \mathrm{mL}) \\
0,10\end{array}$ & $\begin{array}{c}\text { Desvio } \\
\text { Padrão }\end{array}$ & $\begin{array}{c}\text { CV } \\
(\%)\end{array}$ & $\begin{array}{c}\text { Exatidão } \\
(\%)\end{array}$ \\
\hline 0,20 & 0,1066 & 0,0147 & 13,94 & 106,57 \\
0,40 & 0,2124 & 0,0300 & 14,13 & 106,18 \\
0,80 & 0,4155 & 0,0177 & 4,25 & 103,87 \\
2,00 & 1,9464 & 0,1099 & 5,66 & 97,32 \\
4,00 & 4,0256 & 0,0941 & 2,34 & 100,64 \\
\hline
\end{tabular}

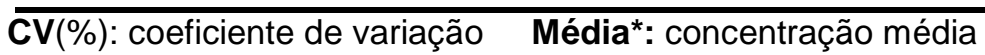

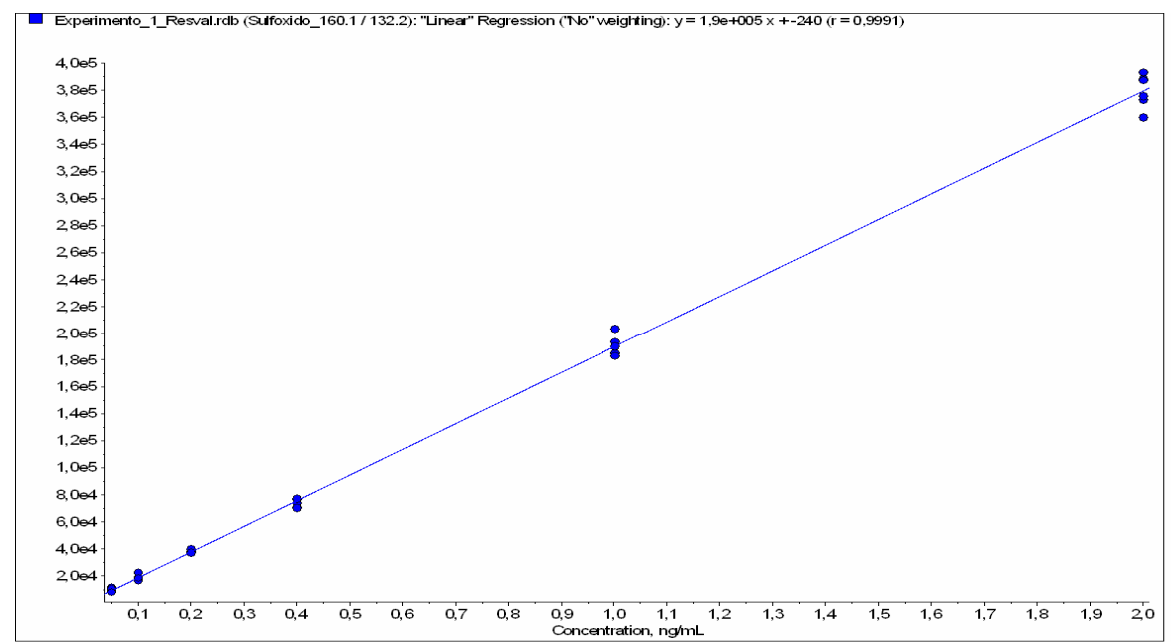

Figura 18 - Curva analítica para quantificação de aldicarbe sulfóxido 
Tabela 17 - Resultados da curva analítica para aldicarbe sulfóxido

\begin{tabular}{ccccc}
\hline $\begin{array}{c}\text { Concentração } \\
(\mathrm{ng} / \mathrm{mL})\end{array}$ & $\begin{array}{c}\text { Média* }^{*}(\mathrm{ng} / \mathrm{mL}) \\
0,05\end{array}$ & $\begin{array}{c}\text { Desvio } \\
\text { Padrão }\end{array}$ & $\begin{array}{c}\text { CV } \\
(\%)\end{array}$ & $\begin{array}{c}\text { Exatidão } \\
(\%)\end{array}$ \\
\hline 0,10 & 0,0526 & 0,0070 & 13,22 & 105,28 \\
0,20 & 0,1004 & 0,0104 & 14,13 & 100,44 \\
0,40 & 0,3927 & 0,0165 & 4,21 & 98,18 \\
1,00 & 1,0028 & 0,0402 & 4,01 & 100,29 \\
2,00 & 1,9997 & 0,0653 & 3,26 & 99,99 \\
\hline
\end{tabular}

CV(\%): coeficiente de variação Média*: concentração média

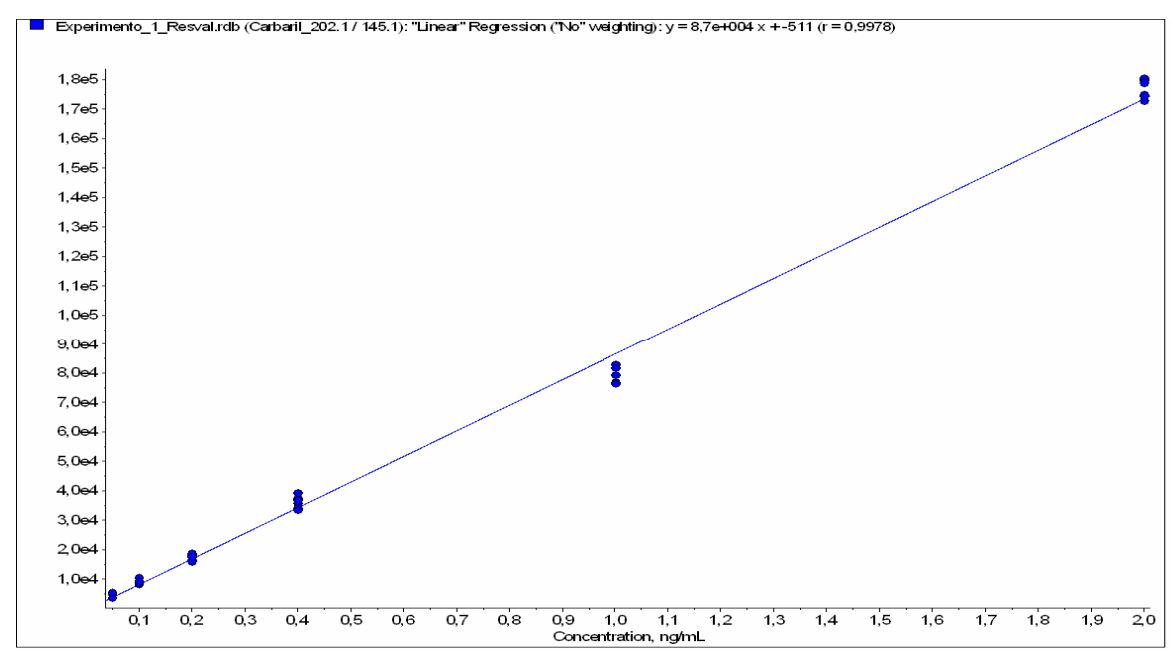

Figura 19 - Curva analítica para quantificação de carbaril

Tabela 18 - Resultados da curva analítica para carbaril

\begin{tabular}{ccccc}
\hline $\begin{array}{c}\text { Concentração } \\
(\mathrm{ng} / \mathrm{mL})\end{array}$ & $\begin{array}{c}\text { Média* } \\
(\mathrm{ng} / \mathrm{mL})\end{array}$ & $\begin{array}{c}\text { Desvio } \\
\text { Padrão }\end{array}$ & $\begin{array}{c}\text { CV } \\
(\%)\end{array}$ & $\begin{array}{c}\text { Exatidão } \\
(\%)\end{array}$ \\
\hline 0,05 & 0,0609 & 0,0075 & 12,32 & 121,83 \\
0,10 & 0,1111 & 0,0083 & 7,47 & 111,07 \\
0,20 & 0,2066 & 0,0119 & 5,75 & 103,29 \\
0,40 & 0,4207 & 0,0242 & 5,75 & 105,18 \\
1,00 & 0,9127 & 0,0324 & 3,56 & 91,27 \\
2,00 & 2,0380 & 0,0373 & 1,83 & 101,90
\end{tabular}

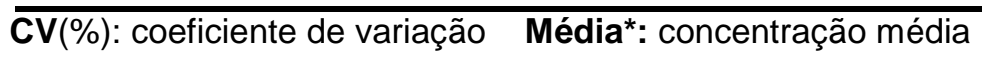




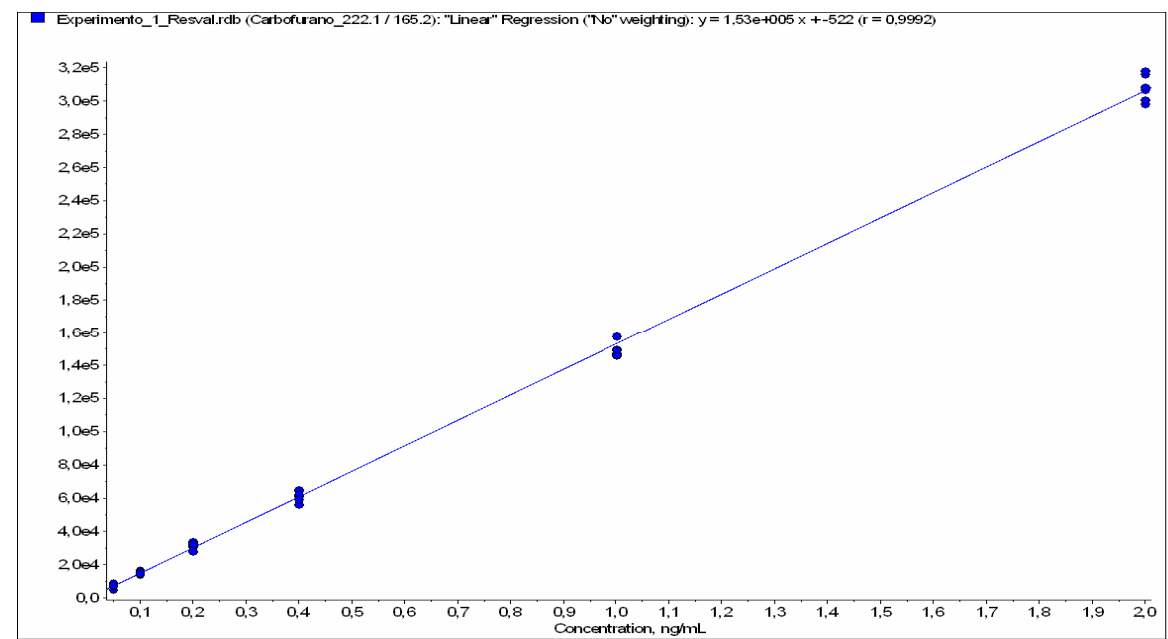

Figura 20 - Curva analítica para quantificação de carbofurano

Tabela 19 - Resultados da curva analítica para carbofurano

\begin{tabular}{ccccc}
\hline $\begin{array}{c}\text { Concentração } \\
(\mathrm{ng} / \mathrm{mL})\end{array}$ & $\begin{array}{c}\text { Média* } \\
(\mathrm{ng} / \mathrm{mL})\end{array}$ & $\begin{array}{c}\text { Desvio } \\
\text { Padrão }\end{array}$ & $\begin{array}{c}\text { CV } \\
(\%)\end{array}$ & $\begin{array}{c}\text { Exatidão } \\
(\%)\end{array}$ \\
\hline 0,05 & 0,0511 & 0,0095 & 18,51 & 102,37 \\
0,10 & 0,1022 & 0,0073 & 7,11 & 102,21 \\
0,20 & 0,2077 & 0,0132 & 6,38 & 103,84 \\
0,40 & 0,4024 & 0,0218 & 5,42 & 100,60 \\
1,00 & 0,9758 & 0,0288 & 2,96 & 97,58 \\
2,00 & 2,0107 & 0,0523 & 2,60 & 100,53
\end{tabular}

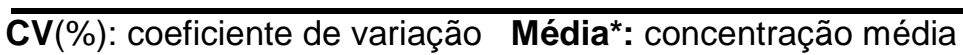

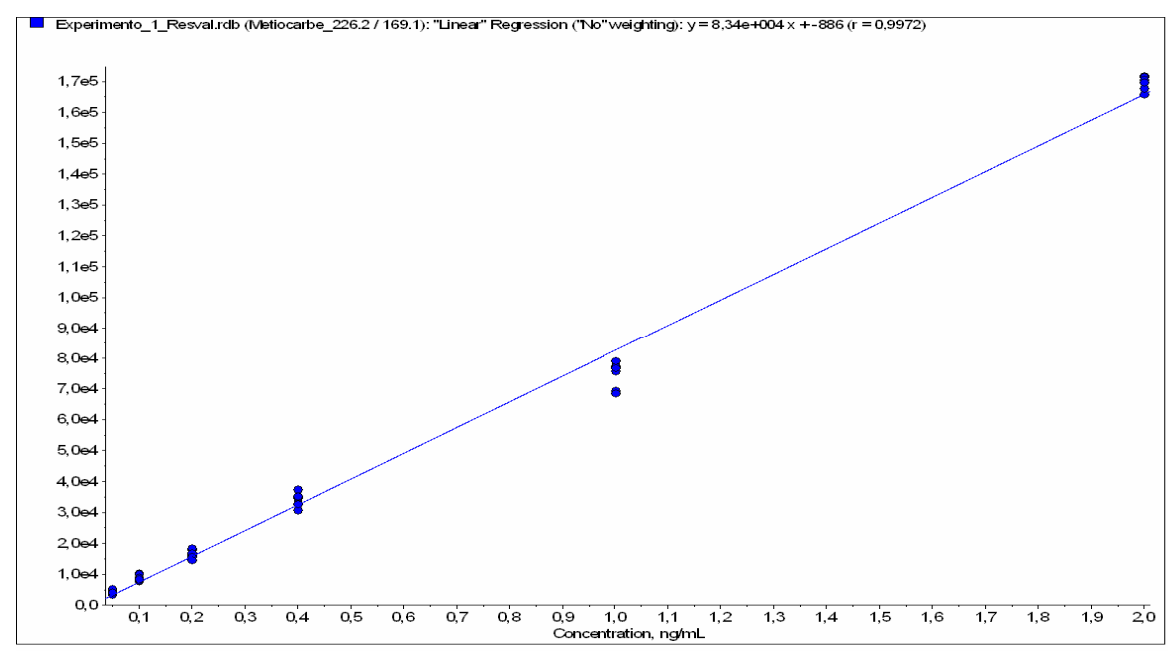

Figura 21 - Curva analítica para quantificação de metiocarbe 
Tabela 20 - Resultados da curva analítica para metiocarbe

\begin{tabular}{ccccc}
\hline $\begin{array}{c}\text { Concentração } \\
(\mathrm{ng} / \mathrm{mL})\end{array}$ & $\begin{array}{c}\text { Média }^{*} \\
(\mathrm{ng} / \mathrm{mL})\end{array}$ & $\begin{array}{c}\text { Desvio } \\
\text { Padrão }\end{array}$ & $\begin{array}{c}\text { CV } \\
(\%)\end{array}$ & $\begin{array}{c}\text { Exatidão } \\
(\%)\end{array}$ \\
\hline 0,05 & 0,0605 & 0,0091 & 15,12 & 121,08 \\
0,10 & 0,1174 & 0,0128 & 10,90 & 117,42 \\
0,20 & 0,2091 & 0,0171 & 8,19 & 104,55 \\
0,40 & 0,4167 & 0,0280 & 6,73 & 104,18 \\
1,00 & 0,9032 & 0,0536 & 5,93 & 90,32 \\
2,00 & 2,0430 & 0,0280 & 1,37 & 102,15 \\
\hline
\end{tabular}

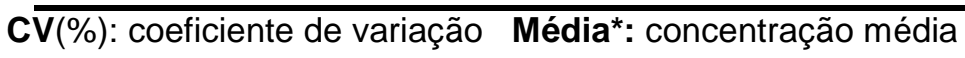

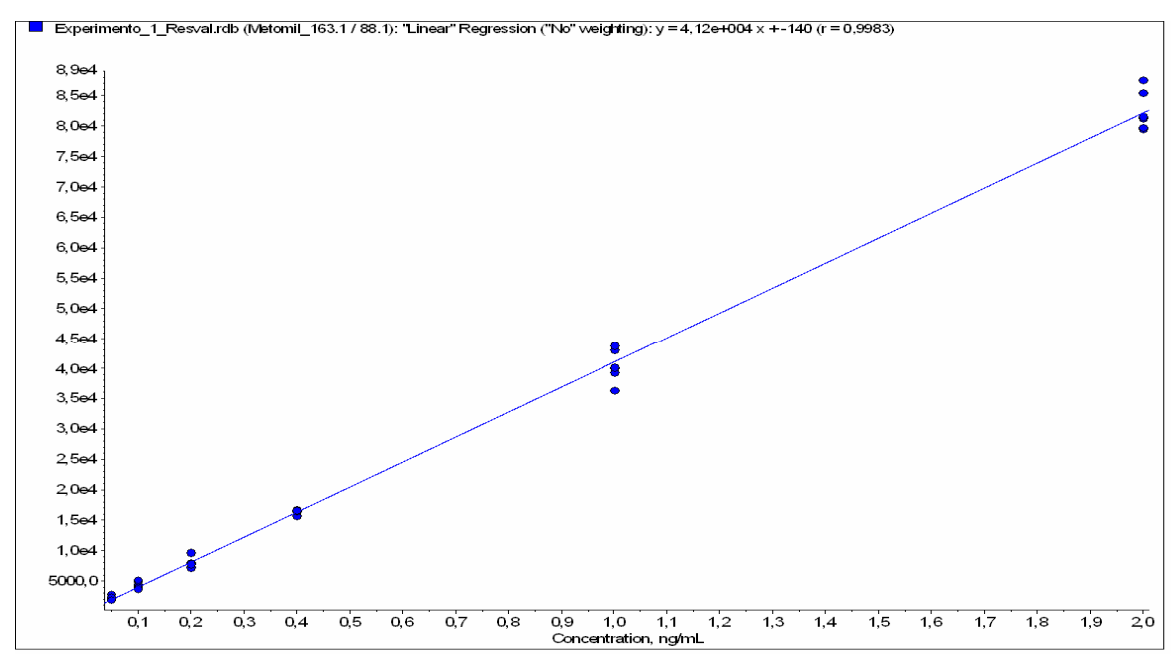

Figura 22 - Curva analítica para quantificação de metomil

Tabela 21 - Resultados da curva analítica para metomil

\begin{tabular}{ccccc}
\hline $\begin{array}{c}\text { Concentração } \\
(\mathrm{ng} / \mathrm{mL})\end{array}$ & $\begin{array}{c}\text { Média* } \\
(\mathrm{ng} / \mathrm{mL})\end{array}$ & $\begin{array}{c}\text { Desvio } \\
\text { Padrão }\end{array}$ & $\begin{array}{c}\text { CV } \\
(\%)\end{array}$ & $\begin{array}{c}\text { Exatidão } \\
(\%)\end{array}$ \\
\hline 0,05 & 0,0553 & 0,0088 & 15,83 & 110,62 \\
0,10 & 0,1084 & 0,0148 & 13,66 & 108,41 \\
0,20 & 0,1954 & 0,0216 & 11,04 & 97,69 \\
0,40 & 0,3977 & 0,0106 & 2,66 & 99,41 \\
1,00 & 0,9857 & 0,0665 & 6,75 & 98,57 \\
2,00 & 2,0075 & 0,0790 & 3,94 & 100,38
\end{tabular}

$\overline{\mathrm{CV}}(\%)$ : coeficiente de variação Média*: concentração média 


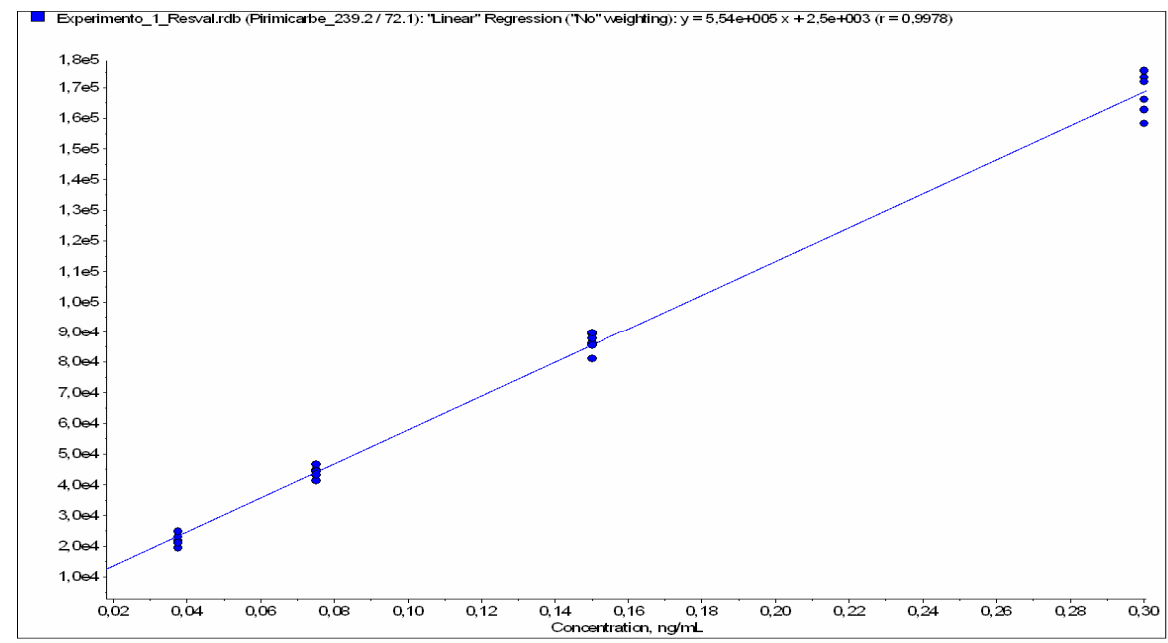

Figura 23 - Curva analítica para quantificação de pirimicarbe

Tabela 22 - Resultados da curva analítica para pirimicarbe

\begin{tabular}{ccccc}
\hline $\begin{array}{c}\text { Concentração } \\
(\mathrm{ng} / \mathrm{mL})\end{array}$ & $\begin{array}{c}\text { Média* }^{*} \\
(\mathrm{ng} / \mathrm{mL})\end{array}$ & $\begin{array}{c}\text { Desvio } \\
\text { Padrão }\end{array}$ & $\begin{array}{c}\text { CV } \\
(\%)\end{array}$ & $\begin{array}{c}\text { Exatidão } \\
(\%)\end{array}$ \\
\hline 0,04 & 0,0363 & 0,0038 & 10,57 & 96,66 \\
0,08 & 0,0749 & 0,0032 & 4,31 & 99,90 \\
0,16 & 0,1523 & 0,0058 & 3,80 & 101,53 \\
0,30 & 0,2990 & 0,0121 & 4,07 & 99,67 \\
\hline
\end{tabular}

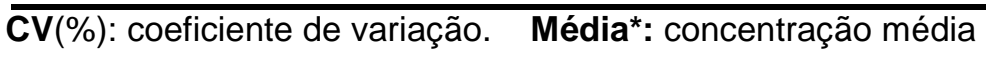

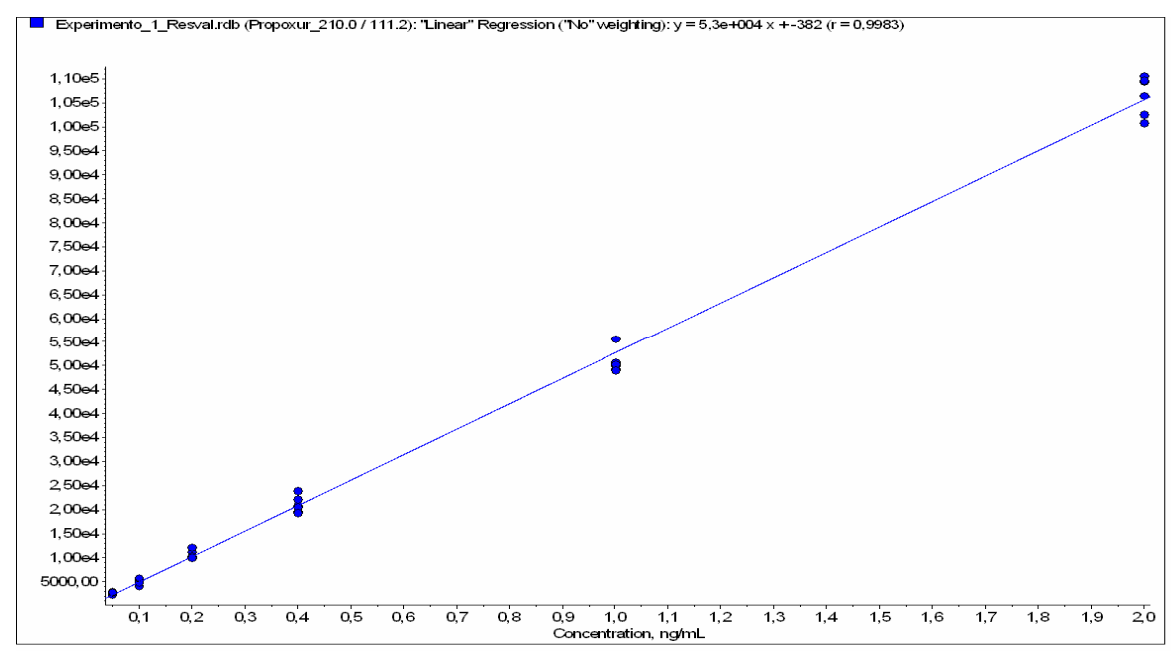

Figura 24 - Curva analítica para quantificação de propoxur 
Tabela 23 - Resultados da curva analítica para propoxur

\begin{tabular}{ccccc}
\hline $\begin{array}{c}\text { Concentração } \\
(\mathrm{ng} / \mathrm{mL})\end{array}$ & $\begin{array}{c}\text { Média }^{*} \\
(\mathrm{ng} / \mathrm{mL})\end{array}$ & $\begin{array}{c}\text { Desvio } \\
\text { Padrão }\end{array}$ & $\begin{array}{c}\text { CV } \\
(\%)\end{array}$ & $\begin{array}{c}\text { Exatidão } \\
(\%)\end{array}$ \\
\hline 0,05 & 0,0568 & 0,0059 & 10,43 & 113,63 \\
0,10 & 0,1036 & 0,0116 & 11,19 & 103,57 \\
0,20 & 0,2062 & 0,0170 & 8,26 & 103,09 \\
0,40 & 0,4029 & 0,0326 & 8,10 & 100,72 \\
1,00 & 0,9642 & 0,0466 & 4,84 & 96,42 \\
2,00 & 2,0164 & 0,0767 & 3,80 & 100,82 \\
\hline
\end{tabular}

$\overline{\mathbf{C V}}(\%)$ : coeficiente de variação. Média*: concentração média

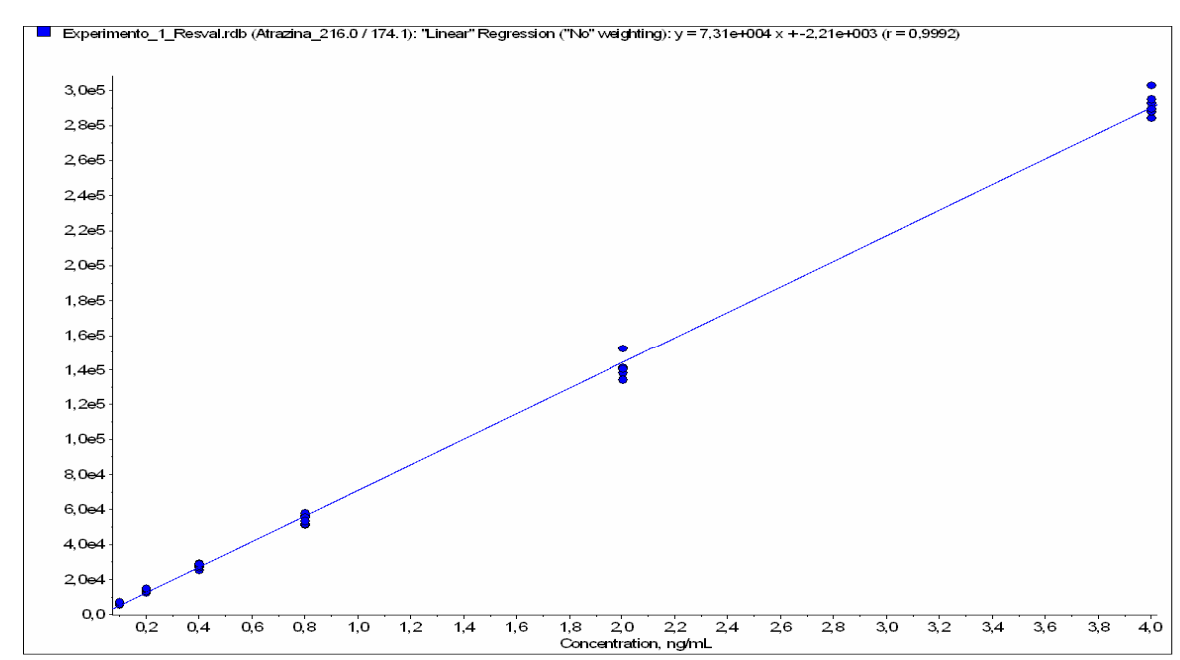

Figura 25 - Curva analítica para quantificação de atrazina

Tabela 24 - Resultados da curva analítica para atrazina

\begin{tabular}{ccccc}
\hline $\begin{array}{c}\text { Concentração } \\
(\mathrm{ng} / \mathrm{mL})\end{array}$ & $\begin{array}{c}\text { Média* }^{*}(\mathrm{ng} / \mathrm{mL}) \\
0,10\end{array}$ & $\begin{array}{c}\text { Desvio } \\
\text { Padrão }\end{array}$ & $\begin{array}{c}\text { CV } \\
(\%)\end{array}$ & $\begin{array}{c}\text { Exatidão } \\
(\%)\end{array}$ \\
\hline 0,20 & 0,21182 & 0,0099 & 8,38 & 118,18 \\
0,40 & 0,4118 & 0,0137 & 6,44 & 106,91 \\
0,80 & 0,7754 & 0,0375 & 4,84 & 96,92 \\
2,00 & 1,9564 & 0,0862 & 4,41 & 97,82 \\
4,00 & 4,0244 & 0,0892 & 2,22 & 100,61
\end{tabular}

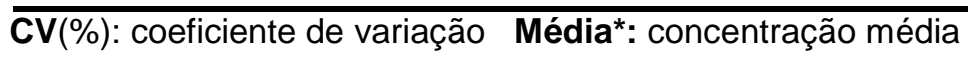




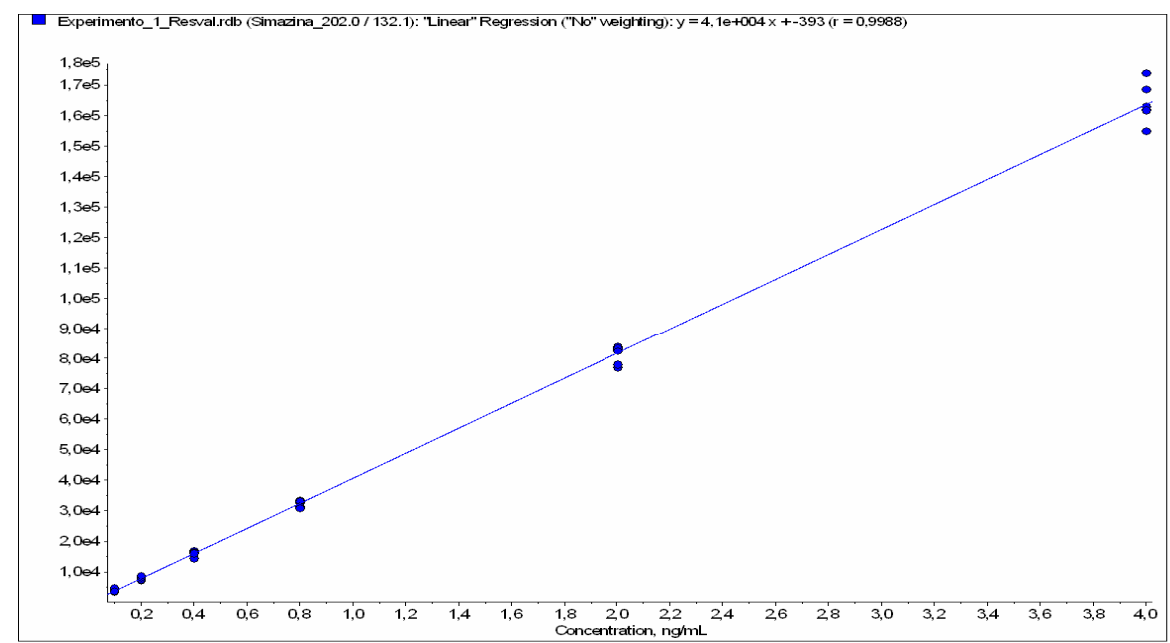

Figura 26 - Curva analítica para quantificação de simazina

Tabela 25 - Resultados da curva analítica para simazina

\begin{tabular}{ccccc}
\hline $\begin{array}{c}\text { Concentração } \\
(\mathrm{ng} / \mathrm{mL})\end{array}$ & $\begin{array}{c}\text { Média* } \\
(\mathrm{ng} / \mathrm{mL})\end{array}$ & $\begin{array}{c}\text { Desvio } \\
\text { Padrão }\end{array}$ & $\begin{array}{c}\text { CV } \\
(\%)\end{array}$ & $\begin{array}{c}\text { Exatidão } \\
(\%)\end{array}$ \\
\hline 0,10 & 0,1109 & 0,0147 & 13,27 & 110,90 \\
0,20 & 0,2030 & 0,0144 & 7,10 & 101,49 \\
0,40 & 0,3990 & 0,0195 & 4,90 & 99,78 \\
0,80 & 0,7906 & 0,0261 & 3,30 & 98,83 \\
2,00 & 1,9898 & 0,0744 & 3,74 & 99,49 \\
4,00 & 4,0066 & 0,1597 & 3,99 & 100,17
\end{tabular}

CV(\%): coeficiente de variação Média*: concentração média

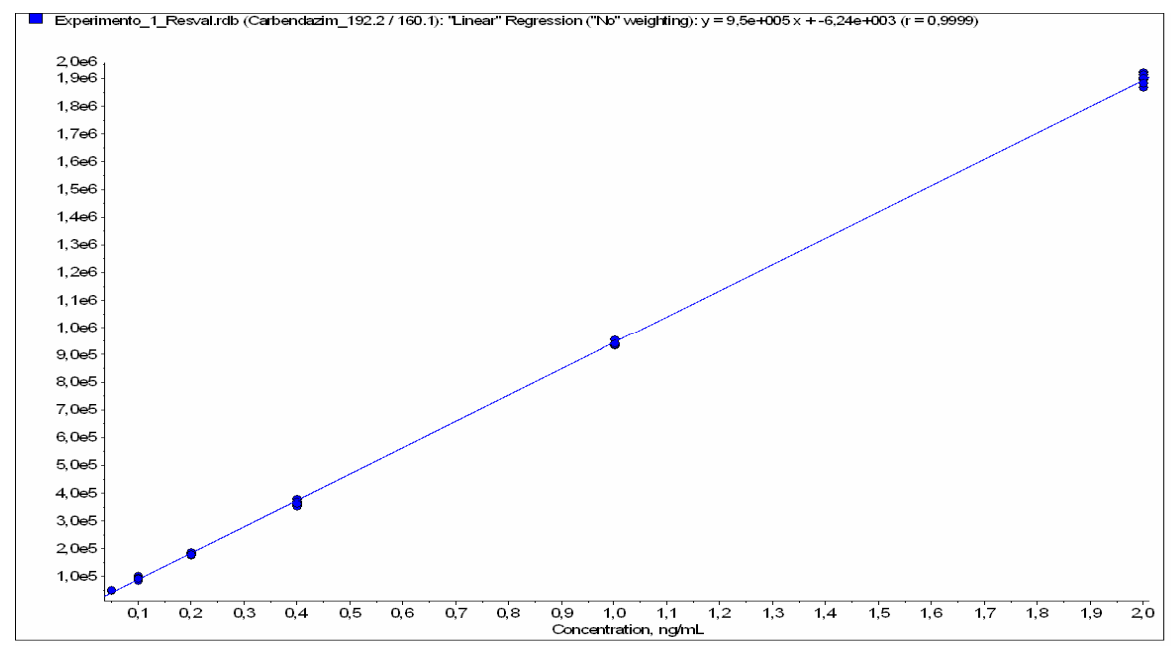

Figura 27 - Curva analítica para quantificação de carbendazim 
Tabela 26 - Resultados da curva analítica para carbendazim

\begin{tabular}{ccccc}
\hline $\begin{array}{c}\text { Concentração } \\
(\mathrm{ng} / \mathrm{mL})\end{array}$ & $\begin{array}{c}\text { Média }^{*} \\
(\mathrm{ng} / \mathrm{mL})\end{array}$ & $\begin{array}{c}\text { Desvio } \\
\text { Padrão }\end{array}$ & $\begin{array}{c}\text { CV } \\
(\%)\end{array}$ & $\begin{array}{c}\text { Exatidão } \\
(\%)\end{array}$ \\
\hline 0,05 & 0,0586 & 0,0018 & 3,02 & 117,17 \\
0,10 & 0,1051 & 0,0070 & 6,67 & 105,10 \\
0,20 & 0,1964 & 0,0044 & 2,21 & 98,23 \\
0,40 & 0,3902 & 0,0104 & 2,67 & 97,55 \\
1,00 & 0,9956 & 0,0093 & 0,94 & 99,56 \\
2,00 & 2,0040 & 0,0213 & 1,07 & 100,20 \\
\hline
\end{tabular}

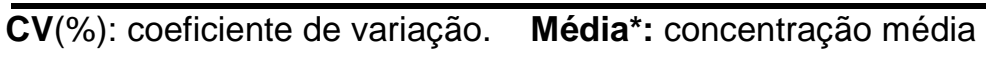

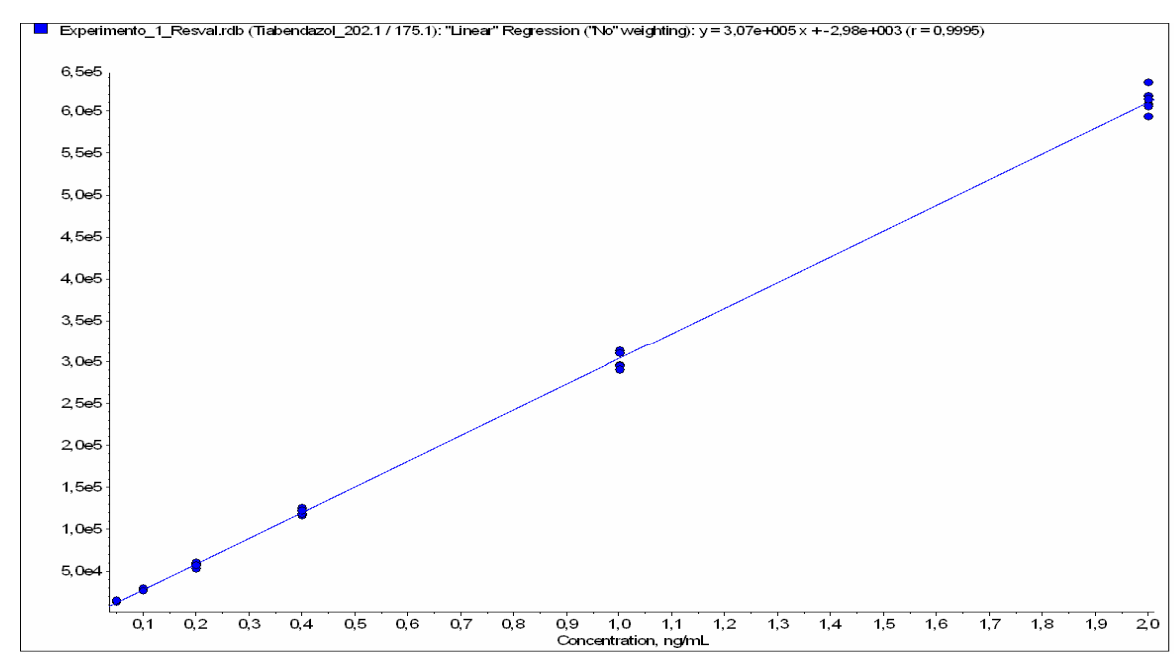

Figura 28 - Curva analítica para quantificação de tiabendazol

Tabela 27 - Resultados da curva analítica para tiabendazol

\begin{tabular}{ccccc}
\hline $\begin{array}{c}\text { Concentração } \\
(\mathrm{ng} / \mathrm{mL})\end{array}$ & $\begin{array}{c}\text { Média* }^{*} \\
(\mathrm{ng} / \mathrm{mL})\end{array}$ & $\begin{array}{c}\text { Desvio } \\
\text { Padrão }\end{array}$ & $\begin{array}{c}\text { CV } \\
(\%)\end{array}$ & $\begin{array}{c}\text { Exatidão } \\
(\%)\end{array}$ \\
\hline 0,05 & 0,0565 & 0,0033 & 5,89 & 112,95 \\
0,10 & 0,1023 & 0,0044 & 4,29 & 102,30 \\
0,20 & 0,1976 & 0,0077 & 3,88 & 98,78 \\
0,40 & 0,4006 & 0,0107 & 2,68 & 100,15 \\
1,00 & 0,9864 & 0,0337 & 3,42 & 98,64 \\
2,00 & 2,0066 & 0,0443 & 2,21 & 100,33
\end{tabular}

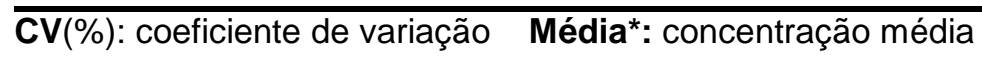




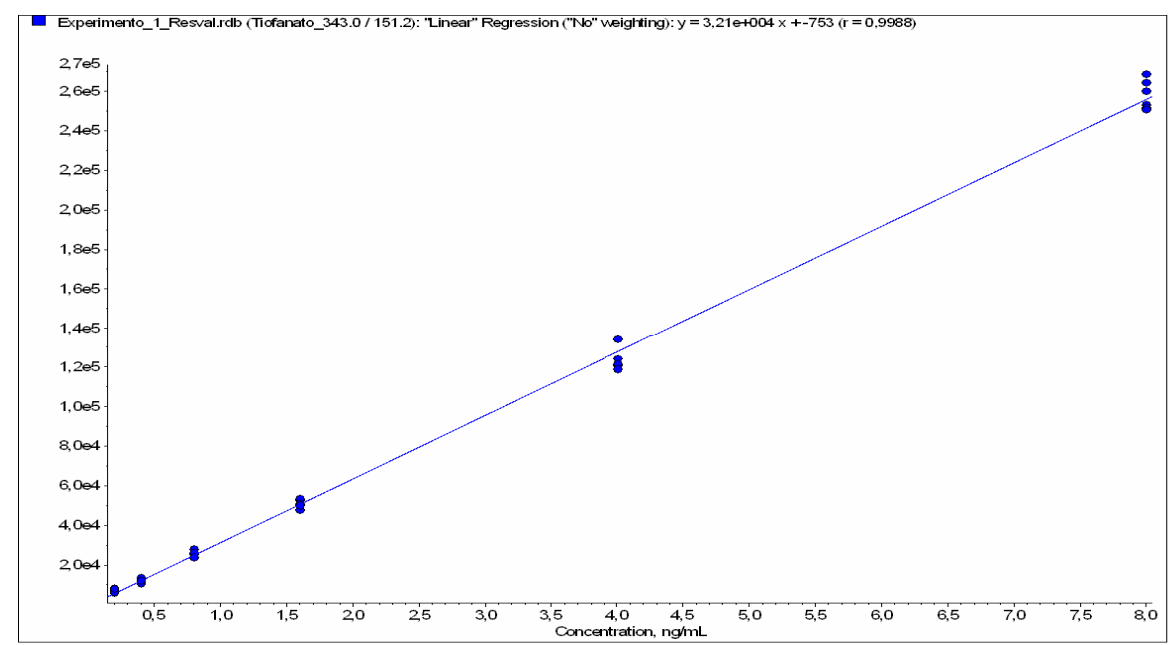

Figura 29 - Curva analítica para quantificação de tiofanato metílico

Tabela 28 - Resultados da curva analítica para tiofanato metílico

\begin{tabular}{ccccc}
\hline $\begin{array}{c}\text { Concentração } \\
(\mathrm{ng} / \mathrm{mL})\end{array}$ & $\begin{array}{c}\text { Média* } \\
(\mathrm{ng} / \mathrm{mL})\end{array}$ & $\begin{array}{c}\text { Desvio } \\
\text { Padrão }\end{array}$ & $\begin{array}{c}\text { CV } \\
(\%)\end{array}$ & $\begin{array}{c}\text { Exatidão } \\
(\%)\end{array}$ \\
\hline 0,20 & 0,2413 & 0,0307 & 12,71 & 120,67 \\
0,40 & 0,4128 & 0,0324 & 7,86 & 103,19 \\
0,80 & 0,8154 & 0,0473 & 5,80 & 101,93 \\
1,60 & 1,6060 & 0,0607 & 3,78 & 100,38 \\
4,00 & 3,8577 & 0,1842 & 4,78 & 96,44 \\
8,00 & 8,0667 & 0,2317 & 2,87 & 100,83 \\
\hline
\end{tabular}

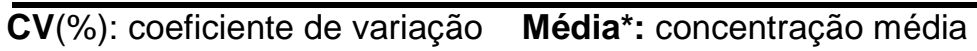

A partir dos dados analisados, as curvas analíticas de quantificação de todos os analitos estudados apresentaram coeficientes de variação menores do que $18,5 \%$, em todas as concentrações estudadas. Estes valores de coeficientes de variação são maiores que $10 \%$, para concentrações mais baixas analisadas, na concentração correspondente a $1 / 4 \mathrm{LOQ}$ (Limite de quantificação) a $1 / 2 \mathrm{LOQ}$, níveis abaixo de LOQ do método. Para as as concentrações mais altas, estes coeficientes de variação são da ordem de $6 \%$ na sua maioria.

A exatidão obtida para as curvas de calibração situam-se num intervalo de 90 a $124 \%$ e para valores de exatidão maiores que $100 \%$, em geral são resultados referentes às baixas concentrações correspondentes a 1/4 LOQ e 1/2 LOQ. Para concentrações iguais e maiores que o LOQ, apresentou média de exatidão de $99 \%$. 
$\mathrm{Na}$ Tabela 29 estão relacionados os dados da equação da reta das curvas analíticas de todos os analitos estudados neste trabalho.

Tabela 29 - Linearidade das curvas analíticas

\begin{tabular}{lcccc}
\hline Analito & $\begin{array}{c}\text { Faixa } \\
(\mathrm{ng} / \mathrm{mL})\end{array}$ & $\begin{array}{c}\text { Inclinação } \\
(\mathrm{a})\end{array}$ & $\begin{array}{c}\text { Intersecção } \\
(\mathrm{b})\end{array}$ & $\begin{array}{c}\text { Correlação } \\
\left(\mathrm{r}^{2}\right)\end{array}$ \\
\hline Aldicarbe & $0,05-2,00$ & 60.700 & -427 & 0,9979 \\
Aldicarbe & $0,10-4,00$ & 36.000 & -480 & 0,9987 \\
sulfona & & & 138 & 0,9982 \\
Aldicarbe & $0,05-2,00$ & 11.200 & -511 & 0,9978 \\
sulfóxido & $0,05-2,00$ & 87.000 & -522 & 0,9992 \\
Carbaril & $0,05-2,00$ & 153.000 & -886 & 0,9972 \\
Carbofurano & 0,340 & -140 & 0,9983 \\
Metiocarbe & $0,05-2,00$ & 42.100 & 2.500 & 0,9978 \\
Metomil & $0,05-2,00$ & 554.000 & -382 & 0,9983 \\
Pirimicarbe & $0,04-1,60$ & 5.300 & -2.210 & 0,9992 \\
Propoxur & $0,05-2,00$ & 73.100 & -393 & 0,9988 \\
Atrazina & $0,10-4,00$ & 41.000 & -6.240 & 0,9999 \\
Simazina & $0,10-4,00$ & 950.000 & -2.980 & 0,9995 \\
Carbendazim & $0,05-2,00$ & 30.700 & -753 & 0,9988 \\
Tiabendazol & $0,05-2,00$ & 32.100 & & \\
Tiofanato & $0,20-8,00$ & & & \\
metílico & & &
\end{tabular}

Os dados da Tabela 29 são referentes a uma equação da reta, denominada também de curva analítica descrita pela equação $\mathbf{y}=\mathbf{a x}+\mathbf{b}$, obtida $\mathbf{a}$ partir 6 injeções a cada ponto no equipamento, em um conjunto de 6 níveis.

Foi utilizado o método de regressão linear para cálculo dos coeficientes a (angular), b (intersecção) e $\mathbf{r}^{2}$ (correlação) obtidos a partir de resultados experimentais, permitindo estimar a qualidade da curva. Verificando-se os dados das curvas analíticas, quase todos os analitos apresentaram valores de $\mathbf{r}^{2}$ próximos a 0,999; segundo Ribani et al. (2004), são consideradas como ajuste ideal dos dados para a linha de regressão.

A norma INMETRO (2003) recomenda uma correlação $\left(\mathbf{r}^{2}\right)$ de valores acima de 0,90 .

$\mathrm{Na}$ Tabela 30, encontram-se os resultados da precisão instrumental da curva analítica para todos os analitos. 
Tabela 30 - Resultados da precisão instrumental da curva analítica para todos os analitos estudados neste trabalho

\begin{tabular}{lccrr}
\hline \multicolumn{1}{c}{ Analito } & $\begin{array}{c}\text { Faixa } \\
(\mathrm{ng} / \mathrm{mL})\end{array}$ & $\begin{array}{c}\text { Média da Precisão } \\
(\%)\end{array}$ & $\begin{array}{r}\text { Desvio } \\
\text { Padrão }\end{array}$ & $\begin{array}{r}\text { CV } \\
(\%)\end{array}$ \\
\hline Aldicarbe & $0,05-2,00$ & 105,06 & 10,89 & 10,3 \\
Aldicarbe sulfona & $0,10-4,00$ & 102,32 & 3,80 & 3,7 \\
Aldicarbe sulfóxido & $0,05-2,00$ & 100,83 & 2,37 & 2,4 \\
Carbaril & $0,05-2,00$ & 105,76 & 10,17 & 9,6 \\
Carbofurano & $0,05-2,00$ & 101,19 & 2,16 & 2,1 \\
Metiocarbe & $0,05-2,00$ & 106,62 & 11,16 & 10,4 \\
Metomil & $0,05-2,00$ & 102,52 & 5,54 & 5,4 \\
Pirimicarbe & $0,04-1,60$ & 99,44 & 2,03 & 2,0 \\
Propoxur & $0,05-2,00$ & 103,04 & 5,77 & 5,6 \\
Atrazina & $0,10-4,00$ & 103,90 & 7,88 & 7,6 \\
Simazina & $0,10-4,00$ & 101,77 & 4,55 & 4,5 \\
Carbendazim & $0,05-2,00$ & 102,97 & 7,45 & 7,2 \\
Tiabendazol & $0,05-2,00$ & 102,19 & 5,43 & 5,3 \\
Tiofanato metílico & $0,20-8,00$ & 103,91 & 8,52 & 8,2 \\
CV: coeficiente de variação & & & &
\end{tabular}

Com relação aos resultados da Tabela 30, o coeficiente de variação (CV), para todos os pesticidas estudados em todas as concentrações, apresentou variações de 2,0 a $10,4 \%$. Os pesticidas que apresentaram CV em torno de $10 \%$ foram: aldicarbe, carbaril e metiocarbe; porém carbaril e metiocarbe apresentaram resultados satisfatórios de médias de recuperações, possivelmente devido a dispersão de dados instrumentais não influenciar no comprometimento da quantificação dos analitos estudados. O aldicarbe, com CV de 10,3\% da precisão instrumental da curva analítica, apresentou baixa porcentagem de recuperação, mas CV satisfatórios de médias de recuperações em todos os níveis de concentração. 


\subsection{Extração}

Para a escolha do solvente na fase de extração dos pesticidas estudados em milho, foram avaliados os resultados das amostras testemunha, fortificadas e extraídas por diferentes solventes. Foi adicionado na amostra testemunha um volume de concentração para o nível $1 \mathrm{LOQ}$ de uma mistura de padrões de todos os princípios ativos estudados (item 4.7), submetido ao mesmo procedimento descrito no item 4.6, utilizando 5 diferentes solventes: água, acetato de etila, acetonitrila, metanol e acetona, conforme resultados apresentados na Tabela 31.

Tabela 31 - Resultados da extração das amostras testemunhas fortificadas com diferentes solventes.

\begin{tabular}{|c|c|c|c|c|c|c|c|c|}
\hline \multirow{2}{*}{ Analito } & \multirow{2}{*}{$\begin{array}{l}\text { Fortificação } \\
(\mathrm{ng} / \mathrm{mL})\end{array}$} & \multirow{2}{*}{$\begin{array}{c}\mathbf{A} \\
(\%)\end{array}$} & \multirow{2}{*}{$\begin{array}{l}\text { B } \\
(\%)\end{array}$} & \multirow{2}{*}{$\begin{array}{l}\text { C } \\
(\%)\end{array}$} & \multirow{2}{*}{$\begin{array}{l}\text { D } \\
(\%)\end{array}$} & \multicolumn{3}{|c|}{$E(\%)$} \\
\hline & & & & & & $10 \mathrm{~min}$ & $20 \mathrm{~min}$ & $\begin{array}{c}30 \\
\min \end{array}$ \\
\hline Aldicarbe & 0,20 & 85 & 5 & 70 & 70 & 85 & 5 & 85 \\
\hline Ald. sulfona & 0,40 & 58 & 63 & 60 & 60 & 108 & 98 & 118 \\
\hline Ald. sulfóxido & 0,20 & 50 & 25 & 80 & 95 & 85 & 5 & 95 \\
\hline Carbaril & 0,20 & 55 & 10 & 95 & 100 & 85 & 5 & 95 \\
\hline Carbofurano & & & 10 & 95 & & & & 75 \\
\hline Metiocarbe & 0 & 35 & 10 & 95 & 8 & 105 & 0 & 95 \\
\hline Metomil & 0,20 & 55 & 55 & 75 & 60 & 0 & & 90 \\
\hline Pirimicarbe & 0,20 & 65 & 10 & 60 & 70 & 80 & 85 & 85 \\
\hline Propoxur & 0,20 & 05 & 0 & 90 & 105 & 110 & 100 & 85 \\
\hline Atrazina & 0,40 & 45 & 13 & 100 & 90 & 0 & u & 90 \\
\hline Simazina & & 58 & 13 & 90 & 100 & 88 & 00 & 85 \\
\hline Carbendazim & 0,20 & 60 & 25 & 85 & 75 & 80 & 90 & 90 \\
\hline Tiabendazol & 0 & 65 & 20 & 110 & 110 & 110 & 110 & 105 \\
\hline Tiof. metílico & 0,80 & 70 & 10 & 101 & 94 & 109 & 101 & 109 \\
\hline \multicolumn{9}{|l|}{ A: Água } \\
\hline \multicolumn{9}{|c|}{$\begin{array}{l}\text { Dentre os solventes testados, para os analitos estudados, o acetato de } \\
\text { etila demonstrou ser o menos eficaz, seguido de água. Os solventes acetonitrila e } \\
\text { metanol não apresentaram recuperação satisfatória para muitos dos analitos, tais } \\
\text { como: aldicarbe, metomil, pirimicarbe e carbendazim. A acetona mostrou ser o } \\
\text { melhor solvente para extração, apresentando níveis de recuperação que variaram }\end{array}$} \\
\hline
\end{tabular}


sulfona, para uma extração de 30 minutos de 118\%. Motohashi et al. (1996) estudaram vários solventes de extração (acetonitrila, metanol-água, acetato de etila e acetona) em frutas, vegetais e solos para a determinação de carbamatos, triazinas e outros, considerando a acetona mais adequada para estes grupos de pesticidas. Hiemstra et al. (1995) também utilizaram a acetona como melhor solvente para a extração de benzimidazóis em frutas e vegetais, o que corroboram com os dados obtidos neste trabalho.

Quanto ao tempo de da fase de extração (com acetona), não se observaram variações acentuadas nas recuperações dos analitos, quando este varia de 10 a 30 minutos, sendo o tempo adequado para extração dos princípios ativos estudados na matriz de milho foi de 20 minutos de agitação.

\subsection{Teste testemunha - seletividade}

Para avaliar a seletividade do método, foram avaliados os resultados do cronograma do experimento 4, Tabela 9, item 4.7.1. No experimento 4, foram analisadas 10 amostras de branco (testemunha) e 10 amostras fortificadas no limite de quantificação.

As figuras 30 e 31 ilustram como exemplos, o cromatograma de uma amostra testemunha e amostra fortificada, respectivamente.

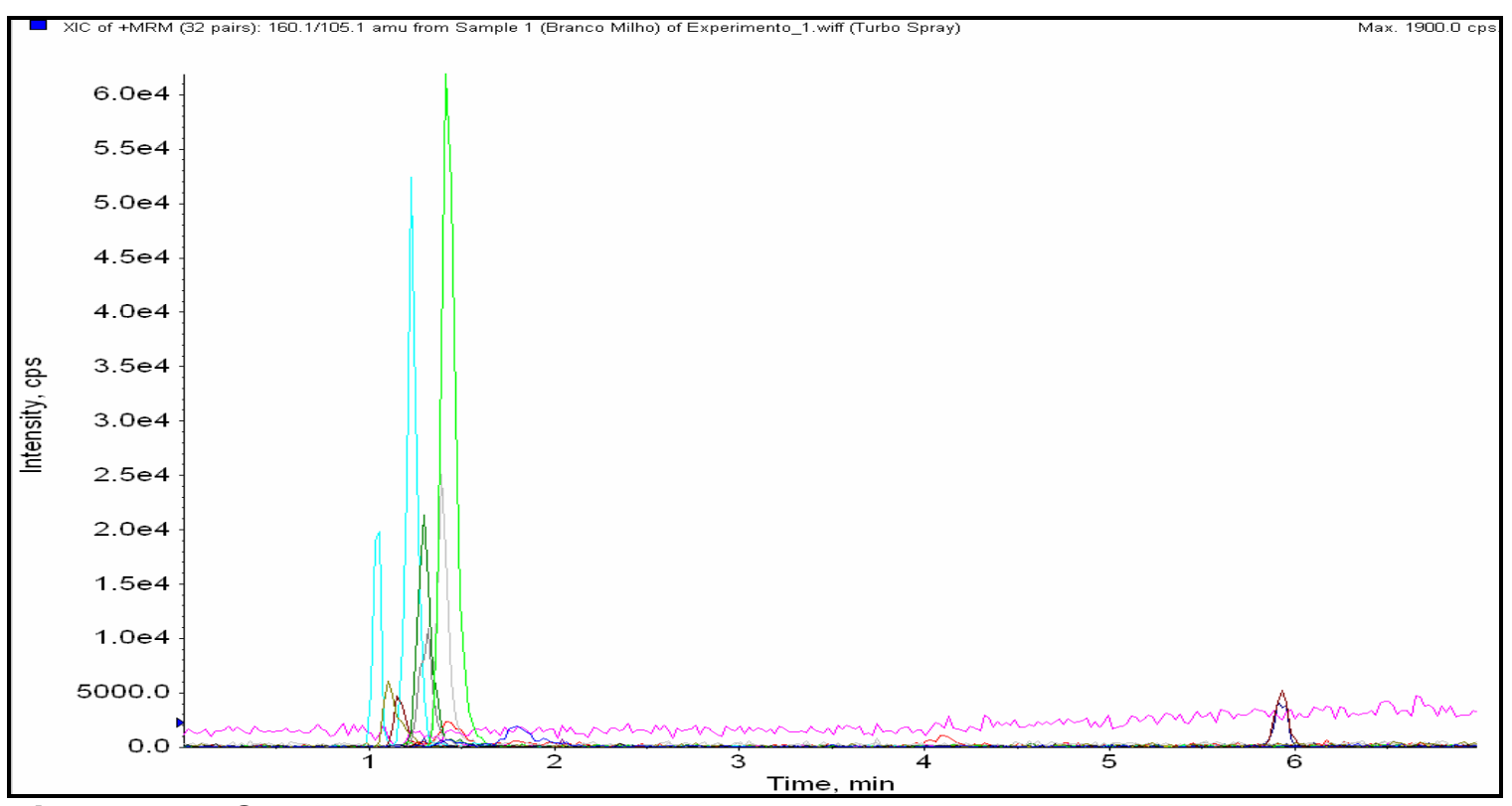

Figura 30 - Cromatograma da amostra testemunha 


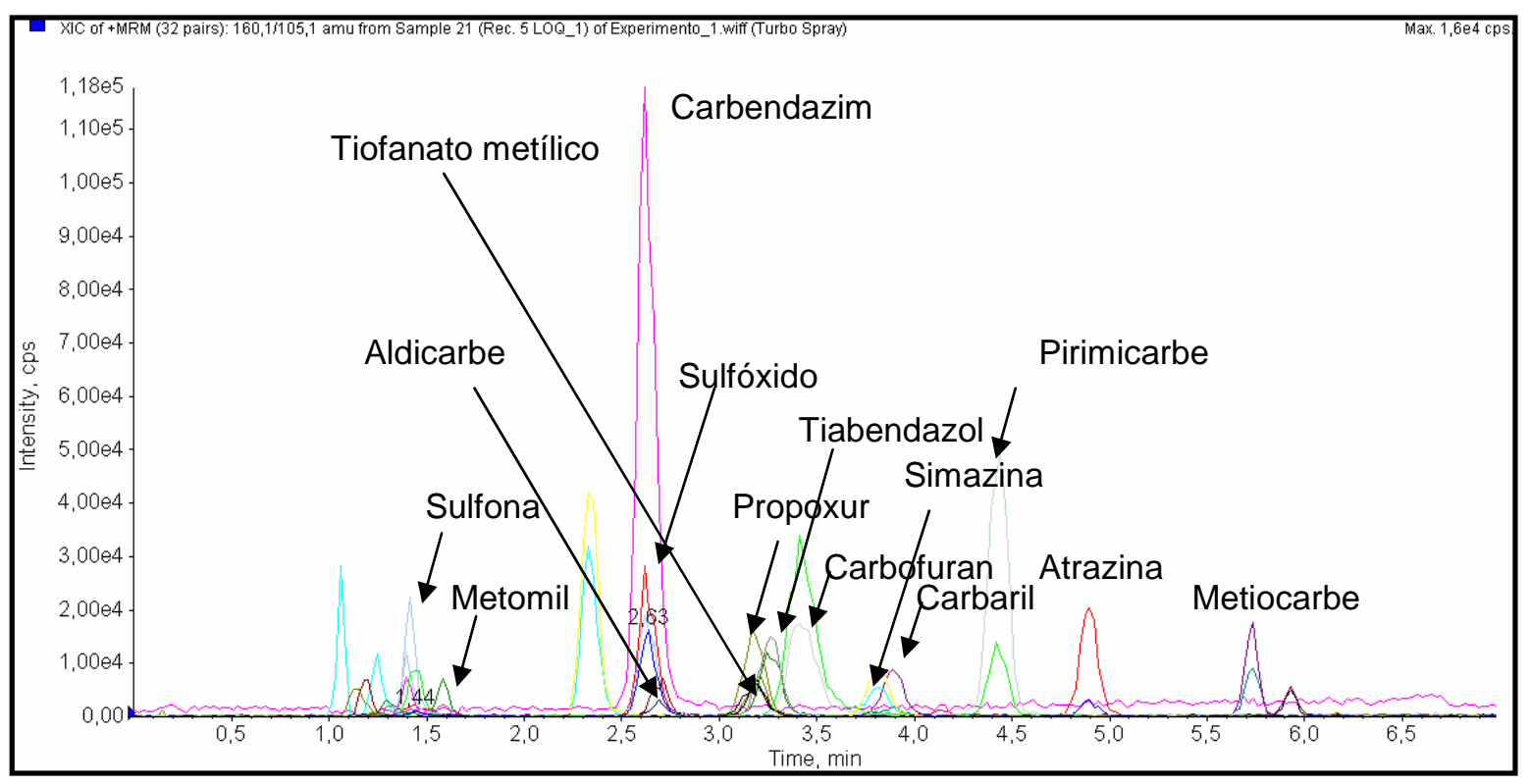

Figura 31 - Cromatograma da amostra fortificada

Por meio dos resultados como dos cromatogramas das Figuras 30 e 31 do experimento 4, não foi detectada a presença de possíveis interferentes, compostos de produtos da degradação (metabólitos ou decomposição) ou outras substâncias que possam estar presentes na matriz e que possam comprometer a quantificação dos analitos ou seja, não foram detectados interferentes (sinal, pico, traços de íons) que poderiam eluir na região de interesse.

O teste mostrou que a metodologia está isenta da falsa identificação e efeitos de supressão ou intensificação de sinais provenientes da matriz, para os analitos estudados.

A identificação e a quantificação do analito não são influenciadas pela presença de um ou mais interferentes provenientes da matriz em estudo.

As avaliações foram efetuadas pela técnida LC-ESI/MS/MS, com sistema de monitoramento de reações múltiplas (MRM) e analisadores de massa triploquadrupolo, técnica de alta sensibilidade de quantificação e especificidade no aspecto de confirmação e quantificação dos analitos e dos possíveis interferentes que possam influenciar ou comprometer na avaliação dos resultados do presente estudo.

A norma Council Directive (2002) denomina os testes acima relatados como um parâmetro de desempenho da especificidade do método. 


\subsection{Recuperação}

Os pesticidas foram fortificados nas amostras testemunhas em cinco diferentes níveis de validação, correspondentes a 1⁄2, 1, 11/2, 2 e $5 \mathrm{LOQ}$, descritos nos itens 4.7 e 4.7.1. O experimento foi realizado em 4 etapas, conforme 0 cronograma do experimento na Tabela 9, item 4.7.1.

\section{7. Linearidade das recuperações}

Os resultados de concentração das recuperações, obtidos nos experimentos 1, 2 e 3 executados conforme cronograma da Tabela 9, item 4.7.1 foi tratado na forma de equações de retas, por método de regressão linear. Para cada princípio ativo, foram avaliadas 3 equações de retas obtidas nos experimentos 1, 2 e 3, totalizando 42 equações de retas para todos os analitos estudados. As retas apresentaram, no eixo das abscissas, os resultados da concentração da recuperação em função da área do pico cromatográfico (coordenada). Os níveis de recuperação estudados para todos os analitos variaram na faixa de 4 a $200 \mu \mathrm{g} / \mathrm{kg}$. As avaliações da linearidade das curvas mostram o comportamento do método dentro de faixa de concentração estudada, quando os pesticidas são fortificados por várias determinações e em níveis crescentes de concentração. As avaliações foram efetuadas de várias formas: diariamente, a avaliação de repetivividade, e, durante três dias diferentes, a reprodutibilidade interna. Com os resultados das retas obtidas, através de tratamentos estatísticos, foram determinados os níveis críticos: limite de decisão $(\mathrm{CC} \alpha)$ e capacidade de detecção (CC $\beta)$.

As Figuras 32 a 73 representam os gráficos para cada analito, nos experimentos 1,2 e 3.

As Tabelas 32 a 45 apresentam os resultados na forma de equações de retas, sendo: $\mathbf{a}$, coeficiente angular, $\mathbf{b}$, intersecção, e $\mathbf{r}^{2}$, coeficiente de correlação e desvio padrão do erro relativo de y (StDev), nos experimentos 1, 2 e 3 , para todos os analitos. O erro relativo (StDev) é o erro relativo da regressão esperado para cada valor de y na regressão, calculado a partir da equação 4 , item 4.8.6.1. 


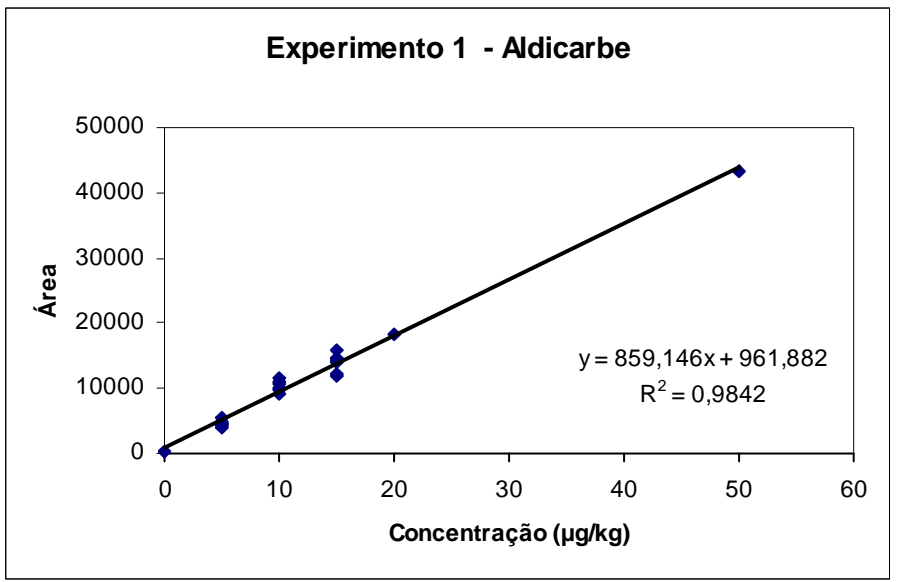

Figura 32 - Equação da reta do experimento 1 - Aldicarbe

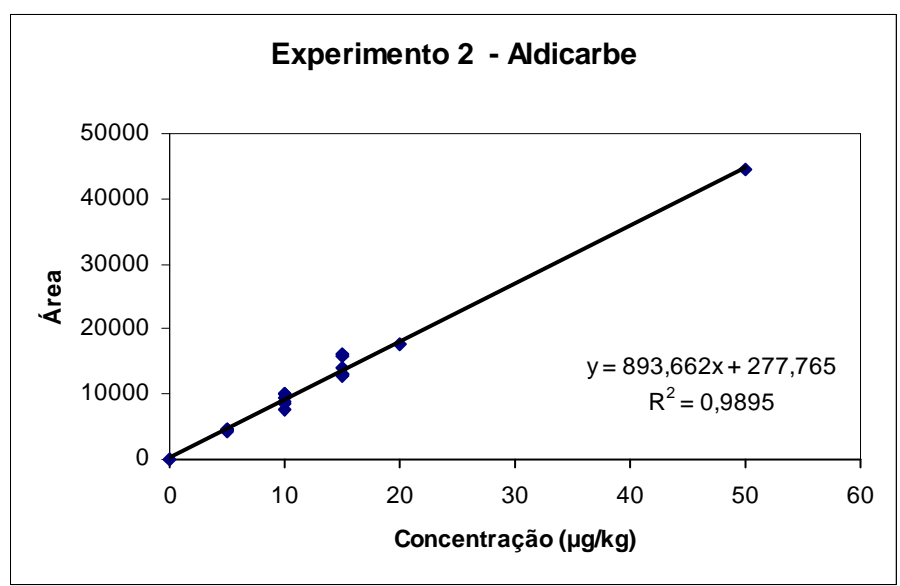

Figura 33 - Equação da reta do experimento 2 - Aldicarbe

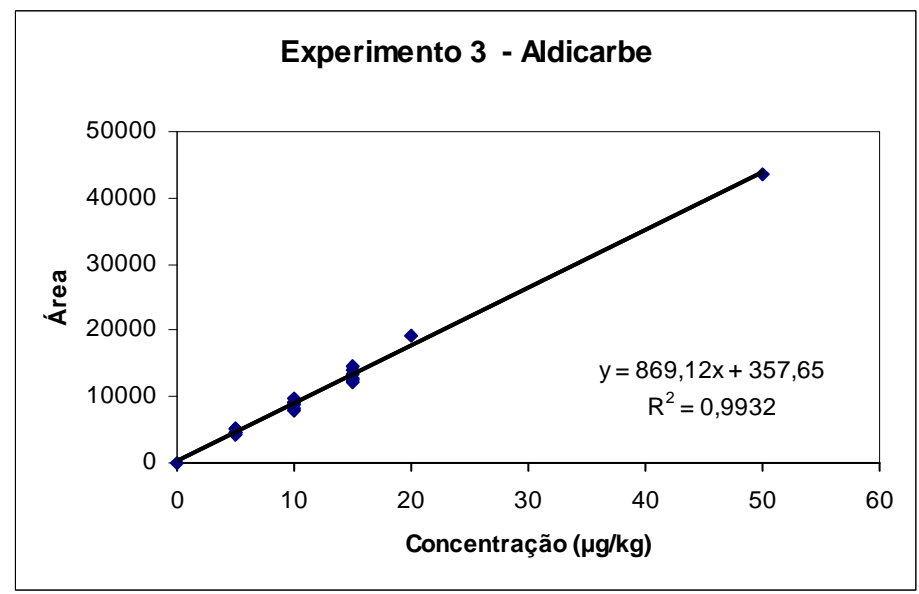

Figura 34 - Equação da reta do experimento 3 - Aldicarbe 
Tabela 32 - Equações das retas dos experimentos 1, 2 e 3 para aldicarbe

\begin{tabular}{cccccc}
\hline Experimento & $\mathbf{n}$ & $\mathbf{a}$ & $\mathbf{b}$ & $\mathbf{r}^{2}$ & StDeV-y \\
\hline 1 & 21 & 859,146 & 961,882 & 0,9842 & 385,5707 \\
2 & 21 & 893,622 & 277,765 & 0,9895 & 325,9994 \\
3 & 21 & 869,118 & 357,647 & 0,9932 & 254,2208 \\
\hline
\end{tabular}

n: número de amostra $\quad$ a: coeficiente angular $\quad$ b: coeficiente de intersecção

$r^{2}$ : coeficiente de correlação StDeV-y: erro relativo y

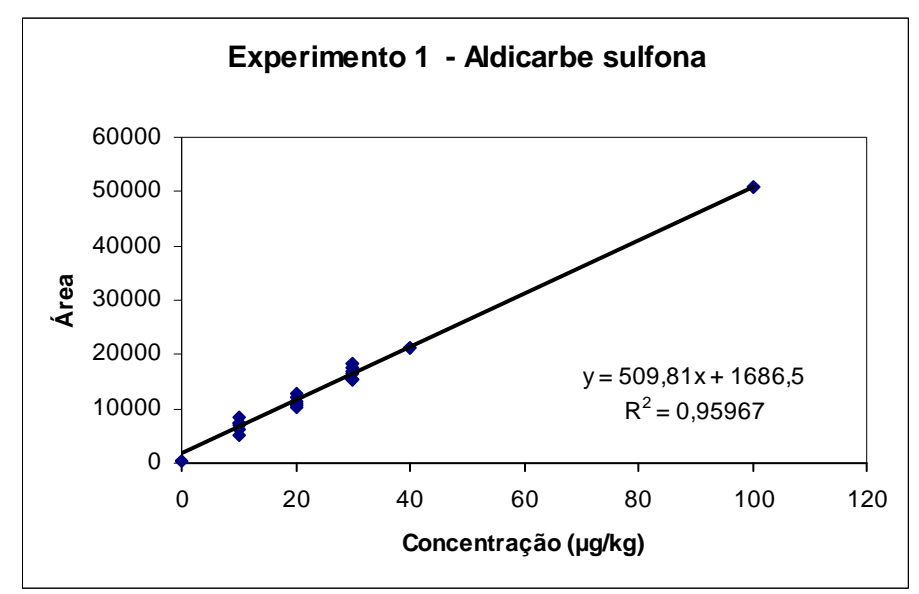

Figura 35 - Equação da reta do experimento 1 - Aldicarbe sulfona

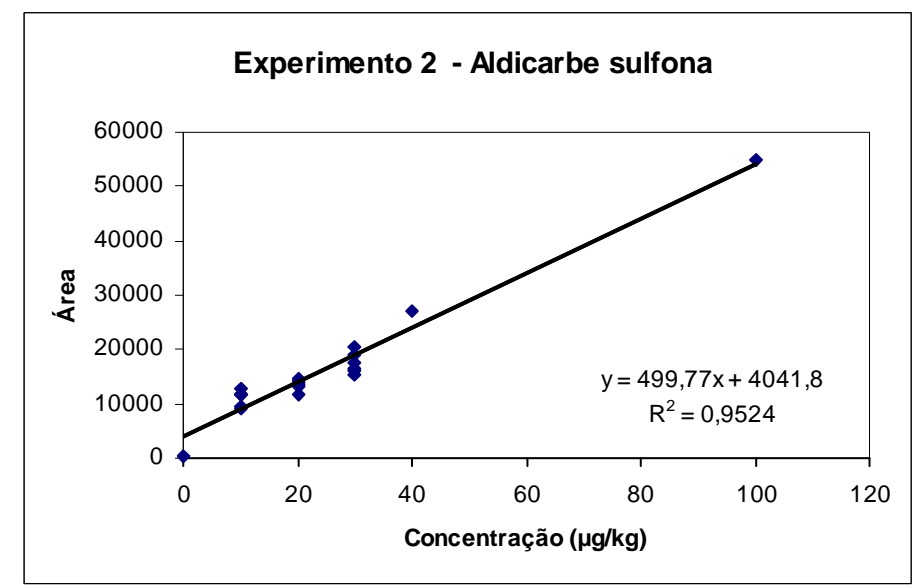

Figura 36 - Equação da reta do experimento 2 - Aldicarbe sulfona 


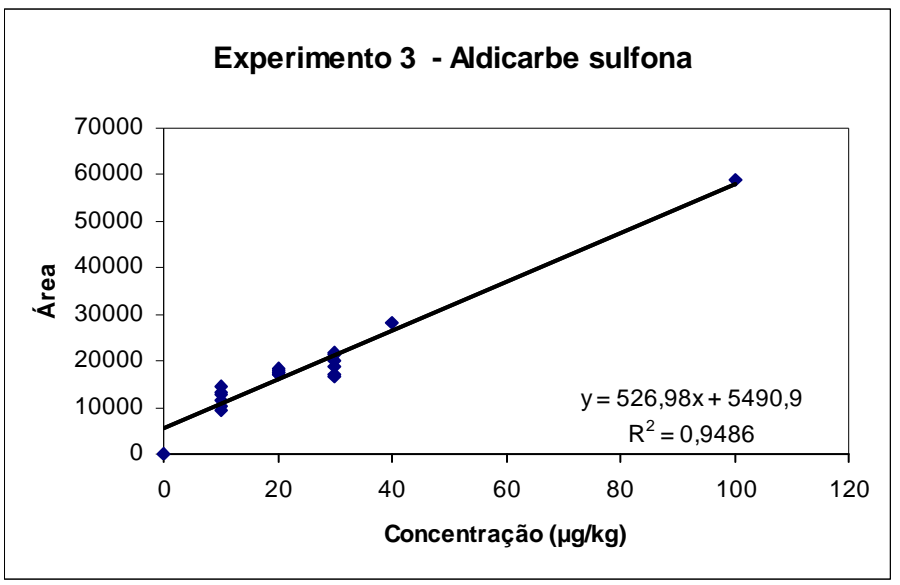

Figura 37 - Equação da reta do experimento 3 - Aldicarbe sulfona

Tabela 33 - Equações das retas dos experimentos 1, 2 e 3 para aldicarbe sulfona

\begin{tabular}{cccccc}
\hline Experimento & $\mathbf{n}$ & $\mathbf{a}$ & $\mathbf{b}$ & $\mathbf{r}^{2}$ & StDeV-y \\
\hline 1 & 21 & 509,808 & $1.686,471$ & 0,9596 & 740,122 \\
2 & 21 & 499,766 & $4.041,765$ & 0,9524 & 790,670 \\
3 & 21 & 526,983 & $5.490,882$ & 0,9486 & 868,454 \\
\hline $\mathbf{n}$ n: número de amostra & \multicolumn{2}{c}{ a: coeficiente angular } & b: coeficiente de intersecção \\
$\mathbf{r}^{2}$ : coeficiente de correlação & StDeV-y: erro relativo y &
\end{tabular}

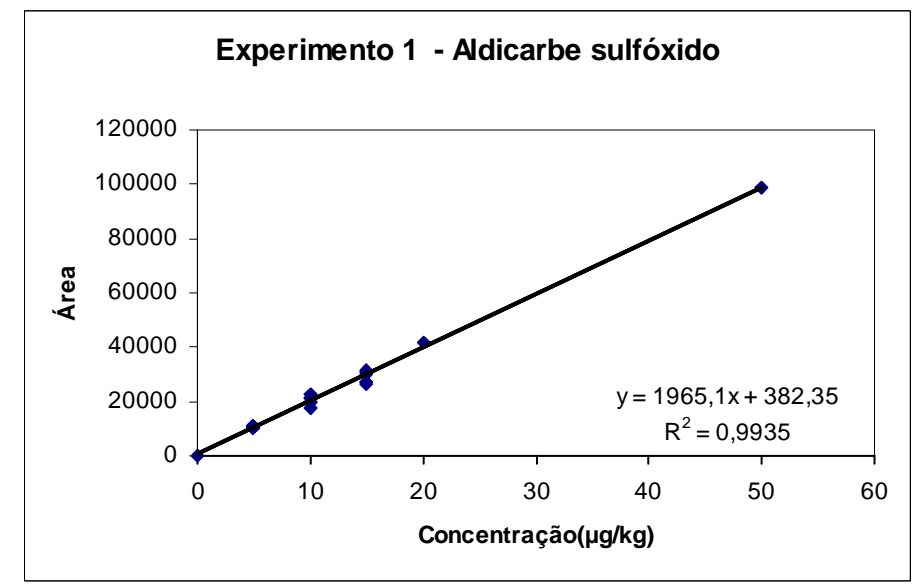

Figura 38 - Equação da reta do experimento 1 - Aldicarbe sulfóxido 


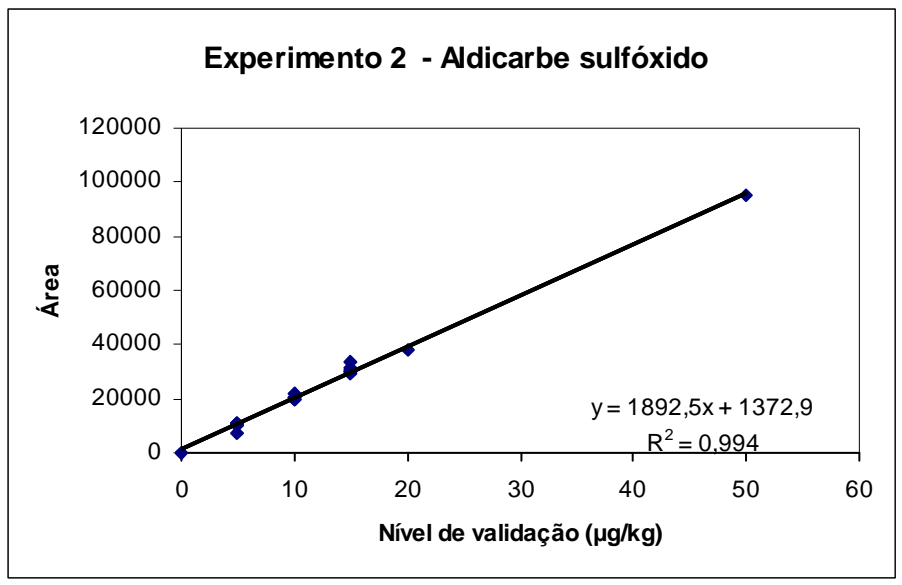

Figura 39 - Equação da reta do experimento 2 - Aldicarbe sulfóxido

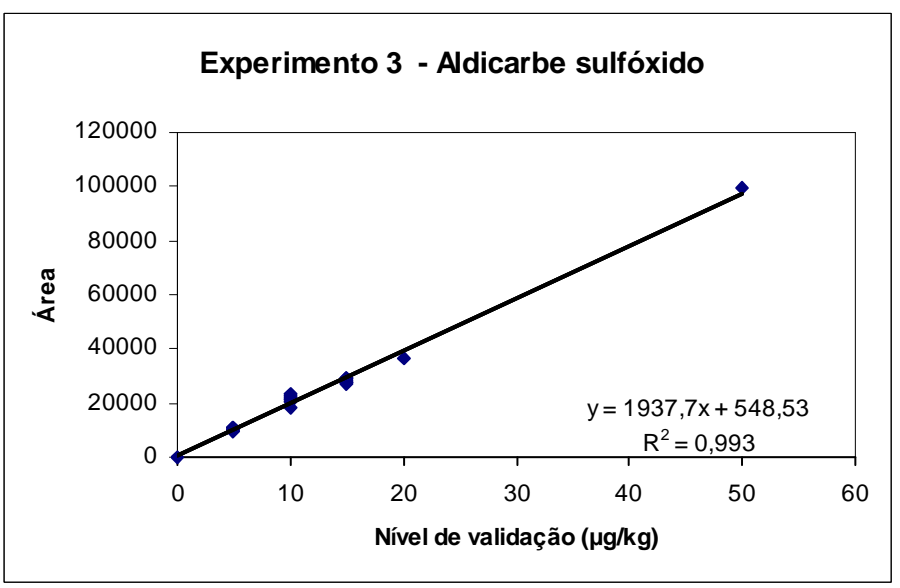

Figura 40 - Equação da reta do experimento 3 - Aldicarbe sulfóxido

Tabela 34 - Equações das retas dos experimentos 1, 2 e 3 para aldicarbe sulfóxido

\begin{tabular}{cccrcc}
\hline Experimento & $\mathbf{n}$ & $\mathbf{a}$ & \multicolumn{1}{c}{$\mathbf{b}$} & $\mathbf{r}^{2}$ & StDeV-y \\
\hline 1 & 21 & $1.965,082$ & 382,353 & 0,9935 & 563,926 \\
2 & 21 & $1.892,513$ & $1.372,941$ & 0,9940 & 522,085 \\
3 & 21 & $1.937,724$ & 548,529 & 0,9930 & 577,023
\end{tabular}

n: número de amostra

a: coeficiente angular

b: coeficiente de intersecção

$\mathbf{r}^{2}$ : coeficiente de correlação StDeV-y: erro relativo y 


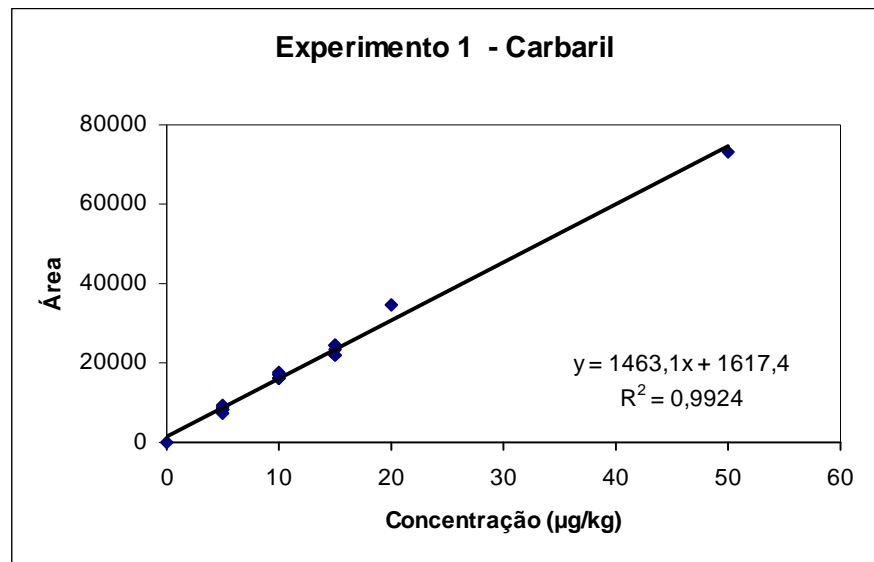

Figura 41 - Equação da reta do experimento 1 - Carbaril

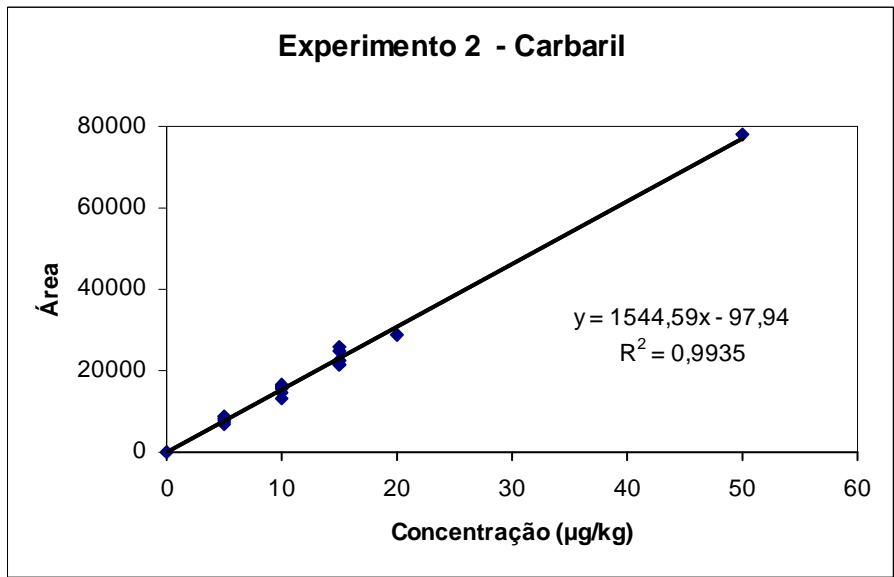

Figura 42 - Equação da reta do experimento 2 - Carbaril

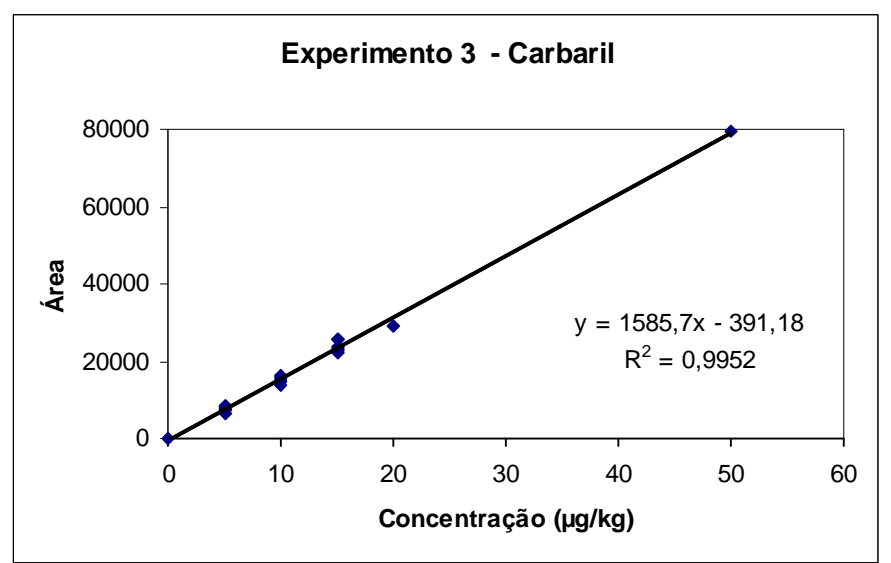

Figura 43 - Equação da reta do experimento 3 - Carbaril 
Tabela 35 - Equações das retas dos experimentos 1, 2 e 3 para carbaril

\begin{tabular}{cccccc}
\hline Experimento & $\mathbf{n}$ & $\mathbf{a}$ & $\mathbf{b}$ & $\mathbf{r}^{2}$ & StDeV-y \\
\hline 1 & 21 & $1.463,062$ & $1.617,353$ & 0,9924 & 454,479 \\
2 & 21 & $1.544,587$ & $-97,941$ & 0,9935 & 442,946 \\
3 & 21 & $1.585,659$ & $-391,176$ & 0,9952 & 389,166 \\
\hline
\end{tabular}

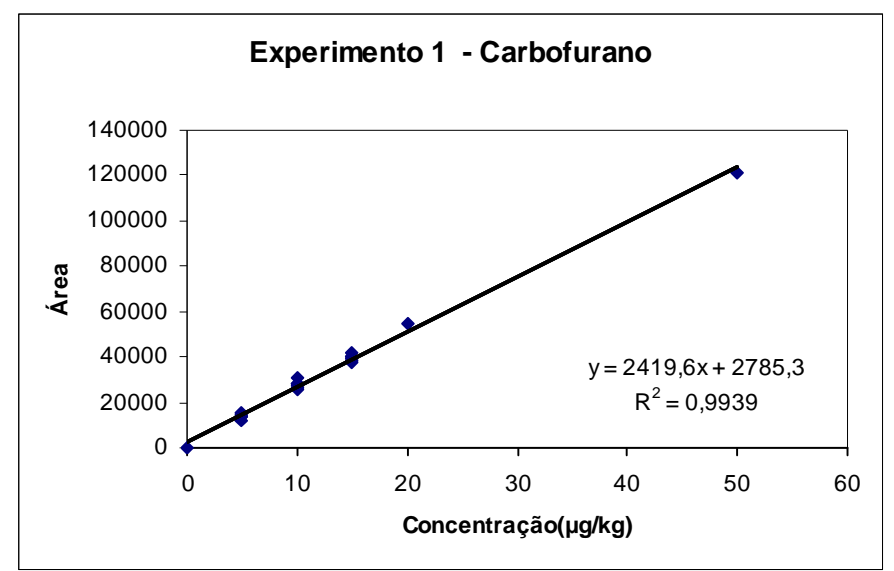

Figura 44 - Equação da reta do experimento 1 - Carbofurano

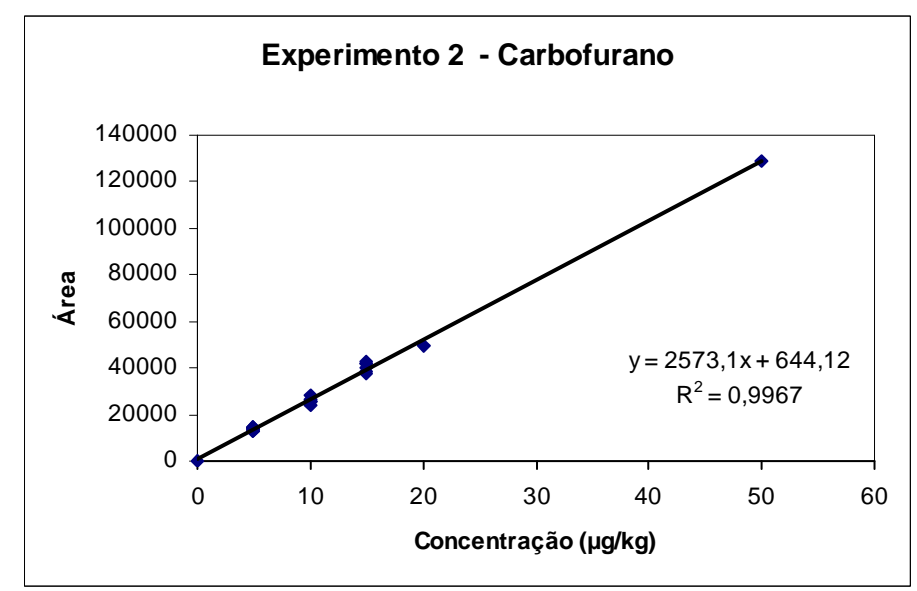

Figura 45 - Equação da reta do experimento 2 - Carbofurano 


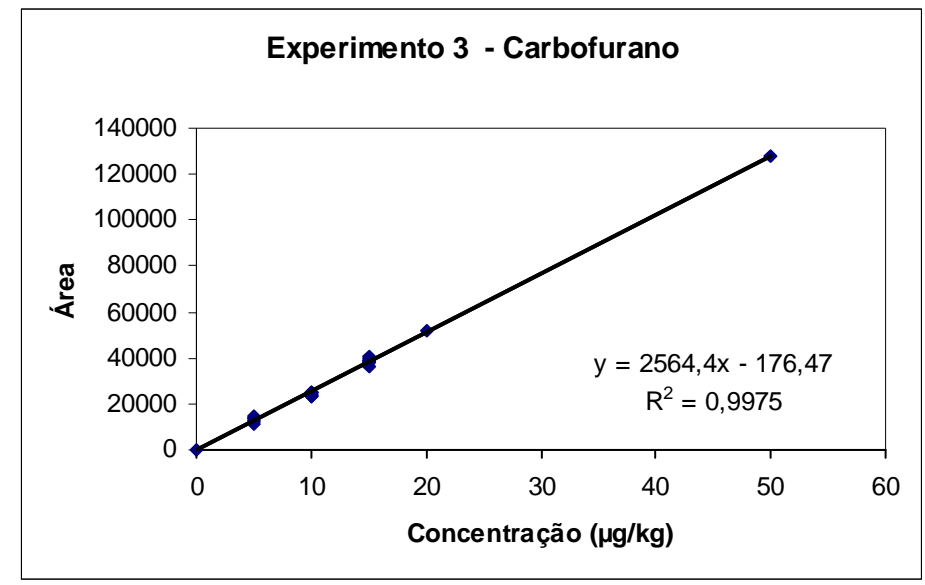

Figura 46 - Equação da reta do experimento 3 - Carbofurano

Tabela 36 - Equações das retas dos experimentos 1, 2 e 3 para carbofurano

\begin{tabular}{cccrcc}
\hline Experimento & $\mathbf{n}$ & $\mathbf{a}$ & $\mathbf{b}$ & $\mathbf{r}^{2}$ & StDeV-y \\
\hline 1 & 21 & $2.419,635$ & $2.785,294$ & 0,9939 & 670,6224 \\
2 & 21 & $2.573,094$ & 644,118 & 0,9967 & 523,2253 \\
3 & 21 & $2.564,424$ & $-176,471$ & 0,9975 & 457,3344
\end{tabular}

n: número de amostra $\quad \mathbf{a}$ : coeficiente angular $\quad \mathbf{b}$ : coeficiente de intersecção

$r^{2}$ : coeficiente de correlação StDeV-y: erro relativo y

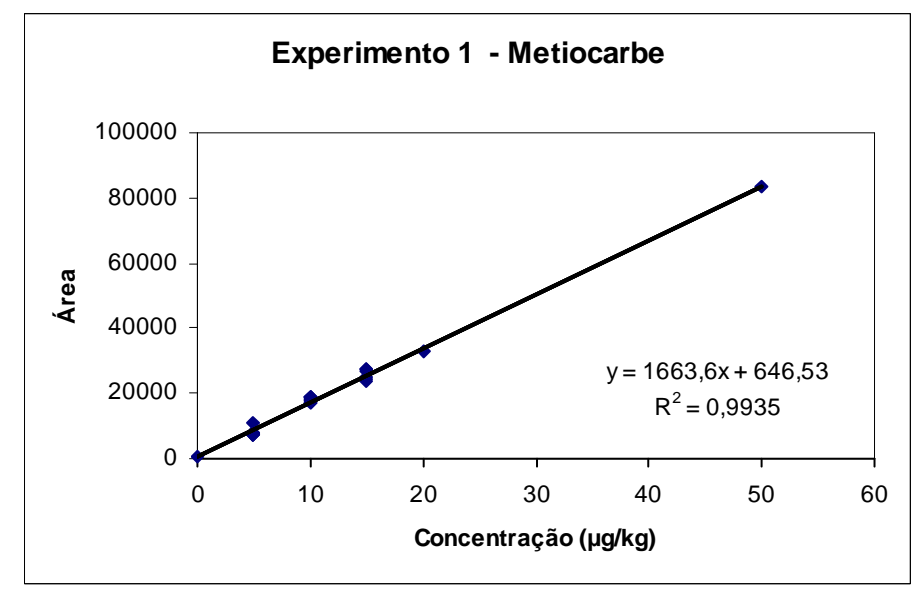

Figura 47 - Equação da reta do experimento 1 - Metiocarbe 


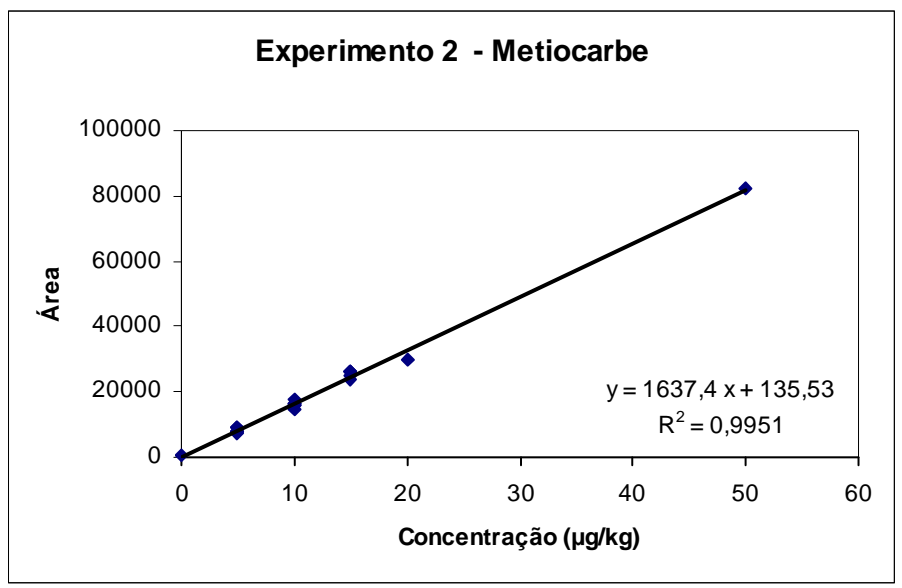

Figura 48 - Equação da reta do experimento 2 - Metiocarbe

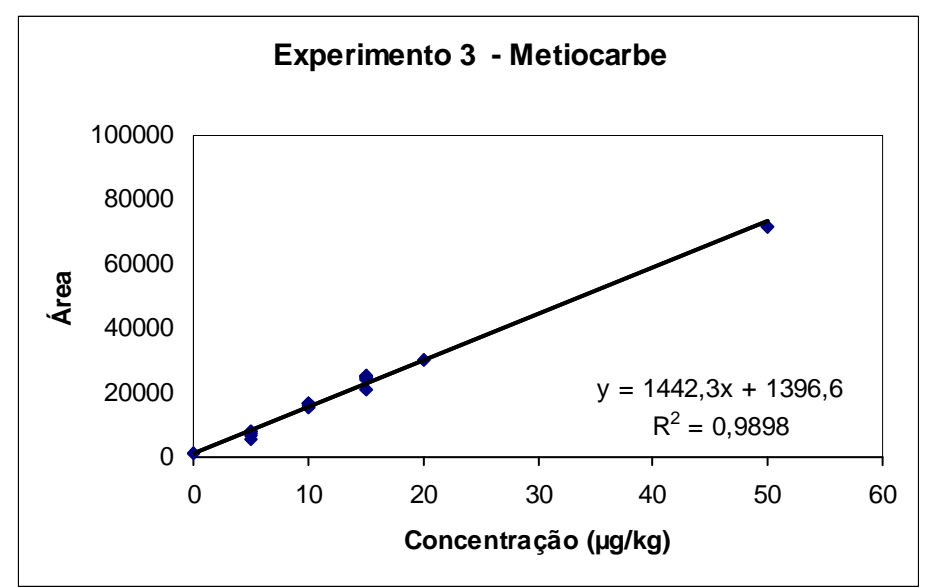

Figura 49 - Equação da reta do experimento 3 - Metiocarbe

Tabela 37 - Equações das retas dos experimentos 1, 2 e 3 para metiocarbe

\begin{tabular}{cccrcc}
\hline Experimento & $\mathbf{n}$ & $\mathbf{a}$ & $\mathbf{b}$ & $\mathbf{r}^{2}$ & StDeV-y \\
\hline 1 & 21 & $1.663,564$ & 646,529 & 0,9935 & 477,2569 \\
2 & 21 & $1.637,444$ & 135,529 & 0,9951 & 405,0430 \\
3 & 21 & $1.442,311$ & $1.396,588$ & 0,9898 & 517,5696
\end{tabular}

n: número de amostra $\quad$ a: coeficiente angular $\quad \mathbf{b}$ : coeficiente de intersecção

$r^{2}$ : coeficiente de correlação StDeV-y: erro relativo y 


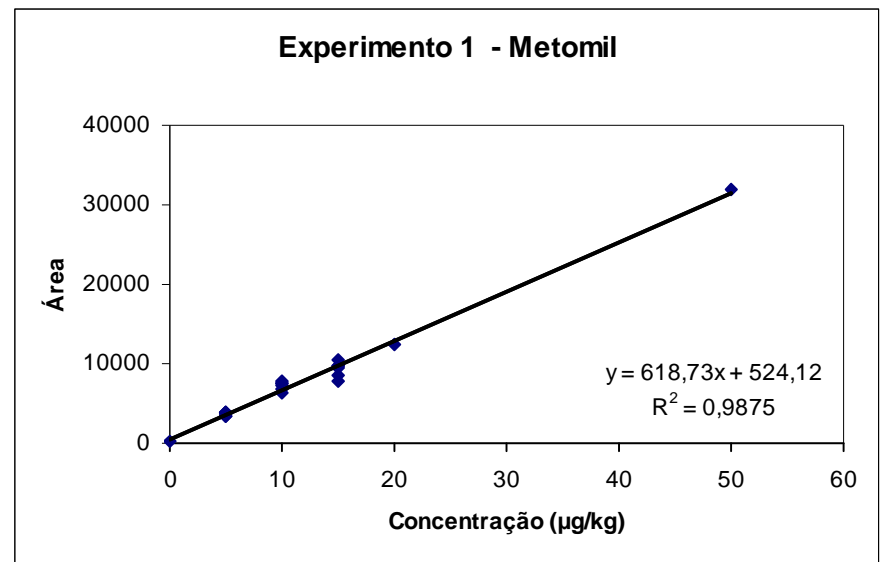

Figura 50 - Equação da reta do experimento 1 - Metomil

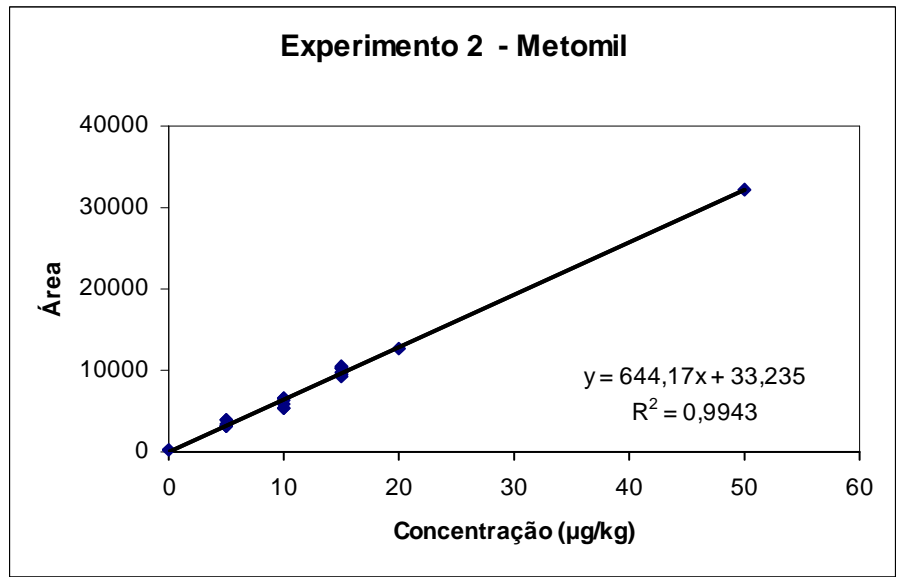

Figura 51 - Equação da reta do experimento 2 - Metomil

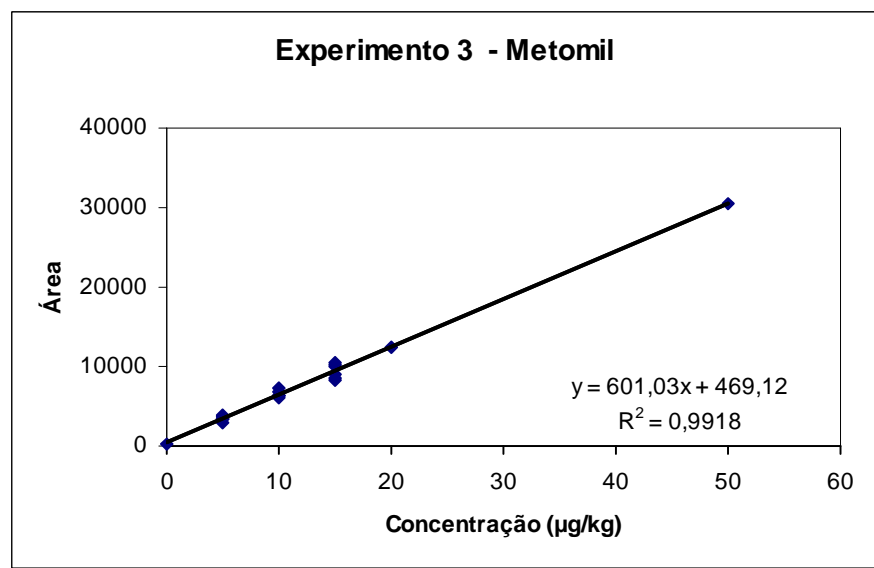

Figura 52 - Equação da reta do experimento 3 - Metomil 
Tabela 38 - Equações das retas dos experimentos 1, 2 e 3 para metomil

\begin{tabular}{cccrcc}
\hline Experimento & $\mathbf{n}$ & $\mathbf{a}$ & \multicolumn{1}{c}{$\mathbf{b}$} & $\mathbf{r}^{2}$ & StDeV-y \\
\hline 1 & 21 & 618,734 & 524,118 & 0,9875 & 246,2038 \\
2 & 21 & 644,168 & 33,235 & 0,9943 & 172,1484 \\
3 & 21 & 601,034 & 469,118 & 0,9918 & 193,6115 \\
\hline
\end{tabular}

n: número de amostra a: coeficiente angular $\quad$ b: coeficiente de intersecção

$r^{2}$ : coeficiente de correlação StDeV-y: erro relativo y

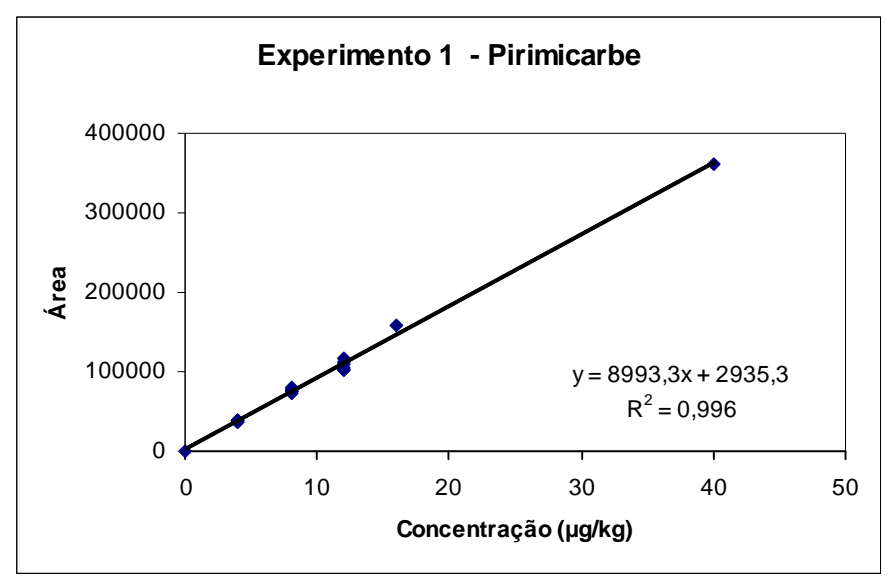

Figura 53 - Equação da reta do experimento 1 - Pirimicarbe

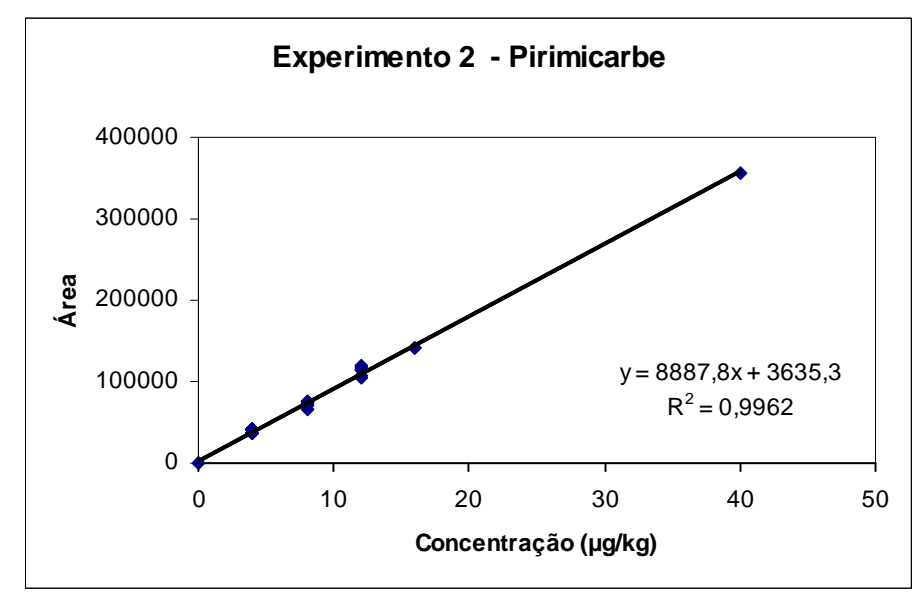

Figura 54 - Equação da reta do experimento 2 - Pirimicarbe 


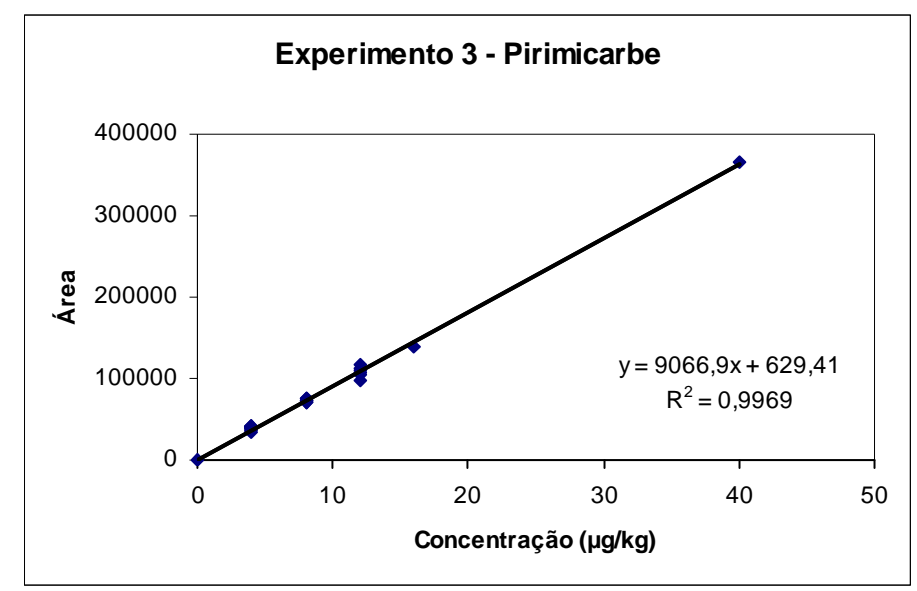

Figura 55 - Equação da reta do experimento 3 - Pirimicarbe

Tabela 39 - Equações das retas dos experimentos 1, 2 e 3 para pirimicarbe

\begin{tabular}{cccccc}
\hline Experimento & $\mathbf{n}$ & $\mathbf{a}$ & $\mathbf{b}$ & $\mathbf{r}^{2}$ & StDeV-y \\
\hline 1 & 21 & $8.993,294$ & $2.935,294$ & 0,9960 & $1.617,5213$ \\
2 & 21 & $8.887,794$ & $3.635,294$ & 0,9962 & $1.557,7618$ \\
3 & 21 & $9.066,912$ & 629,412 & 0,9969 & $1.423,6996$ \\
\hline $\mathbf{n}$ : número de amostra & \multicolumn{2}{c}{$\mathbf{a}$ : coeficiente angular } & $\mathbf{b}$ : coeficiente de intersecção \\
$\mathbf{r}^{2}$ : coeficiente de correlação & StDeV-y: erro relativo y &
\end{tabular}

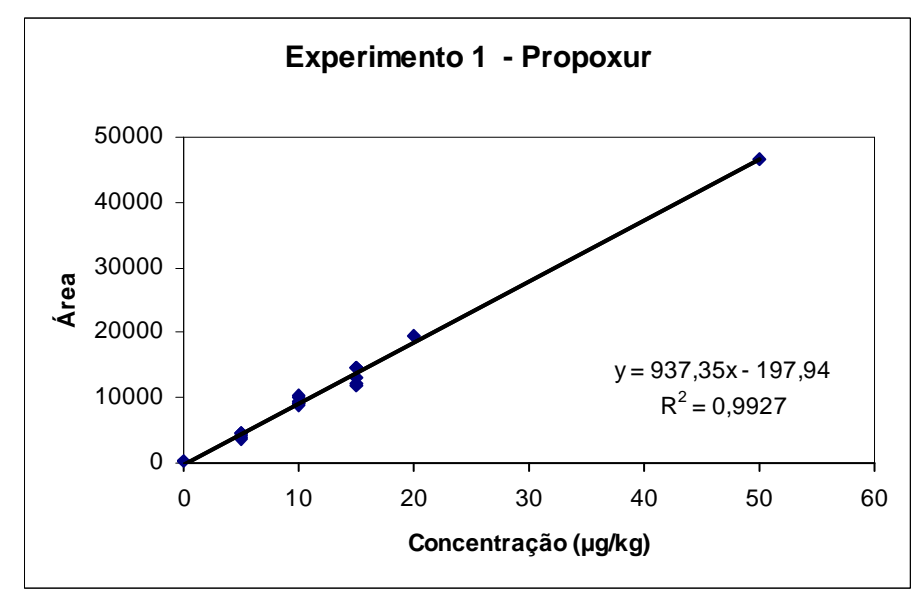

Figura 56 - Equação da reta do experimento 1 - Propoxur 


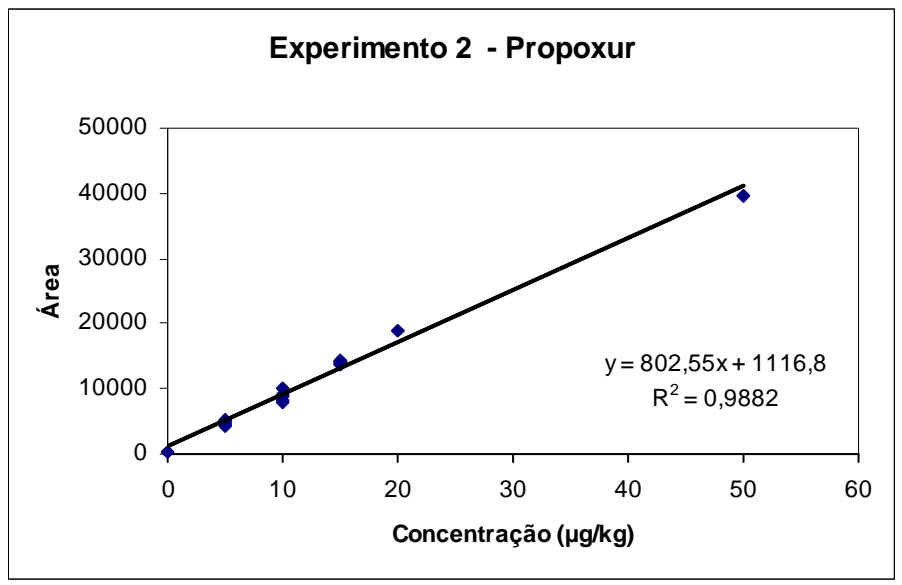

Figura 57 - Equação da reta do experimento 2 - Propoxur

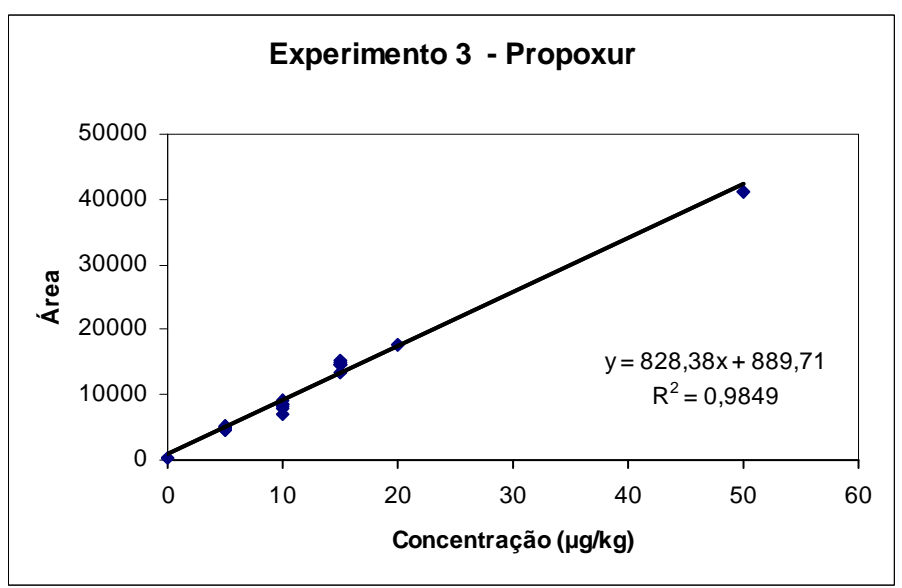

Figura 58 - Equação da reta do experimento 3 - Propoxur

Tabela 40 - Equações das retas dos experimentos 1, 2 e 3 para propoxur

\begin{tabular}{cccrcc}
\hline Experimento & $\mathbf{n}$ & $\mathbf{a}$ & $\mathbf{b}$ & $\mathbf{r}^{2}$ & StDeV-y \\
\hline 1 & 21 & 937,347 & $-197,941$ & 0,9927 & 283,8856 \\
2 & 21 & 802,552 & $1.116,765$ & 0,9882 & 310,6555 \\
3 & 21 & 828,385 & 889,706 & 0,9849 & 363,1954 \\
\hline
\end{tabular}

n: número de amostra a: coeficiente angular b: coeficiente de intersecção

$r^{2}$ : coeficiente de correlação StDeV-y: erro relativo y 


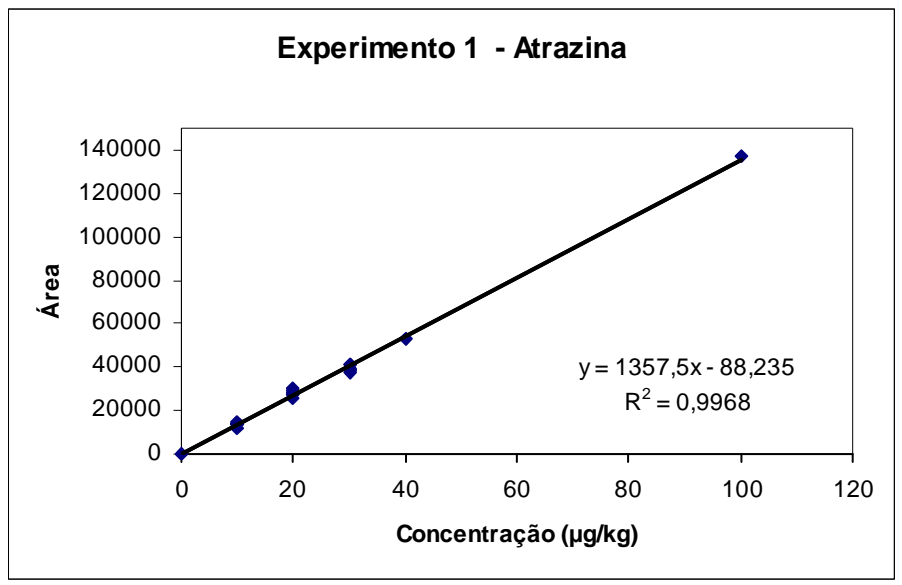

Figura 59 - Equação da reta do experimento 1 - Atrazina

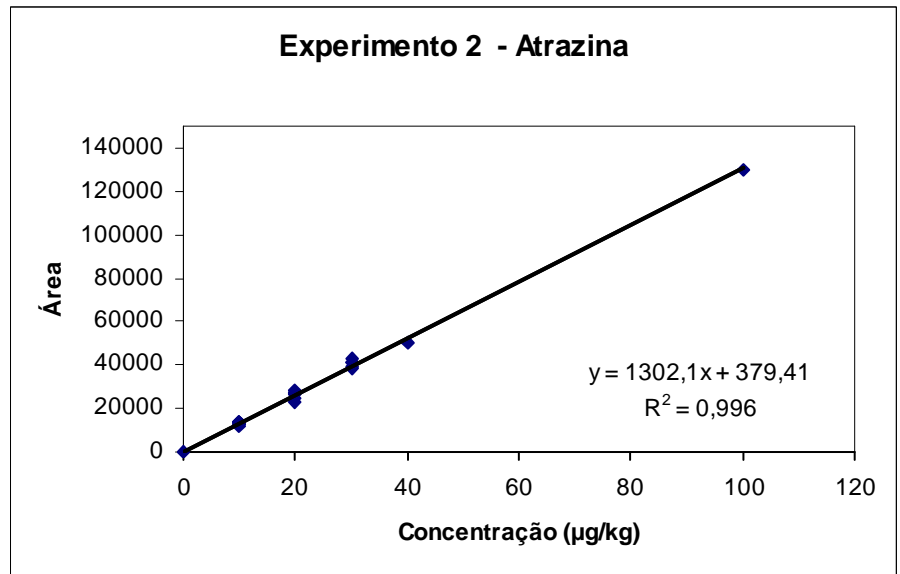

Figura 60 - Equação da reta do experimento 2 - Atrazina

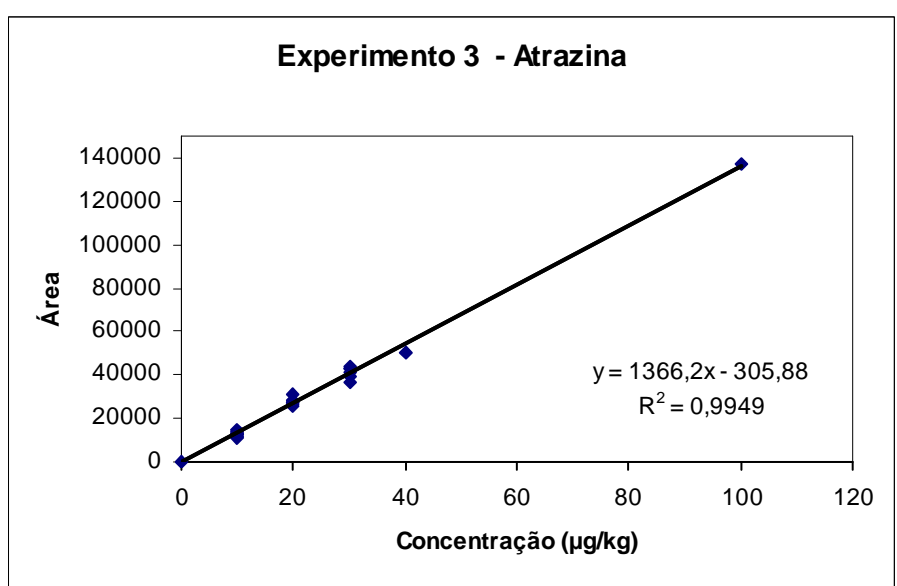

Figura 61 - Equação da reta do experimento 3 - Atrazina 
Tabela 41 - Equações das retas dos experimentos 1, 2 e 3 para atrazina

\begin{tabular}{cccccc}
\hline Experimento & $\mathbf{n}$ & $\mathbf{a}$ & $\mathbf{b}$ & $\mathbf{r}^{\mathbf{2}}$ & StDeV-y \\
\hline 1 & 21 & $1.357,506$ & $-88,235$ & 0,9968 & 542,6801 \\
2 & 21 & $1.302,065$ & 379,412 & 0,9960 & 582,8740 \\
3 & 21 & $1.366,247$ & $-305,882$ & 0,9949 & 690,0240 \\
\hline $\mathbf{n}$ : número de amostra & \multicolumn{2}{c}{$\mathbf{a}:$ coeficiente angular } & $\mathbf{b}$ : coeficiente de intersecção \\
$\mathbf{r}^{2}$ : coeficiente de correlação & StDeV-y: erro relativo y & &
\end{tabular}

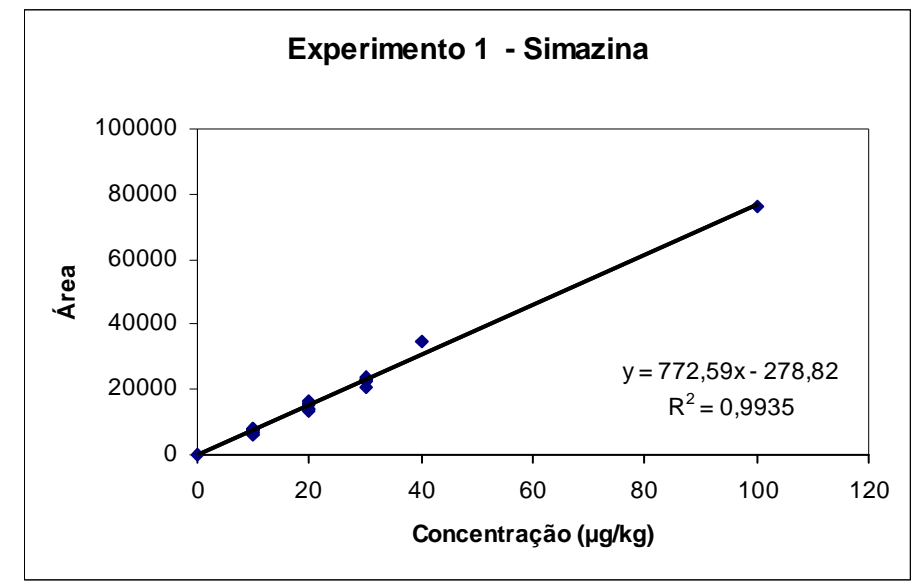

Figura 62 - Equação da reta do experimento 1 - Simazina

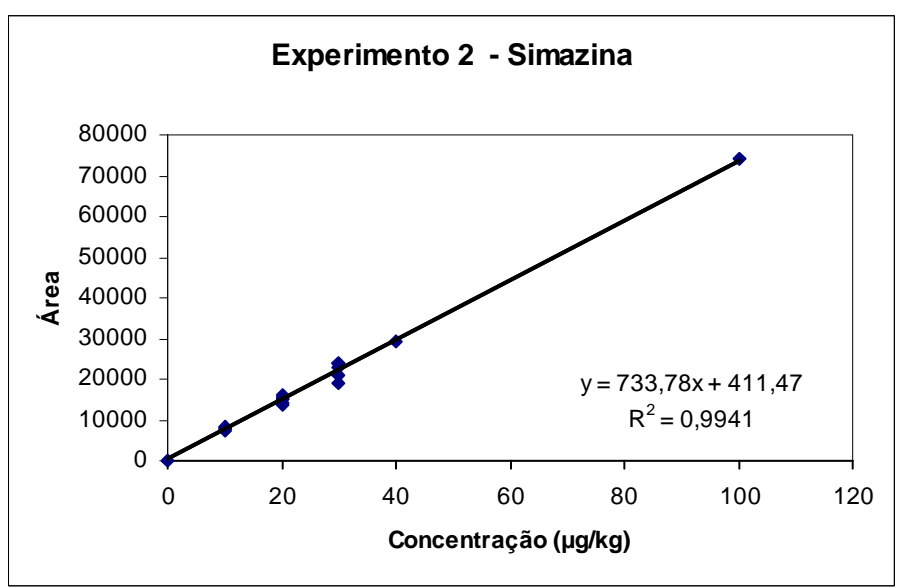

Figura 63 - Equação da reta do experimento 2 - Simazina 


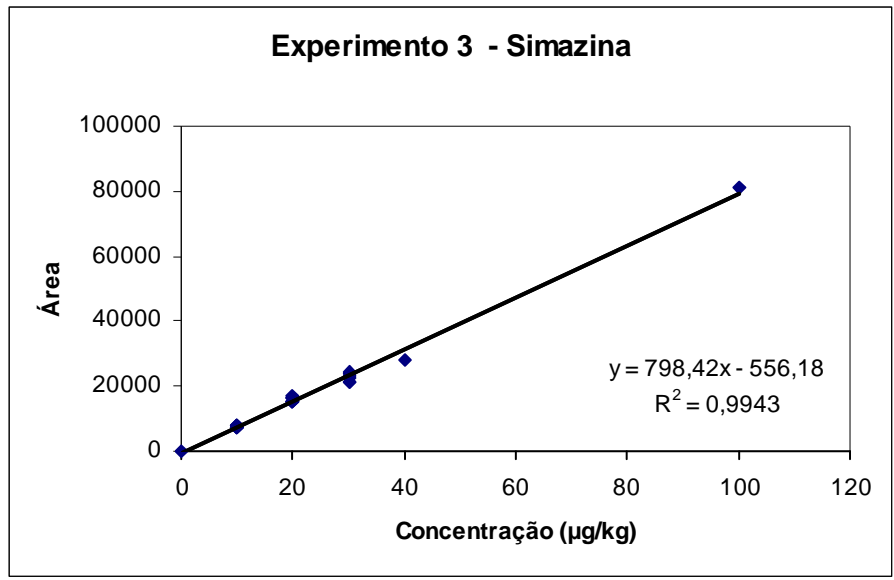

Figura 64 - Equação da reta do experimento 3 - Simazina

Tabela 42 - Equações das retas dos experimentos 1, 2 e 3 para simazina

\begin{tabular}{cccccc}
\hline Experimento & $\mathbf{n}$ & $\mathbf{a}$ & $\mathbf{b}$ & $\mathbf{r}^{2}$ & StDeV-y \\
\hline 1 & 21 & 772,591 & 278,824 & 0,9935 & 441,6764 \\
2 & 21 & 733,778 & 411,471 & 0,9941 & 399,7964 \\
3 & 21 & 798,419 & 556,176 & 0,9943 & 426,3233
\end{tabular}

n: número de amostra $\quad$ a: coeficiente angular $\quad \mathbf{b}$ : coeficiente de intersecção

$r^{2}$ : coeficiente de correlação StDeV-y: erro relativo y

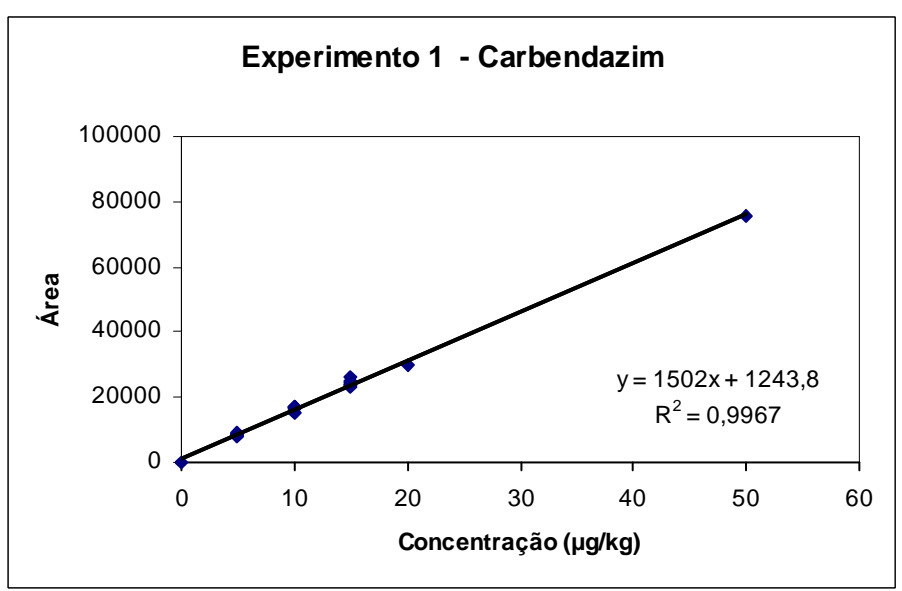

Figura 65 - Equação da reta do experimento 1 - Carbendazim 


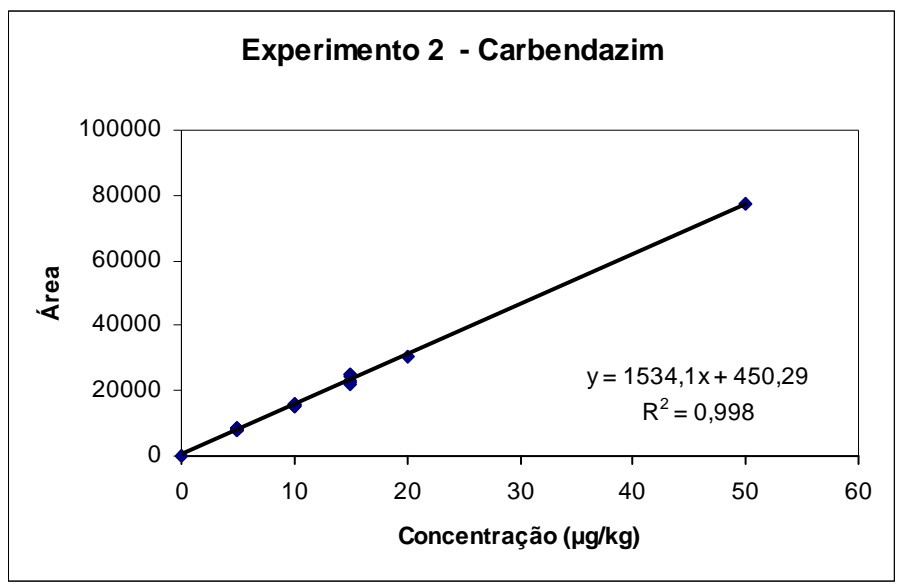

Figura 66 - Equação da reta do experimento 2 - Carbendazim

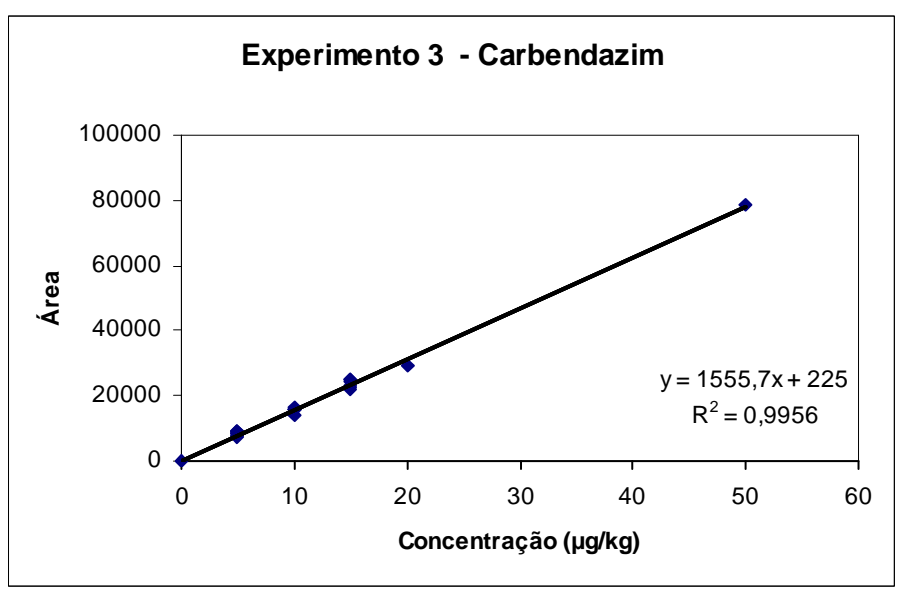

Figura 67 - Equação da reta do experimento 3 - Carbendazim

Tabela 43 - Equações das retas dos experimentos 1, 2 e 3 para carbendazim

\begin{tabular}{|c|c|c|c|c|c|}
\hline Experimento & $\mathrm{n}$ & $\mathbf{a}$ & b & $r^{2}$ & StDeV-y \\
\hline 1 & 21 & $1.502,039$ & $1.243,824$ & 0,9967 & 305,1641 \\
\hline 2 & 21 & $1.534,055$ & 450,294 & 0,9980 & 244,8855 \\
\hline 3 & 21 & $1.555,700$ & 225,000 & 0,9956 & 364,8459 \\
\hline
\end{tabular}




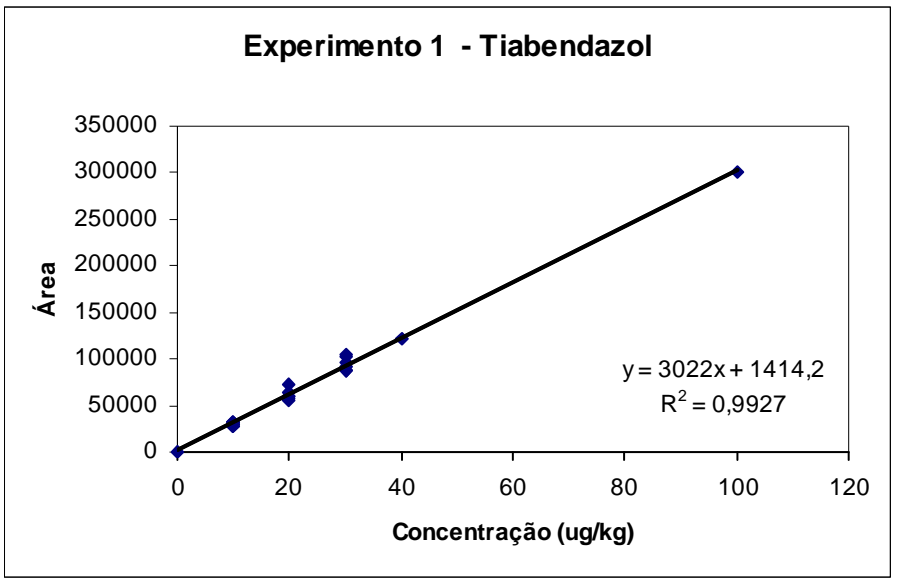

Figura 68 - Equação da reta do experimento 1 - Tiabendazol

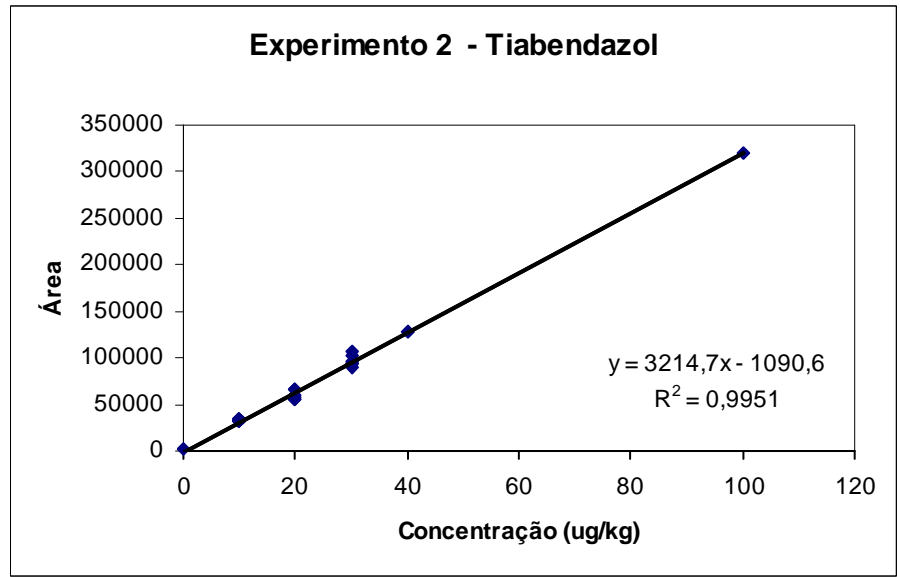

Figura 69 - Equação da reta do experimento 2 - Tiabendazol

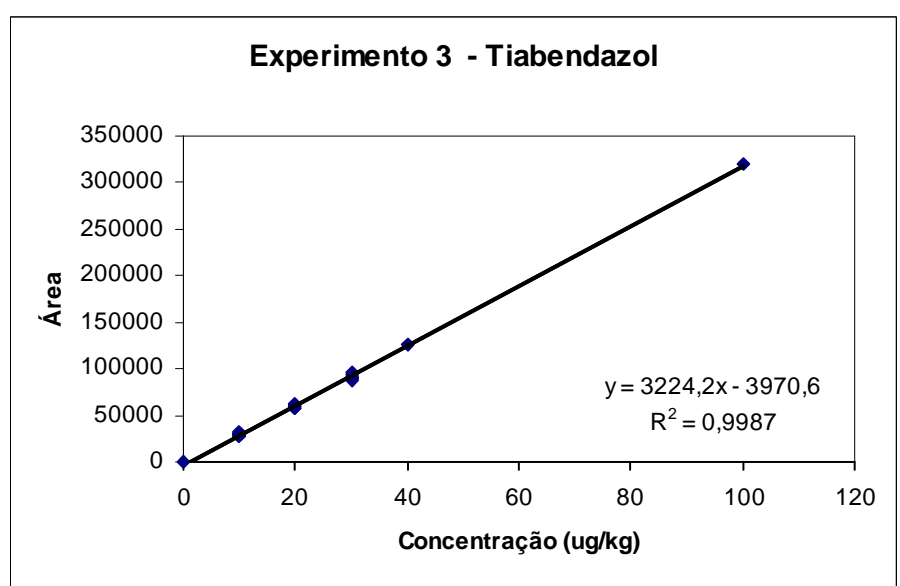

Figura 70 - Equação da reta do experimento 3 - Tiabendazol 
Tabela 44 - Equações das retas dos experimentos 1, 2 e 3 para tiabendazol

\begin{tabular}{cccccr}
\hline Experimento & $\mathbf{n}$ & $\mathbf{a}$ & $\mathbf{b}$ & $\mathbf{r}^{2}$ & StDeV-y \\
\hline 1 & 21 & $3.022,025$ & $1.414,176$ & 0,9927 & $1.828,4837$ \\
2 & 21 & $3.214,665$ & $1.090,588$ & 0,9951 & 1603,2203 \\
3 & 21 & $3.224,165$ & $3.970,588$ & 0,9987 & 810,0546 \\
\hline $\mathbf{n}$ : número de amostra & \multicolumn{2}{c}{ a: coeficiente angular } & $\mathbf{b}$ : coeficiente de intersecção \\
$\mathbf{r}^{2}$ : coeficiente de correlação & StDeV-y: erro relativo y & &
\end{tabular}

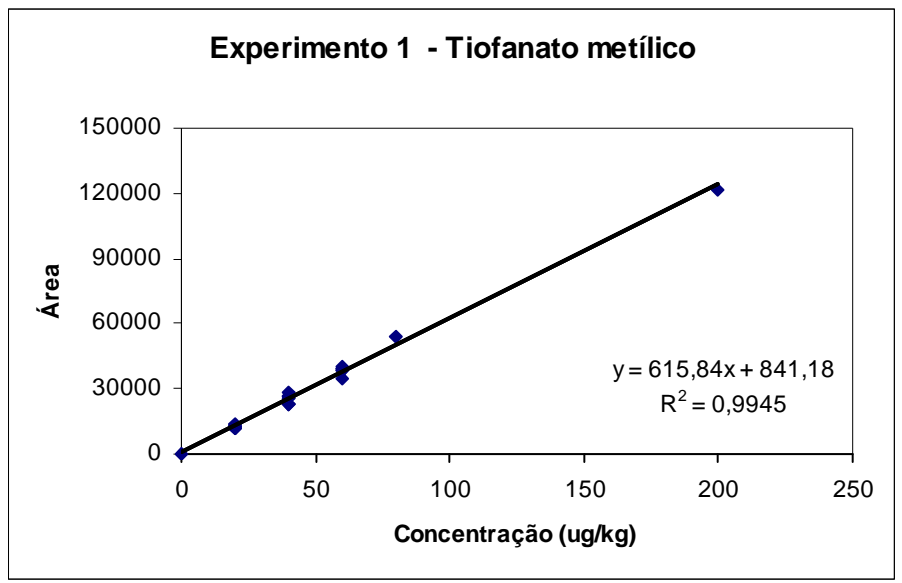

Figura 71 - Equação da reta do experimento 1 - Tiofanato metílico

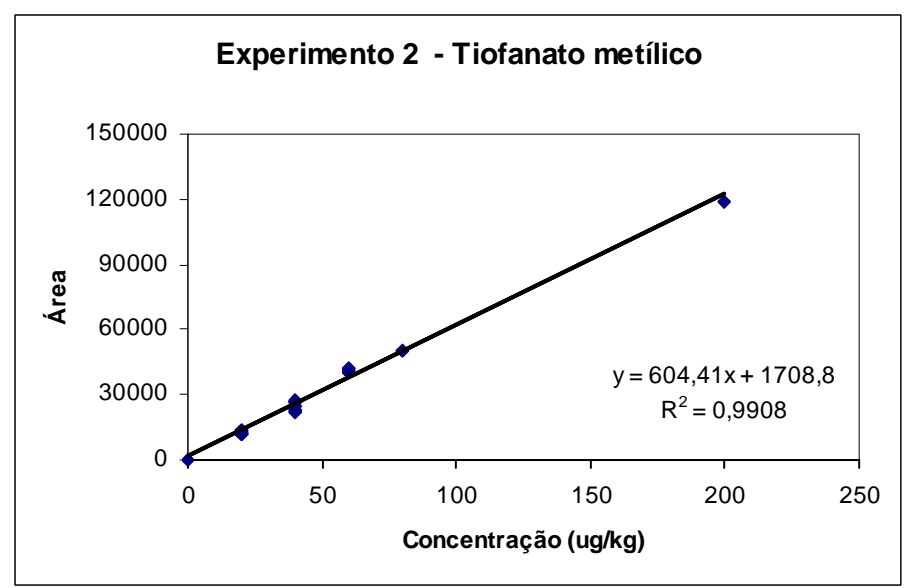

Figura 72 - Equação da reta do experimento 2 - Tiofanato metílico 


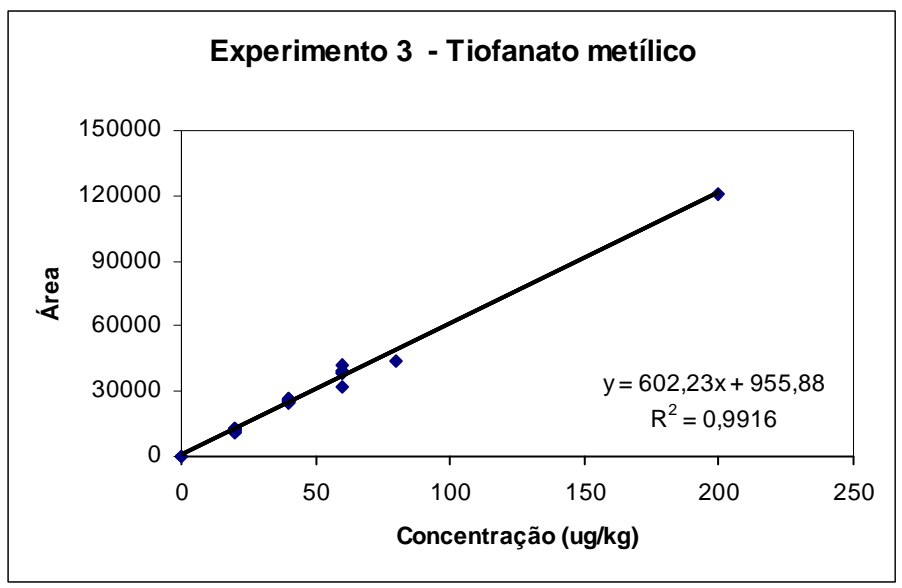

Figura 73 - Equação da reta do experimento 3 - Tiofanato metílico

Tabela 45 - Equações das retas dos experimentos 1, 2 e 3 para tiofanato metílico

\begin{tabular}{cccccc}
\hline Experimento & $\mathbf{n}$ & $\mathbf{a}$ & $\mathbf{b}$ & $\mathbf{r}^{2}$ & StDeV-y \\
\hline 1 & 21 & 615,835 & 841,176 & 0,9945 & 650,9331 \\
2 & 21 & 604,415 & $1.708,824$ & 0,9908 & 823,2733 \\
3 & 21 & 602,226 & 955,882 & 0,9916 & 784,5608 \\
\hline \\
\multicolumn{7}{l}{$\mathbf{n}:$ número de amostra } & a: coeficiente angular & $\mathbf{b}:$ coeficiente de interseç̧ão \\
$\mathbf{r}^{2}$ : coeficiente de correlação & StDeV-y: erro relativo y & &
\end{tabular}

Com relação aos resultados das equações de retas, o coeficiente de correlação $\left(\mathbf{r}^{2}\right)$ foi de valores iguais a ou maiores que 0,99 em todos os analitos e experimentos, com exceção a aldicarbe, que apresentou valor de 0,98 no experimento 1 e aldicarbe sulfona, na faixa de 0,95 a 0,96 , em todos os experimentos. Os resultados permitem concluir que não houve a dispersão do conjunto de concentrações de recuperações na faixa estudada em todos os analitos e experimentos. Os resultados das concentrações das recuperações demonstraram uma linearidade em níveis fortificados e uma correlação recomendada até para curva analítica, de valores acima de 0,90 (INMETRO, 2003).

No estudo seguinte, estão os resultados do cálculo da exatidão, desvio padrão, coeficiente de variação da variação dos níveis de validação de: $1 / 2 \mathrm{LOQ}, 1$ LOQ e 1 1 $1 / 2 \mathrm{LOQ}$, nos experimentos 1,2 e 3; para cada pesticida. Nas Tabelas 46 
a 59, encontram-se os dados de resultados de média de exatidão, desvio padrão, coeficiente de variação dos experimentos 1, 2, 3, para todos os analitos estudados.

Tabela 46 - Resultados da média de exatidão, desvio padrão, coeficiente de variação dos experimentos 1, 2 e 3 para aldicarbe

\begin{tabular}{cccccccccc}
\hline $\begin{array}{c}\text { Nível de } \\
\text { validação } \\
(\mu \mathrm{g} / \mathrm{kg})\end{array}$ & \multicolumn{3}{c}{ Experimento 1 } & \multicolumn{3}{c}{ Experimento 2 } & \multicolumn{3}{c}{ Experimento 3 } \\
\cline { 2 - 9 } & $\begin{array}{c}\text { E } \\
(\%)\end{array}$ & DP & $\begin{array}{c}\text { CV } \\
(\%)\end{array}$ & $\begin{array}{c}\text { E } \\
(\%)\end{array}$ & DP & $\begin{array}{c}\text { CV } \\
(\%)\end{array}$ & $\begin{array}{c}\text { E } \\
(\%)\end{array}$ & DP & $\begin{array}{c}\text { CV } \\
(\%)\end{array}$ \\
\hline 5 & 85,4 & 8,2 & 9,6 & 83,0 & 1,3 & 1,6 & 88,4 & 6,3 & 7,1 \\
10 & 89,7 & 6,9 & 7,7 & 79,4 & 7,7 & 9,7 & 77,1 & 6,1 & 8,0 \\
15 & 78,6 & 8,5 & 10,8 & 80,6 & 7,9 & 9,8 & 75,6 & 5,0 & 6,7 \\
\hline E: Média de exatidão (\%) & \multicolumn{3}{c}{ DP: Desvio padrão } & & CV: Coeficiente de variação (\%)
\end{tabular}

Tabela 47 - Resultados da média de exatidão, desvio padrão, coeficiente de variação dos experimentos 1, 2 e 3 para aldicarbe sulfona

\begin{tabular}{cccccccccc}
\hline $\begin{array}{c}\text { Nível de } \\
\text { validação } \\
(\mu \mathrm{g} / \mathrm{kg})\end{array}$ & \multicolumn{3}{c}{ Experimento 1 } & \multicolumn{3}{c}{ Experimento 2 } & \multicolumn{2}{c}{ Experimento 3 } \\
\cline { 2 - 10 } & $\begin{array}{c}\text { E } \\
(\%)\end{array}$ & DP & $\begin{array}{c}\text { CV } \\
(\%)\end{array}$ & $\begin{array}{c}\text { E } \\
(\%)\end{array}$ & DP & $\begin{array}{c}\text { CV } \\
(\%)\end{array}$ & $\begin{array}{c}\text { E } \\
(\%)\end{array}$ & DP & $\begin{array}{r}\text { CV } \\
(\%)\end{array}$ \\
\hline 10 & 100,0 & 15,7 & 15,7 & 163,4 & 20,8 & 12,7 & 171,5 & 26,2 & 15,3 \\
20 & 81,8 & 6,7 & 8,2 & 98,7 & 7,4 & 7,5 & 125,5 & 3,4 & 2,7 \\
30 & 78,9 & 5,4 & 6,8 & 84,1 & 8,7 & 10,3 & 91,0 & 9,8 & 10,8 \\
\hline
\end{tabular}

Tabela 48 - Resultados da média de exatidão, desvio padrão, coeficiente de variação dos experimentos 1,2 e 3 para aldicarbe sulfóxido

\begin{tabular}{cccccccccc}
\hline $\begin{array}{c}\text { Nível de } \\
\text { validação } \\
(\mu \mathrm{g} / \mathrm{kg})\end{array}$ & \multicolumn{3}{c}{ Experimento 1 } & \multicolumn{3}{c}{ Experimento 2 } & \multicolumn{2}{c}{ Experimento 3 } \\
\cline { 2 - 9 } & $\begin{array}{c}\text { E } \\
(\%)\end{array}$ & DP & $\begin{array}{c}\text { CV } \\
(\%)\end{array}$ & $\begin{array}{c}\text { E } \\
(\%)\end{array}$ & DP & $\begin{array}{c}\text { CV } \\
(\%)\end{array}$ & $\begin{array}{c}\text { E } \\
(\%)\end{array}$ & DP & $\begin{array}{c}\text { CV } \\
(\%)\end{array}$ \\
\hline 5 & 92,1 & 3,5 & 3,8 & 90,8 & 12,0 & 13,2 & 92,3 & 6,2 & 6,7 \\
10 & 90,5 & 7,8 & 8,7 & 89,7 & 4,6 & 5,1 & 94,4 & 7,3 & 7,8 \\
15 & 85,4 & 6,6 & 7,7 & 91,7 & 5,0 & 5,5 & 83,4 & 2,1 & 2,6 \\
\hline E: Média de exatidão (\%) & \multicolumn{3}{c}{ DP: Desvio padrão } & & CV: Coeficiente de variação (\%)
\end{tabular}


Tabela 49 - Resultados da média de exatidão, desvio padrão, coeficiente de variação dos experimentos 1, 2 e 3 para carbaril

\begin{tabular}{cccccccccc}
\hline $\begin{array}{c}\text { Nível de } \\
\text { validação } \\
(\mu \mathrm{g} / \mathrm{kg})\end{array}$ & \multicolumn{3}{c}{ Experimento 1 } & \multicolumn{3}{c}{ Experimento 2 } & \multicolumn{3}{c}{ Experimento 3 } \\
\cline { 2 - 9 } & $\begin{array}{c}\mathrm{E} \\
(\%)\end{array}$ & DP & $\begin{array}{c}\text { CV } \\
(\%)\end{array}$ & $\begin{array}{c}\text { E } \\
(\%)\end{array}$ & DP & $\begin{array}{c}\text { CV } \\
(\%)\end{array}$ & $\begin{array}{c}\text { E } \\
(\%)\end{array}$ & DP & $\begin{array}{c}\text { CV } \\
(\%)\end{array}$ \\
\hline 5 & 102,8 & 7,4 & 7,2 & 96,8 & 8,1 & 8,4 & 94,3 & 8,8 & 9,3 \\
10 & 99,3 & 3,6 & 3,6 & 90,5 & 7,1 & 7,9 & 89,9 & 5,5 & 6,1 \\
15 & 91,8 & 4,8 & 5,2 & 90,3 & 7,0 & 7,7 & 93,0 & 5,5 & 5,9 \\
\hline E: Média de exatidão (\%) & \multicolumn{3}{c}{ DP: Desvio padrão } & \multicolumn{4}{c|}{ CV: Coeficiente de variação (\%) }
\end{tabular}

Tabela 50 - Resultados da média de exatidão, desvio padrão, coeficiente de variação dos experimentos 1, 2 e 3 para carbofurano

\begin{tabular}{ccccccccccc}
\hline $\begin{array}{c}\text { Nível de } \\
\text { validação } \\
(\mu \mathrm{g} / \mathrm{kg})\end{array}$ & \multicolumn{3}{c}{ Experimento 1 } & \multicolumn{3}{c}{ Experimento 2 } & \multicolumn{3}{c}{ Experimento 3 } \\
\cline { 2 - 10 } & $\begin{array}{c}\text { E } \\
(\%)\end{array}$ & DP & $\begin{array}{c}\text { CV } \\
(\%)\end{array}$ & $\begin{array}{c}\text { E } \\
(\%)\end{array}$ & DP & $\begin{array}{c}\text { CV } \\
(\%)\end{array}$ & $\begin{array}{c}\text { E } \\
(\%)\end{array}$ & DP & $\begin{array}{c}\text { CV } \\
(\%)\end{array}$ \\
\hline 5 & 106,5 & 6,4 & 6,0 & 104,7 & 4,4 & 4,2 & 102,2 & 8,2 & 8,0 \\
10 & 98,4 & 5,7 & 5,8 & 92,0 & 4,3 & 4,6 & 87,2 & 3,0 & 3,4 \\
15 & 91,3 & 3,4 & 3,7 & 92,8 & 4,1 & 4,4 & 89,4 & 3,0 & 3,4 \\
\hline E: Média de exatidão (\%) & \multicolumn{4}{c}{ DP: Desvio padrão } & \multicolumn{4}{c|}{ CV: Coeficiente de variação (\%) }
\end{tabular}

Tabela 51 - Resultados da média de exatidão, desvio padrão e coeficiente de variação, dos experimentos 1, 2 e 3 para metiocarbe

\begin{tabular}{cccccccccc}
\hline $\begin{array}{c}\text { Nível de } \\
\text { validação } \\
(\mu \mathrm{g} / \mathrm{kg})\end{array}$ & \multicolumn{3}{c}{ Experimento 1 } & \multicolumn{3}{c}{ Experimento 2 } & \multicolumn{3}{c}{ Experimento 3 } \\
\cline { 2 - 9 } & $\begin{array}{c}\mathrm{E} \\
(\%)\end{array}$ & DP & $\begin{array}{c}\text { CV } \\
(\%)\end{array}$ & $\begin{array}{c}\text { E } \\
(\%)\end{array}$ & DP & $\begin{array}{c}\text { CV } \\
(\%)\end{array}$ & $\begin{array}{c}\text { E } \\
(\%)\end{array}$ & DP & $\begin{array}{c}\text { CV } \\
(\%)\end{array}$ \\
\hline 5 & 108,2 & 15,8 & 14,6 & 108,7 & 9,8 & 9,0 & 96,4 & 9,1 & 9,5 \\
10 & 115,1 & 4,5 & 3,9 & 102,6 & 5,4 & 5,3 & 104,6 & 2,7 & 2,6 \\
15 & 106,3 & 6,6 & 6,2 & 105,9 & 4,0 & 3,7 & 100,1 & 5,9 & 5,9 \\
\hline E: Média de exatidão (\%) & \multicolumn{3}{c}{ DP: Desvio padrão } & & CV: Coeficiente de variação (\%)
\end{tabular}


Tabela 52 - Resultados da média de exatidão, desvio padrão e coeficiente de variação, dos experimentos 1, 2 e 3 para metomil

\begin{tabular}{cccccccccc}
\hline $\begin{array}{l}\text { Nível de } \\
\text { validação } \\
(\mu \mathrm{g} / \mathrm{kg})\end{array}$ & \multicolumn{2}{c}{ Experimento 1 } & \multicolumn{4}{c}{ Experimento 2 } & \multicolumn{3}{c}{ Experimento 3 } \\
\cline { 2 - 10 } & $\begin{array}{c}\text { E } \\
(\%)\end{array}$ & DP & $\begin{array}{l}\text { CV } \\
(\%)\end{array}$ & $\begin{array}{c}\text { E } \\
(\%)\end{array}$ & DP & $\begin{array}{c}\text { CV } \\
(\%)\end{array}$ & $\begin{array}{c}\text { E } \\
(\%)\end{array}$ & DP & $\begin{array}{c}\text { CV } \\
(\%)\end{array}$ \\
\hline 5 & 97,0 & 6,1 & 6,3 & 91,2 & 9,4 & 10,4 & 91,7 & 7,4 & 8,0 \\
10 & 93,1 & 7,2 & 7,8 & 78,6 & 6,8 & 8,6 & 85,1 & 6,1 & 7,2 \\
15 & 79,8 & 7,9 & 9,9 & 84,9 & 3,7 & 4,4 & 80,5 & 7,8 & 9,6 \\
\hline
\end{tabular}

E: Média de exatidão (\%)

DP: Desvio padrão

CV: Coeficiente de variação (\%)

Tabela 53 - Resultados da média de exatidão, desvio padrão e coeficiente de variação, dos experimentos 1, 2 e 3 para pirimicarbe

\begin{tabular}{cccccccccc}
\hline \multirow{2}{*}{$\begin{array}{c}\text { Nível de } \\
\text { validação } \\
(\mu \mathrm{g} / \mathrm{kg})\end{array}$} & \multicolumn{3}{c}{ Experimento 1 } & \multicolumn{3}{c}{ Experimento 2 } & \multicolumn{3}{c}{ Experimento 3 } \\
\cline { 2 - 10 } & $\begin{array}{c}\text { E } \\
(\%)\end{array}$ & DP & $\begin{array}{c}\text { CV } \\
(\%)\end{array}$ & $\begin{array}{c}\text { E } \\
(\%)\end{array}$ & DP & $\begin{array}{c}\text { CV } \\
(\%)\end{array}$ & $\begin{array}{c}\text { E } \\
(\%)\end{array}$ & DP & $\begin{array}{c}\text { CV } \\
(\%)\end{array}$ \\
\hline 4,0 & 90,5 & 1,3 & 1,4 & 93,8 & 5,6 & 6,0 & 90,9 & 5,0 & 5,5 \\
8,0 & 90,2 & 2,4 & 2,6 & 85,3 & 4,7 & 5,5 & 86,5 & 2,3 & 2,7 \\
12,0 & 84,9 & 4,7 & 5,6 & 88,8 & 4,3 & 4,8 & 84,7 & 4,8 & 5,7 \\
\hline E: Média de exatidão (\%) & \multicolumn{3}{c}{ DP: Desvio padrão } & & CV: Coeficiente de variação (\%)
\end{tabular}

Tabela 54 - Resultados da média de exatidão, desvio padrão e coeficiente de variação dos experimentos 1, 2 e 3 para propoxur

\begin{tabular}{cccccccccc}
\hline $\begin{array}{c}\text { Nível de } \\
\text { validação } \\
(\mu \mathrm{g} / \mathrm{kg})\end{array}$ & \multicolumn{3}{c}{ Experimento 1 } & \multicolumn{3}{c}{ Experimento 2 } & \multicolumn{3}{c}{ Experimento 3 } \\
\cline { 2 - 10 } & $\begin{array}{c}\text { E } \\
(\%)\end{array}$ & DP & $\begin{array}{c}\text { CV } \\
(\%)\end{array}$ & $\begin{array}{c}\text { E } \\
(\%)\end{array}$ & DP & $\begin{array}{c}\text { CV } \\
(\%)\end{array}$ & $\begin{array}{c}\text { E } \\
(\%)\end{array}$ & DP & $\begin{array}{c}\text { CV } \\
(\%)\end{array}$ \\
\hline 5 & 86,4 & 8,8 & 10,2 & 95,7 & 8,9 & 9,3 & 100,3 & 6,1 & 6,1 \\
10 & 98,6 & 6,0 & 6,0 & 91,5 & 8,4 & 9,1 & 85,5 & 8,0 & 9,3 \\
15 & 94,0 & 9,0 & 9,6 & 97,3 & 1,5 & 1,6 & 101,5 & 4,7 & 4,6 \\
\hline
\end{tabular}

E: Média de exatidão (\%)

DP: Desvio padrão

CV: Coeficiente de variação (\%) 
Tabela 55 - Resultados da média de exatidão, desvio padrão e coeficiente de variação, dos experimentos 1, 2 e 3 para atrazina

\begin{tabular}{ccccccccccc}
\hline $\begin{array}{c}\text { Nível de } \\
\text { validação } \\
(\mu \mathrm{g} / \mathrm{kg})\end{array}$ & \multicolumn{3}{c}{ Experimento 1 } & \multicolumn{3}{c}{ Experimento 2 } & \multicolumn{3}{c}{ Experimento 3 } \\
\cline { 2 - 10 } & $\begin{array}{c}\mathbf{E} \\
(\%)\end{array}$ & $\mathbf{D P}$ & $\begin{array}{c}\mathbf{C V} \\
(\%)\end{array}$ & $\begin{array}{c}\mathrm{E} \\
(\%)\end{array}$ & $\mathbf{D P}$ & $\begin{array}{c}\mathrm{CV} \\
(\%)\end{array}$ & $\begin{array}{c}\mathbf{E} \\
(\%)\end{array}$ & $\mathbf{D P}$ & $\begin{array}{c}\text { CV } \\
(\%)\end{array}$ \\
\hline 10 & 108,7 & 6,4 & 5,9 & 105,7 & 5,2 & 4,9 & 103,8 & 7,7 & 7,4 \\
20 & 103,9 & 5,7 & 5,5 & 96,4 & 6,5 & 6,7 & 102,9 & 5,8 & 5,6 \\
30 & 95,1 & 3,4 & 3,5 & 98,1 & 4,1 & 4,2 & 98,5 & 5,8 & 5,9 \\
\hline
\end{tabular}

E: Média de exatidão (\%)

DP: Desvio padrão

CV: Coeficiente de variação (\%)

Tabela 56 - Resultados da média de exatidão, desvio padrão e coeficiente de variação, dos experimentos 1, 2 e 3 para simazina

\begin{tabular}{cccccccccc}
\hline $\begin{array}{c}\text { Nível de } \\
\text { validação } \\
(\mu \mathrm{g} / \mathrm{kg})\end{array}$ & \multicolumn{3}{c}{ Experimento 1 } & \multicolumn{3}{c}{ Experimento 2 } & \multicolumn{3}{c}{ Experimento 3 } \\
\cline { 2 - 10 } & $\begin{array}{c}\text { E } \\
(\%)\end{array}$ & DP & $\begin{array}{c}\text { CV } \\
(\%)\end{array}$ & $\begin{array}{c}\text { E } \\
\%\end{array}$ & DP & $\begin{array}{c}\text { CV } \\
(\%)\end{array}$ & $\begin{array}{c}\text { E } \\
(\%)\end{array}$ & DP & $\begin{array}{c}\text { CV } \\
(\%)\end{array}$ \\
\hline 10 & 95,0 & 8,8 & 9,2 & 101,5 & 4,7 & 4,6 & 98,9 & 2,5 & 2,5 \\
20 & 92,7 & 6,4 & 6,9 & 93,7 & 5,6 & 6,0 & 99,7 & 4,3 & 4,3 \\
30 & 93,7 & 4,0 & 4,3 & 92,9 & 8,1 & 8,8 & 93,7 & 5,2 & 5,5 \\
\hline E: Média de exatidão (\%) & \multicolumn{3}{c}{ DP: Desvio padrão } & \multicolumn{4}{c|}{ CV: Coeficiente de variação (\%) }
\end{tabular}

Tabela 57 - Resultados da média de exatidão, desvio padrão e coeficiente de variação, dos experimentos 1, 2 e 3 para carbendazim

\begin{tabular}{ccccccccccc}
\hline $\begin{array}{c}\text { Nível de } \\
\text { validação } \\
(\mu \mathrm{\mu g} / \mathrm{kg})\end{array}$ & \multicolumn{3}{c}{ Experimento 1 } & \multicolumn{3}{c}{ Experimento 2 } & \multicolumn{3}{c}{ Experimento 3 } \\
\cline { 2 - 10 } & $\begin{array}{c}\text { E } \\
(\%)\end{array}$ & DP & $\begin{array}{c}\text { CV } \\
(\%)\end{array}$ & $\begin{array}{c}\text { E } \\
(\%)\end{array}$ & DP & $\begin{array}{c}\text { CV } \\
(\%)\end{array}$ & $\begin{array}{c}\text { E } \\
(\%)\end{array}$ & DP & $\begin{array}{c}\text { CV } \\
(\%)\end{array}$ \\
\hline 5 & 96,5 & 4,6 & 4,8 & 94,3 & 4,1 & 4,3 & 95,1 & 7,0 & 7,4 \\
10 & 89,2 & 4,4 & 4,9 & 84,5 & 1,9 & 2,3 & 85,4 & 3,8 & 4,4 \\
15 & 87,7 & 3,5 & 4,0 & 85,3 & 4,1 & 4,8 & 84,7 & 4,9 & 5,8 \\
\hline E: Média de exatidão (\%) & \multicolumn{3}{c}{ DP: Desvio padrão } & & CV: Coeficiente de variação (\%)
\end{tabular}


Tabela 58 - Resultados da média de exatidão, desvio padrão e coeficiente de variação, dos experimentos 1, 2 e 3 para tiabendazol

\begin{tabular}{cccccccccc}
\hline $\begin{array}{c}\text { Nível de } \\
\text { validação } \\
(\mu \mathrm{g} / \mathrm{kg})\end{array}$ & \multicolumn{3}{c}{ Experimento 1 } & \multicolumn{3}{c}{ Experimento 2 } & \multicolumn{3}{c}{ Experimento 3 } \\
\cline { 2 - 10 } & $\begin{array}{c}\mathrm{E} \\
(\%)\end{array}$ & DP & $\begin{array}{c}\text { CV } \\
(\%)\end{array}$ & $\begin{array}{c}\mathrm{E} \\
(\%)\end{array}$ & DP & $\begin{array}{c}\text { CV } \\
(\%)\end{array}$ & $\begin{array}{c}\text { E } \\
(\%)\end{array}$ & DP & $\begin{array}{c}\text { CV } \\
(\%)\end{array}$ \\
\hline 10 & 107,0 & 5,6 & 5,2 & 115,9 & 3,1 & 2,7 & 104,7 & 4,2 & 4,0 \\
20 & 105,2 & 9,9 & 9,4 & 102,2 & 7,7 & 7,6 & 102,1 & 3,0 & 3,0 \\
30 & 106,6 & 7,7 & 7,2 & 108,5 & 6,8 & 6,2 & 102,7 & 3,0 & 2,9 \\
\hline E: Média de exatidão (\%) & \multicolumn{3}{c}{ DP: Desvio padrão } & & CV: Coeficiente de variação (\%)
\end{tabular}

Tabela 59 - Resultados da média de exatidão, desvio padrão e coeficiente de variação, dos experimentos 1, 2 e 3 para tiofanato metílico.

\begin{tabular}{cccccccccc}
\hline $\begin{array}{c}\text { Nível de } \\
\text { validação } \\
(\mu \mathrm{g} / \mathrm{kg})\end{array}$ & \multicolumn{3}{c}{ Experimento 1 } & \multicolumn{3}{c}{ Experimento 2 } & \multicolumn{3}{c}{ Experimento 3 } \\
\cline { 2 - 10 } & $\begin{array}{c}\text { E } \\
(\%)\end{array}$ & DP & $\begin{array}{c}\text { CV } \\
(\%)\end{array}$ & $\begin{array}{c}\text { E } \\
(\%)\end{array}$ & DP & $\begin{array}{c}\text { CV } \\
(\%)\end{array}$ & $\begin{array}{c}\text { E } \\
(\%)\end{array}$ & DP & $\begin{array}{c}\text { CV } \\
(\%)\end{array}$ \\
\hline 20 & 103,0 & 6,0 & 5,8 & 104,1 & 4,2 & 4,1 & 101,6 & 5,0 & 4,9 \\
40 & 102,2 & 8,2 & 8,0 & 100,1 & 7,8 & 7,8 & 102,7 & 2,7 & 2,6 \\
60 & 101,6 & 5,3 & 5,2 & 108,4 & 2,4 & 2,3 & 101,5 & 8,6 & 8,5 \\
\hline E: Média de exatidão (\%) & \multicolumn{3}{c}{ DP: Desvio padrão } & \multicolumn{4}{c|}{ CV: Coeficiente de variação (\%) }
\end{tabular}

A norma EC/2002/657 não menciona o nível de aceitabilidade de CV em cada experimento e em níveis de fortificações.

Pelos dados das Tabelas 46 a 59, o coeficiente de variação (CV) da média dos resultados de recuperações variou de 1,6 a $15,7 \%$, para todos os analitos, nos níveis de validação estudados e nos experimentos de 1 a 3 . O menor valor de CV refere-se ao propoxur $(1,6 \%)$ e o maior ao aldicarbe sulfona $(15,7 \%)$. Os analitos que apresentaram valores de CV maiores que 10\% em todos os experimentos estudados foram: aldicarbe, aldicarbe sulfóxido, aldicarbe sulfona, metiocarbe, metomil e propoxur. $\mathrm{O}$ aldicarbe apresentou resultados de CV de $10,8 \%$, no nível de validação de $15 \mu \mathrm{g} / \mathrm{kg}$, somente no experimento 1 . Aldicarbe sulfóxido apresentou CV de 13,2\%, no nível de validação de $5 \mu \mathrm{g} / \mathrm{kg}$, experimento 2. O aldicarbe sulfona foi o que apresentou maiores incidências de valores de CV 
maiores que 10\%, no nível da validação de $10 \mu \mathrm{g} / \mathrm{kg}$, nos experimentos 1,2 e 3 e no nível de $30 \mu \mathrm{g} / \mathrm{kg}$, nos experimentos 2 e 3 . Os demais pesticidas, aldicarbe sulfóxido, metiocarbe, metomil e propoxur, apresentaram valores de CV maiores que $10 \%$ no nível de validação de $5 \mu \mathrm{g} / \mathrm{kg}$, correspondente a $1 / 2 \mathrm{LOQ}$, somente em um dos experimentos. Não houve similaridade entre os analitos da medida de dispersão (CV), com relação ao nível crescente de concentração da recuperação. Experimentalmente, observa-se que em outras técnicas de cromatografia gasosa utilizando diferentes metodologias de detecção, na avaliação em menores concentrações de recuperação, maiores valores de CV.

$\mathrm{Na}$ Tabela 60, estão os resultados das médias em concentração e porcentagem de recuperações, em 5 níveis de: 1/2, 1, 1 1/2, 2 e 5 LOQ, desvio padrão, coeficiente de variação e número de determinações, para todos os princípios ativos estudados. As recomendações da norma são estabelecidas para porcentagem da média de recuperação, conforme Tabela 10, item 4.8. 4, e coeficiente de variação, Tabela 11 item 4.8.5.

A norma recomenda, para níveis de recuperação entre $>1 \mu \mathrm{g} / \mathrm{kg}$ a 10 $\mu \mathrm{g} / \mathrm{kg}$, que os valores de média de recuperação devem estar na faixa de 70 a $110 \%$ e em nível $\geq 10 \mu \mathrm{g} / \mathrm{kg}$, média de recuperação de 80 a $110 \%$. Pelos resultados da Tabela 60 , todos os analitos estudados em níveis de recuperação, apresentaram resultados satisfatórios, exceto para os pesticidas aldicarbe e aldicarbe sulfona. $\mathrm{O}$ aldicarbe apresentou média de recuperação de 73 a $78 \%$, em níveis de 15 a $50 \mu \mathrm{g} / \mathrm{kg}$, e o aldicarbe sulfona, de $145 \%$ para nível de $10 \mu \mathrm{g} / \mathrm{kg}$, e $77 \%$, para nível de $100 \mu \mathrm{g} / \mathrm{kg}$. Com relação ao coeficiente de variação, CV(\%), recomendado pela norma, para níveis de recuperação entre $\geq 10 \mu \mathrm{g} / \mathrm{Kg}$ a 100 $\mu \mathrm{g} / \mathrm{kg}$, este deve ser de até $20 \%$ e entre 100 a $1000 \mu \mathrm{g} / \mathrm{kg}$, de até $15 \%$. Todos os analitos apresentaram CV dentro da faixa recomendada pela norma, exceto para aldicarbe sulfona, que apresentou CV de 25,5\% em nível de $10 \mu \mathrm{g} / \mathrm{kg}$. 
Tabela 60 - Resultados da média das recuperações, dos desvios padrões e dos coeficientes de variação.

\begin{tabular}{|c|c|c|c|c|c|c|}
\hline Composto & $\begin{array}{c}\text { Nível } \\
(\mu \mathrm{g} / \mathrm{Kg})\end{array}$ & $\begin{array}{c}\text { Recuperação } \\
(\mu \mathrm{g} / \mathrm{Kg})\end{array}$ & $\begin{array}{c}\text { Recuperação } \\
(\%)\end{array}$ & DP & $\begin{array}{l}\text { CV } \\
(\%)\end{array}$ & $\mathbf{n}$ \\
\hline \multirow{5}{*}{ Aldicarbe } & 5,0 & 4,4 & 85 & 0,3 & 7,0 & 18 \\
\hline & 10,0 & 8,0 & 80 & 1,0 & 13,1 & 28 \\
\hline & 15,0 & 11,7 & 78 & 1,0 & 8,3 & 18 \\
\hline & 20,0 & 15,5 & 78 & 0,7 & 4,4 & 3 \\
\hline & 50,0 & 36,5 & 73 & 0,5 & 1,4 & 3 \\
\hline \multirow{5}{*}{$\begin{array}{l}\text { Aldicarbe } \\
\text { Sulfona }\end{array}$} & 10,0 & 14,5 & 145 & 3,7 & 25,5 & 18 \\
\hline & 20,0 & 20,4 & 102 & 3,7 & 18,1 & 28 \\
\hline & 30,0 & 27,5 & 92 & 6,0 & 20,0 & 18 \\
\hline & 40,0 & 40,4 & 101 & 2,0 & 5,0 & 3 \\
\hline & 100,0 & 77,3 & 77 & 5,3 & 6,9 & 3 \\
\hline \multirow{5}{*}{$\begin{array}{l}\text { Aldicarbe } \\
\text { Sulfóxido }\end{array}$} & 5,0 & 4,6 & 92 & 0,4 & 8,7 & 18 \\
\hline & 10,0 & 8,9 & 89 & 0,7 & 7,8 & 28 \\
\hline & 15,0 & 13,0 & 87 & 0,9 & 6,9 & 18 \\
\hline & 20,0 & 17,1 & 86 & 1,1 & 6,4 & 3 \\
\hline & 50,0 & 43,5 & 87 & 1,1 & 2,5 & 3 \\
\hline \multirow{5}{*}{ Carbaril } & 5,0 & 4,9 & 98 & 0,4 & 8,1 & 18 \\
\hline & 10,0 & 9,4 & 94 & 0,6 & 6,4 & 28 \\
\hline & 15,0 & 13,8 & 92 & 0,7 & 5,0 & 18 \\
\hline & 20,0 & 18,1 & 91 & 1,8 & 9,9 & 3 \\
\hline & 50,0 & 44,5 & 89 & 1,9 & 4,3 & 3 \\
\hline \multirow{5}{*}{ Carbofurano } & 5,0 & 5,2 & 104 & 0,3 & 5,7 & 18 \\
\hline & 10,0 & 9,4 & 94 & 0,7 & 7,4 & 28 \\
\hline & 15,0 & 13,7 & 91 & 0,5 & 3,6 & 18 \\
\hline & 20,0 & 17,8 & 89 & 0,8 & 4,5 & 3 \\
\hline & 50,0 & 44,5 & 89 & 1,9 & 4,3 & 3 \\
\hline \multirow{5}{*}{ Metiocarbe } & 5,0 & 5,2 & 104 & 0,6 & 11,5 & 18 \\
\hline & 10,0 & 10,5 & 105 & 0,7 & 6,6 & 28 \\
\hline & 15,0 & 15,6 & 104 & 0,9 & 5,8 & 18 \\
\hline & 20,0 & 19,2 & 96 & 0,9 & 4,6 & 3 \\
\hline & 50,0 & 47,9 & 96 & 3,9 & 8,1 & 3 \\
\hline \multirow{5}{*}{ Metomil } & 5,0 & 4,7 & 94 & 0,4 & 8,5 & 18 \\
\hline & 10,0 & 8,4 & 84 & 0,8 & 9,5 & 28 \\
\hline & 15,0 & 12,3 & 82 & 1,0 & 8,1 & 18 \\
\hline & 20,0 & 16,0 & 80 & 0,2 & 1,3 & 3 \\
\hline & 50,0 & 40,0 & 80 & 1,6 & 3,0 & 3 \\
\hline \multirow{5}{*}{ Pirimicarbe } & 4,0 & 3,7 & 93 & 0,2 & 5,0 & 18 \\
\hline & 8,0 & 7,0 & 88 & 0,3 & 4,3 & 28 \\
\hline & 12,0 & 10,3 & 86 & 0,6 & 5,8 & 18 \\
\hline & 16,0 & 13,7 & 86 & 1,0 & 7,3 & 3 \\
\hline & 40,0 & 33,7 & 84 & 0,5 & 1,3 & 3 \\
\hline \multirow{5}{*}{ Propoxur } & 5,0 & 4,7 & 94 & 0,5 & 10,6 & 18 \\
\hline & 10,0 & 9,2 & 92 & 0,9 & 9,8 & 28 \\
\hline & 15,0 & 14,6 & 97 & 1,0 & 6,8 & 18 \\
\hline & 20,0 & 19,6 & 98 & 0,9 & 4,6 & 3 \\
\hline & 50,0 & 45,0 & 90 & 3,9 & 8,7 & 3 \\
\hline
\end{tabular}


Continuação da Tabela 60

\begin{tabular}{|c|c|c|c|c|c|c|}
\hline Composto & $\begin{array}{l}\text { Nível } \\
(\mu \mathrm{g} / \mathrm{Kg})\end{array}$ & $\begin{array}{l}\text { Recuperação } \\
(\mu \mathrm{g} / \mathrm{Kg})\end{array}$ & $\begin{array}{c}\text { Recuperação } \\
(\%)\end{array}$ & DP & $\begin{array}{l}\text { CV } \\
(\%)\end{array}$ & $\mathbf{n}$ \\
\hline \multirow{5}{*}{ Triazina } & 10,0 & 10,6 & 106 & 0,6 & 5,7 & 18 \\
\hline & 20,0 & 19,9 & 100 & 1,2 & 6,0 & 28 \\
\hline & 30,0 & 29,2 & 97 & 1,4 & 4,8 & 18 \\
\hline & 40,0 & 36,6 & 91 & 1,2 & 3,3 & 3 \\
\hline & 100,0 & 93,7 & 94 & 2,8 & 3,0 & 3 \\
\hline \multirow{5}{*}{ Simazina } & 10,0 & 9,9 & 99 & 0,6 & 6,1 & 18 \\
\hline & 20,0 & 19,1 & 96 & 1,1 & 5,8 & 28 \\
\hline & 30,0 & 28,0 & 93 & 1,7 & 6,1 & 18 \\
\hline & 40,0 & 37,9 & 95 & 4,2 & 11,1 & 3 \\
\hline & 100,0 & 94,3 & 94 & 4,4 & 4,7 & 3 \\
\hline \multirow{5}{*}{ Carbendazim } & 5,0 & 4,8 & 96 & 0,6 & 6,1 & 18 \\
\hline & 10,0 & 8,6 & 86 & 0,4 & 4,6 & 28 \\
\hline & 15,0 & 12,9 & 86 & 0,6 & 4,7 & 18 \\
\hline & 20,0 & 16,1 & 80 & 0,4 & 2,5 & 3 \\
\hline & 50,0 & 41,0 & 82 & 0,8 & 2,0 & 3 \\
\hline \multirow{5}{*}{ Tiabendazol } & 10,0 & 10,9 & 109 & 0,6 & 5,5 & 18 \\
\hline & 20,0 & 21,1 & 105 & 1,5 & 14,6 & 28 \\
\hline & 30,0 & 31,8 & 80 & 1,9 & 6,0 & 18 \\
\hline & 40,0 & 41,8 & 105 & 1,0 & 2,4 & 3 \\
\hline & 100,0 & 103,4 & 103 & 4,0 & 3,9 & 3 \\
\hline \multirow{5}{*}{$\begin{array}{l}\text { Tiofanato } \\
\text { metílico }\end{array}$} & 20,0 & 20,6 & 103 & 1,0 & 4,9 & 18 \\
\hline & 40,0 & 39,5 & 99 & 3,3 & 8,4 & 28 \\
\hline & 60,0 & 62,3 & 104 & 3,9 & 6,3 & 18 \\
\hline & 80,0 & 78,1 & 98 & 7,6 & 9,7 & 3 \\
\hline & 200,0 & 189,2 & 95 & 2,4 & 1,2 & 3 \\
\hline
\end{tabular}

Os resultados obtidos para aldicarbe e aldicarbe sulfona podem ser explicados pela possibilidade de degradação do princípio ativo aldicarbe a aldicarbe sulfona em alguma das etapas analíticas do método.

Segundo Nunes et al. (2000), o aldicarbe degrada a aldicarbe sulfóxido e sulfona. Dentre eles, aldicarbe sulfóxido é o mais importante pela forte atividade sistêmica e presistência no solo. O mesmo estudo, realizado com batata no nível de $100 \mu \mathrm{g} / \mathrm{Kg}$, encontrou média de recuperações (\%) e CV (\%) de: 68 e 12,3\%, respectivamente, para aldicarbe; 83 e 8,4\%, para aldicarbe sulfóxido, e 75 e 13,0 $\%$, para aldicarbe sulfona, o que corrobora com os dados obtidos neste trabalho. 
Hernández et al. (2006) estudaram as recuperações de aldicarbe em tomate, limão, uva seca e abacate em níveis de $10 \mu \mathrm{g} / \mathrm{Kg}$ e $100 \mu \mathrm{g} / \mathrm{Kg}$. O aldicarbe apresentou médias de recuperação (\%) e CV (\%) em tomate de: 31 e 16 $\%$, respectivamente, para nível de $10 \mu \mathrm{g} / \mathrm{Kg} ; 45$ e $4 \%$, para nível de $100 \mu \mathrm{g} / \mathrm{Kg}$. Para o limão, as médias de recuperações (\%) e CV (\%) foram de: 58 e $8 \%$, respectivamente, para nível de $10 \mu \mathrm{g} / \mathrm{Kg} ; 71$ e $4 \%$, para nível de $100 \mu \mathrm{g} / \mathrm{Kg}$. Para uva seca, de 58 e $10 \%$, para nível de $10 \mu \mathrm{g} / \mathrm{Kg}$; 42 e $9 \%$, para nível de 100 $\mu \mathrm{g} / \mathrm{Kg}$; e para abacate: 60 e $10 \%$, para nível de $10 \mu \mathrm{g} / \mathrm{Kg}$, e $61 \%$ de recuperação e $7 \%$ de $\mathrm{CV}$, para nível de $100 \mu \mathrm{g} / \mathrm{Kg}$.

O estudo em leite obteve média de recuperação (\%) e coeficiente de variação (\%) de 72 e $5 \%$, para aldicarbe em nível de fortificação de $100 \mu \mathrm{g} / \mathrm{Kg}$ (Boglialli et al. 2004).

Pelos estudos de metodologias validadas, o aldicarbe tem apresentado baixo nível médio de recuperação para diferentes matrizes e em níveis de fortificação, concordando com os valores que se obteve neste trabalho.

\section{8. Níveis críticos - $C C \alpha$ e $C C \beta$}

Segundo a norma Council Directive (2002), os níveis críticos denominados de limite de decisão $(C C \alpha)$ e capacidade de detecção $(C C \beta)$ foram calculados de acordo com equações 3 e 4, item 4.8.6.1 e equação 5, do item 4.8.6.2, respectivamente. Na Tabela 61, encontram-se os resultados da média de CCa e $C C \beta$. 
Tabela 61 - Média de $C C \alpha$ e $C C \beta$ do experimento 1 a 3

\begin{tabular}{lcc|lcc}
\hline \multicolumn{1}{c}{ Analito } & $\begin{array}{c}\boldsymbol{C C \alpha} \\
(\mu \mathrm{g} / \mathrm{Kg})\end{array}$ & $\begin{array}{c}\boldsymbol{C} \boldsymbol{C} \boldsymbol{\beta} \\
(\mu \mathrm{g} / \mathrm{Kg})\end{array}$ & \multicolumn{1}{c}{ Analito } & $\begin{array}{c}\boldsymbol{C C \alpha} \\
(\mu \mathrm{g} / \mathrm{Kg})\end{array}$ & $\begin{array}{c}\boldsymbol{C C} \boldsymbol{\beta} \\
(\mu \mathrm{g} / \mathrm{Kg})\end{array}$ \\
\hline Aldicarbe & 0,88 & 1,50 & Pirimicarbe & 0,40 & 0,68 \\
Aldicarbe sulfona & 3,64 & 6,20 & Propoxur & 0,88 & 1,49 \\
Aldicarbe sulfóxido & 0,67 & 1,14 & Atrazina & 1,05 & 1,79 \\
Carbaril & 0,65 & 1,12 & Simazina & 1,28 & 2,18 \\
Carbofurano & 0,51 & 0,87 & Carbendazim & 0,46 & 0,79 \\
Metiocarbe & 0,69 & 1,12 & Tiabendazol & 1,05 & 1,79 \\
Metomil & 0,77 & 1,31 & Tiofanato & 2,89 & 4,93 \\
\hline
\end{tabular}

Pela Tabela 61, a média de $C C \alpha$ para todos os analitos variou de 0,40 a 3,64 $(\mu \mathrm{g} / \mathrm{Kg})$ e o aldicarbe sulfona foi o que apresentou o maior valor. Para os valores de $C C \beta$, todos os pesticidas apresentaram valores menores que o limite de quantificação do método. $O$ menor valor $C C \beta$ foi obtido para o pirimicarbe $(0,68 \mu \mathrm{g} / \mathrm{Kg})$ e o limite de quantificação alvo do método de $8 \mu \mathrm{g} / \mathrm{Kg}$ e o maior valor para aldicarbe sulfona $(6,20 \mu \mathrm{g} / \mathrm{Kg})$ para o limite de quantificação alvo de 20 $\mu \mathrm{g} / \mathrm{Kg}$.

\subsection{Cálculo da incerteza}

O cálculo da incerteza $(U)$, descrito no item 4.8.7, é determinado em função das variâncias, da variância $\left(S_{\mathrm{r}}^{2}\right)$ da repetibilidade, pela equação 6 do item 4.8.7.1; $\left(\mathrm{S}_{\mathrm{L}}{ }^{2}\right)$ da variância entre experimentos, equações de 7 a 9, do item 4.8.7.1; e da variância da reprodutibilidade $\left(S_{R}{ }^{2}\right)$, equação 10 , do item 4.8.7.1; e da incerteza, equação 11 do item 4.8.7.2. Os resultados da medida de incerteza, no limite de quantificação do método dos analitos, encontram-se na Tabela 62.

As medidas de incerteza para os analitos avaliados no nível do limite de quantificação variaram de 14 a 19\%, exceto para aldicarbe sulfona, que apresentou incerteza de 45,5\%, no nível de $20 \mu \mathrm{g} / \mathrm{kg}$. Estudos de métodos multirresíduos para estes pesticidas não relatam dados quanto à medida de incerteza, o que dificulta a predição em relação aos resultados obtidos neste estudo. 
Tabela 62 - Resultados de variâncias e incerteza dos experimentos 1, 2 e 3

\begin{tabular}{|c|c|c|c|c|c|}
\hline Analito & $\begin{array}{c}\text { Nível de } \\
\text { validação } \\
(\mu \mathrm{g} / \mathrm{kg})\end{array}$ & $S_{r}^{2}$ & $\mathrm{~S}_{\mathrm{L}}{ }^{2}$ & $S_{R}^{2}$ & U \\
\hline \multirow{3}{*}{ Aldicarbe } & 5,0 & 0,0886 & 0,0036 & 0,0922 & \multirow{3}{*}{1,85} \\
\hline & 10,0 & 0,4839 & 0,3741 & 0,8580 & \\
\hline & 15,0 & 1,2007 & 0,0000 & 1,2007 & \\
\hline \multirow{3}{*}{$\begin{array}{l}\text { Aldicarbe. } \\
\text { sulfona }\end{array}$} & 10,0 & 3,1129 & 14,8216 & 17,9345 & \multirow{3}{*}{9,1} \\
\hline & 20,0 & 1,4880 & 19,2142 & 20,7022 & \\
\hline & 30,0 & 6,0134 & 2,2883 & 8,3018 & \\
\hline \multirow{3}{*}{$\begin{array}{l}\text { Aldiarbe } \\
\text { sulfóxido }\end{array}$} & 5,0 & 0,0425 & 0,0000 & 0,0425 & \multirow{3}{*}{1,35} \\
\hline & 10,0 & 0,4540 & 0,0000 & 0,4540 & \\
\hline & 15,0 & 0,5519 & 0,3228 & 0,8747 & \\
\hline \multirow{3}{*}{ Carbaril } & 5,0 & 0,1100 & 0,0293 & 0,1393 & \multirow{3}{*}{1,47} \\
\hline & 10,0 & 0,3125 & 0,2279 & 0,5403 & \\
\hline & 15,0 & 0,7621 & 0,0000 & 0,7621 & \\
\hline \multirow{3}{*}{ Carbofurano } & 5,0 & 0,0901 & 0,0000 & 0,0901 & \multirow{3}{*}{1,51} \\
\hline & 10,0 & 0,1973 & 0,2858 & 0,4831 & \\
\hline & 15,0 & 0,2793 & 0,0182 & 0,2975 & \\
\hline \multirow{3}{*}{ Metiocarbe } & 5,0 & 0,2770 & 0,0752 & 0,3522 & \multirow{3}{*}{1,55} \\
\hline & 10,0 & 0,1896 & 0,4147 & 0,6043 & \\
\hline & 15,0 & 0,7064 & 0,1483 & 0,8548 & \\
\hline \multirow{3}{*}{ Metomil } & 5,0 & 0,0765 & 0,0127 & 0,0892 & \multirow{3}{*}{1,9} \\
\hline & 10,0 & 0,4528 & 0,4504 & 0,9032 & \\
\hline & 15,0 & 1,0222 & 0,0004 & 1,0226 & \\
\hline \multirow{3}{*}{ Pirimicarbe } & 4,0 & 0,0140 & 0,0030 & 0,0169 & \multirow{3}{*}{0,72} \\
\hline & 8,0 & 0,0702 & 0,0293 & 0,0994 & \\
\hline & 12,0 & 0,3067 & 0,0261 & 0,3328 & \\
\hline \multirow{3}{*}{ Propoxur } & 5,0 & 0,0963 & 0,1104 & 0,2066 & \multirow{3}{*}{1,9} \\
\hline & 10,0 & 0,5621 & 0,3365 & 0,8987 & \\
\hline & 15,0 & 0,7880 & 0,1885 & 0,9765 & \\
\hline \multirow{3}{*}{ Atrazina } & 10,0 & 0,3313 & 0,0058 & 0,3371 & \multirow{3}{*}{2,72} \\
\hline & 20,0 & 1,4331 & 0,4214 & 1,8545 & \\
\hline & 30,0 & 1,8718 & 0,0000 & 1,8718 & \\
\hline \multirow{3}{*}{ Simazina } & 10,0 & 0,2776 & 0,0597 & 0,3373 & \multirow{3}{*}{2,91} \\
\hline & 20,0 & 1,2066 & 0,3714 & 1,5780 & \\
\hline & 30,0 & 3,2725 & 0,0000 & 3,2725 & \\
\hline \multirow{3}{*}{ Carbendazim } & 5,0 & 0,0585 & 0,0000 & 0,0585 & \multirow{3}{*}{1,15} \\
\hline & 10,0 & 0,1249 & 0,0403 & 0,1651 & \\
\hline & 15,0 & 0,3961 & 0,0000 & 0,3961 & \\
\hline & 10,0 & 0,1617 & 0,3196 & 0,4813 & \\
\hline Tiabendazol & 20,0 & 2,2355 & 0,0000 & 2,2355 & 2,99 \\
\hline & 30,0 & 3,4245 & 0,2162 & 3,6406 & \\
\hline & 20,0 & 0,8070 & 0,0000 & 0,8070 & \\
\hline Tiofanato & 40,0 & 7,2524 & 0,0000 & 7,2524 & 5,83 \\
\hline & 60,0 & 12,9836 & 3,4459 & 16,4295 & \\
\hline $\begin{array}{l}\mathbf{s}_{\mathrm{r}}^{2}: \text { variância } \\
\mathbf{S}_{\mathrm{L}}^{2}: \text { variância }\end{array}$ & $\begin{array}{l}\text { de } \\
\text { nentos }\end{array}$ & & $\begin{array}{l}\mathbf{S}_{\mathbf{R}}{ }^{2} \text { : variâ̂ } \\
\mathbf{U}: \text { incerte }\end{array}$ & $\begin{array}{l}\text { da reprodi } \\
\text { la medida }\end{array}$ & \\
\hline
\end{tabular}




\section{10. Limites de quantificação do método}

Os limites de quantificação do método, para os pesticidas estudados, foram estabelecidos após as avaliações dos resultados da Tabela 60 e satisfeitas as condições da norma Council Directive (2002) quanto à porcentagem de recuperação (exatidão) e precisão (incerteza) dos resultados da média de recuperação em diferentes níveis de fortificação.

Os limites de quantificação do método e a incerteza foram: aldicarbe, $10,0 \pm 1,9 \mu \mathrm{g} / \mathrm{Kg}$; aldicarbe sulfona, 20,0 $\pm 9,1 \mu \mathrm{g} / \mathrm{Kg}$; aldicarbe sulfóxido, 10,0 \pm $1,3 \mu \mathrm{g} / \mathrm{Kg}$; carbaril, $10,0 \pm 1,5 \mu \mathrm{g} / \mathrm{Kg}$; carbofurano, $10,0 \pm 1,5 \mu \mathrm{g} / \mathrm{Kg}$; metiocarbe, $10,0 \pm 1,6 \mu \mathrm{g} / \mathrm{Kg}$; metomil, $10,0 \pm 1,9 \mu \mathrm{g} / \mathrm{Kg}$; pirimicarbe, $8,0 \pm 0,7 \mu \mathrm{g} / \mathrm{Kg}$; propoxur, 10,0 $\pm 1,9 \mu \mathrm{g} / \mathrm{Kg}$; atrazina, $20,0 \pm 2,7 \mu \mathrm{g} / \mathrm{Kg}$; simazina, $20,0 \pm 2,9 \mu \mathrm{g} / \mathrm{Kg}$; carbendazim, 10,0 $\pm 1,2 \mu \mathrm{g} / \mathrm{Kg}$; tiabendazol, $20,0 \pm 3,0 \mu \mathrm{g} / \mathrm{Kg}$ e tiofanato metílico, $40,0 \pm 5,8 \mu \mathrm{g} / \mathrm{Kg}$.

Os limites de quantificação do método dos analitos estudados apresentam alta sensibilidade e confiabilidade, em níveis que variaram de 8,0 a $40,0 \mu \mathrm{g} / \mathrm{Kg}$, para 14 princípios ativos de 3 grupos químicos de pesticidas.

Os limites de quantificação dos analitos estudados atendem ao Limite Máximo de Resíduo da legislação brasileira, bem como de organismos internacionais, como o Codex Alimentarius (Codex Alimentarius, 2007) e a União Européia (EFSA, 2007).

Os LMR estabelecidos em todo o território brasileiro, quando comparados com órgãos internacionais (Codex Alimentarius, 2007; EFSA, 2007), muitas vezes são valores menores, como é o caso do carbofurano $(0,05 \mathrm{mg} / \mathrm{kg})$, metomil $(0,02 \mathrm{mg} / \mathrm{kg})$ e tiabendazol $(0,05 \mathrm{mg} / \mathrm{kg})$. Para produtos destinados à exportação, os LMR dos pesticidas a serem obedecidos são referentes aos países de destino do produto. A metodologia estudada atende à quantificação dos pesticidas no produto milho destinado à exportação, países que adotam os LMR acima citados.

Os estudos realizados de métodos multirresíduos validados em diferentes alimentos normalmente são referidos a uma faixa de valores de limite de quantificação do método ou no nível da menor concentração de recuperação. 
Granby et al. (2004) desenvolveram método multirresíduo para frutas, vegetais e cereal e os limites de quantificação do método variaram na faixa de 0,1 a $0,02 \mathrm{mg} \cdot \mathrm{kg}^{-1}$. Os pesticidas estudados foram: aldicarbe, aldicarbe sulfóxido, aldicarbe sulfona, carbaril, carbendazim, metiocarbe, metomil, propoxur, tiabendazol, tiofanato metílico e outros.

Blasco et al. (2005) pesquisaram método multirresíduo em matrizes de diferentes espécies de laranja e encontraram limite de quantificação de 0,025 a $0,25 \mathrm{mg} / \mathrm{kg}$. Dentre outros pesticidas, estudaram: carbendazim, tiibendazol e metiocarbe.

Pelo método multirresíduo estudado por Hernández et al. (2006) em tomate, limão, uva seca e abacate, o limite de quantificação do método foi de 0,01 $\mathrm{mg} / \mathrm{kg}$. Os pesticidas estudados foram: aldicarbe, aldicarbe sulfóxido, aldicarbe sulfona, carbendazim, metomil, tiabendazol, carofuram, propoxur, atrazina, metiocarbe e outros.

Jansson et al. (2004) validaram método multirresíduo de uma mistura de frutas e vegetais com limite de quantificação de $0,01 \mathrm{mg} / \mathrm{kg}$. Ao autores estudaram os pesticidas: aldicarbe, aldicarbe sulfona, aldicarbe sulfóxido, carbaril, carbendazim, carbofurano, metiocarbe, metomil, propoxur, tiabendazol, tiofanato metílico e outros.

Ortelli et al. (2004) pesquisaram método multirresíduo de pesticidas como: aldicarbe, carbaril, carbendazim, carbofurano, metomil, metiocarbe, pirimicarbe, tizbendazol e tiofanto metílico aplicados em frutas e vegetais; com limite de quantificação do método de $0,01 \mathrm{mg} / \mathrm{kg}$.

Pizzutti et al. (2007) estudaram 169 pesticidas em soja e o limite de quantificação do método variou na faixa de 10 a $50 \mu \mathrm{g} \mathrm{kg}^{-1}$. O limite de detecção instrumental foi de 0,1 a $0,25 \mathrm{ng} \cdot \mathrm{mL}^{-1}$. Os pesticidas estudados foram: aldicarbe sulfóxido, aldicarbe sulfona, metomil, carbendazim, propoxur, carbofurano, tiabendazol, metiocarbe e outros.

Ferrer et al. (2005) descreveram método multirresíduo para frutas e verduras. O limite de detecção instrumental foi de 0,0005 a 0,03 mg/kg. O limite de quantificação de carbendazim foi de: $4 \mu \mathrm{g} \mathrm{kg}^{-1}$, para laranja; $5 \mu \mathrm{g} \mathrm{kg}^{-1}$, para pimenta, e $8 \mu \mathrm{g} \mathrm{Kg}^{-1}$, para brocoli; de tiabendazol: $5 \mu \mathrm{g} \mathrm{kg}^{-1}$; $10 \mu \mathrm{g} \mathrm{kg}^{-1}$ e $5 \mu \mathrm{gg}^{-1}$ e, para metomil, de 10,30 e $50 \mu \mathrm{g} \mathrm{kg}^{-1}$, respectivamente. 


\section{11 - Limites de detecção do método}

O limite de detecção (LD) do método para cada analito foi calculado em relação ao sinal da concentração padrão no nível de 1/4 LOQ de cada analito para o sinal ruído do equipamento, na proporção de (3/1), conforme as Figuras 74 a 87.

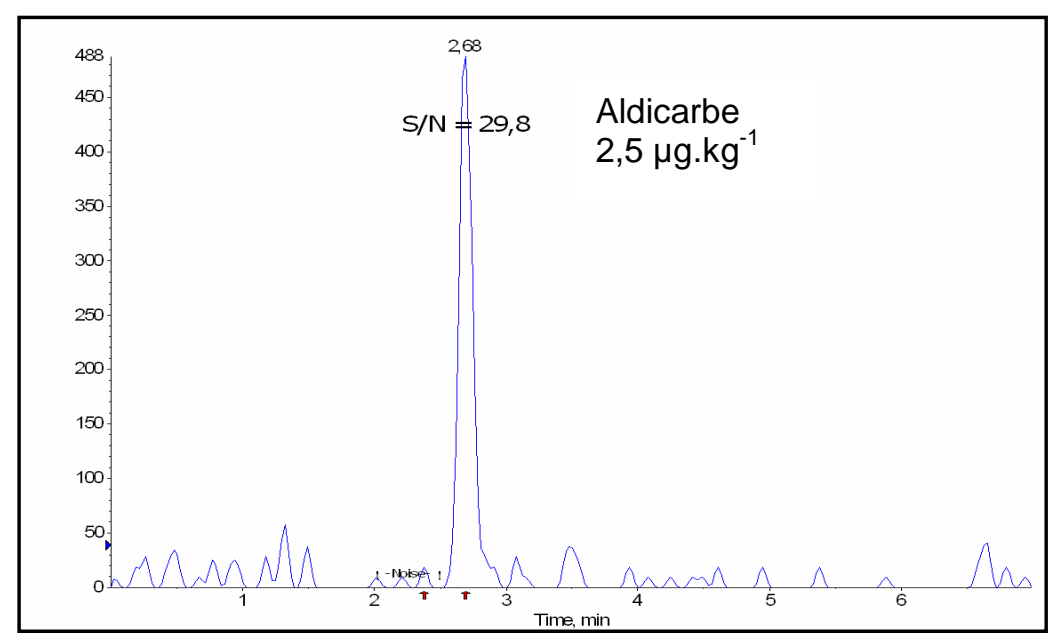

Figura 74 - Cromatograma de aldicarbe, concentração de 0,05 ng. $\mathrm{mL}^{-1}$

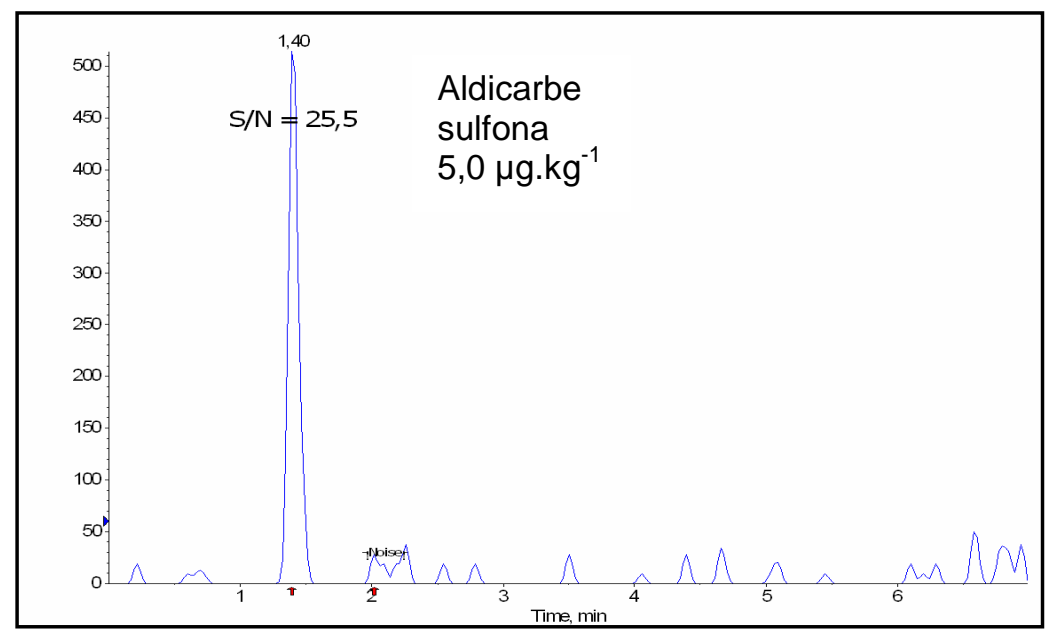

Figura 75 - Cromatograma de aldicarbe sulfona, concentração de 0,10 $\mathrm{ng} \cdot \mathrm{mL}^{-1}$ 


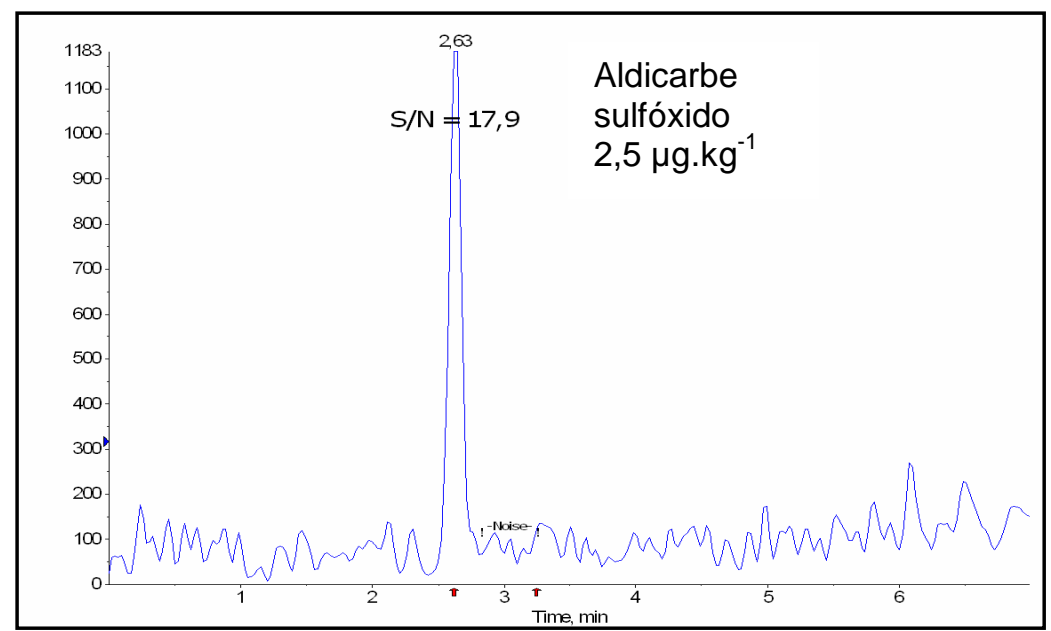

Figura 76 - Cromatograma de aldicarbe sulfóxido, concentração de $0,05 \mathrm{ng} \cdot \mathrm{mL}^{-1}$

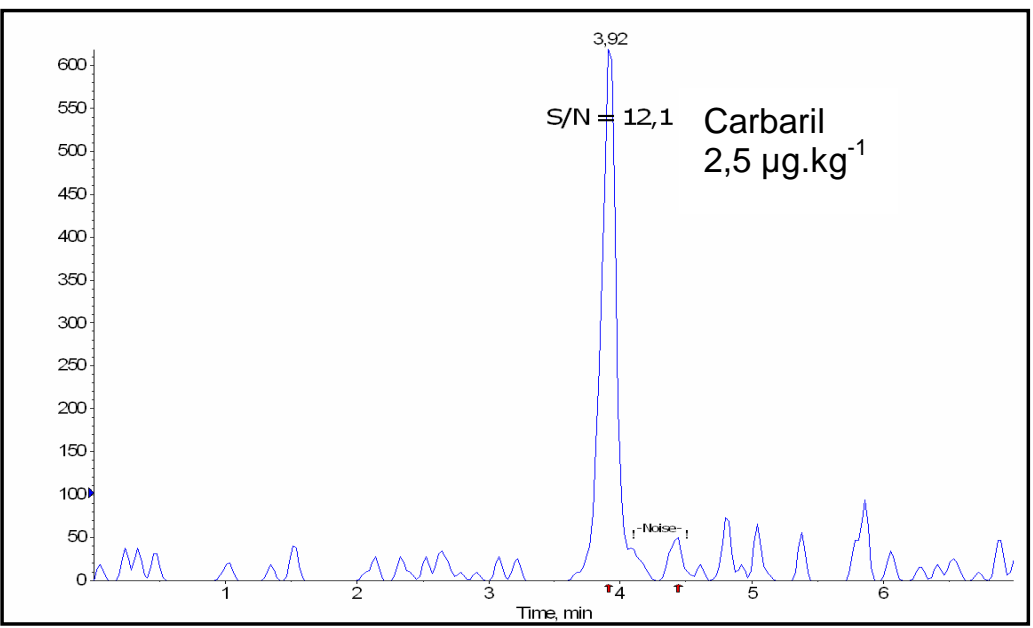

Figura 77 - Cromatograma de carbaril, concentração de $0,05 \mathrm{ng} \cdot \mathrm{mL}^{-1}$

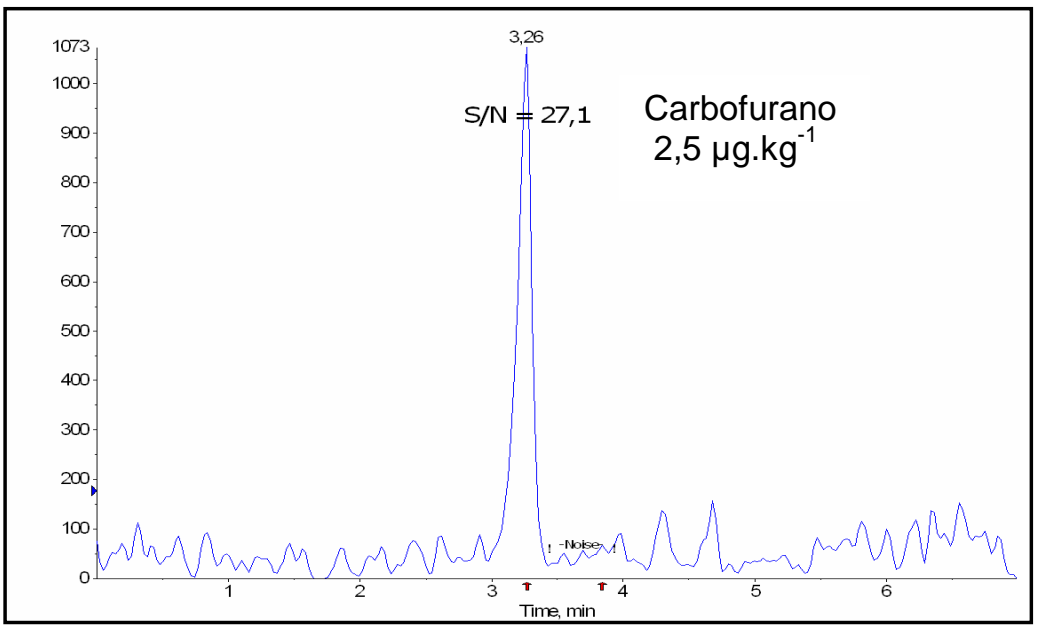

Figura 78 - Cromatograma de carbofurano, concentração de 0,05 ng. $\mathrm{mL}^{-1}$ 


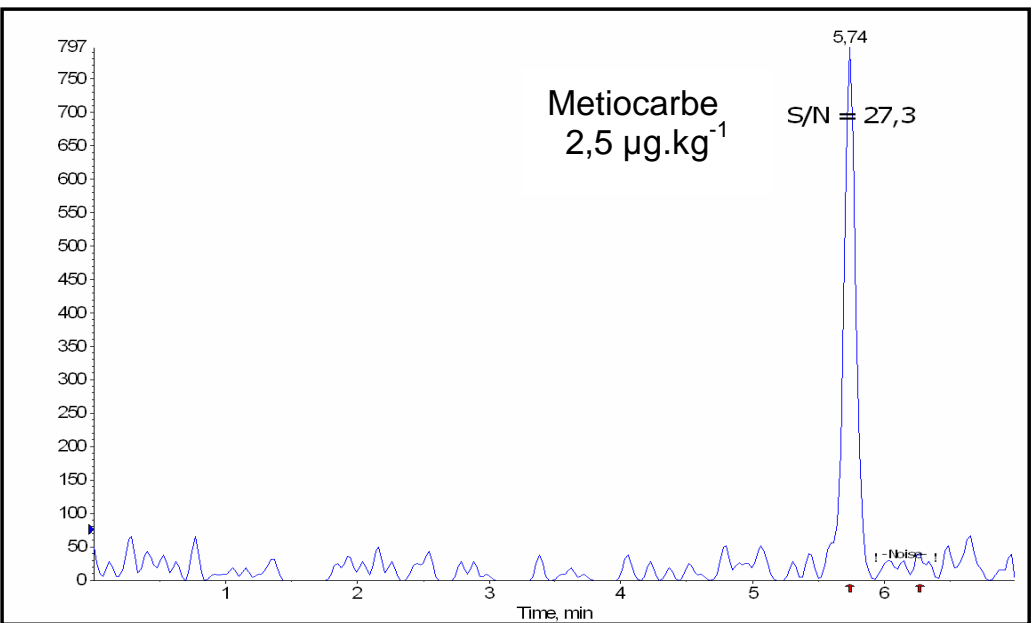

Figura 79 - Cromatograma de metiocarbe, concentração de 0,05 $\mathrm{ng} \cdot \mathrm{mL}^{-1}$

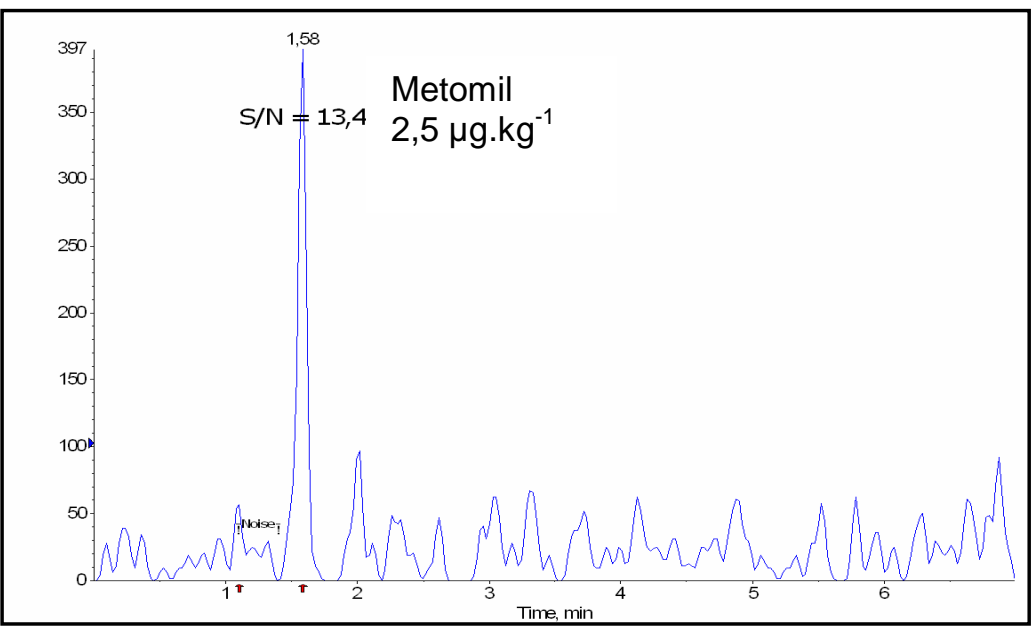

Figura 80 - Cromatograma de metomil, concentração de 0,05 ng. $\mathrm{mL}^{-1}$

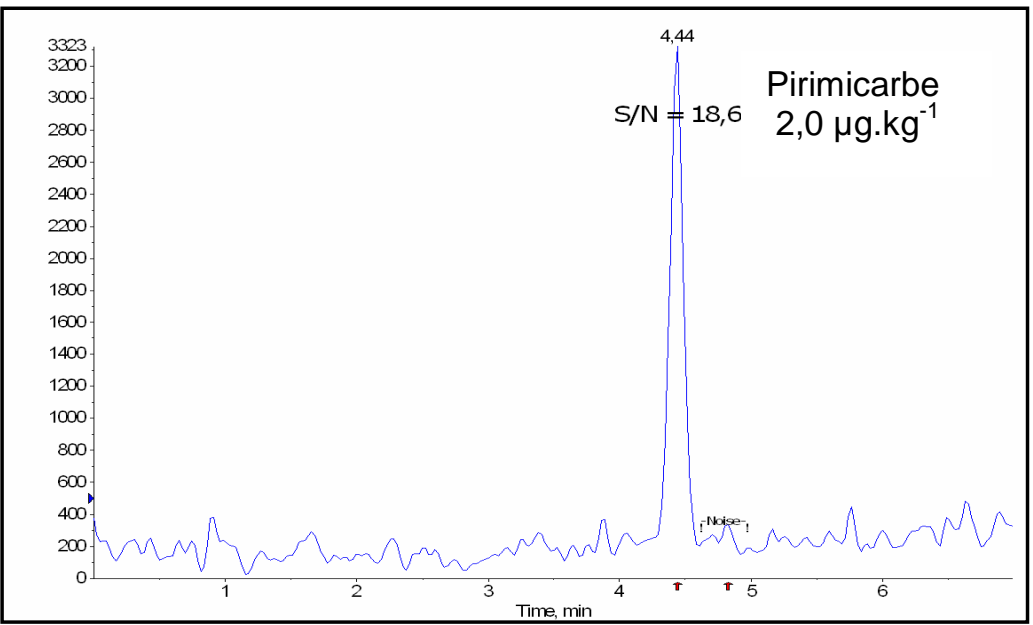

Figura 81 - Cromatograma de pirimicarbe, concentração de 0,04 ng. $\mathrm{mL}^{-1}$ 


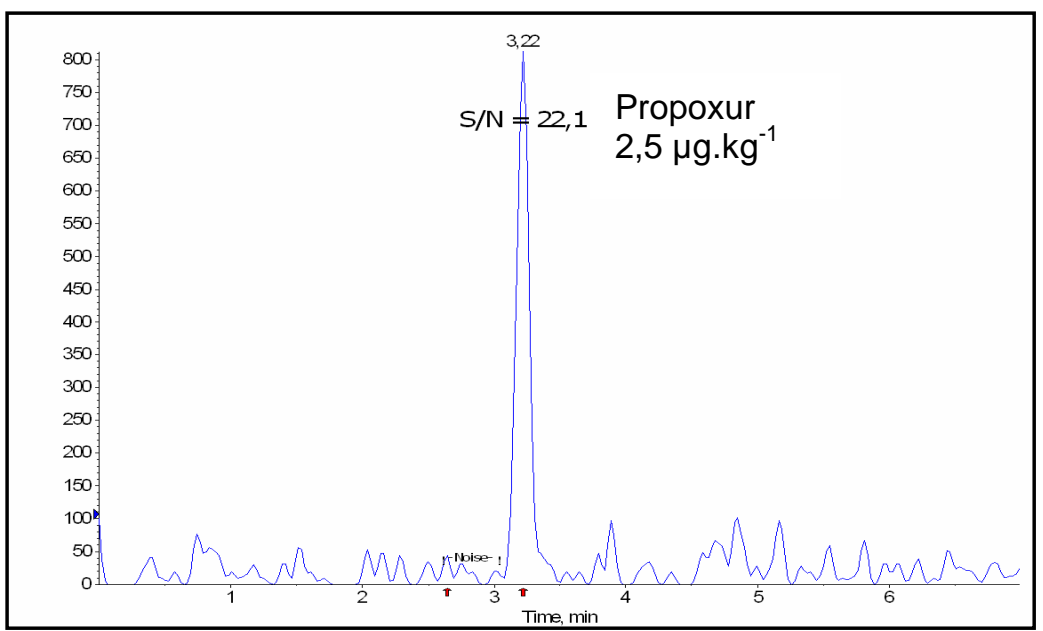

Figura 82 - Cromatograma de propoxur, concentração de 0,05 ng.mL ${ }^{-1}$

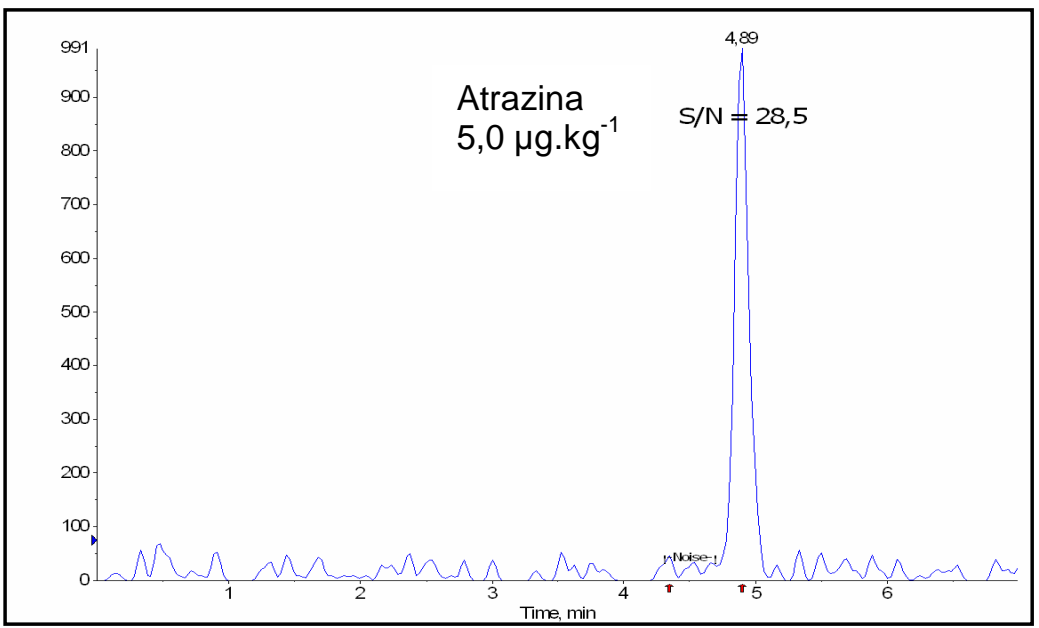

Figura 83 - Cromatograma de atrazina, concentração de $0,10 \mathrm{ng} \cdot \mathrm{mL}^{-1}$

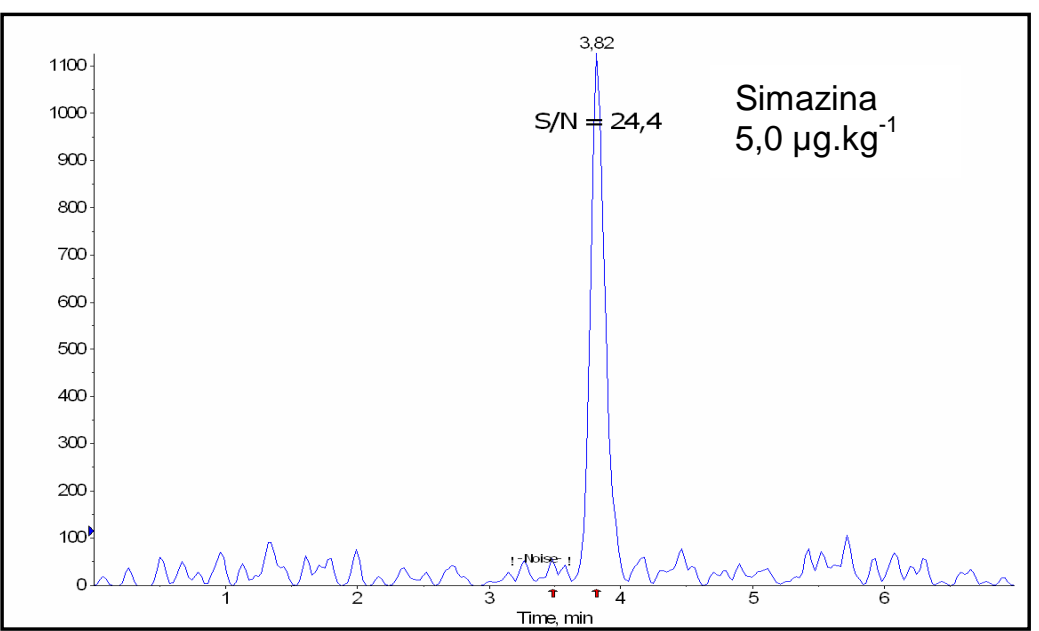

Figura 84 - Cromatograma de simazina, concentração de 0,10 ng. $\mathrm{mL}^{-1}$ 


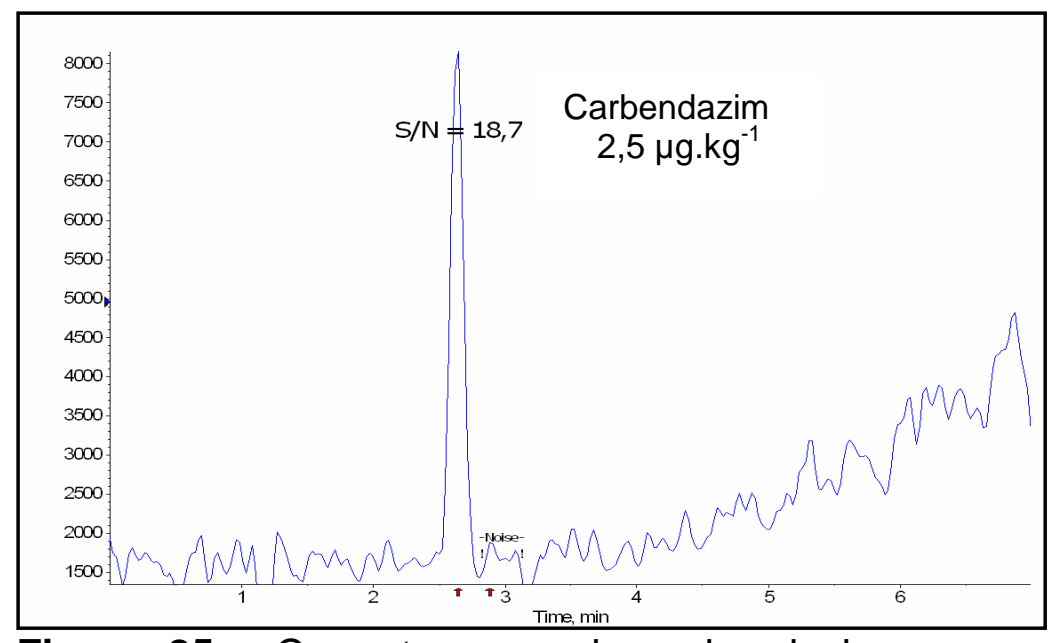

Figura 85 - Cromatograma de carbendazim, concentração de 0,05 $\mathrm{ng} \cdot \mathrm{mL}^{-1}$

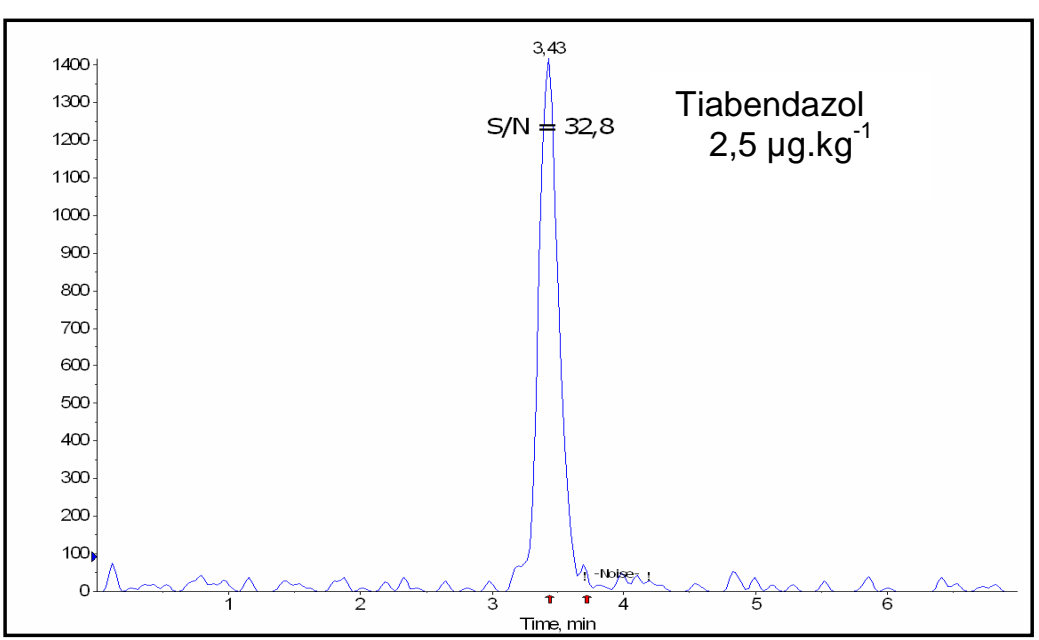

Figura 86 - Cromatograma de tiabendazol, concentração de 0,05 $\mathrm{ng} \cdot \mathrm{mL}^{-1}$

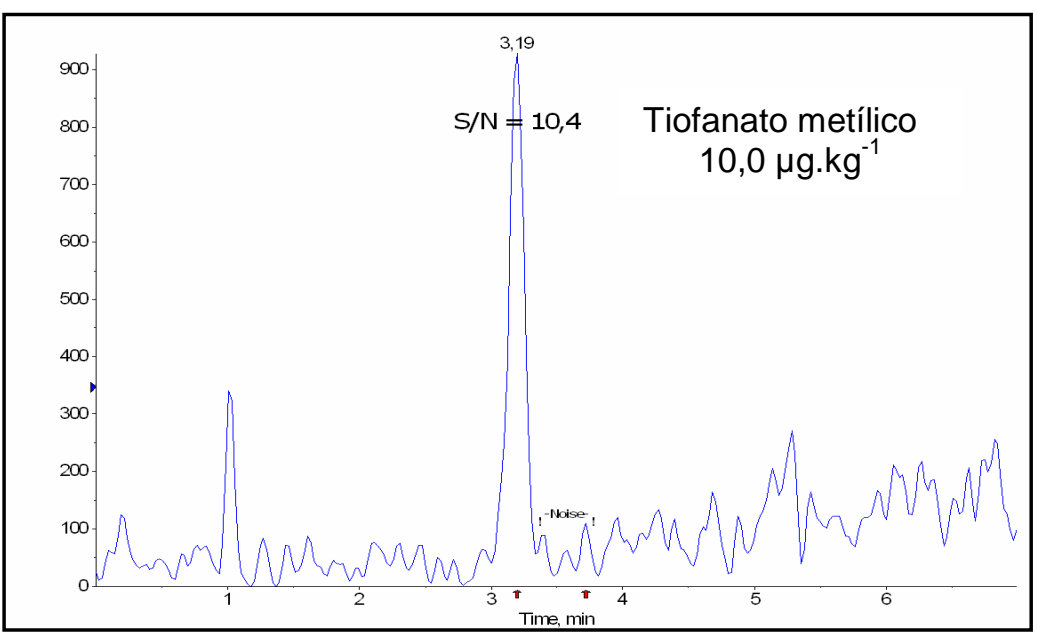

Figura 87 - Cromatograma de tiofanato metílico, concentração de 0,20 $\mathrm{ng} \cdot \mathrm{mL}^{-1}$ 
Os limites de detecção do método para os analitos foram: aldicarbe, carbofuran, metiocarbe, pirimicarbe e propoxur, 0,3 $\mu \mathrm{g} / \mathrm{kg}$; aldicarbe sulfona, carbaril, metomil, simazina, 0,6 $\mathrm{\mu g} / \mathrm{kg}$; aldicarbe sulfóxido e carbendazim, 0,4 $\mu \mathrm{g} / \mathrm{kg}$; atrazina, 0,5 $\mu \mathrm{g} / \mathrm{kg}$; tiabendazol, 0,2 $\mu \mathrm{g} / \mathrm{kg}$ e tiofanato metílico, 2,9 $\mu \mathrm{g} / \mathrm{kg}$. Estes limites representam a menor concentração do analito que pode ser detectada, mas não quantificada.

\section{12. Resultado das amostras}

Para a avaliação do método desenvolvido, analisou-se 10 amostras de milho verde in natura, que foram provenientes de redes de supermercados e hortifrutas da cidade de São Paulo, zona Sul. Na tabela 63, encontram-se os resultados obtidos para amostras analisadas.

Tabela 63 - Resultado das amostras de milho verde

\begin{tabular}{|c|c|c|c|c|c|c|c|c|c|c|c|}
\hline Pesticidas & $\begin{array}{c}\text { LMR } \\
(\mathrm{mg} / \mathrm{kg})\end{array}$ & 1 & 2 & 3 & 4 & 5 & 6 & 7 & 8 & 9 & 10 \\
\hline Aldicarbe & NA & + & - & + & - & + & + & + & - & + & + \\
\hline Aldicarbe sulfona & NA & - & + & + & + & + & - & + & + & + & + \\
\hline $\begin{array}{l}\text { Aldicarbe } \\
\text { sulfóxido }\end{array}$ & NA & - & - & - & - & - & + & + & - & - & - \\
\hline Carbaril & NA & - & - & - & - & - & - & - & - & - & - \\
\hline Carbofurano & $0,1^{*}$ & + & + & + & - & + & - & - & - & + & + \\
\hline Metiocarbe & NA & + & + & + & + & + & - & - & + & - & + \\
\hline Metomil & 0,1 & + & + & + & + & + & + & + & + & + & + \\
\hline Pirimicarbe & NA & - & - & - & - & - & - & - & - & - & - \\
\hline Propoxur & NA & - & - & + & + & - & + & - & - & + & - \\
\hline Atrazina & 0,25 & - & + & + & + & + & + & + & + & + & + \\
\hline Simazina & 0,02 & + & + & + & + & + & - & + & - & + & + \\
\hline Carbendazim & NA & + & + & + & + & + & + & + & + & + & + \\
\hline Tiabendazol & $0,2^{*}$ & + & + & + & + & + & + & + & + & + & + \\
\hline $\begin{array}{l}\text { Tiofanato } \\
\text { metílico }\end{array}$ & NA & - & - & + & + & - & + & + & - & - & - \\
\hline
\end{tabular}


As Figuras 88 e 89 apresentam-se cromatogramas de uma dentre as amostras analisadas onde se mostra as transições para a quantificação e confirmação de carbendazim, a título de ilustração.

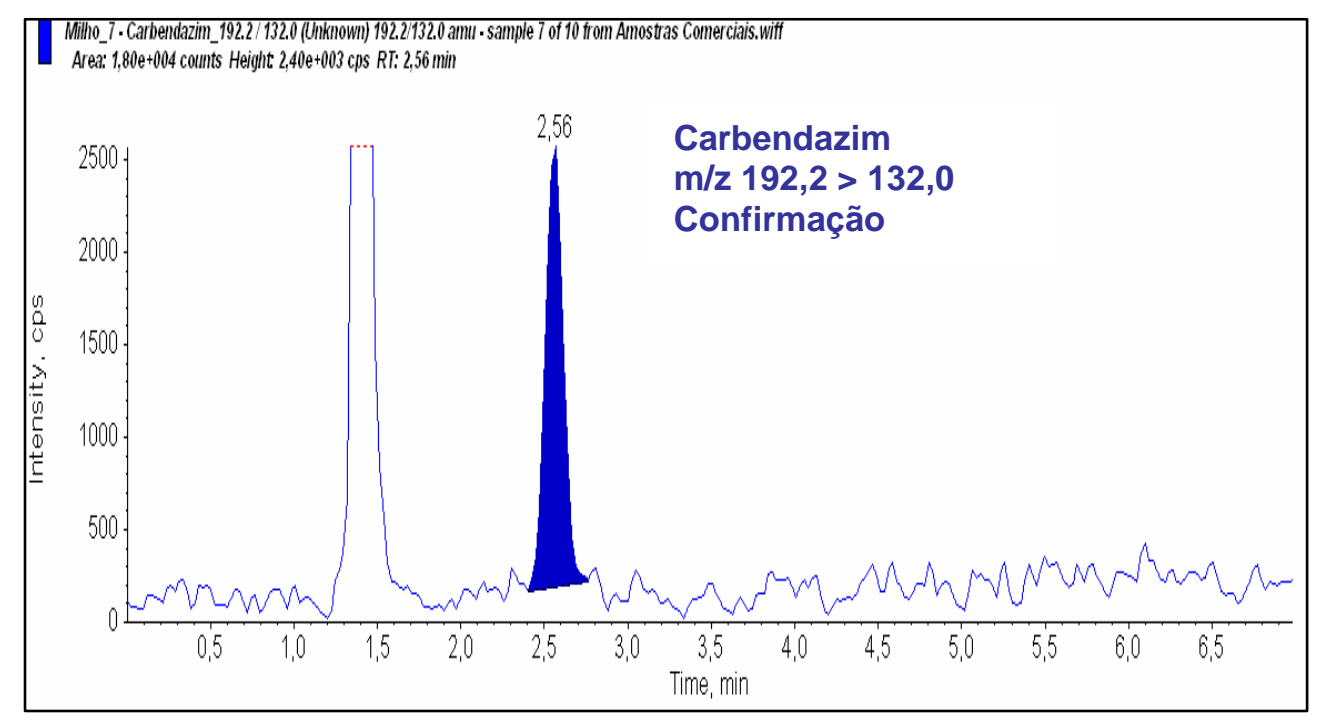

Figura 88 - Cromatograma de carbendazim da amostra 7

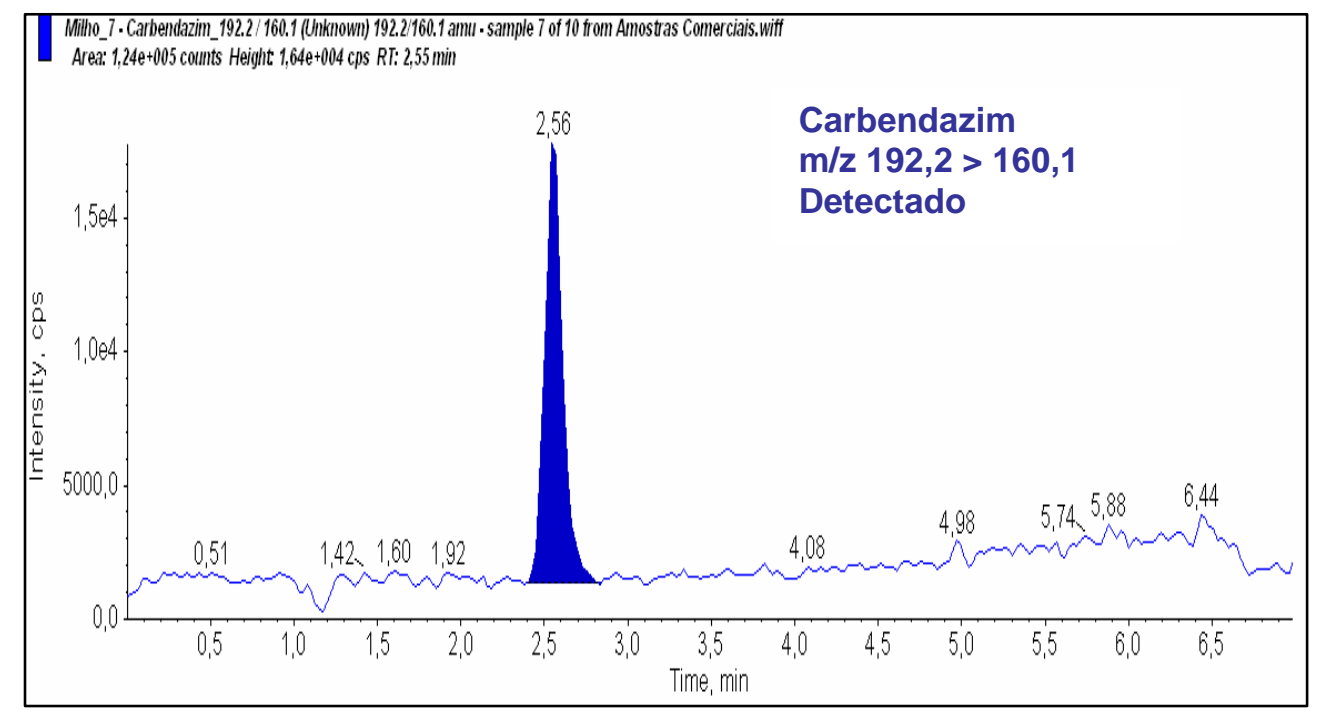

Figura 89 - Cromatograma de carbendazim da amostra 7

Nas amostras de milho verde analisadas, resultados na Tabela 63, não foram encontrados resíduos de pesticidas acima do limite de quantificação do método. Por outro lado, todos os pesticidas estudados, exceto para carbaril e pirimicarbe, foram detectados resíduos de pesticidas, segundo técnica utilizada e ilustrada para carbendazim, nas Figuras 88 e 89. 
Pela legislação brasileira muitos dos pesticidas estudados não são autorizados para uso na cultura de milho. Dentre as amostras, 20\% apresentaram a presença de aldicarbe sulfóxido, $40 \%$ de propoxur e tiofanato metílico, $70 \%$ aldicarbe e metiocarbe, $80 \%$ aldicarbe sulfona e $100 \%$ carbendazim.

Em muitas amostras foram detectadas a presença de resíduos múltiplos. Estes resultados corroboram com os dados da literatura quanto à presença de resíduos múltiplos em uma mesma amostra (Ortelli et al., 2004; EU, 2007; FDA, 2005), o que é uma tendência mundial constatada através de resultados de programas de monitoramento. A presença de resíduos múltiplos de pesticidas em alimentos tem sido uma das preocupações das autoridades governamentais de muitos países. Esta alta incidência de presença nas amostras analisadas se deve, possivelmente, ao uso inadequado de agrotóxico para esta cultura, ou proveniente de alguma fonte de contaminação, como o tratamento de agrotóxicos aplicados em outras lavouras cultivadas em um mesmo solo. 


\section{CONCLUSÕES}

Com base no estudo teórico e experimental realizado e nos resultados obtidos neste trabalho, conclui-se que:

- O estudo de método multirresíduo de pesticidas dos grupos de carbamatos, atrazinas e de benzimidazóis em amostras de milho verde utilizando a técnica de quantificação e confirmação por Cromatografia Líquida acoplada à Espectrometria de Massas em Tandem com ionização por Electrospray (LC-ESI/MS/MS) apresentou resultados em níveis aceitáveis na avaliação de desempenho do método, em todos os analitos, exceto para aldicarbe e aldicarbe sulfona. A validação do método foi conduzida pela da norma EC/2002/657 recomendada pela Comunidade Européia, empregando-se o software ResVal (versão 2.0).

- O método apresentou alta sensibilidade de detecção e quantificação para os analitos estudados. O limite de detecção do método apresentou-se na faixa de 0,2 a $2,9 \mu \mathrm{g} / \mathrm{kg}$ e o limite de quantificação do método foi de 8 a $40 \mu \mathrm{g} / \mathrm{kg}$ em uma matriz não citada em literatura: o milho verde na forma vegetal.

- Os limites de quantificação do método para os princípios ativos estudados de pesticidas atendem aos limites máximos de resíduos (LMR) permitidos pela legislação brasileira em vigor e por outros organismos internacionais, como a União Européia e o Codex Alimentarius. 
- Os níveis de resíduos de pesticidas para os analitos estudados nas amostras de milho verde coletadas na zona sul da cidade de São Paulo estão abaixo dos LMR estabelecidos e não significam um risco para a saúde do consumidor, dentro da área estudada. Por outro lado, foi detectada alta incidência de resíduos múltiplos.

- A metodologia desenvolvida neste estudo poderá auxiliar em estudos de métodos multirresíduos em matrizes e outros princípios ativos com características similares, tornando viável a aplicação em programa de monitoramento de resíduos de pesticidas, principalmente em alimentos.

- A metodologia contribui para ampliação de tecnologia quanto aos princípios ativos estudados, quando aplicados, para a qualidade e a segurança alimentar da população em relação ao uso de agrotóxicos 


\section{REFERÊNCIAS BIBLIOGRÁFICAS}

1. ABAD, A.; MORENO, M.J.; PELEGRI, R.; MARTINEZ, M.I.; SÁEZ, A.; GÁMON, M.; MONTOYA, A. Determination of carbaryl, carbofuran, and methiocarb in cucumbers and strawberries by monoclonal enzyme immunoassays and high-performance liquid chromatography with fluorescence detection: An analytical comparison. Journal of Chromatography A, 833, p. 3-12, 1999.

2. [ABIMILHO] Associação Brasileira das Indústrias de Milho. Cereal que enriquece a alimentação humana. Disponível na internet <http://www. abimilho.com.br/ocereal.htm >. Acesso em 25 de setembro de 2006.

3. ALESSI, M.O.; RAUPP, D.S.; GARDINGO, J.R. Ciências Exatas e da Terra, Ciências Agrárias e Engenharias, 9(2), p. 31-39, 2003.

4. ANASTASSIADES, M.; SCWACK, W. Analysis of carbendazim, benomyl, thiophante methyl and 2, 4-diclorophenoxyacetic acid in fruits and vegetables after supercritical fluid extraction. Journal of Chromatography A, 825, p.45-54, 1998.

5. [ANVISA] Agência Nacional de Vigilância Sanitária do Ministério da Saúde; Resolução RE № 869, de 29 de maio de 2003. Guia para validação de métodos analíticos e bioanalíticos. Diário Oficial da União. 02 de junho de 2003. Disponível na internet <URL:http://www.anvisa.gov.br> Acesso em 18 de outubro de 2007.

6. [ANVISA a] Agência Nacional de Vigilância Sanitária do Ministério da Saúde. Agrotóxicos e Toxicologia. Monografias. Disponível na internet $<$ http://www.anvisa.gov.br/toxicologia/resíduos/index.htm>. Acesso em 08 de março de 2006.

7. [ANVISA] Agência Nacional de Vigilância Sanitária do Ministério da Saúde. Resolução da Diretoria Colegiada. RDC no 216, de 15 de dezembro de 2006. Estabelece parâmetros mínimos para validação de método analítico, para estudos de resíduos de agrotóxicos e afins em produtos de origem vegetal e em cogumelos in natura destinados ao consumo humano e/ou animal. Diário Oficial da União. 18 de dezembro de 2006. Disponível na internet <URL:http://www.anvisa.gov.br> Acesso em 24 de setembro de 2007. 
8. [ANVISA b] Agência Nacional de Vigilância Sanitária do Ministério da Saúde. Agrotóxicos e Toxicologia. Programa de Análise de Resíduos de Agrotóxicos em alimentos (PARA). Relatório de atividades: 20012004. 2005, 98p. Disponível na internet http://www.anvisa.gov.br/toxicologia/resíduos/index.htm>. Acesso em 08 de março de 2006.

9. [ANVISA] Agência Nacional de Vigilância Sanitária do Ministério da Saúde. Agrotóxicos e Toxicologia. Programa de Análise de Resíduos. Relatório de atividades: 2001-2006. Disponível na internet $<$ http://www.anvisa.gov.br/toxicologia/resíduos/index.htm>. Acesso em 24 de setembro de 2007.

10. [AOAC] Association of Official Analytical Chemists. Peer-verified program. Manual on policies and procedures, 1998. Disponível na internet $<$ http://www.aoaoc.org/vmeth/peerverimtd[1].htm>. Acesso em 10 de setembro de 2007.

11. ASHCROFF, A.E. Ionization Methods in Organic Mass Sapectrometry. Cambridge, United Kingdom, Royal Society Chemistry, Analytical Spectrometry Monographs, 1997.

12.BANKS, D.; SOLIMAN, M.R. Protective effects of antioxidants against benomyl-induced lipid peroxidation and gluthatione depletion in rats. Toxicology, 16 (1-3), p.177-181, 1997.

13.BENN, F.R.; MC AULIFFE, C.A. traduzido por Luiz Roberto Moraes Pitombo e Sérgio Massaro. Química e Poluição, 1a edição, p. 40 - 65, EDUSP, 1991.

14. BLASCO, C.; FONT, G.; MANẼS, J.; PICÓ, Y. Solid-phase microextraction liquid chromatography/Tandem mass spectrometry to determine post harvest fungicides in fruits. Analitycal Chemistry, 75 (14), p. 3606-3615, 2003.

15. BLASCO, C.; FONT, G.; PICÓ, Y. Analysis of pesticides in fruits by pressurized liquid extraction and liquid chromatography-ion trap-triple stage mass spectrometry. Journal of Chromatography A, 1098, p. 37-43, 2005.

16. BOCQUENÉ, G.; FRANCO, A. Pesticide contamination of the coastline of Martinique. Marine Pollution Bulletin, 51, p. 612-619, 2005. 
17.BOGIALLI, S.; CURINI, R.; DI CORCIA, A.; LAGÀNA, A.; NAZZARI, M.; $\mathrm{TONCl}, \mathrm{M}$. Simple and rapid assay for analyzing residues of carbamate insecticides in bovine milk: hot water extraction followed by liquid chromatography-mass spectrometry. Journal of Chromatography A, 1054, p.351-357, 2004.

18. BRASIL. Decreto $\mathrm{n}^{\circ} 4074$, de 04 de janeiro de 2002. Regulamenta a Lei $\mathrm{n}^{\circ}$ 7.802 , de 11 de julho de 1989, que dispõe sobre pesquisa, experimentação, produção, embalagem e rotulagem, transporte, armazenamento, comercialização, propaganda comercial, utilização, importação, exportação, destino final dos resíduos e embalagens, registro, classificação, controle, inspeção e fiscalização de agrotóxicos, seus componentes e afins, e dá outras providências. Diário Oficial da União, Brasília, 08 de jan. 2002.p. 1-12. Disponível na Internet $<$ http://www.anvisa.gov.br/legis/decretos/4074 02.htm.> Acesso em 25 de abril de 2005.

19.BUSTILLOS, O.V.; SASSINE, A.; MARCH, R. A espectrometria de massas quadrupolar. Editora Scortecci, 1르 edição, 162 p., 2003.

20.CABALLO-LÓPEZ, A.; CASTRO, M.D.L. Continuos ultrasound-assisted extraction-column liquid chromatography-post column derivatisationfluorescence detection for the determination of $\mathrm{N}$-methylcarbamates in soil and food. Journal of Chromatography A, 988, p. 51-59, 2003.

21.CAI, Z.; WANG, D.; MA, W.T. Gas chromatography/ion trap mass spectrometry applied for the analysis of triazine herbicides in environmental waters by an isotope dilution technique. Analytica Chimica Acta, 503, p.263-270, 2004.

22. CALDAS, E.; SOUZA, L.C. K. Avaliação do risco crônico da ingestão de resíduos de pesticidas na dieta brasileira. Revista de Saúde Pública, 34(5), p. 529-537, 2000.

23. CALLEGARO, M.G.K.; DUTRA, C.B.; HUBER, L.S.; BECKER, L.V.; ROSA, C.S.; KUBOTA, E.H.; HECTHEUR, L.H. Determinação da fibra alimentar insolúvel, solúvel e total de produtos derivados do milho. Ciência e Tecnologia de Alimentos, 25(2), p.271-274, 2005.

24.CAPOBIANGO, M.; VIEIRA, C.R.; SILVA, A.LS.; COELHO, J.V.; SEGALL, S.D.; SILVESTRE, M.A.P. Extração química e enzimática das proteínas do fubá de milho. Ciência e Tecnologia de Alimentos, 26(4), p.884-890, 2006.

25. CLOSE, M.E.; PANG, L.; WATT, J.P.C.; VINCENT, K.W. Leaching of picloran, atrazine and simazine through two New Zealand soils. Geoderma, 84, p. 45-63, 1998. 
26. CODEX ALIMENTARIUS. Residuos de plaguicidas em los alimentos. Límites Máximos de Residuos. Límites Máximos de Resíduos Estranõs. $\quad<$ http://www.codexalimentarius/net/mrls/pestdes/jsp/pest q. s.jsp > Acesso em 19 de setembro de 2007.

27. COUNCIL DIRECTIVE 2002/657/EC. Official Journal of the European Communities, L221,8, 2002.

28. CRAVEN, A.; HOY, S. Pesticide persistent and bound residues in soilregulatory significance. Environmental Pollution, 133, p. 5-9, 2005.

29. CURRIE, L.A. Nomenclature and evaluation of methods and including detection and quantification capabilities. Pure Applied Chemistry, 67, p.1699-1723, 1995.

30.DELGADO, M.J. S.; BARROSO, S.R.; FERNANDEZ-TOSTADO, G.T.; POLO-DÍEZ, L.M. Stability studies of carbamate pesticides and analysis by gas chromatography with flame ionization and nitrogen-phosphorus detection. Journal of Chromatography A, 921, p.287-296, 2001.

31.DU PREEZ, L.H.; JANSEN van RENSBURG, P. J.; JOOSTE, A.M.; CARR, J.A.; GIESY, J.P.; GROSS, T.S.; KENDALL, R.J.; SMITH, E.E.; KRAAK, G.V. SOLOMON, K.R. Seasonal exposures to triazine and other pesticides in surface waters in the western Higveld corn-production region in south Africa. Environmental Pollution, 135, p. 131-141, 2005.

32. DUYZER, J. Pesticides concentrations in air and precipitation in The Netherlands. Journal Environmental Monitoring, 5N, p.77-80, 2003.

33. [EFSA] European Food Safety Autority. Council Directive 86/362/EFC establishing MRLs for cereals and cereal products. $<$ http://www.efsa.europa.eu/EFSA/ScientificPanela/FRAPER/efsa_locale. 117620753820-Maximum ResiduesLevels.htm > Acessado em 19 de setembro de 2007.

34. [EPA] Environmental Protection Agency. Office of Prevention, Pesticide and Toxic Substances. Residue chemistry test guidelines. Washington, 1996.

35. [EMBRAPA] Empresa Brasileira de Pesquisa Agropecuária. Milho e Sorgo. $<$ http://www.cnpms.embrapa.br/publicacoes/milho/produtosmilho.php>. Acesso em 20 de setembro de 2007. 
36. [EU] European Comission. Monitoring pesticides residues in products of plant origin in the European Union, Norway, Iceland and Liechtenstein 2004. 39p. Disponível na Internet $<$ http://www.ec.europa.eu/food/fvo/specialreports/pesticide_residues/report. 2004.en.pdf $>$. Acesso em 07 de outubro de 2007.

37. EURACHEM WORKING GROUP. The Fitness for Purpose of Analitycal Methods. A Laboratory Guide to Method Validation and Related Topics, $1^{\text {st }}$ edtition, Copyright CLGC (Teddington) Ltd, 75p., 1998.

38. [FAO/WHO] Food and Agriculture Organization of the United Nations/World Health Organization. Food Standards Programme Codex Alimentarius Commission. Good Laboratory practice on pesticides in food. Rome. Supl 1.v.2, Section 4.2, 164p, 1993.

39. [FAO/OMS] Food and Agriculture Organization of the United Nations /Organização Mundial da Saúde. Es enormemente alta la cifra de plaguicidas de mala calidad vendida em los paises em desarrollo. $2001 . \quad<$ http://www.fao.org/WAICENT/ois/PRESSNE/PRESSSPA/2001/prsp0105.htm >. Acesso em 18 de setembro de 2007.

40. [FAOMHO] Food and Agriculture Organization of the United Nations/World Health Organization. Definiciones para los fines del Codex Alimentarius. <http://www.fao.org/docrep/W59755/w5975s08.htm > Acesso em 17 de setembro 2007.

41. [FDA] Food and Drug Administration. Food and Drug Administration Program Residues Monitoring 2003. U.S.A, 24p, 2005. Disponível na Internet <http://www.cfsan.fda.gov/ dms/pesrpts.html>. Acesso em $07 \mathrm{de}$ outubro de 2007.

42. FERNÁNDEZ, M.; RODRÍGUEZ, R.; PICÓ, Y.; MANÉS, J. Liuquid chromatographic-mass spectrometric determination of post-harvest fungicides in citrus fruits. Journal of Chromatography A, 912, p. 301-310, 2001.

43.FERRER, I.; GARCIA-REYES, J.F.; MEZCUA, M.; THURMAN, E.M.; FERNÁNDEZ-ALBA, A.R. Multi-residue pesticide analysis in fruits and vegetables by liquid chromatography-time-of-flight mass spectrometry. Journal of Chromatography A, 1082, p. 81- 90, 2005.

44.FREITAS, E.R.; SAKOMURA, N.K.; NEME, R.; BARBOSA, N.A.A. Valor nutricional do milho termicamente processado, usado na ração pré-inicial para frangos de corte. Arquivo Brasileiro de Medicina Veterinária e Zootecnia, 57(4), p.510-517, 2005. 
45. GALLI, A.; DE SOUZA, D.; GARBELLINI, G.S.; COUTINHO, C.F.B.; MAZO, L.H.; AVACA, L.A.; MACHADO, S.A.S. Utilização de técnicas eletroanalíticas na determinação de pesticidas em alimentos. Química Nova, 29(1), p. 105-112, 2006.

46. GOTO, T.; ITO, Y.; OKA, H.; SAITO, I.; MATSUMOTO, H.; SUGIYAMA, H.; ONKUBO, C.; NAKAZAWA, H.; NAGASE, H. The high throughput analysis of $\mathrm{N}$-methyl carbamate pesticides in wine and juice by electrospray ionization liquid chromatography tandem mass spectrometry with direct sample injection into a short column. Analytica Chimica Acta, 531, p.7986, 2005.

47. GOTO, T.; ITO, Y.; YAMADA, S.; MATSUMOTO, H.; OKA, H.; NAGAE, H. The high throughput analysis of $\mathrm{N}$-methyl carbamate pesticides in fruits and vegetables by liquid chromatography electrospray ionization tanden mass spectrometry using a short column. Analytica Chimica Acta, 555, p.225232, 2006.

48. GRANBY, K.; ANDERSEN, J.H.; CHRISTENSEN, H.B. Analysis of pesticides in fruit, vegetables and cereals using methanolic extraction and detection by liquid chromatography-tandem mass spectrometry. Analytica Chimica Acta, 520, p.165-176, 2004.

49.GUAN, X.; DAVIS, M.R.; JIN, L.; BAILLIE, T.A. Identification of S-(nbutylcarbamyl) glutathione, a reactive carbamoylating agent, as boliary metabolite of benomyl in the rat. Journal of Agricultural and Food Chemistry, 42, p. 2953-2957, 1994.

50. GUZELLA, L.; POZZONI, F.; GIULIANO, G. Herbicide contamination of surficial groundwater in Northern Italy. Environmental Pollution, 142, p. 344-353, 2006.

51.HAMERS, T.; SMIT, M.G.D.; MURK, A.J.; KOEMAN, J.H. Biological and chemical analysis of the toxic potency of pesticides in rainwater. Chemosphere, 45, p. 609-624, 2001.

52. HARNER, T.; BARTKOW, M.; HOLOUBEK, I.; KLANOVA, J.; WANIA, F.; GIOIA, R, MOECKEL, C.; SWEETMAN, A.J.; JONES, K.C. Passive air sampling for persistent organic pollutants: introductory remarks to the special issue. Environmental Pollution, 144, p. 361-364, 2006.

53. HERNÁNDEZ, F.; POZO, O.J.; SANCHO, J.V.; BIJLSMA, L.; BARREDA, M.; PITARCH, E. Multiresidue liquid chromatography tandem mass spectrometry determination of 52 non gas chromatography-amenable pesticides and metabolites in different food commodities. Journal of Chromatography A, v.1109, p. 242-252, 2006. 
54. HIEMSTRA, M.; JOOSTEN, J.A.; KOK, A. Fully automated solid-phase extraction cleanup and on-line liquid chromatographic determination of benzimidazole fungicide in fruit and vegetables. Journal of AOAC International, 75, p. 1267-1275, 1995.

55. HIEMSTRA, M.; KOK, A. Comprehensive multi-residue method for the target analysis of pesticides in crops using liquid chromatography-tandem mass spectrometry. Journal of Chromatography A, 1154, p. 3 - 25, 2007.

56. [IARC] International Agency for Research on Cancer. Occupational exposures in Insecticide Application, and Some Pesticides. $<$ http:www.monographs.iarc.fr/ENG/monographs/vol53/volume53.pdf>. 09/26/07. Acesso em 26 de setembro de 2007.

57. $[\mathrm{ICH}$ a] International Conference on Harmonization. Validation of Analytical Procedures: Definitions and Terminology. Q2A (CPM/ICH/381/95), 1995.

58. $[\mathrm{ICH}$ b] International Conference on Harmonization. Validation of Analytical Procedures: Methodology. Q2B(CPM/ICH/281/95), 1995.

59. [IEA] Instituto de Economia Agrícola. Defensivos agrícolas: mantém-se cenário de declínio nas vendas em 2006. Disponível na internet $<$ http://www.iea.sp.gov.br/out/verTexto.php/codTexto=6452>. Acesso em 10 de setembro de 2007.

60. [INMETRO] Instituto Nacional de Metrologia, Normalização e Qualidade Industrial. Orientação sobre validação de métodos de ensaios químicos. DOQ-CGCRE-008, 36p, 2003.

61. [IPCS] International Programme on Chemical Safety. Pesticides Data Sheetes. <http:www.inchem.org/documents/pds/pds>. Acesso em 25 de setembro de 2007.

62. [ISO] International Standard Organization. General Requirements for the Competence of Testing and Calibrations Laboratories, ISO/IEC 17025, 1999.

63. [IUPAC] International Union of Pure and Apllied Chemistry. Harmonized guidelines for single-laboratory validation of methods of analysis. Pure and Applied Chemistry, 74, p.835-855, 2002.

64.JANSSON, C.; PIHLSTRÖM, T.; ÖSTERDAHL, B.; MARKIDES, K. E. A new-residue method for analysis of pesticides residues in fruit and vegetables using liquid chromatography with tandem mass spectrometry detection. Journal of Chromatography A, 1023, p. 93-104, 2004. 
65.JEONG, M.L.; CHESNEY, D.J. Determination of N-methylcarbamate pesticide from spiked matrices using supercritical fluid extraction. Analytica Chimica Acta, 389, p.53-57, 1999.

66. JONES, R.L.; ESTES, T.L. Summary of aldicarb monitoring and research programs in the U.S.A. Journal of Contaminant Hidrology, 18, p. 107140, 1995.

67.KOVALCZUKI, T.; JECH, M.; POUSTKA, J.; HAJŠLOVÁ, J. Ultraperformance liquid chromatography-tandem mass spectrometry: A novel challenge in multiresidue pesticide analysis in food. Analytica Chimica Acta, 577, p. 8-17, 2006.

68. LACASSIE, E.; DREYFUSS, M.F.; DAGUET, J.L.; VIGNAUD, M.; MARQUET, P.; LACÂTRE, G. Multiresidue determination of pesticides in apples and pears by gas chromatography. Journal of Chromatography A, 805, p. 319-326, 1998.

69. LAMBROPOULOU, D.A.; ALBANIS, T.A. Liquid-phase micro-extration techniques in pesticide residue analysis. Review. Journal of Biochemical and Biophysical Methods, 70 p. 195-228, 2007.

70.LARA, W.H.; BATISTA, G.C. Pesticidas. Química Nova, 823(12), p.161165, 1992.

71. LEANDRO, C.; HANCOCK, P.; FUSSELL, R J.; KEELY, B.J. Ultraperformance liquid chromatography for the determination of pesticide residues in food by tandem quadrupole mass spectrometry with polarity switching. Journal of Chromatography A, 1144, p. 161-169, 2007.

72. LÓPEZ-BLANCO, M.C.; CANCHO-GRANDE, B.; SIMAL-GÁNDARA, J. Comparison of solid-phase extraction and solid-phase microextraction for carbofuran in water analyzed by high-performance liquid chromatographyphotodiode-array detection. Journal of Chromatography A, 963, p. 117123, 2002.

73. LOOSER, N.; ZIPPER, H.; KOSTELAC, D; SCHERBAUM, E.; ANASTASSIADES, M. Pesticide residues in strawberries sampled from the market of the German state of Baden-Württemberg in the period between 2002 and 2005. In: Book of Abstracts of the $6^{\text {th }}$ European Pesticide Residue Workshop; 2006, may 21-25; Corfu. Greece: National Agricultural Research Foundation, 95p., 2006

74. MACEDO, J.A.B. Introdução a Química Ambiental. Química \& Meio Ambiente \& Sociedade, 1aㅡ Edição, p. 191-259, 2002. 
75.[MAPA] Ministério da Agricultura, Pecuária e Abastecimento. Brasil: Vendas de defensivos agrícolas, por categoria. Disponível na internet $<$ http://www.agricultura.gov.br/pls/portal/docs/page/mapa/estatisticas/meios produção/1.4.xls>. Acesso em 05 de novembro de 2005.

76. [MAPA] Ministério da Agricultura, Pecuária e Abastecimento. Brasil: Milho - produção, área colhida e rendimento médio. Disponível na Internet $<$ http://www. agricultura.gov.br/estatística/milho $>$. Acesso em 08 de março de 2006.

77.MARQUES, J.A.; PRADO, I.N.; ZEOULA, L.M.; ALCALDE, C.R.; NASCIMENTO, W.G. Avaliação da mandioca e seus resíduos industriais em substituição ao milho no desempenho de novilhas confinadas. Revista Brasileira de Zootecnia, 29(5), p. 1528-1536, 2000.

78. MARTINS Jr, H. Estudo de determinação de resíduos de glifosato e ácido aminometilfosfônico (AMPA) em amostras de soja e água usando cromatografia líquida acoplada à espectrometria de massas em tandem com ionização por electrospray (LC-ESI/MS/MS). 2005. Dissertação (mestrado) 2005. Instituto de Pesquisas Energéticas e Nucleares, São Paulo.

79. MATOS, A.T. Uso racional de recursos naturais e seus reflexos no meio ambiente - Poluição Ambiental e seus efeitos. ABEAS - Associação Brasileira de Educação Agrícola Superior, Módulo 6, Brasília, p.121, 2001.

80.MELO, L.F.C.; COLLINS, C.H.; JARDIM, I.C.S.F. High-performance liquid chromatography determination of pesticides in tomatoes using laboratorymade $\mathrm{NH}_{2}$ and $\mathrm{C} 18$ solid-phase extraction materials. Journal of Chromatography A, 1073, p. 75-81, 2005.

81.MOREIRA, I.; OLIVEIRA, G.C.; FURLAN, A.C.; PATRICIO, V.M.I, MARCOS Jr. M. Utilização da farinha pré-gelatinizada de milho na alimentação de leitões na fase de creche. Digestibilidade e desempenho. Revista Brasileira de Zootecnia, 30(2), p. 440 - 448, 2001.

82. MOTOHASHI, N.; NAGASHIMA,H.; PÁRKÁN, Y.I.C.; SUBRAHMANYAM, B.; ZHANG, G. Official multiresidue methods of pesticide analysis in vegetables, fruits and soil. Journal of Chromatography A. Review. 754, p. 333-346, 1996. 
83. NUNES, G.S.; ALONSO, R.M.; RIBEIRO, M.L.; BARCELÓ, D. Determination of aldicarb, aldicarb sulfoxide and aldicarb sulfone in some fruits and vegetables using high-performance liquid chromatographyatmospheric pressure chemical ionization mass spectrometry. Journal of Chromatography A, 888, p.113-120, 2000.

84. ORTELLI, D.; EDDER, P.; CORVI, C. Multiresidue analysis of 74 pesticidas in fruits and vegetables by liquid chromatography-electrospray-tandem mass spectrometry. Analytica Chimica Acta, 520, p.33-45, 2004.

85. OTERO, R.R.; CANCHO GRANDE, B.; GÁNDARA, J.S. Multiresidue method for fourteen fungicides in white grapes by liquid-liquid and solid phase extraction followed by liquid chromatography-diode array detection. Food Chemitry, 105, p. 711-719, 2007.

86. PALMA, G.; SÁNCHEZ, A.; OLAVE, Y.; ENCINA, F.; PALMA, R.; BARRA, $R$. Pesticide level in surface waters in an agricultural-forestry basin in Southern Chile. Chemosphere, 57, p. 763-770, 2004.

87.PANG, G.; CAO, Y.; ZHANG, J.; FAN, C.; LIU, Y.; LI, X.; JIA, G.; LI, Z.; SHI, Z.; WU, Y.; GUO, T. Validation study on 660 pesticide residues in animal tissues by gel permeation chromatography cleanup/gas chromatography-mass spectrometry and liquid chromatography-tandem mass spectrometry. Journal of Chromatography A, 1125, p. 1-30, 2006.

88. PEREIRA, R.G.L. Critérios de avaliação do risco de praguicidas em aliementos vegetais como ferramenta de gerenciamento de segurança alimentar no Brasil. 2005. Dissertação (mestrado) - Faculdade de Ciências Farmacêuticas, São Paulo.

89.PINTO, G.M F.; JARDIM, I.C.S.F. Use of solid-phase extraction and highperformance liquid chromatography for the determination of triazine residues in water: validation method. Journal of Chromatography A. 869, p. 463-469, 2000.

90.PIZZUTTI, I.R.; KOK, A.; ZANELLA, R.; ADAIME, M.B.; HIEMSTRA, M.; WICKERT, C.; PRESTES, O. Method validation for analysis of 169 pesticides in soya grain, without clean-nup, by liquid chromatographytandem mass spectrometry using positive and negative elestrospray ionization. Journal of Chromatography A, 1142, p. 123-136, 2007.

91.PROENÇA, P.; TEIXEIRA, H.; MENDONÇA, M. M.; CASTANHEIRA, F.; MARQUES, E.P.; CORTE-REAL, F.; VIEIRA, D.N. Aldicarb poisoning: one case report. Forensic Science International, 146S, p.S79-81, 2004. 
92. RAVEN, P.H.; BERG, L.R.; JONHSON, G.B. Environment. Orlando: Saunders College Publishing, p.569, 1995.

93.RIBANI, M.; BOTOLI, C.B.G.; COLLINS, C.H.; JARDIM, I.C.S.F. Validação em métodos cromatográficos e eletroforéticos. Química Nova, 27, v.27(5), p.771-780, 2004.

94.RODRIGUES, P.B.; ROSTAGNO, H. S.; ALBINO, L.F.T.; GOMES, P.C.; BARBOZA, W.A.; SANTANA, R.T. Valores energéticos do milheto, milho e subprodutos do milho, determinados com frangos de corte e galos adultos. Revista Brasileira de Zootecnia, 30(6), p. 1767-1778, 2001.

95.SANCHES, S.M.; Da SILVA, C.H.T. P.; CAMPOS, S.X.; VIEIRA, E.M. Pesticidas e seus respectivos riscos associados à contaminação da água. Pesticidas: Revista Ecotoxicologia e Meio Ambiente, 13, p.53-58, 2003.

96.SANINO, A.; BOLZONI, L.; BANDINI, M. Application of liquid chromatography with electrospray tandem mass spectrometry to the determination of a new generation of pesticides in processed fruits and vegetables. Journal of Chromatography A, 1031, p.161-169, 2004.

97.SATTLER, C.; KÄCHELE, H.; VERCH, G. Assessing the intensity of pesticide use in agriculture. Agriculture Ecosystems and Environmental, 119, p. 299-304, 2007.

98. [SINGAG] Sindicato Nacional das Indústrias para Defesa Agrícola. Dados do mercado. Disponível na internet <http://www.sindag.com.br. $>$. Acesso em 13 de setembro de 2007.

99.SOLOMON, K.R.; BAKER, D.B.; RICHARDS, R.P.; DIXON, K.R.; KLAINE, S.J.; LAPOINT,T.W.; KENDALL,R.J. ; WEISSKOPF, C.P.; GIDDINGS, J.M.; GEISY, J.P.; HALL Jr., L.W.; WILLIANS, W.M. Ecological risk assessment of atrazine in North American Surface waters - Annual Review. Environmental Toxicology and Chemistry, 15, p. 31-76, 1996.

100. SUN, L.; LEE, H.K. Stability studies of propoxur herbicide in environmental water samples by liquid chromatography-atmospheric pressure chemical ionization ion-trap mass spectrometry. Journal of Chromatography A, 1014, p.153-163, 2003.

101. THÉ, P.M.P.; NUNES, R.P.; MAIA, G.A.; SILVA Jr., A.; GUIMARÃES, A.C. Composição mineral e ácidos graxos da fração lipídica de três cultivares de milho (Zea mays, L) selecionados para o estado de Ceará. Ciências Agronônicas, Fortaleza, 20(1/2), p. 145-148, 1989. 
102. TOMLIN, C. (editor). The Pesticides Manual: incorporating the agrochemicals handbook, $10^{\text {th }}$ ed. Cambridge: British Crop. Protection Council, the Royal Society of Chemistry, 1341p., 1994.

103. URANI C.; CHIESARA, E.; GALVANI, P.; MARABINI, L.; SANTAGOSTINHO, A.; CAMATINI, M. Benomyl effects the microtubule cytoskeleton hepatocytes. Toxicology Letters, 76 (2), 135-144, 1995.

104.VENEZIANO, A.; VACCA, G.; ARANA, S.; DE SIMONE, F.; RASTRELLI, L. Determination of carbendazim, thiabendazole and thiophanate-methyl in banana (Musa acuminata) samples imported to Italy. Food Chemistry, 87, p.383-386, 2004.

105.[WHO] World Health Organization. The WHO Recommended Classification of Pesticide by Hazard and Guidelines to Classification 2004. $<$ http//.who.int/ipcs/publications/pesticides_hazard/en>. Acesso em $26 \mathrm{de}$ setembro de 2007.

106.WILKIPÉDIA. Enciclopédia livre. Milho . Dipsponível na internet $<$ http://www. pt. wilkipedia.org/wiki/Milho\#Hist.C3.B3ria >. Acesso em 11 de setembro de 2007.

107.WORRAL, F.; BESIEN, T. The vulnerability of groundwater to pesticide contamination estimated directly from observations of presence or absence in wells. Journal of Hydrology, 303, p. 92-107, 2005.

108.ZAMORA, T; POZO, O.J.; LÓPEZ, F.J.; HERNÁNDEZ, L.P. Determination of tridemorf and other fungicide residues in fruit samples by liquid chromatography-electrospray tandem mass spectrometry. Journal of Chromatography A, 1045, p. 137- 143, 2004. 